\title{
Estudio fitolítico de la Formación Tezanos Pinto (Pleistoceno Tardío-Holoceno Temprano) en la provincia de Entre Ríos, Argentina
}

Tesista: Lic. Georgina Erra

Director: Dr. Alejandro F. Zucol

Codirectora: Dra. Analía E. E. Artabe

Tesis presentada para optar al título de Doctor en Ciencias

Naturales 


\section{INDICE}

Agradecimientos

Resumen

Abstract

\section{INTRODUCCIÓN}

1.1. ASPECTOS GENERALES

1.2. HIPÓTESIS DE TRABAJO

1.2.1. Premisas para el planteo de hipótesis $\quad 5$

1.2.2. Hipótesis $\quad 5$

1.3. OBJETIVOS 6

$\begin{array}{ll}\text { 1.3.1. Objetivo general } & 6\end{array}$

$\begin{array}{ll}\text { 1.3.2. Objetivos particulares } & 6\end{array}$

\section{ASPECTOS GEOLÓGICOS}

2.1. EL CUATERNARIO

2.2. LA LLANURA PAMPEANA

2.2.1. El loess pampeano. Definiciones $\quad 8$

2.2.2. Ambiente pampeano 9

2.2.3. La Pampa Norte 10

2.2.4. El Sistema Eólico Pampeano 10

2.2.5. Génesis del loess pampeano 12

2.2.6. Formación Tezanos Pinto 14

2.2.7. Lomadas Loéssicas de Crespo $\quad 15$

2.2.8. La Formación Tezanos Pinto en Entre Ríos 16

2.3. MARCO GEOGRÁFICO Y GEOMORFOLÓGICO 18

$\begin{array}{ll}\text { 2.3.1. Clima } & 18\end{array}$

$\begin{array}{lr}\text { 2.3.2. Flora } & 19\end{array}$

\section{ANTECEDENTES DEL ESTUDIO DE FITOLITOS}

3.1. BIOMINERALIZACIONES 25

3.2. FITOLITOS

$\begin{array}{ll}\text { 3.2.1. Beneficios de la acumulación de sílice } & 27\end{array}$

3.2.2. Producción de fitolitos, asignación sistemática y 28 patrones fotosintéticos

3.2.3. Incorporación de los fitolitos al suelo $\quad \mathbf{3 0}$

3.2.4. Dispersión de los fitolitos 31

3.2.5. Concepto de "asociación fitolítica" 31

3.2.6. Historia del estudio de los fitolitos 32 


\section{MATERIALES Y MÉTODOS}

4.1. SELECCIÓN DEL ÁREA DE ESTUDIO

4.2. TRABAJO DE CAMPO

4.3. PROCESAMIENTO EN EL LABORATORIO

4.4. TRABAJO DE GABINETE

$\begin{array}{ll}\text { 4.4.1. Multiplicidad y redundancia } & 47\end{array}$

4.5. CLASIFICACIÓN DE LOS MORFOTIPOS

4.6. DESCRIPCION DE LOS MORFOTIPOS UTILIZADOS PARA

ESTE ANÁLISIS

4.7. RECUENTO DE FITOLITOS Y OBTENCIÓN DE LA $\mathbf{5 8}$

MUESTRA MÍNIMA

4.8. ABUNDANCIA RELATIVA

\section{RESULTADOS}

$\begin{array}{ll}\text { 5.1. PERFIL VIAL MAT } & 67\end{array}$

$\begin{array}{ll}\text { 5.1.1. Descripción del perfil } & 67\end{array}$

5.1.2. Caracterización fitolítica de las muestras $\quad 69$

5.2. PERFIL GAUCHITO GIL

$\begin{array}{ll}\text { 5.2.1. Descripción del perfil } & 74\end{array}$

5.2.2. Caracterización fitolítica de las muestras $\quad 75$

5.3. PERFIL LAS CUEVAS

$\begin{array}{ll}\text { 5.3.1. Descripción del perfil } & 81\end{array}$

5.3.2. Caracterización fitolítica de las muestras $\quad 82$

5.4. PERFIL DIAMANTE NORTE

5.4.1. Descripción del perfil $\quad 88$

5.4.2. Caracterización fitolítica de las muestras $\quad 89$

5.5. PERFIL ALVEAR $\quad 98$

$\begin{array}{ll}\text { 5.5.1. Descripción del perfil } & 98\end{array}$

5.5.2. Caracterización fitolítica de las muestras $\quad 99$

$\begin{array}{lr}\text { 5.6. PERFIL PROTESTANTE } & 104\end{array}$

$\begin{array}{ll}\text { 5.6.1. Descripción del perfil } & 104\end{array}$

5.6.2. Caracterización fitolítica de las muestras 106

5.7. PERFIL LA JUANITA

$\begin{array}{ll}\text { 5.7.1. Descripción del perfil } & 115\end{array}$

$\begin{array}{ll}\text { 5.7.2. Caracterización fitolítica de las muestras } & 117\end{array}$

5.8. PERFIL TIPO TEZANOS PINTO

5.8.1. Descripción del perfil $\quad 122$

5.8.2. Caracterización fitolítica de las muestras 125

PERFILES ACCESORIOS

5.9. PERFIL RINCÓN DEL DOLL

5.9.1. Descripción del perfil 135

$\begin{array}{ll}\text { 5.9.2. Caracterización fitolítica de las muestras } & 139 \\ \text { PERFIL VILLA VALLE MARIA } & 139\end{array}$

5.10.1. Descripción del perfil 139 
6. INTEGRACIÓN DE LOS PERFILES Y ANÁLISIS DE LA INFORMACIÓN

7. DISCUSIÓN, CONCLUSIONES Y CONSIDERACIONES

FINALES

BIBLIOGRAFÍA CITADA

APÉNDICE

INDICE DE FIGURAS Y TABLAS 
A mis hijas, Sofía y María. 


\title{
AGRADECIMIENTOS
}

\author{
"Es mejor intentar y fallar, \\ que preocuparse y ver la vida pasar; \\ es mejor intentar, aunque en vano, \\ que sentarse haciendo nada hasta el final. \\ Yo prefiero en la lluvia caminar, \\ a que en días tristes en casa esconderme. \\ Prefiero ser feliz, aunque loco, \\ a que en conformidad vivir..."
}

Martin Luther King

Quiero agradecerles muy especialmente a mis hijas quienes me acompañaron desde el comienzo de esta etapa, quienes padecieron mis ausencias, mis nervios, mis apuros, pero también compartieron las alegrías y los logros, SOFIA y MARIA, mis amores, mi razón de ser y hacer, de seguir, de no caer, de creerme capaz de todo........... tan compañeras, entre orgullosas y confundidas con la tarea maternal. A mi familia, mi mamá, mis hermanos, sobrinos y cuñados. A Fer, tan dulce compañero y a su mamá, Mary. A mis amigos y hermanos del alma, incondicionales escuchantes de tantas cosas raras Mariela Clemente, Silvia Torres, Gisel Pocai, Javier Abait, Negro Rizzo, Guille Bakis y Marianela Rinaldi. A Fredy Carlini por el constante apoyo. A mi amiga y compañera de laboratorio, Josefina Bodnar, y a toda la división paleobotánica, Ari Iglesias, Alba Zamuner, Adolfo Zuñiga, Daniel Ganuza, especialmente al jefe de División Eduardo Morel por brindar su apoyo, confianza y permitir desarrollar mi tesis en la División que él dirige. A Manuel Copello por los dibujos de los esquemas, a Ceci Morgan por la traducción y colaboración en el armado del trabajo, y Raúl Herrera, por la gran ayuda con mapas, por el total desinterés y entusiasmo de su colaboración. A mis amigos del museo de La Plata, Mariana Grossi, Carolina Acosta, Pati Pérez, Ceci Krompotic, Alejo Scarano, Pete Soibelzon, Chino Gasparini, Alejandra Alcaraz, por sus consejos y sugerencias, especialmente a Itatí Olivares y Diego Verzi, quienes siempre me acopañaron. A mis amigos y compañeros del CICTTP de 
Diamante, Brenda Ferrero, Griselda Gottardi y Nacho Noriega. A la murga "Los Farabutes del Adoquín", por darme tanta alegría y entender tanta locura. A la gente que me apoyo con su aliento, con su confianza, dándome impulso para seguir cuando no me creía capaz, y también a la que no, ayudando a mi fortalecimiento e independencia.

A la gente del laboratorio de Diamante.

A la gente que me acompañó y me brindo su apoyo incondicionalmente, alentándome en todo momento Guiomar Vucetich, Diego Verzi, Richard Madden, Edgardo Ortiz Jaureguizar, Paula Posadas.

A mis directores de tesis Alejandro Zucol y Analía Artabe.

A la Dra. Daniela Kröhling que me permitió encuadrar los estudios paleontologicos en un marco geológico apropiado.

Al Director del Centro de Investigaciones Científicas CICyTTP -Diamante, Dr. Marcelo Cabada por permitir desarrollar parte de mi tesis en la Institución que él dirige.

A todos aquellos que contribuyeron a mi formación profesional y personal durante esta etapa.

La realización de este trabajo fue subsidiada por el proyecto PICT 07-13864, ANPCyT, y posteriormente por CONICET. 


\section{RESUMEN}

El análisis de los fitolitos es una de las disciplinas paleobotánicas utilizadas para la reconstrucción de ecosistemas pasados ya que proporcionan un registro preciso de una parte de la vegetación, en áreas concretas y en un momento determinado. Un fitolito es una biomineralización de origen vegetal, de composición principalmente silícea (sílice amorfa) y tamaño microscópico, que puede ser hallado formando parte de un tejido vegetal, o bien en forma desagregada del mismo. Al ser los fitolitos microrestos resistentes, con buen grado de especificidad, constituyen una importante herramienta para estudios taxonómicos y de diversidad biológica en el pasado, ya que ciertas formas son diagnósticas de determinados grupos vegetales.

Teniendo en cuenta la importancia de estos análisis se estudió la composición y variabilidad fitolítica de los sedimentos loéssicos cuaternarios de la Formación Tezanos Pinto en el sudoeste de la provincia de Entre Ríos. Los datos de base obtenidos permitieron caracterizar la paleocomunidad existente al momento de depositación de los sedimentos loéssicos, e interpretar las condiciones paleoambientales imperantes en el sudoeste de Entre Ríos durante el lapso Pleistoceno Tardío-Holoceno Temprano.

Como área de estudio se seleccionó el sudoeste de Entre Ríos, donde está presente la Formación Tezanos Pinto. La elección de los diez perfiles representativos se realizó siguiendo una transecta SE-NO a lo largo de la unidad geomorfológica "Colinas Loéssicas de Crespo". El trabajo de campo abarcó el muestreo intensivo de los perfiles. El procesamiento en el laboratorio incluyó la preparación de 106 muestras y el estudio de las muestras contempló un recuento mínimo de 400 fitolitos/muestra bajo microscopio óptico. Debido a la falta de consenso en la clasificación fitolítica se definió el criterio para la determinación de los morfotipos, atendiendo al problema nomenclatural existente en esta temática de estudio. El diagrama de la investigación permitió analizar la variabilidad fitolítica en sentido horizontal (geográfico) y vertical (estratigráfico). En cuanto a los resultados se definieron cuarenta (40) morfotipos fitolíticos, denominados: Globulolithum sphaeroechinulathum, Globulolithum sphaeropsilathum, Elíptico, Halteriolita, Euhalteriolita centro largo, Euhalteriolita faseolata, Euhalteriolita botulata, Euhalteriolita tipo Stipa, 
Euhalteriolita testicaudiculata, Euhalteriolita testilobata, Plurihalteriolita inequilobata, Euhalteriolita bitestata, Plurihalteriolita trilobata, Plurihalteriolita catenulata, Elemento de conducción, Euhalteriolita cruciformata, Aculeolithum, Aculeolithum rostrathum, Aculeolithum ancistrathum, Aculeolithum acuminathum, Aculeolithum aciculathum, Estrobilolita equidimensionata, Estrobilolita complanata, Estrobilolita elongata, Estrobilolita aplanada, Flabelolithum, Flabelolithum euflabelathum, Flabelolithum complanathum, Flabelolita elongata, Flabelolita excavata, Macroprismatolithum ondulathum, Macroprismatolithum psilaristathum, Euprismatolita elongata, Euprismatolita serrata, Macroprismatolitthum denticulathum, Euprismatolita excavata, Doliolita elongata, Doliolita oblata, Poliédricos y otros. Con los morfotipos definidos, se establecieron las asociaciones fitolíticas (una por cada muestra analizada), y con estas asociaciones se realizaron los análisis multivariados tendientes a evaluar el grado de vinculación existente entre las muestras, en primera instancia, de la columna de cada perfil, y en segunda instancia de los diferentes perfiles, y así determinar el grado de correlación para la posterior definición de biozonas. Las dos técnicas utilizadas fueron el análisis de componentes principales (PCA) y el análisis de agrupamiento. Los análisis de agrupamiento permitieron construir fenogramas que agrupan muestras permitiendo visualizar las relaciones entre las asociaciones fitoliticas.

Los datos obtenidos revelaron la ausencia de diferenciación suficiente para permitir zonificar toda el área estudiada. Sin embargo, se evidencia claramente es una diferenciación geográfica marcada en cuanto a la composición fitolítica entre los perfiles del área $\mathrm{NO}$ de la transecta respecto de aquellos ubicados al SE de la misma. A pesar de que los espesores sedimentarios de la Formación Tezanos Pinto disminuyen en sentido NO-SE, las secciones del SE no tendrían que ser necesariamente secuencias parciales de aquellas presentes al NO, sino que podría tratarse de asociaciones diferentes, debidas, quizás, a la variación geográfica, o que conjuntamente completarían la columna total integrada.

Estas diferencias composicionales podrían corresponderse con variaciones paleoclimáticas o paleocológicas muy locales, que merecerían un extenso estudios que excede el presente trabajo de Tesis. 


\section{ABSTRACT}

Phytolith analysis is one of the paleobotanic disciplines used for the reconstruction of past ecosystems, because they provide a precise record of part of the vegetation for a specific time and place. Phytoliths are biomineralizations generated by plants; they are microscopic and mostly siliceous in composition (amorphous silica), and can be found within plant tissues or disaggregated. Because phytoliths are resistant and highly specific microremains, they represent an important tool for studies of taxonomy and biological diversity in the past, since some forms are diagnostic for certain plant groups.

In this context, the composition and variability of phytoliths in Quaternary loessic sediments from the Tezanos Pinto Formation in southwestern Entre Ríos province. The data obtained allowed characterizing the paleocommunity that existed at the time when the loessic sediments were deposited, and interpreting the paleoenvironmental conditions that prevailed in southwestern Entre Ríos during the Late Pleistocene-Early Holocene lapse.

The selected study area was the southwest region of Entre Ríos where the Tezanos Pinto Formation is present. Ten representative profiles were chosen along a SE-NW transect that followed the geomorphological unit "Colinas Loéssicas de Crespo". Fieldwork included intensive sampling of the profiles. Laboratory processing involved the preparation of 106 samples, which were analyzed by means of counts of at least 400 phytoliths/sample under light microscope. Due to the lack of consensus regarding phytolith classification, a criterion was defined for the determination of morphotypes, taking into account the nomenclatural issues that exist in this field of knowledge. This analytical design allowed performing both horizontal (geographical) and vertical (stratigraphic) analyses of phytolith variability. As part of the results of this study, forty (40) phytolith morphotypes were defined, designated as: Globulolithum sphaeroechinulathum, Globulolithum sphaeropsilathum, Elíptico, Halteriolita, Euhalteriolita centro largo, Euhalteriolita faseolata, Euhalteriolita botulata, Euhalteriolita tipo Stipa, Euhalteriolita testicaudiculata, Euhalteriolita testilobata, Plurihalteriolita inequilobata, Euhalteriolita bitestata, Plurihalteriolita trilobata, Plurihalteriolita catenulata, Elemento de conducción, Euhalteriolita 
cruciformata, Aculeolithum, Aculeolithum rostrathum, Aculeolithum ancistrathum, Aculeolithum acuminathum, Aculeolithum aciculathum, Estrobilolita equidimensionata, Estrobilolita complanata, Estrobilolita elongata, Estrobilolita aplanada, Flabelolithum, Flabelolithum euflabelathum, Flabelolithum complanathum, Flabelolita elongata, Flabelolita excavata, Macroprismatolithum ondulathum, Macroprismatolithum psilaristathum, Euprismatolita elongata, Euprismatolita serrata, Macroprismatolitthum denticulathum, Euprismatolita excavata, Doliolita elongata, Doliolita oblata, Poliédricos and others. Once these morphotypes were defined, phytolith associations were established (one per analyzed sample), and these associations were used for subsequent multivariate analyses in order to assess the degree of similarity among the samples; this was evaluated first for the column of each profile, and then between different profiles, with the goal of determining the degree of correlation between samples and defining biozones if possible.

These analyses were made using Principal Components Analysis and Clustering Analyses. On the basis of the latter, phenograms were built with the grouped samples that allowed visualization of the relationships between phytolith associations.

The results showed that the degree of differentiation was not enough to divide the area into biozones. However, phytolith composition showed marked geographic differentiation between the profiles in the NW area of the transect and those in the SE sector. Although the thickness of sediments corresponding to Tezanos Pinto Formation decreases from NW to SE, the sections in the SE area are not necessarily partial sections of the NW sequences, but could represent different associations, due perhaps to geographical variation, or be combined with the latter to obtain a complete integrated column.

These compositional differences could respond to very local paleoclimatic or paleoecological changes, which deserve extensive analysis beyond the scope of this thesis work. 


\section{INTRODUCCIÓN}

\subsection{ASPECTOS GENERALES}

El loess es un depósito de origen eólico que cubre extensas áreas. En Argentina, el loess de la Región Pampeana representa el material eólico fino típico del Cuaternario de Sudamérica, abarca la superficie loéssica más extensa del Hemisferio Sur (Kröhling y Orfeo, 2002), cubriendo la mayor parte de la llanura Pampeana y parte de las áreas circundantes (Sayago et al., 2001; Zárate, 2003) y es el material parental de secuencias pedosedimentarias del Cuaternario.

El sudoeste de la Provincia de Entre Ríos forma parte del borde noreste de la Faja Periférica Loéssica (FPL) del Sistema Eólico Pampeano (figura 2.3.) (SEP sensu Iriondo y Kröhling, 1995). Dicha faja compone la superficie loéssica más extensa del Hemisferio Sur. La Formación Tezanos Pinto (Iriondo, 1980) constituye la unidad sedimentaria cuaternaria representativa del loess de la Pampa Norte (figura 2.2.), en general cubriendo el este de Córdoba, centro-sur de Santa Fe y sudoeste de Entre Ríos (Erra et al., 2006). Los materiales que componen esta Formación fueron depositados durante el Estadio Isotópico del Oxígeno 2 (EIO2) (figura 2.1.), en un rango que abarca entre los 36.000 a los 8.500 años AP (Pleistoceno Tardío- Holoceno Temprano) (Iriondo y Kröhling, 1996).

En esta área (sudoeste de Entre Ríos) la Formación Tezanos Pinto constituye la Unidad Geomorfológica "Colinas Loéssicas de Crespo" (Iriondo, 1998) (figura 2.4.), donde se dispone cubriendo el relieve en forma de manto de 2-5 metros de espesor. Hacia el este se encuentra parcialmente erodada y se halla presente sólo en las partes altas del paisaje hasta las cercanías del río Gualeguay. La facies de loess primario de la formación en estudio domina ampliamente en el sudoeste de Entre Ríos (Kröhling et al., 2005).

A nivel mundial, los depósitos loéssicos se caracterizan por presentar microfósiles vegetales como fitolitos, estructuras caulinares y carbones (Behrensmeyer et al., 1992). Este tipo de depósitos también se encuentran asociados al desarrollo de pastizales abiertos (Oligoceno-Mioceno de Norteamérica, Retallack, 1982) y en estepas y márgenes de desiertos 
(Pleistoceno de China, Wu y Gao, 1985; este de Europa, Kukla 1975, 1989). Se observa que tanto sabana, pradera y estepa, son sitios propicios de acumulación de depósitos loéssicos (Spalletti, 1992). La presencia de asociaciones de microfósiles en sedimentos loéssicos pleistocenos también fueron descriptas en sedimentos cuaternarios pampeanos de la Argentina (Gonzales y Osterrieth 1996; Osterrieth, 2001; Zucol et al., 2004). Los depósitos loéssicos contienen información sobre la vegetación del pasado y los análisis fitolíticos de estos depósitos pueden ser un trabajo útil para mejorar la comprensión del pasado climático y las condiciones ambientales bajo las cuales se formaron. Preservados en suelos o sedimentos, estos microrestos resultan valiosos para realizar estudios de las paleocomunidades vegetales que existieron al momento de su depositación.

Así, el estudio de los fitolitos de la Formación Tezanos Pinto representa un avance en la aproximación a un conocimiento más completo y comprensivo de la biodiversidad del Pleistoceno Tardío-Holoceno Temprano de la región. En particular, resulta una herramienta válida para comprender la historia evolutiva reciente de una comunidad de importancia desde el punto de vista ecológico, humano y económico como lo es el pastizal pampeano en el sector norte de la región pampeana.

Como se dijo, el loess es el material parental típico de secuencias pedosedimentarias del Cuaternario, sin embargo, no hay consenso en la interpretación de la evolución de estas secuencias durante el Cuaternario y las condiciones ambientales en los cuales ellos se desarrollaron. La vegetación que habría dominado la Pampa durante el Cuaternario Tardío fue principalmente una estepa de gramíneas (Osterrieth et al., 2006; Osterrieth et al., 2009), y las gramíneas son los productores más prolíficos de fitolitos (Piperno, 2006).

El análisis de los fitolitos es una de las disciplinas paleobotánicas utilizadas para la reconstrucción de ecosistemas pasados ya que proporcionan un registro preciso de una parte de la vegetación, en áreas concretas y en un momento determinado. Un fitolito es una biomineralización de origen vegetal, de composición principalmente silícea (sílice amorfa) y tamaño microscópico, que puede ser hallado formando parte de un tejido vegetal, o bien en forma desagregada del mismo. Cuando se presentan dispersos, los fitolitos pueden 
encontrarse en forma aislada (un único elemento celular mineralizado o parte de él) o en forma articulada (varios elementos celulares mineralizados en forma conjunta) (Zucol y Brea, 2005). Al ser los fitolitos microrestos resistentes, con buen grado de especificidad, constituyen una importante herramienta para estudios taxonómicos y de diversidad biológica en el pasado, ya que ciertas formas son diagnósticas de determinados grupos.

Para hacer la reconstrucción de comunidades vegetales e inferir paleoambientes desarrollados en distintas regiones del mundo, son ampliamente utilizados los análisis paleopalinológicos. Sin embargo cuando se intenta interpretar paleopastizales los análisis paleopalinológicos presentan ciertas limitaciones ya que estos biomas están dominados por especies de la familia Poaceae. Esta familia constituye un grupo estenopolínico (no existe variación en los granos de polen por debajo de la categoría de familia, por lo que no se puede diferenciar entre subfamilia y géneros a través de su estudio). Es aquí donde los análisis fitolíticos toman real importancia y constituyen una herramienta de creciente aplicación en el mundo que permite abordar de manera satisfactoria el estudio de los paleopastizales.

La familia Poaceae es uno de los grupos con mayor abundancia y diversidad en la producción de fitolitos, lo que permite la identificación de esta familia y sus subfamilias, y como consecuencia, las comunidades vegetales que conforman, a partir del análisis de los fitolitos. Además, dado que ellos son altamente resistentes a la degradación, se los puede encontrar en una gran diversidad de suelos y sedimentos (Twiss et al., 1969; Rovner, 1971; Bertoldi de Pomar, 1975; Piperno, 1988; Fredlund y Tieszen, 1994; Alexandre et al., 1997; Barboni et al., 1999; Osterrieth, 2000; Strömberg, 2004; Thorn, 2004a; Bremond et al., 2005; Lu et al., 2006).

Para la realización del presente trabajo se muestrearon perfiles representativos en el área sudoeste de Entre Ríos, donde está presente la Formación Tezanos Pinto, siguiendo una transecta SE-NO (figura 4.1.) a lo largo de la unidad geomorfológica "Colinas Loéssicas de Crespo" (figura 2.4.).

Con el sedimento obtenido de los muestreos, se realizó el procesamiento para la obtención del concentrado portador de fitolitos, su observación bajo microscopio, identificación de los diferentes tipos de fitolitos presentes en las muestras y el análisis de estas asociaciones. Los análisis 
fitolíticos realizados en estos sedimentos, buscaron evaluar la fertilidad existente, la diversidad morfológica y las características de la paleocomunidad que los habría originado, y a partir de su estudio realizar interpretaciones de tipo paleoambiental y paleoclimático. 


\subsection{HIPÓTESIS DE TRABAJO}

En el marco de los antecedentes presentados en los apartados anteriores, se resumen las siguientes premisas que permiten definir el planteo de hipótesis y objetivos de este trabajo de tesis.

\subsubsection{Premisas de las que se partió para el planteo de hipótesis}

- Los análisis fitolíticos son ampliamente utilizados para hacer la reconstrucción de comunidades vegetales e inferir paleoambientes desarrollados en distintas regiones del mundo.

- Los análisis fitolíticos permiten interpretar con mayor precisión a los paleopastizales que los estudios palinológicos (apartado 1.1.) ya que los elementos que los componen son principalmente integrantes de la familia Poaceae.

- Las regiones de sabana, estepa y pradera son sitios más que apropiados para la generación de depósitos loéssicos, ya que las áreas vegetadas son las trampas más adecuadas para este tipo de depósitos (Spalletti, 1992).

- Las condiciones predominantes durante el depósito de sedimentos loéssicos fueron interpretadas como correspondientes a ambientes áridos o semiáridos (Iriondo y Kröhling 1996).

\subsubsection{Hipótesis}

El análisis fitolítico de los sedimentos loéssicos cuaternarios de la Formación Tezanos Pinto, permite obtener información sobre la paleocomunidad presente en el SO de Entre Ríos, en el pasado reciente, e inferir las condiciones climáticas en las que ellas se desarrollaron. 


\subsection{OBJETIVOS}

\subsubsection{Objetivo general}

Estudiar la composición y variabilidad fitolítica de los sedimentos loéssicos cuaternarios de la Formación Tezanos Pinto (Pleistoceno TardíoHoloceno Temprano) en el sudoeste de la provincia de Entre Ríos. A través de este estudio caracterizar la paleocomunidad existente al momento de depositación de los sedimentos loéssicos, e interpretar las condiciones paleoambientales imperantes en el sudoeste de Entre Ríos durante el lapso Pleistoceno Tardío-Holoceno Temprano.

\subsubsection{Objetivos particulares}

- Evaluar la fertilidad fitolítica existente en los sedimentos loéssicos de la Formación Tezanos Pinto en el sudoeste de Entre Ríos.

- Identificar y cuantificar los fitolitos presentes en las diferentes muestras.

- Detectar variaciones en la composición fitolítica de base a techo en cada uno de los perfiles estudiados.

- Hacer la integración areal de los perfiles mediante análisis multivariado de los datos obtenidos.

- Caracterizar la paleocomunidad que habría originado los fitolitos objeto de este análisis.

- Realizar interpretaciones de tipo paleoambiental y paleoclimático.

- Comparar los resultados obtenidos en los sedimentos de la Formación Tezanos Pinto con las características fitolíticas de la flora actual de pastizales desarrollados bajo similares condiciones ambientales.

- Comparar las interpretaciones paleoambientales que resulten de este trabajo con aquellas propuestas desde otras fuentes (e.g. estudio de vertebrados fósiles y sedimentología). 


\section{ASPECTOS GEOLÓGICOS}

\subsection{EL CUATERNARIO}

El Cuaternario es el último Período de la historia de la Tierra. El concepto clásico del mismo está vinculado a la aparición de la especie humana y la ocurrencia de glaciaciones, por ello fue conocido como la "Edad del Hombre" o la "Gran Edad de Hielo". Abarca 2,6 millones de años y estuvo caracterizado por frecuentes cambios climáticos globales que llevaron a una sucesión de edades glaciales e interglaciales (Iriondo y Kröhling, 2008). El Período Cuaternario se divide en dos épocas: Pleistoceno y Holoceno (figura 2.1.). La cronoestratigrafía del Cuaternario ha sido objeto de intensas discusiones a través del tiempo, discusiones que persisten aún hoy. EI INQUA (Unión Internacional para el Estudio del Cuaternario, 1987) ha aceptado las siguientes divisiones del Pleistoceno (figura 2.1.): Temprano (o Inferior), Medio, y Tardío (o Superior), basadas en edades que tienen su fundamento en fenómenos naturales importantes. El límite inferior del Pleistoceno se corresponde con el inicio de la primera glaciación en Eurasia. El límite Pleistoceno Temprano-Medio con la reversión de polaridad magnética terrestre Brunhes-Matuyama $(0,78 \mathrm{Ma} \mathrm{AP})$, mientras que el límite Pleistoceno MedioTardío fue fijado en el comienzo del Último Interglacial (base del Estadio -PisoIsotópico Marino del Oxígeno 5e-EIO5e). El límite Pleistoceno-Holoceno fue fijado por ISC, 2007, en 11,8 ka, fecha que corresponde a la finalización del evento Younger Dryas en el Hemisferio Norte, de todos modos sigue siendo de uso corriente la fecha arbitraria de diez mil "años radiocarbono", muy cercano a 10.000 años calendario. Recientemente la Comisión Internacional de Estratigrafía (IUGS -Unión Internacional de Ciencias Geológicas-) ha presentado la nueva columna estratigráfica internacional (Gradstein et al., 2004) en la que el Cuaternario queda comprendido en el Período Neógeno de la Era Cenozoica. (Iriondo y Kröhling, 2008). 


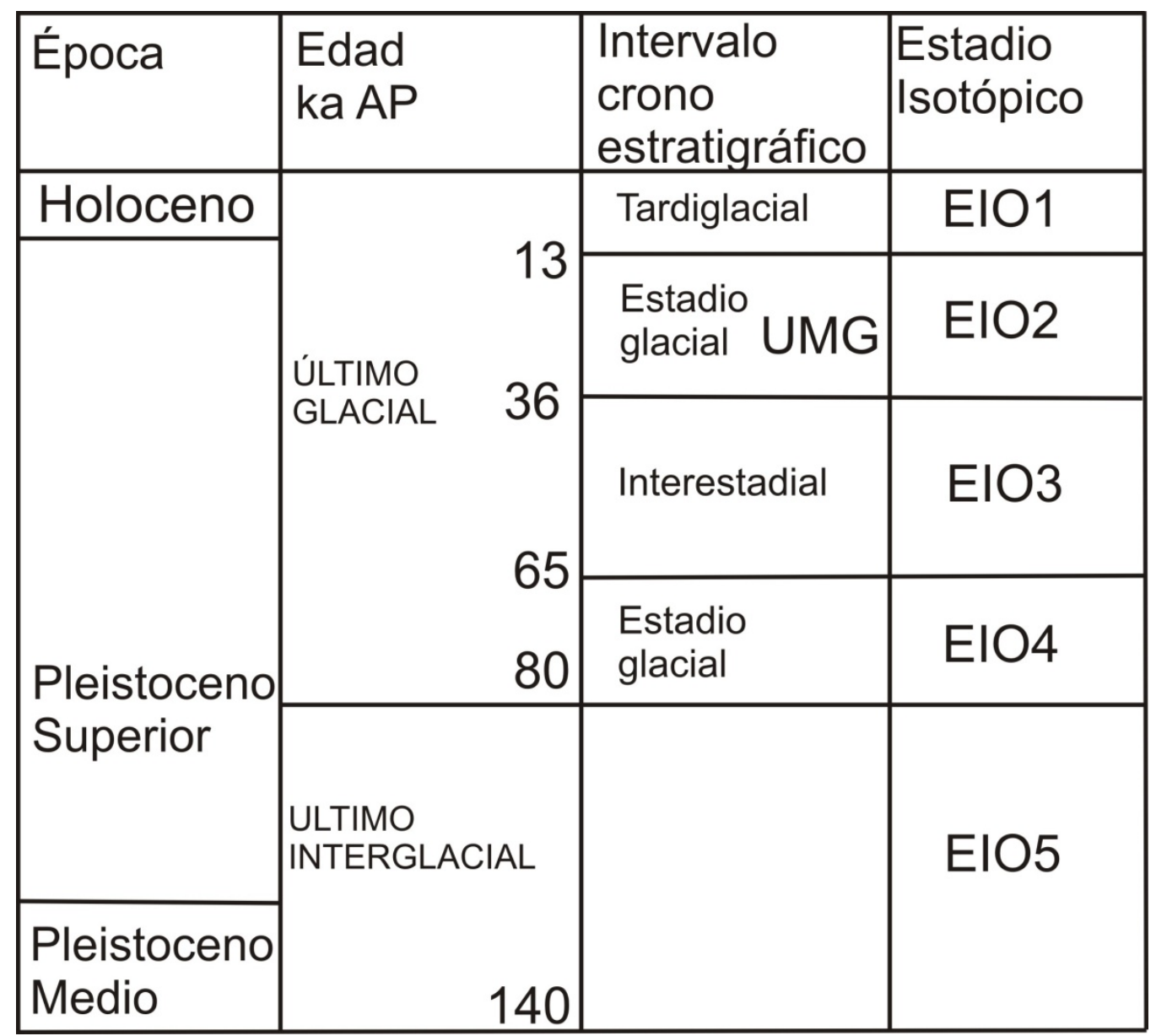

Figura 2.1. Esquema cronológico del Cuaternario Superior, según Iriondo y Kröhling (2008).

\subsection{LA LLANURA PAMPEANA}

La llanura pampeana con una extensión de $600.000 \mathrm{~km}^{2}$, es un área particularmente favorable para estudios paleoclimáticos. Su extensión, homogeneidad geológica y geomorfológica, bajo relieve y cobertura sedimentaria de grano fino, le confieren una gran sensibilidad ante los cambios ambientales (Iriondo, 1994).

\subsubsection{EL LOESS PAMPEANO. DEFINICIONES}

Los sedimentos que cubren la llanura pampeana, fueron denominados originalmente por d'Orbigny (1842) como "argille pampéenne" (arcillas pampeanas) y casi simultáneamente por Darwin (1846) como "Pampean Formation". Bravard (1857) los denomina "Formación pampeana" y unos años más tarde, son llamados "loess pampeano" (Church, 1898; Marshall et al., 
1984; Zárate, 2003). Ameghino (1881) observó que los diferentes estratos de esta "formación" sólo presentan pequeñas diferencias de color que dificultan su diferenciación estratigráfica, indicando que "su color es generalmente rojooscuro, a veces pardo o amarillento. Su composición es en todas partes la misma; una mezcla de arcilla y arena...y conteniendo generalmente una infinidad de concreciones calcáreas..." (1889:27). Frenguelli (1950, 1955), según un criterio netamente geológico, diferenció a los sedimentos pampeanos (denominados por él con un criterio cronoestratigráfico como "Serie Pampiano") en loess y limos. De esta manera, según dicho autor, el loess corresponde a aquellos sedimentos de color uniforme (dentro de la gama del pardo), aspecto homogéneo y muy deleznable, de acumulación eólica sobre superficies secas (loess primario); y el limo, que es el loess removido o resedimentado por las aguas, corresponde a los sedimentos de cauces y cuencas (loess secundario).

El loess de la región pampeana representa el material eólico fino típico del Cuaternario de Sudamérica, abarcando la superficie loéssica más extensa del Hemisferio Sur (Iriondo, 1990a, 1994, Zárate, 2003, Iriondo y Kröhling, 2007), abarcando el centro y norte de Argentina (Bidegain et al., 2007).

Es conveniente aclarar que "loess" es un concepto genético mientras que "limo" implica una granulometría (Tonni com. pers.) concepto que no fue siempre comprendido por los distintos autores.

\subsubsection{AMBIENTE PAMPEANO}

El ambiente pampeano está representado por acumulaciones de sedimentos limo-arcillosos, homogéneos, de color castaño con abundante carbonato de calcio en forma de concreciones, calcretos, venas y tabiques. Constituyen los materiales típicos del Cuaternario de la llanura pampeana, cubriendo la mayor parte de la provincia de Buenos Aires, Santa Fe, y Córdoba, y extensas regiones de provincias vecinas (figura 2.2.). Se depositaron en un ambiente general árido o semiárido, con transporte eólico generalizado y numerosos cuerpos de agua permanentes y semipermanentes. Los sedimentos provienen de regiones periféricas situadas al sur y al oeste, fueron aportados por el viento mediante transporte en suspensión, en forma de polvo atmosférico o nubes de cenizas volcánicas y depositados lentamente en 
una región llana, con dinámica hídrica muy escasa (Iriondo, 1985). Dentro de la homogeneidad general de los depósitos pampeanos, existen tres facies sedimentarias que reflejan los procesos locales a que fueron sometidos los limos y arcillas en el momento de su sedimentación. La facies eólica propiamente dicha está constituida por un loess que forma mantos continuos, independientes de las condiciones morfológicas de su piso, sin estratificación, aspecto terroso homogéneo y deleznable depositado en ambiente subaéreo. Su masa está recorrida por finos canalículos ramificados radiciformes (Iriondo, 1985). Presenta textura migajosa y concreciones calcáreas nodulares (Frenguelli, 1955). Existe una facies palustre bien desarrollada y otra formada por depósitos de derrame (las que no son objeto de este estudio) (Iriondo, 1985).

\subsubsection{LA PAMPA NORTE}

La Pampa es una unidad geográfica y ambiental bien definida en la actualidad y en el Cuaternario superior. Pero esto no ha sido siempre así. La Pampa Norte fue definida por Iriondo (1994) en base a su notable identidad estratigráfica y geomorfológica durante el Cuaternario, que la diferencian claramente de la Pampa Sur. Durante el Pleistoceno y Holoceno, la Pampa Norte (figura 2.2.) estuvo sometida a la influencia de los grandes ríos del litoral y de los sistemas menores provenientes de las Sierras Pampeanas, especialmente los ríos Dulce, Tercero y Quinto en ese orden. Sus sedimentos contienen mayores porcentajes de cuarzo y feldespatos potásicos y menos cantidad de productos volcánicos que los de la Pampa Sur (Iriondo y Kröhling, 2003).

\subsubsection{EL SISTEMA EÓLICO PAMPEANO}

La cubierta loéssica pampeana forma parte del sistema sedimentario eólico cuaternario de la gran Ilanura argentina, denominado "Sistema Eólico Pampeano" (SEP) por Iriondo (1990a) e Iriondo y Kröhling (1995) (figura 2.3.). Este sistema está compuesto por el "Mar de Arena Pampeano" (MAP), que integra la mitad sur de la Pampa y por la "Faja Periférica Loéssica" (FPL), 
desarrollada al noreste del Mar de Arena. Los sedimentos que componen este sistema sedimentario fueron acumulados durante los primeros estadios de desarrollo de la última glaciación pleistocénica. Posteriormente fueron retrabajados durante fases áridas sucesivas y sujetos a pedogénesis en períodos húmedos (Iriondo y Kröhling, 1995).

El Sistema Eólico Pampeano fue formado durante el Último Máximo Glacial. El manto de hielo cubrió entonces una gran área al sur de los $28^{\circ} \mathrm{S}$, permitiendo la ocurrencia de un anticiclón que produjo vientos de dirección SSO-NNE. El resto de la cordillera Argentina, al norte de los $28^{\circ} \mathrm{S}$, estuvo casi libre de hielo (figura 2.3.). La razón de esto fue la severa sequedad del clima, más que una temperatura moderada. Tal ambiente se volvió muy eficiente en la producción de limo, arena fina e illita, a partir de la meteorización física. El sedimento fue transportado hacia el sur a lo largo del piedemonte cordillerano por el sistema fluvial del Bermejo-Desaguadero- Salado, y llevado hacia el norte por vientos del SSO desde el Desaguadero inferior (en el sur de las provincias de Mendoza y La Pampa) (Iriondo, 1994). En aquella región, cerca del límite norte de la Patagonia, el mar de arena comenzó a desarrollarse en condiciones de desierto frío. Los campos de dunas longitudinales vuelven evidente el clima desértico imperante y el abundante suministro de arena. Hacia el NNE, el clima en la llanura fue peridesértico, lo que permitió la precipitación y la fijación del polvo transportado en suspensión por el viento y así la formación del manto de loess (Iriondo, 1994). La provincia climática Patagónica avanzó hacia el noreste unos $750 \mathrm{~km}$, alcanzando el centro de Santa Fe, y el sur de Entre Ríos (figura 2.3.) (Iriondo y García, 1993).

La Faja Periférica de Loess (FPL) bordea al MAP por tres costados: este, norte y este-sureste (figura 2.3.). El perímetro del contacto con el mismo tiene una extensión de unos $1800 \mathrm{~km}$. El ancho típico de la faja oscila entre 250 y $300 \mathrm{~km}$. El loess cubre las zonas más pobladas del norte y este de Buenos Aires, sur de Santa Fe y este de Córdoba (Iriondo y Kröhling, 1995) y extensas regiones de provincias vecinas, (Iriondo, 1985). En realidad la cobertura loéssica es parcial en algunas áreas, tiene un espesor típico de 7 a $10 \mathrm{~m}$ en las zonas planas del centro de Santa Fe y Córdoba y de 4 a 7 m más al norte. En las barrancas de los arroyos aparece sistemáticamente con $2 \mathrm{~m}$ de potencia. Está compuesto por limo arenoso o por una mezcla franca limosa suelta, de 
color castaño, friable, con disyunción columnar y frecuentes concreciones de carbonato de calcio. Presenta crotovinas, moldes de raíces, grandes hormigueros rellenados y surcos de erosión eólica dentro de la columna sedimentaria. Asociados a la facies típica aparecen en el perfil de la formación depósitos de pantanos. (Iriondo y Kröhling, 1995).

El contacto entre el Mar de Arena Pampeano y la Faja de Loess es una zona de transición de 5 a $15 \mathrm{~km}$ de ancho, la que resulta sorprendentemente estrecha si se consideran las dimensiones de ambos ambientes sedimentarios. El límite "externo" del loess es difícil de definir en todo el norte y el oeste del sistema, debido a que pasa en transición a sistemas semejantes en el Chaco y en los bolsones. Por el contrario, en Entre Ríos y en la República Oriental del Uruguay limita con unidades geológicas claramente diferentes. Se ven en ese sector límites netos, donde el loess desaparece en pocos metros en el terreno en una línea bien marcada (Iriondo y Kröhling, 1995).

\subsubsection{GÉNESIS DEL LOESS PAMPEANO}

De acuerdo con Iriondo y Kröhling (1995), el origen de los sedimentos del SEP está vinculado a los procesos y sistemas geomorfológicos ubicados al oeste, en la Alta Cordillera y Precordillera y el Piedemonte Cordillerano. El más importante de éstos es el sistema hidrográfico del Bermejo-DesaguaderoSalado. En la actualidad la red está desintegrada y es básicamente inactiva, debido al clima desértico del área. Durante períodos más húmedos del Cuaternario superior los cauces condujeron grandes caudales (Iriondo y Kröhling, 1995). Durante el Cuaternario superior los ríos formaron terrazas periglaciales en los valles y extensos abanicos aluviales en zonas de piedemonte. El escenario completo sugiere una alta producción de sedimentos finos y transporte de los mismos por crecidas de deshielo hacia las tierras bajas. En general, existe en toda la región gran cantidad de sedimentos similares a los limos y arenas de la Pampa (Iriondo y Kröhling, 1995). Teruggi (1957) postula que los sedimentos pampeanos se originaron en lluvias de cenizas de volcanes cordilleranos. Para Blarasín y Sánchez (1987) los sedimentos pampeanos provienen de las Sierras Pampeanas, un complejo ígneo-metamórfico ubicado entre los $27^{\circ}$ y los $34^{\circ} \mathrm{S}$, al norte del MAP (Iriondo y 
Kröhling, 1995). Otros autores sostienen que el loess pampeano corresponde a sedimentos eólicos, ricos en magnetita y titanomagnetita, transportados por vientos fuertes procedentes de la Cordillera Patagónica durante periodos glaciales (Bidegain et al., 2007). Estos trabajos, que incluyen estudios de susceptibilidad magnética, señalan que el modelo de depositación del loess en Argentina es intermedio entre el de China (pedogenesis model) y el de Siberia (wind vigourous model) (Bidegain et al., 2001; Bidegain y Rico, 2004; Bidegain et al., 2007). Por último, Rabassa et al. (2005) adjudican el depósito del loess pampeano a la actividad eólica generada por las condiciones climáticas glaciales, las cuales influenciaron los centros anticiclónicos marinos (tanto en el Pacífico como en el Atlántico), desplazándolos hacia el norte (Rabassa et al, 2005).

El modelo sobre el origen del sistema morfosedimentario desarrollado en la llanura pampeana durante el Último Máximo Glacial (UMG), que se adoptó en este trabajo de tesis, fue el propuesto por Iriondo y Kröhling $(1995,2007)$ basado en estudios geomorfológicos, granulométricos y mineralógicos.

De la misma manera que otros grandes sistemas eólicos derivados de glaciaciones ubicados en Asia y América del Norte, el SEP está compuesto por un Mar de Arenas (MAP) en la región central y una Faja Periférica de Loess (FPL). Ello se debe a que los vientos que soplan desde los campos de hielo transportan la arena por saltación y arrastre en las planicies más afectadas por la aridez. Los mismos vientos transportan más lejos en suspensión, en forma de nubes de polvo, a las fracciones limo y arcilla. Estas quedan atrapadas por la vegetación herbácea de las zonas peridesérticas y forman finalmente un manto de loess. El Mar de Arena Pampeano (MAP) forma en superficie un cuerpo irregular de $200.000 \mathrm{~km}^{2}$, que se extiende en el centro de Argentina entre las longitudes de $59^{\circ} \mathrm{O}$ y $67^{\circ} \mathrm{O}$ y las latitudes de $33^{\circ} \mathrm{S}$ y $38^{\circ} \mathrm{S}$. Está compuesto en su mayor parte por arena muy fina y fina limosa, con arcillas dominadas por minerales del grupo de la illita. Tiene pocos metros de espesor y cubre limos endurecidos del Pleistoceno Medio en los sectores este y norte. En el oeste (provincias de La Pampa y San Luis) el espesor del MAP es aún desconocido, debido a que esta arena cubre otras formaciones arenosas de similar granulometría. (Iriondo y Kröhling ,1995). 


\subsubsection{FORMACIÓN TEZANOS PINTO}

Esta Formación fue definida formalmente por Iriondo en las provincias de Entre Ríos y Santa Fe (1980 y 1987, respectivamente). Está compuesta por limos eólicos, cubriendo en forma de manto tabular continuo las formaciones del Cuaternario Inferior de la cuenca, con un espesor de 2 a $7 \mathrm{~m}$, constituyendo la unidad típica del Cuaternario de la llanura pampeana. Dentro de la homogeneidad de este depósito Iriondo (1987) e Iriondo y Manavella (1990) reconocieron una serie de facies sedimentarias que reflejan los procesos locales a los que fue sometido el limo en el momento de su sedimentación. La más importante de estas facies es la de loess primario o facies eólica. Arealmente el espesor común de loess primario oscila entre 2 y $4 \mathrm{~m}$, aparece con buen desarrollo en canteras ubicadas en las zonas de interfluvios del centro-sur de la provincia de Santa Fe y del SE de Córdoba (Iriondo y Kröhling, 1995). La facies primaria está integrada por un loess pardo brillante en húmedo (7,5 YR 5/6) y pardo anaranjado mate en seco (7,5 YR 7/3), constituido por limos con poca cantidad de arcilla y escasa o nula fracción arenosa apreciable, masivo, de estructura migajosa, pulverulento y friable, estructurado en general en bloques angulares medios a gruesos, muy débiles. En general con alto contenido de carbonato de calcio (Iriondo y Kröhling, 1995). En las zonas de interfluvio, Kröhling, 1998a y b, diferencia dos miembros, separados por una discordancia erosiva intraformacional. El miembro inferior, de 2 a $3 \mathrm{~m}$ de potencia, es un loess de consolidación media. Fue acumulado en ambiente subaéreo y en sectores con drenaje deficiente, representado por pantanos no permanentes con períodos de exposición subaérea. El miembro superior, de 2 a $4 \mathrm{~m}$ de espesor, corresponde al típico loess pampeano, friable, masivo y poco calcáreo, característico de un ambiente de depositación subaéreo. Localmente aparecen relictos de un suelo intraformacional coincidente con el nivel de discordancia (Kröhling, 1998a y b).

En la Pampa Norte la Formación Tezanos Pinto descansa en discordancia erosiva sobre arenas eólicas de un campo de dunas originado en el Pleistoceno Superior ("Gran Mar de Arenas Pampeano", (muy probablemente del EIO 4) y posteriormente afectado por disipación (Formación Carcarañá, EIO 3; Kröhling, 1998a y b). El techo de la Formación Tezanos 
Pinto está generalmente señalado por una discordancia erosiva bien visible sobre la que yace la Formación San Guillermo, mientras que en algunos lugares la Formación Tezanos Pinto corona la secuencia estratigráfica (Iriondo y Kröhling, 1995).

La Formación Tezanos Pinto fue originada en un rango de depositación que abarca entre los 36.000 a los a los 8.500 a A.P. (Pleistoceno TardíoHoloceno Temprano) (Iriondo y Kröhling, 1996). De acuerdo con dataciones por TI y OSL ((Optically Stimulated Luminescence) de la Formación Tezanos Pinto (Kröhling, 1998a y b), el miembro inferior se depositó durante el Último Máximo Glacial-entre 36.000 y 16.000 años A.P.-, mientras que el miembro superior fue acumulado durante el Período Seco del Pleistoceno Tardío-Holoceno Temprano -entre 14.000 y 8.000 años A.P-.

\subsubsection{LOMADAS LOÉSSICAS DE CRESPO}

Iriondo (1998) distingue en la provincia de Entre Ríos siete regiones (figura 2.4.) desde el punto de vista geomorfológico: 1. Pantanos del Yacaré; 2. Superficie Feliciano-Federal; 3. Faja arenosa del río Uruguay; 4. Lomadas Loéssicas de Crespo; 5 . Colinas de Gualeguaychú; 6. Unidad de Rosario del Tala; 7. Delta del Paraná.

La Unidad Geomorfológica Lomadas Loéssicas de Crespo se extiende en el sudoeste de la provincia, y están caracterizadas por un paisaje de planicie ondulada a suavemente ondulada, con pendientes cortas y compuestas de 3$5 \%$ de inclinación. El material de origen eólico o loess (Formación Tezanos Pinto) presenta moderado espesor (1 a $5 \mathrm{~m}$ ), cubre la región como un manto continuo, adelgazándose hacia el este-sureste con el consiguiente afloramiento de los materiales más antiguos subyacentes del Grupo Punta Gorda. Es característica del área la erosión fluvial en épocas de grandes lluvias. En esta región se registran las mayores alturas topográficas del territorio con 100 m.s.n.m. (Iriondo, 1998). 


\subsubsection{LA FORMACIÓN TEZANOS PINTO EN ENTRE RÍOS}

Durante el Cuaternario la provincia de Entre Ríos ha sufrido una evolución geológica de origen básicamente climático. En el Pleistoceno Inferior los grandes ríos Paraná y Uruguay depositaron las formaciones Ituzaingó y Salto Chico, arenosas y con decenas de metros de espesor. Después se estableció un ambiente pampeano con sedimentación de limos calcáreos (Grupo Punta Gorda) que evolucionó hacia la aridez en el Pleistoceno Superior (Formación Hernandarias) posteriormente se produjo la erosión generalizada de los valles semiárido (Formación Tezanos Pinto) durante el Holoceno se produjo un clima árido (arenas eólicas asociadas al río Uruguay) y finalmente se establecieron las condiciones actuales (Iriondo, 1998; Iriondo y Kröhling, 2008). La estratigrafía aflorante en el sudoeste de Entre Ríos se presenta en la figura 2.5 .

Como se dijo anteriormente, en el sudoeste de la provincia de Entre Ríos la Formación Tezanos Pinto forma la Unidad Geomorfológica Colinas Loéssicas de Crespo (figura 2.4.) (Iriondo, 1998), que se halla en contacto lateral por el noreste con la Unidad Geomorfológica Superficie FelicianoFederal (Formación Hernandarias, Pleistoceno Temprano) y por el sudoeste con el Complejo deltaico (=Complejo Litoral del Paraná, Holoceno) (Iriondo, 1998). En dicha área, la Formación Tezanos Pinto cubre el relieve en forma de manto de 2-5 $\mathrm{m}$ de espesor. Hacia el este ha sido parcialmente erodada y se encuentra presente sólo en las partes altas del paisaje hasta cerca del río Gualeguay. Al norte del arroyo Antoñico (ciudad de Paraná) aparece con reducidos espesores (1-1,5 $\mathrm{m}$ ) cubriendo una faja de 5-10 km de ancho hasta cerca de La Paz. En los valles fluviales del área este paisaje se interrumpe con el afloramiento de dos tipos de terrazas: la más antigua correspondiente a la Formación Arroyo Feliciano subyacente a los depósitos de la Formación Tezanos Pinto, y la terraza más reciente que corresponde a la Formación La Picada (Iriondo, 1998). En la barranca del río Paraná y en las áreas de interfluvio cercanas, la Formación Tezanos Pinto yace en discordancia erosiva sobre las unidades que integran el Grupo Punta Gorda (Formación Alvear; Formación La Juanita y Formación Punta Gorda), del Pleistoceno Temprano (Iriondo y Kröhling, 2008), con espesores típicos de 2 a $3 \mathrm{~m}$. En el interior de 
paleovalles fluviales, la unidad apoya en discordancia erosiva sobre la Formación Arroyo Feliciano. En el área norte de las "Colinas Loéssicas de Crespo", la Formación Tezanos Pinto yace en discordancia sobre la Formación Hernandarias (Iriondo et al., 2000).

La facies de loess primario de la formación en estudio domina ampliamente en el SO de Entre Ríos. En cuanto a su composición, es una unidad loéssica constituida granulométricamente por limo arcilloso y muy escasa arena fina (menos del $5 \%$ ); la grava basal aparece solo en el fondo de los valles. Es friable, contiene abundante carbonato en concreciones de hasta un centímetro de largo. Mineralógicamente está constituida por cuarzo con escasas plagioclasas y fragmentos de vidrio volcánico; la asociación de minerales pesados comprende turmalina, circón, rutilo, estaurolita, entre otros, típica de materiales provenientes del escudo brasileño. Esta formación fue originada por sedimentación de partículas finas transportadas en suspensión por el viento en una época de clima árido o semiárido. Cubre en forma de manto las irregularidades preexistentes del paisaje. Considerando su composición mineralógica y distribución, se deduce que la mayor parte de sus materiales originarios proviene de fuentes locales (Iriondo, 1980). 


\subsection{MARCO GEOGRÁFICO Y GEOMORFOLÓGICO}

La región mesopotámica incluye una amplia región comprendida entre los ríos Paraná y Uruguay e involucra los territorios de las provincia de Misiones, Corrientes y Entre Ríos, abarcando una superficie de aproximadamente $200.000 \mathrm{~km}^{2}$ (Aceñolaza, 2007). La provincia de Entre Ríos abarca un área de aproximadamente $70.000 \mathrm{~km}^{2}$ y está localizada entre las latitudes de $28^{\circ}$ y $32^{\circ} \mathrm{S}$ y entre las longitudes de $58^{\circ}$ y $60^{\circ} 30^{\prime} \mathrm{O}$. El paisaje general está determinado por la morfología resultante de la acción de los ríos principales: Paraná y Uruguay, y sus tributarios. Entre los últimos debe destacarse el Río Gualeguay, que a modo de columna vertebral, divide el territorio provincial en dos amplias regiones (Iriondo, 1998; Aceñolaza, 2007). El paisaje dominante es la peniplanicie, formación estructural muy antigua, que fuera elevada y basculada como consecuencia de las últimas etapas de la orogénesis sobre los bloques de las formaciones pampeanas a fines del Terciario (Mioceno- Plioceno, sensu Frenguelli, 1920). En la actualidad ésta peniplanicie es en su mayor parte ondulada o suavemente ondulada e interrumpida por relleno de materiales coluvio-aluviales sobre los principales fallamientos que constituyen los arroyos más importantes de la región, es sobre este paisaje que se depositaría finalmente el material loéssico de origen eólico (manto de loess) de moderado espesor de acuerdo a las condiciones del paisaje previo.

\subsubsection{CLIMA}

La zona pertenece al clima templado húmedo de la llanura, que se caracteriza por su condición de peniplanicie abierta sin restricciones a la influencia de los vientos húmedos del noreste, al accionar de los vientos secos y refrigerantes del sudoeste (causantes de los cambios repentinos del tiempo) y a los vientos del sudeste (aire frío saturado de humedad, que da lugar a semanas enteras de cielo cubierto, lluvias y temperaturas muy estables). Su temperatura es templada, la media anual es de $18,2^{\circ} \mathrm{C}$ y varía entre $24,7^{\circ} \mathrm{C}$ en enero y $12^{\circ} \mathrm{C}$ en julio, representando una amplitud térmica de $12,7^{\circ} \mathrm{C}$.; las precipitaciones es uno de los factores más importantes en la climatología 
general, la media anual es de $985,4 \mathrm{~mm}$ (Plan Mapa de Suelos, INTA, 1991). Otros datos más recientes informan una temperatura media anual de $18^{\circ} \mathrm{C}$ y una amplitud térmica de $13,5^{\circ} \mathrm{C}$. Las precipitaciones cuentan con una media mensual de 89,1 mm y anual de 1069,1 mm (Climograma de la ciudad de Paraná, INTA 1991).

\subsubsection{FLORA}

En cuanto a la vegetación, el área de estudio se encuentra fitogeográficamente dentro de la Provincia Pampeana (del Dominio Chaqueño) Distrito Uruguayense, con excepción de las costas que sustentan comunidades serales de selvas marginales pertenecientes a la Provincia Paranaense, Distrito de la Selvas Mixtas. (Cabrera, 1976; Cabrera y Willink, 1973), o Región Neotropical, Subregión Chaqueña, Provincia Pampeana (Morrone, 2001). En líneas generales la Provincia Pampeana es la de mayor extensión y se caracteriza por la predominancia absoluta de gramíneas, principalmente de las tribus Paniceae y Andropógeneae (Paspalum sp., Axonopus sp., Digitaria sp. Schyzachyrium sp., Botrhiochloa sp., etc.) Entre las hierbas no graminiformes hay una serie de géneros primaverales muy constantes como Gamochaeta, Chaptalia, Aster, Chevreulia, Oxalis, Adesmia, etc. Entre los arbustos son comunes los géneros Heimia, Baccharis, Eupatorium y otros. (Plan Mapa de Suelos, INTA, 1991).

Los pastizales templado-húmedos en América del Sur, denominados Pastizales del Río de la Plata, se extienden desde los $28^{\circ}$ a los $38^{\circ} \mathrm{S}\left(31^{\circ}-39^{\circ}\right.$, Cabrera, 1976), e incluyen las planicies centro-este de Argentina, Uruguay y Sur de Brasil. Se dividen en dos subregiones denominadas pampas (provincia de Buenos Aires y parte de Santa Fe, Córdoba, la Pampa, San Luis y Entre Ríos) y campos (Uruguay y el sur de Brasil) (Soriano, 1991).

Por su extensión, las Pampas constituyen el más importante ecosistema de praderas de la Argentina, y suman en total unos $600.000 \mathrm{~km}^{2}$. Poseen un relieve relativamente plano, con una suave pendiente hacia el Océano Atlántico. Existen suelos aptos para la agricultura y la ganadería, aunque esta aptitud declina acompañando un gradiente de isohietas anuales que varía entre los $1.000 \mathrm{~mm}$ al noreste y los $400 \mathrm{~mm}$ al sudoeste. La región pampeana puede 
subdividirse en seis regiones relativamente homogéneas: Pampa Ondulada, Pampa Central, Pampa Semiárida, Pampa Austral, Pampa Deprimida y Pampa Mesopotámica (Viglizzo et al. 2005). La flora nativa de las Pampas comprende unas mil especies de plantas vasculares (León, 1991). La praderas estuvieron originalmente dominadas por gramíneas, entre las que predominaron los géneros Stipa, Poa, Piptochaetium y Aristida. Aunque disminuida en la actualidad, la fauna nativa de la pradera pampeana incluía abundantes mamíferos y aves (Krapovickas y Di Giacomo, 1998; Real et al., 2003; en Viglizzo et al. 2005). 


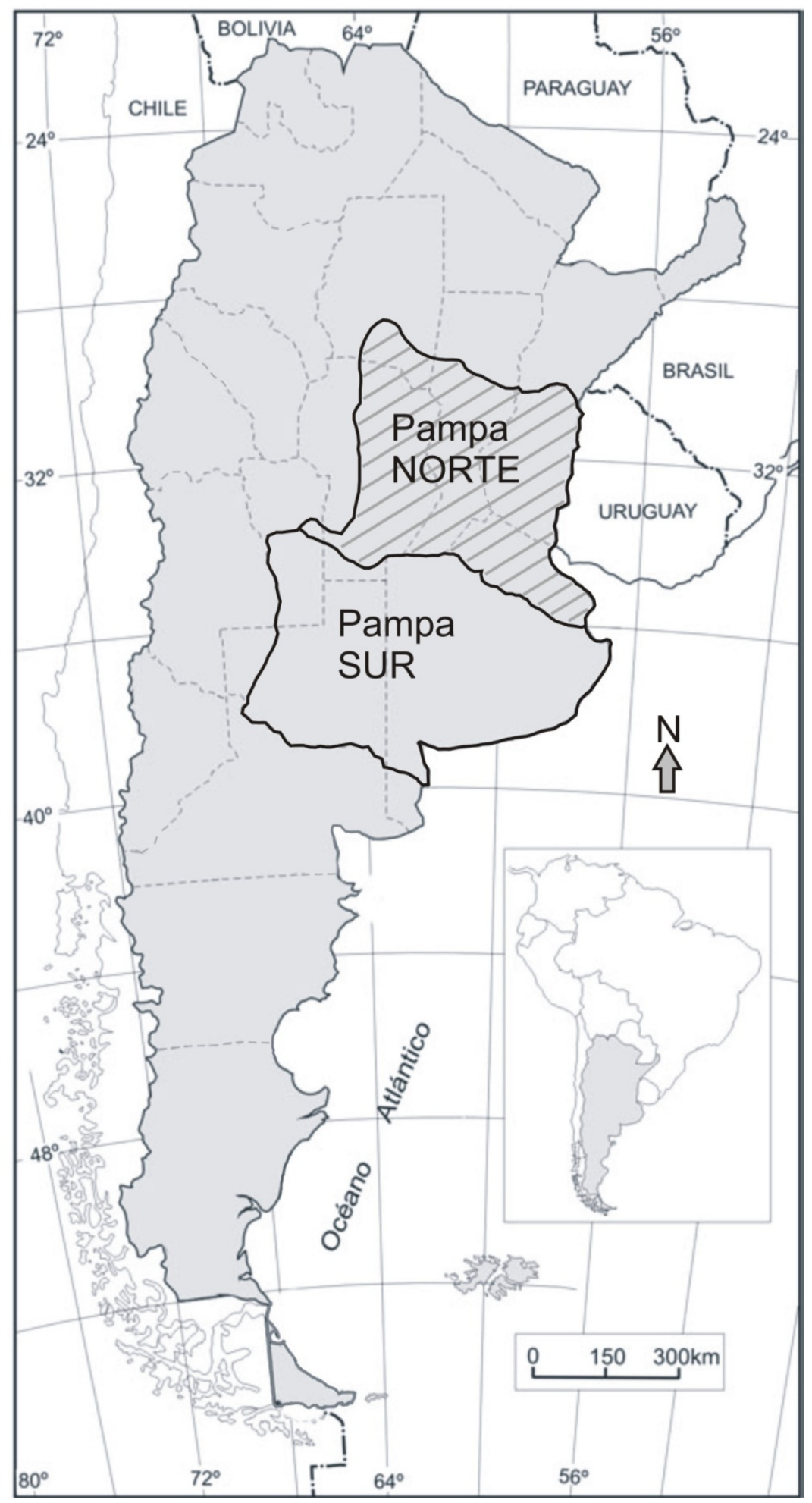

Figura 2.2. Mapa de ubicación de la Pampa Norte y la Pampa Sur, modificado de Iriondo (1994). 


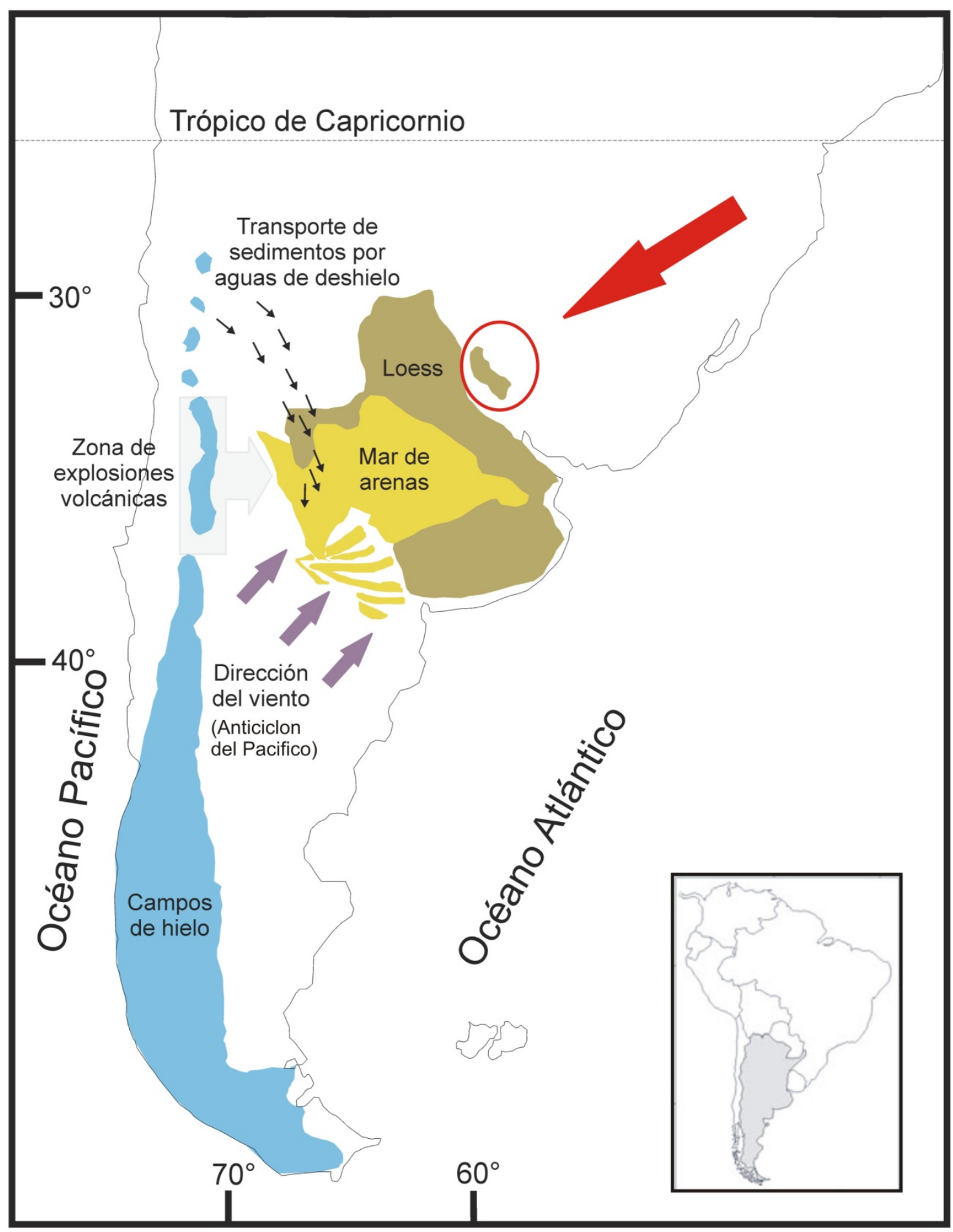

Figura 2.3. Mapa donde se esquematiza el sistema morfosedimentario desarrollado en la Ilanura pampeana durante el Último Máximo Glacial (UMG), según Iriondo y Kröhling (1995). 


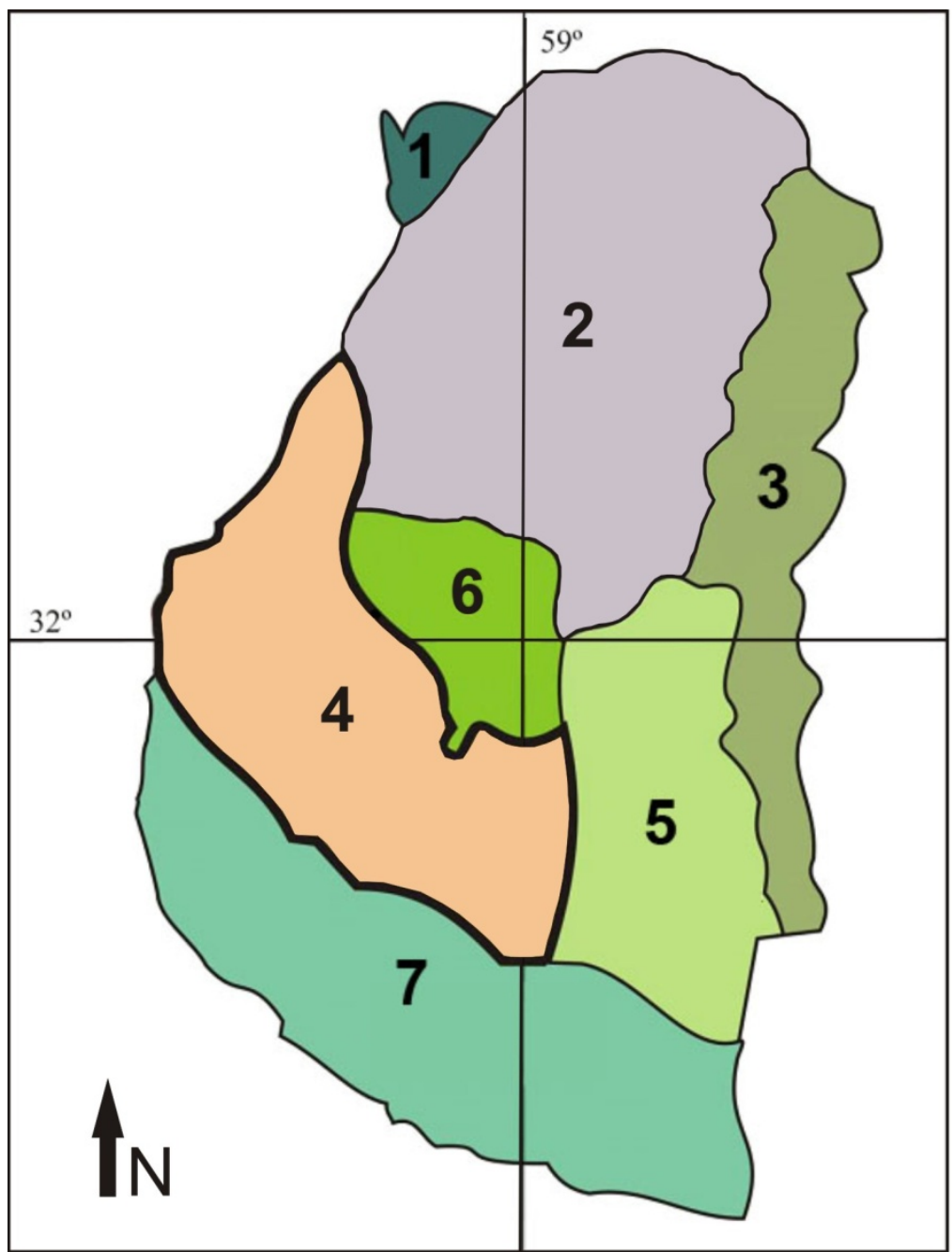

1.Pantano del Yacaré

2.Superficie Feliciano Federal

3.Faja Arenosa del Río Uruguay

4.Lomadas Loéssicas de Crespo

5.Colinas del Gualeguaychú

6.Unidad Rosario del Tala

7.Complejo Deltaico

Figura 2.4. Mapa de la provincia de Entre Ríos donde se diferencian las Unidades geomorfológicas según Iriondo (1998).Nótese que la Unidad 4, Lomadas Loéssicas de Crespo, se corresponde con el área circunscripta en rojo en la figura 2.3 . 


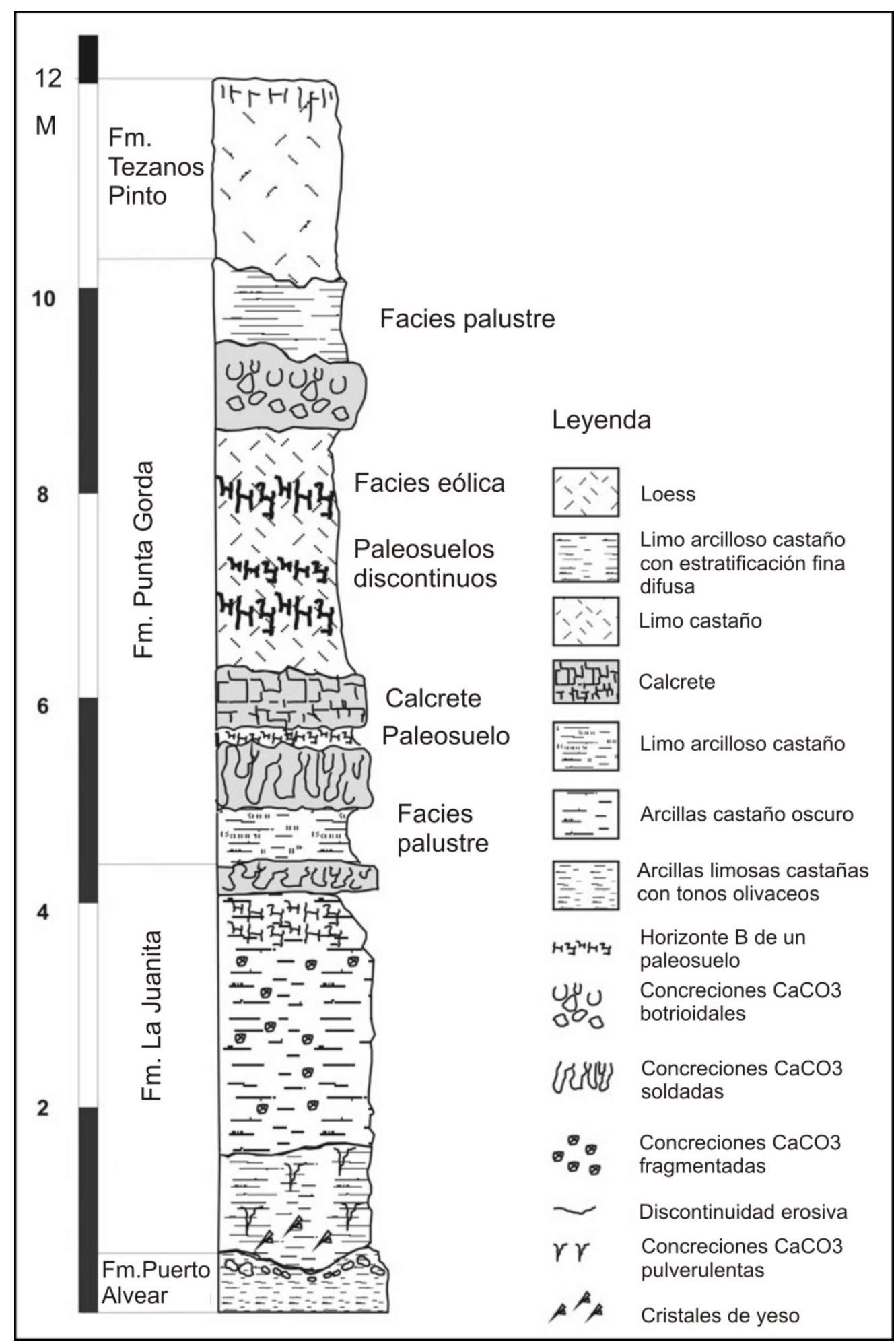

Figura 2.5. Perfil Punta Gorda, representativa del sudoeste de la provincia de Entre Ríos, según Iriondo y Kröhling (2009). 


\subsection{BIOMINERALIZACIONES}

La biomineralización es el proceso de precipitación de minerales como resultado del funcionamiento metabólico de los organismos vivos. La producción de estos minerales es consecuencia de la actividad celular y es lo que distingue la biomineralización de la mineralización inorgánica (Osterrieth, 2007a).

Las funciones biológicas beneficiosas de los biominerales son numerosas, aparte de conferir una integridad estructural al organismo, los biominerales actúan como un sistema de almacenamiento de los iones que deben ser movilizados en caso de ser requeridos (Osterrieth, 2007a).

Una biomineralización se forma generalmente con carbonato de calcio, oxalato de calcio, sílice amorfo, óxidos y oxihidróxidos de hierro y/o manganeso (Lowenstam, 1981) como material predominante, y por desintegración de los tejidos a la muerte de los organismos que la producen estos corpúsculos pasan a formar parte de los materiales clásticos con carácter de subfósiles, permaneciendo in situ o dispersándose por los agentes geológicos que los llevan a participar así del circuito de los materiales terrestres (Bertoldi de Pomar, 1970).

Se designa con el nombre de biolito a todo cuerpo mineralizado integrante de tejidos orgánicos producido por sustancias ergásticas (sustancias producidas por la actividad metabólica propia o como resultado de la misma, Zucol et al., 2005c; productos visibles del metabolismo que se depositan en células o cavidades; Metcalfe, 1963; Bertoldi de Pomar, 1975). Estos biolitos, se pueden clasificar según el tipo de organismo productor de la biomineralización en: fitolitos (phytolitharien para Ehrenberg, 1841; 1854), aquellos de origen vegetal, y zoolitos (zoolitharien para Bailey, 1856), los de origen animal (Bertoldi de Pomar, 1970 y 1975; Zucol, 1992). En el primer grupo se encuentran, por ejemplo, las células silíceas de gramíneas, estomatocistes de Chrysostomataceae y frústulos de diatomeas; el segundo incluye las espículas de esponjas (Bertoldi de Pomar, 1975). Del mismo modo en que se los diferencia según el organismo productor, se los puede diferenciar por su composición química, así, los formados por compuestos silíceos se denominan silicobiolitos (silicofitolitos o silicozoolitos), y los formados por 
compuestos cálcicos calcibiolitos (calcifitolitos o calcizoolitos), (Bertoldi de Pomar, 1975).

\subsection{FITOLITOS}

Si bien ya se aclaró la diferencia entre los términos "fitolitos" y "silicofitolitos" estos suelen utilizarse de manera indistinta aunque se haga referencia a fitolitos de sílice exclusivamente. En el presente trabajo de tesis se usará término "fitolitos" para designar a aquellas biomineralizaciones de origen vegetal y composición silícea (compuestos amorfos de sílice hidratada), que son el propósito del estudio.

Los fitolitos se originan como depósitos de sílice amorfa hidratada $\left(\mathrm{SiO}_{2} \cdot \mathrm{nH}_{2} \mathrm{O}\right)$ en espacios inter o intracelulares de los tejidos vegetales (Blackman, 1971; Piperno, 1988; 2006). La concentración de los fitolitos en la planta varía con la etapa fenológica del vegetal, como así también, en relación con las diferentes partes de la planta (Bertoldi de Pomar, 1975; Zucol, 2001). La concentración de sílice amorfa varía de acuerdo a los procesos metabólicos que acompañan la vida de la planta, y a la localización de muchos de estos procesos en ciertos órganos. Parry y Smithson (1958) describen el proceso de silicificación de células bulliformes foliares de gramíneas, y observan que esta biomineralización se incrementa en etapas próximas a la desecación de la hoja, que es cuando estas células pierden su importancia funcional en la apertura y cierre higroscópico de la hoja, como así también en el almacenamiento de agua.

El silicio es absorbido por las raíces en forma de ácido monosilícico $\left(\mathrm{H}_{4} \mathrm{SiO}_{4}\right)$ de la solución del suelo y llega a su destino final transportado por el xilema. Las morfologías que adoptan estas biomineralizaciones, generalmente, reflejan la forma de la célula vegetal donde han sido depositados (Parry y Smithson, 1964; Blackman, 1971; Epstein, 1994). El contenido de sílice y la formación de fitolitos en las plantas dependen de factores intrínsecos y/o extrínsecos o ambientales. Entre los primeros suelen citarse el estado fenológico del ejemplar analizado, el órgano estudiado, la capacidad y el mecanismo de absorción de ácido monosilícico y de su depositación. Entre los factores extrínsecos que influyen a corto o largo plazo se mencionan el 
contenido y disponibilidad de ácido monosilícico en el suelo (el que a su vez depende del $\mathrm{pH}$ del suelo y de la presencia de óxidos de hierro y aluminio), temperatura (ya que incrementa la tasa de transpiración, la que estaría asociada al proceso de depositación y/o absorción de sílice) y herbivoría (Parry y Smithson, 1964; Jones y Handreck, 1967; Sangster y Parry, 1971; Bertoldi de Pomar, 1975; McNaughton et al., 1985; Epstein, 1994). Sin embargo, estudios recientes consideran que el contenido de sílice en un taxón sería más dependiente de su posición filogenética que de los factores ambientales (Hodson et al., 2005).

\subsubsection{Beneficios de la acumulación de sílice}

La acumulación de sílice en los tejidos vegetales resulta beneficioso para ciertas especies ya que constituye un mecanismo de defensa frente a la herbivoría, ataques fúngicos y de parásitos. Asimismo, representa un componente que le otorga soporte y sostén a las hojas y tallos. La incorporación de sílice a la pared celular tiene dos efectos energéticos positivos: por un lado el rol de la sílice es análogo al de la lignina, ya que es un componente estructural compresivo-resistente. El costo energético de incorporar sílice es $3,7 \%$ del costo de la lignina. Por otro lado, favorece el hábito erecto y la disposición de las hojas lo que permite una mayor intercepción solar y mayor tasa fotosintética (Epstein, 1994). Algunos estudios han demostrado que la adición de sílice al suelo incrementa la producción de biomasa vegetal y disminuye la toxicidad de determinados metales pesados como el manganeso, el plomo y el zinc. A niveles tóxicos de $\mathrm{Mn}$, el agregado de Si disminuye la toxicidad, ya que aumenta la capacidad del tejido foliar a tolerar el $\mathrm{Mn}$ en plantas de arvejas. En algunos casos (cebada), el Si no disminuye la concentración de $\mathrm{Mn}$ sino que favorece su mejor distribución en toda la planta (Jones y Handreck, 1967; McNaughton et al., 1985; Epstein, 1994). El Si favorece la resistencia al estrés salino en arroz y trigo, disminuyendo la concentración de $\mathrm{Na}$ (Epstein, 1994). 
3.2.2. Producción de fitolitos, asignación sistemática y patrones fotosintéticos

Debido a que los fitolitos adoptan, en general, la forma de la célula vegetal hospedante, es que se hace posible asociar una morfología fitolítica con una célula vegetal y un tejido. Varios trabajos anatómicos describen y clasifican las células silíceas (o fitolitos), según los tejidos y órganos analizados (Metcalfe, 1960; Tomlinson, 1961; Ellis, 1979). De la misma manera, es posible identificar las familias, subfamilias y en algunos casos, los géneros y/o especies que los han producido, constituyendo una importante herramienta de identificación de taxones vegetales. Numerosos estudios han señalado y demostrado la relación entre las morfologías fitolíticas y la sistemática (Twiss et al., 1969; Brown, 1984; Piperno, 1988; Rapp y Mulholland, 1992) (figuras 3.1. y 3.2.).

Los fitolitos están presentes en todo el reino vegetal, pero es en los vegetales superiores donde su identificación y asignación sistemática se torna más controvertida. En lo que respecta a su producción, los fitolitos se encuentran en representantes de pteridofitas, gimnospermas y angiospermas (Piperno, 1988; Pearsall, 2000), siendo ciertas familias de las monocotiledóneas (como Poaceae, Cyperaceae, Arecaceae) las principales productoras. En estos vegetales la presencia de sílice se encuentra asociada no sólo a procesos metabólicos intrínsecos, sino también al crecimiento y productividad del vegetal, y a fenómenos de resistencia a enfermedades, toxicidades, ataques de insectos y efectos producidos por la herbivoría (Rovner, 1988).

La familia Poaceae es la principal productora de fitolitos, por lo que constituye el taxón más estudiado (Piperno, 1988). Los primeros trabajos que describen y clasifican los fitolitos dentro de esta familia son principalmente anatómicos (Metcalfe, 1960; Ellis, 1979). Posteriormente, la aplicación de estas biomineralizaciones como indicadores de comunidades vegetales impulsó a los estudios fitolíticos y surgieron numerosos trabajos que no sólo clasifican las morfologías, sino que también logran asociarlas con las distintas subfamilias (Twiss et al., 1969; Brown, 1984; Mulholland, 1989; Rapp y Mulholland, 1992). 
Asimismo, fue posible asociar las morfologías con los patrones fotosintéticos $\mathrm{C}_{3}$ y $\mathrm{C}_{4}$ (figuras 3.1. y 3.2.) de la especie productora, permitiendo la utilización de los fitolitos en estudios paleoambientales no sólo como indicadores de cambios en las comunidades vegetales a lo largo del tiempo sino también de los cambios climáticos (Twiss, 1992). El potencial diagnóstico de los fitolitos de gramíneas y su durabilidad en suelos hacen del análisis fitolítico una importante herramienta para el estudio y reconstrucción de la vegetación pasada en pastizales (Sendulsky y Labouriau, 1966; Blackman, 1971; Twiss, 1987; Alexandre et al., 1997; Barboni et al., 1999). Las formas de los fitolitos aislados pertenecientes a las gramíneas, formados en células epidérmicas de las hojas, son indicadores de rutas fotosintéticas $C_{3}$ y $C_{4}$ (Twiss, 1992) (figura 3.1.). Para Twiss (1992), altas proporciones de fitolitos de Pooideae sobre el total de Pooideae, Chloridoideae, Panicoideae indicarían temperaturas frías en una región dada, mientras que altas proporciones de fitolitos de Chloridoideae sobre el total de Chloridoideae y Panicoideae indicarían temperaturas cálidas de ambientes áridos o semiáridos en la región (Twiss, 1992). Según Gallego y Distel (2004), las gramíneas $C_{4}$ (en el caldenal de la pampa) están dominadas por bilobados simples y bilobados tipo panicoide, cruces y sillas de montar, mientras que las $\mathrm{C}_{3}$ están dominadas por formas de la Clase pooide (Twiss, 1992) y bilobados tipo Stipa (figura 3.1.).

Otras monocotiledóneas como las familias Cyperaceae y Arecaceae, son importantes productoras de fitolitos con morfologías notablemente diferentes a las producidas por las gramíneas (Piperno, 1988; Ollendorf, 1992; Pearsall, 2000; Wallis, 2003). Dentro de las dicotiledóneas, varias familias producen fitolitos en diversas proporciones y morfologías claramente distintivas. Entre las principales productoras es posible nombrar a las familias Annonaceae, Asteraceae, Fabaceae, Magnoliaceae, Moraceae, Ulmaceae, Urticaceae (Piperno, 1988; Rapp y Mulholland, 1992; Pearsall, 2000; Wallis, 2003). Dentro de las Gimnospermas las principales familias productoras son Araucariaceae, Cupressaceae, Pinaceae, Taxodiaceae y Taxaceae (Piperno, 1988; Pearsall, 2000; Carnelli et al., 2004; Blinnikov, 2005). Si bien son escasos los estudios en Pteridophytas, se han registrado fitolitos en Hymenophyllaceae, Polypodiaceae, Selaginellaceae y Equisetaceae (Piperno, 1988). 


\subsubsection{Incorporación de los fitolitos al suelo}

Los fitolitos son liberados al suelo luego de la desintegración y descomposición del material vegetal que los contenía (hojas, tallos, raíces, inflorescencia, etc.). El mecanismo más común ocurre una vez que los restos vegetales caen a la superficie del suelo, donde comienzan a ser degradados por la fauna microbiana y fúngica. El fuego puede acelerar el proceso de descomposición de la materia vegetal y permitir la incorporación de grandes volúmenes de fitolitos en poco tiempo. También la acción de los herbívoros contribuye a la incorporación de los fitolitos de las plantas que consumen a través de sus heces. Una vez en el suelo son integrados a la fracción mineral y pueden comportarse como el resto de las partículas minerales en los procesos pedológicos. Los fitolitos pueden preservarse o disolverse para volver a ser absorbidos como ácido monosilícico por las plantas o formar otros minerales silíceos, según el ciclo biogeoquímico de la sílice (Bertoldi de Pomar, 1971 y 1975; Borrelli y Osterrieth, 2001 y 2002; Borrelli et al., 2004; Osterrieth, 2006). Si bien en general se considera que no sufren dispersión, pueden ser transportados por el viento o como consecuencia del efecto conjunto fuegoviento, ya que constituyen partículas de entre 5 y 200 micrones (Piperno, 1988; Twiss, 1983). Dada su baja tasa de disolución en suelos y sedimentos con pH entre 3-9, es posible hallarlos en secuencias estratigráficas y paleosuelos tan antiguos como el Paleoceno (Zucol et al., 2004) y hasta Cretácicos (Prasad et al., 2005). Algunos autores consideran que el depósito fitolítico presente en el suelo es el resultado del aporte de la vegetación circundante, otorgándole una impronta local a la asociación fitolítica (Piperno, 1988). En general se considera que el depósito de fitolitos es de carácter local, es decir que la asociación fitolítica del suelo refleja la vegetación que se desarrolla inmediatamente por encima del perfil. Se trata de un depósito que se forma in situ, por acumulación de fitolitos que provienen del material vegetal que se está desintegrando y que corresponde a la vegetación suprayacente al suelo. Otros en cambio (Fredlund y Tieszen, 1994), consideran que la asociación fitolítica, especialmente en pastizales, depende, además del aporte de la vegetación, del contenido de fitolitos presentes en el material parental y de los procesos de dispersión. Dentro de estos últimos cabe mencionar el proceso gravitacional, el transporte 
eólico, fuego en conjunto con la acción eólica, la herbivoría y la acción fluvial/coluvial (Fredlund y Tieszen, 1994).

La asociación fitolítica depositada en el suelo está influida además por las características morfológicas y físico-químicas de los mismos. Si bien la asociación fitolítica del suelo depende de la producción fitolítica de la vegetación, las características edáficas pueden influir de diferentes formas (Osterrieth, 2008). La acidez es determinante en el grado de disolución que pueden sufrir estas partículas, si bien se considera que los fitolitos se mantienen estables en un rango amplio de $\mathrm{pH}$ (entre 3 y 9 ). Los procesos de disolución remueven aquellos fitolitos con menor grado de silicificación o más frágiles y desarticula los fragmentos compuestos, quedando solo las morfologías más robustas (Hart y Humphreys, 2003; Albert et al., 2006).

\subsubsection{Dispersión de los fitolitos}

Al igual que cualquier partícula clástica resultante de la meteorización de rocas preexistentes, los fitolitos están sujetos desde su liberación al medio a partir de la destrucción de los vegetales que los contenían, a dispersión por diversos agentes ambientales, muy especialmente fluidos en movimiento. Los agentes más comunes de dispersión son el agua y el viento, los cuales actúan sobre cualquier partícula sedimentaria seleccionando los materiales que transportan y los modifican de diversas maneras. Finalmente, estos materiales llegan a asentarse formando parte de un depósito sedimentario y eventualmente, conformando la futura roca sedimentaria. De manera que el estudio de la procedencia y dispersión de los fitolitos no puede encararse sin tener en cuenta el contexto sedimentario en el cual se encuentran depositados, es decir, incluyendo en el estudio las partículas clásticas que componen el depósito sedimentario.

\subsubsection{Concepto de "asociación fitolítica"}

Una asociación fitolítica se define por el conjunto de morfotipos fitolíticos que caracterizan a un taxón y la frecuencia relativa de cada uno de ellos. Es decir, cuando se trabaja con una asociación fitolítica no se trabaja con una sola 
forma, sino con el conjunto de morfotipos (este tema se amplía en el apartado "Multiplicidad y redundancia" de "Materiales y métodos").

\subsubsection{Historia del estudio de los fitolitos}

La primera cita donde se hace mención a células silíceas en los vegetales la realizó Saussure (1804), en su trabajo "Recherches sur la végétation" (citado en Frenguelli, 1930). Diez años más tarde, Davy (1814), hace algunas observaciones de este tipo de células en variedades de cereales y en Equisetum sp (Brea et al., 2008). Struve (1835) observa al microscopio pequeñas partículas singulares que provenían de vegetales vivos.

Las primeras referencias sobre el estudio de fitolitos per se fueron proporcionadas por Christian Ehrenberg (1841), pionero de la microbiología animal y vegetal, que describe a estas partículas como cuerpos de naturaleza silícea y las denomina "phytolitaria", término griego que significa "planta piedra" y en su acepción germana "phytolitarien" como posteriormente haría referencia en sus trabajos Baker $(1959,1960)$. En 1854 Ehrenberg desarrolla el primer sistema de clasificación de fitolitos llegando a identificar más de 89 tipos. Esta clasificación reconoce que al menos a nivel de familia pueden establecerse diferencias morfológicas en los fitolitos. Después de estas incursiones en el descubrimiento de los fitolitos, hubo un período de estudios (1895-1936) en el que gran número de botánicos en Europa, especialmente en Alemania, comienzan a hablar de la ocurrencia de "cuerpos silíceos" en muchas familias del reino vegetal (en Brea et al., 2008). Se realizaron descripciones detalladas y dibujos, derivando en estudios exploratorios sistemáticos de producción y taxonomía. Se llevan a cabo los primeros estudios cuantitativos de contenido de sílice en plantas actuales y se postulan posibles mecanismos de deposición en tejidos. Hacia el 1900 en Alemania se registran los primeros trabajos en arqueología. Netolitzky (1900) utiliza espodogramas (residuo inorgánico, incluyendo fitolitos, que se obtiene después de incinerar tejidos vegetales) para identificar granos de cereales en diversos sitios arqueológicos de Europa. Schellenberg (1908) identifica restos de trigo y cebada incorporados en la matriz de fragmentos de cerámicas prehistóricas de Turquía. Helbaek (1961) reconoce diferencias en células epidérmicas silicificadas de vainas de trigo, 
arroz, mijo y cebada, sentando así las bases para identificar tales cultivos en ausencia de macro-restos botánicos. En 1969 Twiss y colaboradores compararon los espodogramas y los fitolitos obtenidos en 17 especies de gramíneas, con lo que llegaron a distinguir 4 clases morfológicas diferentes. Twiss también utilizó los fitolitos en geología arqueológica, pudiendo realizar una diferenciación de gramíneas $\mathrm{C}_{3}$ y $\mathrm{C}_{4}$ (Twiss, 1992). Rovner (1971) publica un importante trabajo evaluando el valor potencial de los fitolitos aplicado en estudios arqueológicos que estimula a los arqueobotánicos y le da un nuevo impulso a la disciplina. A partir de 1975, los análisis de fitolitos se incrementan y se consolidan como técnica sistemática en arqueología de regiones tropicales donde la preservación de restos vegetales es muy pobre y ellos proporcionan evidencias importantes acerca del origen de la agricultura y la historia ambiental; creándose una línea de estudio que será muy prolífica en las siguientes décadas (ver bibliografía citada en Zucol et al., 2008).

Las primeras referencias de estudios fitolíticos en Argentina fueron proporcionadas por Ehrenberg en el siglo diecinueve, quien estudia material coleccionado por Charles Darwin. Analiza sedimentos de Monte Hermoso (Bahía Blanca), limos asociados a mamíferos fósiles (Bahía Blanca), superficies dentarias de un Mastodon (Santa Fé) y raíces de plantas de Patagonia y Tierra del Fuego (ver Frenguelli 1930). Entre 1925 y 1955, Frenguelli cita por primera vez la presencia de células silíceas de gramíneas en sedimentos terciarios, cuaternarios y recientes de Argentina, describiendo con gran detalle los rasgos morfológicos de los elementos epidérmicos (células largas, cortas, estomas, pelos), xilemáticos y fibrosos de las gramíneas actuales (Frenguelli 1925, 1930, 1955). El mismo autor (1930), realiza un importante aporte en su trabajo sobre "Partículas de sílice organizada en el loess y en los limos pampeanos. Células silíceas de gramíneas" en donde destaca que en los limos de pantanos suelen ser muy abundantes y en muchas ocasiones se conservan en forma articulada, mientras que en el loess, por el efecto del arrastre, los diferentes elementos aparecen desarticulados, fragmentados y dispersos. Teruggi (1955) propone una técnica para diferenciar el vidrio volcánico del ópalo organógeno en sedimentos pampeanos. Posteriormente, entre 1969 y 1983, Bertoldi de Pomar, desarrolla sus estudios en esta disciplina contribuyendo con la clasificación morfológica de los 
silicofitolitos (Bertoldi de Pomar 1969a, 1969b, 1970a, 1970b, 1971; Bertoldi de Pomar y Tur 1970). En su trabajo "Ensayo de clasificación morfológica de los silicofitolitos" (Bertoldi de Pomar, 1971) da a conocer su clasificación morfológica en donde se incluyen 70 diferentes morfotipos. La clasificación propuesta contempla no sólo los fitolitos de gramíneas, sino también están descriptos aquellos presentes en Ciperaceae, Equisetaceae, Arecaceae y Podostemaceae. Sus contribuciones incluyen una serie de trabajos referidos a las asociaciones fitolíticas halladas en los sedimentos de la llanura santafesina (Bertoldi de Pomar 1969b, 1972), sedimentos de fondo de la laguna Guadalupe (Bertoldi de Pomar 1973), sedimentos de los cauces fluviales correntinos (Bertoldi de Pomar 1974) y en sedimentos continentales provenientes de varias localidades ubicadas en diferentes puntos del territorio argentino (llanura de inundación del río Paraná, suelos de la llanura de Santa Catalina (Corrientes), suelos de monte en Riachuelo (Corrientes), sedimentos de fondo del lago Mascardi (Río Negro) y turba del Cuaternario superior de Infiernillo, departamento de Tafí (Tucumán) (Bertoldi de Pomar, 1980). También, analizó las asociaciones fitolíticas contenidas en sedimentos del cauce del río Paraguay (Bertoldi de Pomar, 1983). Propuso un conjunto de metodologías utilizadas en el procesamiento de sedimentos clásticos, para su observación al microscopio óptico (Bertoldi de Pomar, 1976) y su trabajo "Los silicofitolitos. Sinopsis de su conocimiento" (1975), es su contribución de síntesis más importante en la fitolitología argentina. Más tarde, diversos autores, a nivel mundial, realizarían propuestas de clasificaciones morfológicas y técnicas de extracción del material fitolítico (Piperno 1988, 1995, 2006; Piperno y Pearsall 1993, 1998; Bertoldi de Pomar 1999, 2006; Flórez y Parra 1999; Parra y Flórez 2001; Zucol 1992, 1995, 1999; Pearsall 2000; Zucol y Brea 2005; Zucol y Osterrieth 2002; Coil et al. 2003; Babot y Bru de Labanda, 2005).

La interpretación de las asociaciones fitolíticas de los sedimentos debe basarse en las descripciones fitolíticas de las especies vegetales locales (Zucol et al., 2005a). En nuestro país, los estudios fitolíticos en especies vegetales son relativamente escasos en comparación con los estudios realizados en suelos y sedimentos. Los estudios previos incluyen especies vegetales de las provincias de Buenos Aires (Gallego y Distel, 2004; Fernández Honaine et al., 2005, Fernández Honaine, 2007, Fernández Honaine et al., 2009) y Entre Ríos 
(Zucol, 1996, 1998, 1999, 2000 y 2001; Zucol et al., 2006a). Los análisis fitolíticos en suelos, paleosuelos y sedimentos se han ido incrementado a lo largo de las décadas del 80', 90' y 2000, tanto en la provincia de Buenos Aires (González y Osterrieth, 1996; Osterrieth et al., 1998a; Zucol y Osterrieth, 1999; Osterrieth, 2000; Borrelli, 2001; Borrelli y Osterrieth, 2001; Borrelli y Osterrieth, 2002; Osterrieth et al., 2002a; Zucol et al., 2002; Álvarez, 2003; Álvarez y Osterrieth, 2004; Borrelli et al., 2004; Osterrieth et al., 2004; Álvarez et al., 2005; Osterrieth, 2005; Osterrieth y Tassara, 2005; Osterrieth et al., 2005a, 2005b y 2005c; Zucol y Bonomo, 2005; Osterrieth, 2006 y Osterrieth et al., 2006; Osterrieth y Fernández Honaine, 2007), en Entre Ríos (Zucol y Brea, 2000; Zucol y Brea, 2005; Zucol et al., 2005b; Zucol y Brea, 2006; Erra et al., 2006; Erra y Zucol, 2007; 2008; Brea y Zucol, 2007; Patterer, 2008), en La Pampa (Gallego et al., 2004) y en Chubut (Zucol et al., 1999; Zucol et al., 2001; Zucol et al., 2004; Zucol et al., 2006b).

\begin{tabular}{|c|c|c|c|c|}
\hline & $\begin{array}{l}\text { Pooideae=Festucoideae } \\
\text { (Twiss, 1992) trigo, } \\
\text { avena, cebada, centeno }\end{array}$ & $\begin{array}{l}\text { Chloridoideae (Twiss, } \\
\text { 1992) no cereales }\end{array}$ & $\begin{array}{l}\text { Panicoideae(Twiss, } \\
\text { 1992) } \\
\text { Maiz, sorgo, caña } \\
\text { azúcar }\end{array}$ & $\begin{array}{l}\text { Arundinoideae } \\
\text { (Twiss, 1992) } \\
= \\
\text { Dantonoideas. }\end{array}$ \\
\hline $\begin{array}{l}\text { Ruta } \\
\text { metabólica }\end{array}$ & $\mathrm{C}_{3}$ & $\mathrm{C}_{4}$ & $\mathrm{C}_{3} \mathrm{y} \mathrm{C}_{4}$ & La mayoría $\mathrm{C}_{3}$ \\
\hline Morfotipos & $\begin{array}{l}\text { Circulares, } \\
\text { rectangulares, elípticos, } \\
\text { en luna creciente, } \\
\text { oblongos }\end{array}$ & $\begin{array}{l}\text { Sillas de montar } \\
\text { (saddle-shaped) }\end{array}$ & Cruces, bilobados & \\
\hline $\begin{array}{l}\text { Distribución } \\
\text { geográfica }\end{array}$ & $\begin{array}{l}\text { Altas latitudes, y altas } \\
\text { elevaciones. } \\
\text { Dominan en zonas } \\
\text { templadas a frías }\end{array}$ & $\begin{array}{l}\text { Regiones cálidas, áridas } \\
\text { o semiáridas }\end{array}$ & $\begin{array}{l}\text { Regiones cálidas } \\
\text { tropicales a } \\
\text { subtropicales. Algunas } \\
\text { adaptadas a regiones } \\
\text { áridas. }\end{array}$ & \\
\hline $\begin{array}{l}\text { Gallego y } \\
\text { Distel (2004) }\end{array}$ & $\begin{array}{l}\text { Clase Pooide, elípticos, } \\
\text { en sombrero, } \\
\text { biconvexos, en luna } \\
\text { creciente, oblongos, } \\
\text { esféricos, rectangulares, } \\
\text { ausencia de saddle. }\end{array}$ & $\begin{array}{l}\text { Clase Chloridoide, } \\
\text { saddle normal, cruces, } \\
\text { bilobado, y } \\
\text { especialmente saddle }\end{array}$ & $\begin{array}{l}\text { Clase Panicoide, cruces, } \\
\text { bilobados de cuello } \\
\text { corto y de cuello largo, } \\
\text { con final recto, o } \\
\text { convexo Bilobados } \\
\text { complejos, regulares e } \\
\text { irregulares y crenados. }\end{array}$ & $\begin{array}{l}\text { Grupo } \\
\text { heterogéneo } \\
\text { formas } \\
\text { dominantes: } \\
\text { rectangulares, } \\
\text { oblongos, } \\
\text { crenados y } \\
\text { bilobados }\end{array}$ \\
\hline
\end{tabular}

Figura 3.1. Esquema diseñado a partir de los trabajos de Twiss (1992) y Gallego y Distel (2004) relacionando morfotipos presentes, ruta metabólica y distribución geográfica. 
Georgina Erra/ "Estudio fitolítico de la Formación Tezanos Pinto......"

\begin{tabular}{|l|l|l|}
\hline $\begin{array}{l}\text { Fredlund y Tieszen } \\
(\mathbf{1 9 9 4 )}\end{array}$ & & \\
\hline morfotipo fitolítico & $\begin{array}{l}\text { taxa en los que se halla } \\
\text { presente }\end{array}$ & $\begin{array}{l}\text { ruta } \\
\text { metabólica }\end{array}$ \\
\hline & & \\
\hline crenados & Pooideae & $\mathrm{C}_{3}$ \\
\hline cónicos y piramidales & Pooideae & $\mathrm{C}_{3}$ \\
\hline saddle & Chlorideae & $\mathrm{C}_{4}$ \\
\hline tipo-Stipa & Stipa & $\mathrm{C}_{3}$ \\
\hline lobado simple & Panicoideae & $\mathrm{C}_{4}$ \\
\hline tipo-panicoide & Panicoideae & $\mathrm{C}_{4}$ \\
\hline Cruces & Panicoideae & $\mathrm{C}_{4}$ \\
\hline otros lobados & Panicoideae & $\mathrm{C}_{4}$ \\
\hline
\end{tabular}

Figura 3.2. Esquema diseñado a partir del trabajo de Fredlund y Tieszen (1994) relacionando morfotipos presentes-ruta metabólica (exclusivamente para células cortas de gramíneas). 


\section{MATERIALES Y MÉTODOS}

\subsection{SELECCIÓN DEL ÁREA DE ESTUDIO}

La Formación Tezanos Pinto (Iriondo, 1980) constituye la unidad sedimentaria cuaternaria representativa del loess de la Pampa Norte, su estudio representa un avance en el conocimiento de la biodiversidad del Pleistoceno Tardío-Holoceno Temprano de la región. Para la realización del presente trabajo se muestrearon perfiles representativos en el área sudoeste de Entre Ríos (figura 4.1. y 4.2.), donde está presente la Formación Tezanos Pinto, siguiendo una transecta SE-NO a lo largo de la unidad geomorfológica "Colinas Loéssicas de Crespo" (Iriondo, 1980).

Los depósitos loéssicos retienen información sobre la vegetación del pasado y los análisis fitolíticos de estos depósitos son útiles para comprender el pasado climático y las condiciones ambientales bajo las cuales se formaron.

Preservados en el sedimento estudiado, estos microrestos brindan información sobre las paleocomunidades vegetales que existían al momento de su depositación.

La selección del área de estudio se fundamentó en tareas de prospección previas donde se evidenció la presencia de microfósiles en las principales formaciones del Cenozoico superior del SO de Entre Ríos. (Zucol et al., 2004). También se consideraron las investigaciones realizadas en la vegetación actual de la pradera entrerriana que fuera estudiada en sus componentes generales (Zucol 1996a, b, 1998, 1999, 2000, 2001) y que sirvieron como referencia para la comparación con los estudios llevados a cabo en el presente trabajo.

\subsection{TRABAJO DE CAMPO}

Luego de un exhaustivo análisis de la bibliografía geológica de la región, se comenzó la tarea de reconocimiento de la geología regional a campo para realizar posteriormente el levantamiento de los perfiles sedimentológicos de detalle. 
En una primer etapa, los perfiles se organizaron siguiendo 3 transectas: una en sentido SE-NO (sobre la margen izquierda del río Paraná, donde la Formación Tezanos Pinto posee mayor potencia), y dos en sentido SO-NE perpendiculares a la primera (donde disminuyen los espesores de dicha formación hacia el E) (figura 4.1. y 4.2.).

El levantamiento de la Formación Tezanos Pinto en perfiles aflorantes (en barrancas naturales y en perfiles artificiales) se realizó teniendo en cuenta sus características litológicas (textura-composición), la definición de las estructuras sedimentarias primarias (caracteres, dimensiones, orientación), la determinación de la geometría de los cuerpos y el reconocimiento de los contactos formacionales. Las tareas geológicas y sedimentológicas de campo fueron supervisadas por la Dra. D. Kröhling, quién tiene experiencia en estos aspectos de la investigación y en el área misma de trabajo. Para identificar y muestrear la Formación Tezanos Pinto (facies eólica primaria o loéssica) de la provincia de Entre Ríos, se realizaron entre los años 2005-2007 varios viajes de campaña al área de estudio.

Se diferenciaron las facies sedimentarias de la formación a fin de discriminar la facies eólica o primaria (loess típico) que permitió efectuar el estudio de detalle. La ubicación de los perfiles muestreados dependió de:

* la existencia de la facies típica de la Formación Tezanos Pinto (representatividad)

* potencia (buenos afloramientos, accesibilidad y espesor)

Se observó que las potencias disminuyen en sentido SO-NE y es por esta razón hay mayor densidad de muestreos hacia la costa del Paraná.

A fin de resaltar la identidad de la composición fitolítica del loess de la Formación Tezanos Pinto típica se muestrearon una serie de perfiles que representan otras unidades Cuaternarias ubicadas en la misma área de estudio, el sudoeste de Entre Ríos, que se compararán. Estos perfiles serán denominados "Perfiles accesorios" (figuras 4.1. y 4.2.). 


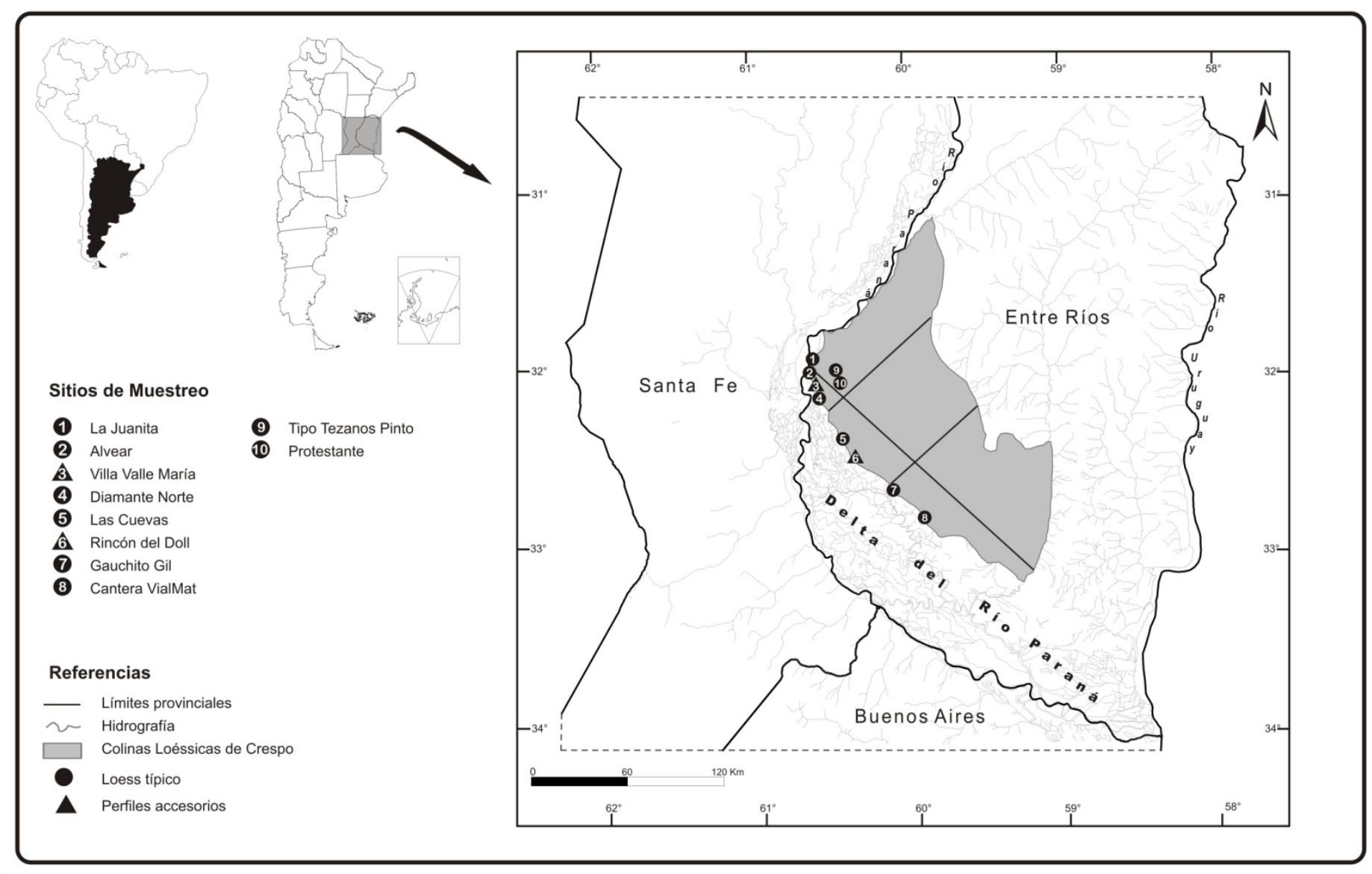

Figura 4.1. Mapa de la provincia de Entre Ríos, con la ubicación del área de estudio (Colinas Loéssicas de Crespo) y sitios de muestreo.

Como parte de la tarea de campo, se describieron los perfiles sedimentológicos, teniéndose como premisas de selección su representatividad en el área y su desarrollo. De esta forma los perfiles seleccionados se denominaron "Perfil Diamante Norte" (S 32 03' 59,6" - O 60 37' 32,3"), "Perfil Ex- campo de Regimiento" (S $32^{\circ} 03^{\prime} 35,6^{\prime \prime}$ - O 60 37' 46,0"), "Perfil Alvear" (S

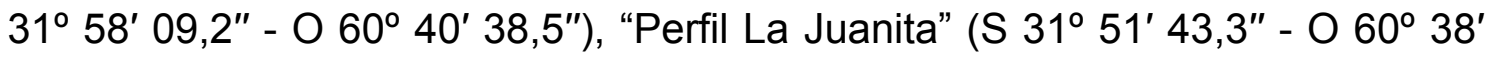
53,2" ), "Perfil Arroyo Salto Puente" (S 310 53' 49,2' - O 60 33' 01,7"), "Perfil Arroyo Pelado" (S 32 02' 19,6" - O 60 30' 42,7"), "Perfil Crespo" (S 32 03' 07,8" - O 60 21' 11,8"), "Perfil Las Cuevas" (S 320 18' 51,5" - O 60 28' 01,8"), "Perfil Tipo Tezanos Pinto" (S 310 53' 20,5" - O 60 32' 27,8"), "Perfil Protestante" (S 320 01' 19,4" - O 60 30'38,2"), "Perfil Vial-Mat (Rincón del Nogoyá Norte, Cantera Vial-Mat)" (S $32^{\circ} 46^{\prime}$ 05,2" - O 59 56' 26,2"), "Perfil Gauchito Gil" (S $32^{\circ} 36^{\prime} 37,3^{\prime \prime}$ - O 60 08' 34,3"), y se tomaron muestras de los perfiles accesorios "Perfil Rincón del Doll” (S 32 25' 22,2" - O 60 23' 52,9" ), 
"Perfil Villa Valle Maria" (S $32^{\circ} 00^{\prime} 35,2^{\prime \prime}$ - O 60 $38^{\prime} 14,9^{\prime \prime}$ ), y "Perfil Toma Vieja"

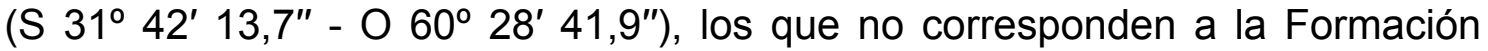
Tezanos Pinto típica, sino a una unidad correlacionable temporalmente con la Formación San Guillermo (producto de la deflación de materiales superficiales y su posterior redepósito -Kröhling, com. pers.-) y a Formación La Picada (una unidad holocena típica de los valles de la provincia de Entre Ríos).

Los nombres propuestos se deben a la localidad más próxima donde fueron relevados (figura 4.1. y 4.2.).

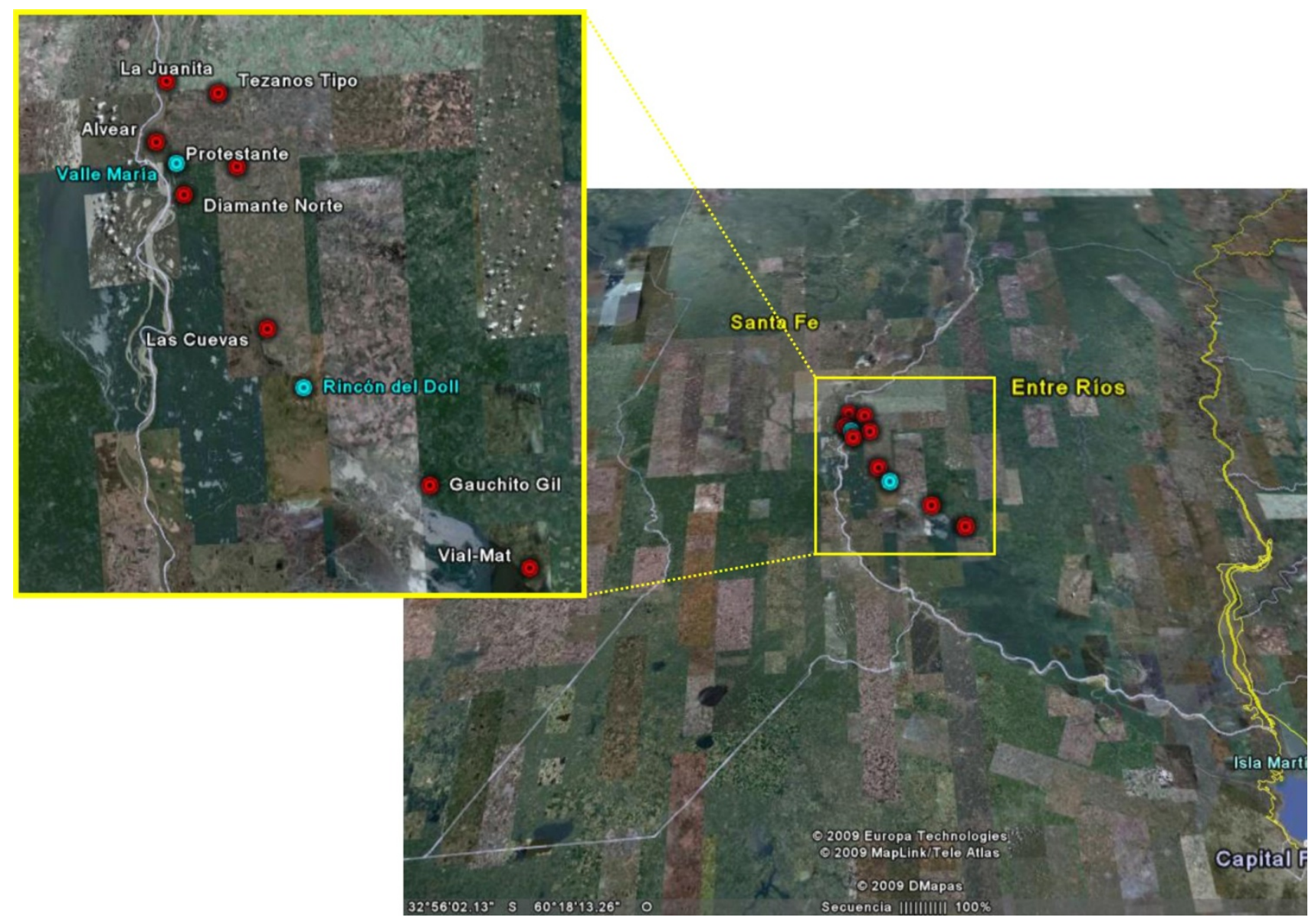

Figura 4.2. Imagen satelital del área de estudio en la que se señalan los perfiles muestreados.

El muestreo se realizó de manera continua cada $10 \mathrm{~cm}$ en todos los perfiles estudiados (sólo el perfil "Rincón del Doll" se muestreó cada $25 \mathrm{~cm}$ ). Estas muestras fueron obtenidas mediante las normas básicas de trabajo a campo con el fin de evitar contaminaciones del material, donde se limpió el perfil y se muestreó de abajo hacia arriba en cada perfil; una vez embolsadas y rotuladas, las muestras de aproximadamente $250 \mathrm{gr}$, fueron incorporadas a la 
colección de muestras sedimentarias del Laboratorio de Paleobotánica (tabla 4.3.) y se comenzaron las tareas de procesamiento de las mismas con la finalidad de concentrar los microrestos vegetales objeto de este estudio.

\subsection{PROCESAMIENTO EN EL LABORATORIO (figura 4.3.)}

\section{Preparación de la muestra}

En esta etapa se buscó acondicionar la muestra procedente del campo para luego comenzar su procesamiento en el laboratorio garantizando su homogeneidad y representatividad acorde con la técnica de obtención realizada en el muestreo de campo. Para ello las tareas realizadas fueron el secado, la molienda y el tamizado grueso del material uniformándolo y eliminando restos orgánicos grandes que pudieran poseer. Asimismo, se realizó la reducción de la muestra mediante cuarteo y la extracción de la alícuota de trabajo. El secado se realizó colocando el sedimento muestreado en bandejas metálicas donde se lo distribuyó uniformemente y luego llevado a estufa a temperaturas no mayores a $60^{\circ} \mathrm{C}$. La molienda se realizó mediante mortero manual, triturando los agregados y homogeneizando el material hasta que la mayor parte pase por un tamiz $\mathrm{N}^{\circ} 18$ (malla de 1000 micrones, $\mu \mathrm{m}$ ), también fue manual el cuarteo del material, el que se realizó para reducir la muestra total a una submuestras representativa de la cual se obtuvo la alícuota de trabajo de aproximadamente 10-15 grs para el posterior tratamiento preliminar (a la separación granulométrica) (Zucol y Osterrieth, 2002).

\section{$\underline{\text { Tratamiento preliminar }}$}

El tratamiento preliminar tuvo por objetivo limpiar y desagregar física y químicamente la muestra permitiendo la liberación de los fitolitos que puedan estar atrapados en los agregados del depósito. Para ello se buscó la eliminación de todas las sustancias presentes en la muestra que puedan actuar como cementantes entre las partículas, impidiendo la desagregación de las mismas o interfiriendo con la dispersión química que se realiza mediante la adición de un electrolito fuerte como el sodio el cual carga eléctricamente las partículas posibilitando que estas se repelan unas a otras. El tratamiento también incluye la eliminación de las acumulaciones de óxidos de hierro que en 
forma de películas o barnices puedan estar presentes en la superficie de los fitolitos y que dificultan su observación al microscopio. El tratamiento preliminar consistió en primer lugar en la eliminación de sales solubles, en la que se colocó la alícuota en un vaso de precipitado de $250 \mathrm{ml}$, con $200 \mathrm{ml}$ de agua destilada, se agitó con varilla de vidrio, se dejó decantar durante 30 minutos. Luego se eliminó por sifonado el líquido sobrenadante por encima de los $2 \mathrm{~cm}$ desde el fondo del vaso. Este paso se repitió 3 veces en frío y una vez a calentamiento en baño María. La eliminación de carbonatos de calcio, barnices y cementos se llevó a cabo agregando $25-50 \mathrm{ml}$ de ácido clorhídrico diluido al $10 \%$ y calentando en baño María por el lapso de 1 hora. La reacción de carbonatos y cementos cálcicos se evidencia mediante el desprendimiento gaseoso que produce en burbujeo en la muestra tanto mas intenso cuanto mayor sea el contenido de los mismos. La presencia de barnices y óxidos de hierro se manifiesta por una coloración amarillenta de la solución. Se dejó enfriar y decantar durante 30 minutos, eliminando por sifonado el ácido sobrenadante por encima de los $2 \mathrm{~cm}$ desde el fondo del vaso. Las muestras se lavaron con abundante agua destilada hasta no detectar iones cloruros en la misma (la presencia de cloruros se testeó sobre el agua de lavado con solución $1 \%$ de nitrato de plata, donde, en caso de conservar residuos de ácido se forma una solución blanquecina). La eliminación de materia orgánica se realizó agregando $25-50 \mathrm{ml}$ de agua oxigenada de 100 volúmenes, al $30 \%$, al vaso de precipitado. Se dejó actuar durante 24 horas, agitando periódicamente con varilla de vidrio. Luego se calentó en baño María hasta sequedad. Para la dispersión de las arcillas, se agregó a la muestra $25 \mathrm{ml}$ de solución $1 \mathrm{~N}$ de hexametafosfato de sodio y $225 \mathrm{ml}$ de agua destilada para proceder con la dispersión química de cada submuestra para la subsiguiente liberación de las arcillas, batiendo con batidora mecánica durante 3-5 minutos y dejando reposar durante 24 horas. Estas etapas, como se dijo anteriormente, tienen la finalidad de eliminar los compuestos que puedan provocar la aglomeración de los elementos micropaleontológicos. 


\section{Separación granulométrica}

Sobre la muestra limpia se realizó la separación granulométrica en varias fracciones (separación granulométrica por tamizado). Mediante ella se obtuvieron tres fracciones: fina (partículas con diámetro entre 8-53 $\mu \mathrm{m}$ ), mediana (partículas con diámetro entre $53-250 \mu \mathrm{m}$ ) y gruesa (partículas con diámetro mayor a $250 \mu \mathrm{m}$ ) con la utilización de tamices $\mathrm{N}^{\circ} 60$ (apertura de malla de $250 \mu \mathrm{m}$ ) y $\mathrm{N}^{\circ} 270$ (apertura de malla de $53 \mu \mathrm{m}$ ). Se dispusieron los tamices en una columna en el siguiente orden de arriba hacia abajo: Tamiz $\mathrm{N}^{\circ}$ 60 (malla $250 \mu \mathrm{m}$ ), Tamiz № 270 (malla $53 \mu \mathrm{m}$ ) y fondo. La muestra dispersada se vertió por la parte superior de la columna, y con ayuda de una piseta con agua destilada se removió el material retenido en la malla a fin de que todas las partículas de menor tamaño pasen a través del tamiz. El lavado se continuó hasta que el agua que pase por el tamiz sea límpida. Se filtró el material retenido en el tamiz 60 sobre un papel de filtro colocado en un embudo. Con ayuda de la piseta de agua destilada se removió el material retenido en el tamiz $\mathrm{N}^{\circ} 270$ a fin de que todas las partículas de menor tamaño pasen a través del tamiz, el lavado se continuó hasta que el agua que pase por el tamiz sea límpida. Se filtró el material retenido en el tamiz $N^{\circ} 270$ sobre un papel de filtro colocado en un embudo. Se dejó secar al aire, y se guardaron las fracciones separadas en los filtros debidamente etiquetados. El contenido del fondo del tamiz se vertió en una probeta de $1000 \mathrm{ml}$ lavando bien de modo que no quede ninguna partícula en el fondo. Se agregó agua destilada hasta alcanzar el áforo de $1000 \mathrm{ml}$. Luego se agitó enérgicamente con agitador de movimiento vertical durante 30 segundos. Se tomó la temperatura del líquido y en función de ella se determinó el tiempo de decantación para partículas menores a 7,8 $\mu \mathrm{m}$ (Ley de Stokes). Se dejó actuar el tiempo indicado para luego introducir el sifón a una profundidad de $10 \mathrm{~cm}$ desde el áforo y se eliminó por sifonado todo el sobrenadante (conteniendo las partículas menores a $8 \mu \mathrm{m}$ ) que está por encima de dicha profundidad. Se repitió esta técnica operatoria hasta que transcurrido el tiempo de decantación los $10 \mathrm{~cm}$ superiores de la columna de líquido se vieron límpidos. Por última vez, se eliminó por sifonado todo el sobrenadante que está por encima de dicha profundidad. Se filtró el material remanente en la probeta sobre un papel de filtro colocado en un embudo. Se 
dejó secar al aire, y se guardó la fracción separada en los filtros debidamente etiquetados.

Por último la separación densimétrica. En esta etapa se realizó la separación densimétrica con politungstato de sodio (densidad 2,3) como líquido pesado, por la técnica de centrifugación (Bertoldi de Pomar, 1976), separando la porción liviana y pesada, de las fracciones fina y media, de acuerdo a los pasos detallados por Rovner (1990). La técnica operatoria consistió en verter 20-25 ml de solución acuosa de politungstato de sodio en un tubo de centrífuga de $50 \mathrm{ml}$. Se tomó una alícuota de la fracción de tamaño separada en la etapa anterior y se la vertió dentro del tubo. Se agitó ligeramente para que se disperse el material en el seno del líquido. Se centrifugó a 1200 rpm durante 5 a 10 minutos. Se retiró el tubo de la centrífuga y se dejó reposar unos minutos. Se colocaron 2 papeles de filtro sobre sendos embudos de vidrio y se filtró separadamente la fracción liviana (en flotación) y la pesada (acumulada en el fondo). Se dejó secar al aire, y se guardó la fracción separada en los filtros debidamente etiquetados.

\section{Obtención de los preparados}

Con el material obtenido de las separaciones densimétricas de las fracciones fina y media (8-53 $\mu \mathrm{m}$ y $53-250 \mu \mathrm{m})$, se realizaron los preparados. Las fracciones se montaron sobre portaobjetos biológicos estándar. Uno en medio líquido (aceite de inmersión) para facilitar la rotación de los fitolitos (el índice de refracción del aceite provee del contraste necesario para las observaciones microscópicas de los fitolitos). La observación, identificación y el análisis cuali- y cuantitativo y posterior toma de microfotografías, se realizó bajo microscopio óptico. Otro preparado se montó en medio sólido (preparado fijo, montado en bálsamo de Canadá) quedando material en repositorio. Los preparados microscópicos fijos, el concentrado obtenido del procesamiento en el laboratorio, y las muestras sedimentarias fueron incorporados a la Colección del Laboratorio de Paleobotánica del Centro de Investigaciones CientíficasDiamante (CICyTTP, Diamante, Entre Ríos) (CDPalbomic) y en el repositorio del laboratorio de Procesamiento de material sedimentológico-paleontológico de esta misma institución. (tabla 4.3.). 


\begin{tabular}{|l|}
\hline EXTRACCIÓN DE FITOLITOS \\
PREPARACIÓN DE LA MUESTRA \\
SECADO \\
MOLIENDA \\
TAMIZADO GRUESO \\
TRATAMIENTO PRELIMINAR \\
ELIMINACIÓN DE SALES SOLUBLES \\
ELIMINACIÓN DE CARBONATOS, BARNICES Y CEMENTOS \\
ELIMINACIÓN DE MATERIA ORGÁNICA \\
DISPERSIÓN \\
SEPARACIÓN GRANOMÉTRICA \\
Obtención de 3 fracciones: \\
fina 8 a 53 micrones \\
media 53 a 250 \\
gruesa mayor a 250 \\
SEPARACIÓN DENSIMÉTRICA \\
Fracción liviana \\
Fracción pesada \\
OBTENCIÓN DE PREPARADOS \\
líquidos \\
fijos
\end{tabular}

Figura 4.3. Procesamiento en el laboratorio. 


\subsection{TRABAJO DE GABINETE}

La identificación, clasificación y cuantificación de los morfotipos fitolíticos observados se realizó sobre los elementos aislados encontrados en las diferentes muestras, en los preparados líquidos. Las observaciones microscópicas fueron realizadas en un microscopio binocular Hokenn modelo WPB 100 del Laboratorio de Paleobotánica (CICYTTP-Diamante) con un aumento de 640x (16x de ocular y 40x de objetivo); las fotografías fueron obtenidas con una cámara digital Sony DSC-W30 de 6 megapixeles.

En el caso de los fitolitos articulados fueron observados pero no descriptos, ya que no son el propósito del presente análisis, al igual que otros tipos de biolitos (además de los fitolitos) como los estomatocistes de Chrysostomatáceas, los frústulos de diatomeas y las espículas de espongiarios. La consideración de estos tres tipos de biolitos complementa la descripción de las asociaciones fitolíticas de cada muestra y puede ofrecer otro tipo de información relevante para la interpretación, como por ejemplo evidenciar eventos de saturación del suelo o hidromorfismo (a través de la presencia o abundancia de diatomeas y estomatocistes).

Los estomatocistes de Chrysostomatáceas, corresponden a protistas silíceos, cuyos quistes están conformados por una caparazón o lórica esférica, lageniforme o piriforme, lisa o diversamente ornamentada, con un poro oral provisto o no de cuello. Estos organismos planctónicos parecen preferir las aguas estancadas de variado tenor salino, más o menos cargadas de materia orgánica en descomposición, ricas en hierro y pobres en sales calcáreas, sus lóricas miden de 10 a $20 \mu \mathrm{m}$ y se las puede encontrar en limos, a su vez pueden ser transportadas por el viento, así que también están presentes en el loess (Frenguelli, 1930; 1955; Bertoldi de Pomar, 1970; Patterer, 2008). Los espongiarios, son organismos animales capaces de producir elementos silicificados (zoolitos), macro y micro escleras de variadas dimensiones, llegando a medir hasta $600 \mu \mathrm{m}$ de largo por $50 \mu \mathrm{m}$ de diámetro. Por último también se hallaron formando parte de estos sedimentos, frústulos de diatomeas, vegetales unicelulares muy sensibles a las modificaciones del medio ambiente, pueden hallarse en sedimentos de medio aerófilo, húmedo o francamente acuático, de diferente naturaleza química y diferentes lugares 
geográficos, forman parte de las partículas granulométrica más finas, por deposición "in situ" o por difusión fluvial y/o eólica. (Bertoldi de Pomar, 1972). Cabe aclarar que estos cuerpos silíceos solo fueron observados y no cuantificados como en el caso de los fitolitos.

Otro punto que se tuvo en cuenta al momento de realizar las interpretaciones fue determinar el grado de transporte sufrido por el material estudiado. Fue fundamental establecer la procedencia del material objeto de este análisis (autóctono vs transportado) ya que revelaría si las asociaciones fitolíticas identificadas eran representativas de la vegetación local o no. En términos tafonómicos, esto es si fueron sepultadas al momento de depositación del loess, o aportadas al sedimento con posterioridad.

Las evidencias que se tuvieron en cuenta para develar si se trataría de elementos autóctonos o no, fueron el rango de tamaños observados, el estado de preservación de los fitolitos y la presencia de estructuras frágiles conservadas. Por otra parte, datos obtenidos desde otras fuentes, como la paleontología de vertebrados y la sedimentología también fueron considerados.

\subsubsection{Multiplicidad y redundancia}

Para el estudio de los fitolitos se debieron tener presentes las dos características que éstos poseen. La redundancia, que implica que un mismo morfotipo puede ser producido por distintos taxones; y la multiplicidad, que indica que un solo taxón puede producir varios morfotipos diferentes (Rovner, 1971). La asignación de un morfotipo fitolítico a un taxón debe considerar claramente estas dos propiedades. Existen dos metodologías para la asignación taxonómica de los fitolitos. Una consiste en la utilización de los morfotipos diagnósticos, donde un solo morfotipo fitolítico permite identificar un taxón. En este caso es imprescindible no solo estudiar detalladamente el taxón, sino también aquellos taxones afines al analizado, ya que hay que tener en cuenta las dos propiedades antes mencionadas. Un morfotipo diagnóstico debe ser abundante en el taxón estudiado, de fácil identificación y buena preservación en el sustrato, y ser lo suficientemente diferente de los producidos por otros taxones. Además, para la utilización de esta metodología es necesario tener en cuenta la variabilidad natural que presenta el morfotipo 
fitolítico en el tejido vegetal. La segunda aproximación metodológica es la utilización de la asociación fitolítica. En este caso un taxón está representado por un conjunto de morfotipos fitolíticos que lo caracterizan y la frecuencia relativa de cada uno de ellos. Es decir, no se trabaja con una sola forma, sino con el conjunto de morfotipos. Para ello es necesario realizar recuentos fitolíticos en varios especímenes de un mismo taxón, y calcular las frecuencias relativas de todos los morfotipos fitolíticos descriptos. La metodología que se ha utilizado en este trabajo hace principal hincapié en la segunda aproximación. 


\subsection{CLASIFICACIÓN DE LOS MORFOTIPOS}

Los fitolitos son cuerpos minerales tridimensionales que pueden presentar una morfología regular o irregular. Entre los fitolitos regulares se hallan cuerpos cónicos, prismáticos, cilíndricos, piramidales y esféricos; no obstante gran parte de los fitolitos regulares pueden interpretarse como cuerpos prismáticos (paralelepípedos) (Zucol y Brea, 2005a).

Los estudios fitolíticos tuvieron una evolución en estrecha vinculación con distintas disciplinas científicas como consecuencia de sus aplicaciones y de la potencialidad de estos estudios en Botánica, Paleobotánica, Pedología, Sedimentología y Arqueología, entre otras (Zucol, 1992).

En los comienzos del estudio de los fitolitos, éstos fueron estudiados como parte componente de los tejidos vegetales, pero pronto surgió la necesidad de establecer su tratamiento en forma desarticulada del vegetal que los originó.

La primera clasificación de fitolitos que se conoce es la de Ehrenberg (1841, 1846 y 1854) quien los consideró microrganismos vegetales, otorgándoles la categoría de géneros y especies. Estableció 10 géneros y 90 especies. Grob (1896) reconoció los morfotipos de 13 tribus. Posteriormente, se intentaron nuevas clasificaciones, referidas específicamente a los fitolitos de gramíneas. Pratt (1932) y Metcalfe (1960), distinguieron entre subfamilias de gramíneas, y lo mismo hizo Smithson (1958), entre otras dos subfamilias. El sistema propuesto por Ehrenberg (1854) fue modificado más tarde por Deflandre (1963). En 1969, Twiss y colaboradores intentaron una nueva clasificación morfológica de fitolitos de gramíneas, estableciendo 4 clases (Festucoide, Chloridoide, Panicoide y Elongada). Bertoldi de Pomar (1971) propuso un ensayo de clasificación morfológica definiendo 13 morfotribus con 70 variantes de fitolitos a los cuales da una denominación particular. Ambos sistemas clasificatorios y nomenclaturales, en un primer momento independientes, fueron integrados por Taugourdeau-Lantz y colaboradores (1976) en una propuesta clasificatoria. Estos autores, por principio de prioridad, tomaron las categorías de Ehrenberg, y las recategorizan en grupo, género y especies morfológicas, incluyendo las clases morfológicas propuestas por Bertoldi de Pomar. En forma coetánea surgieron varias clasificaciones de 
fitolitos, las que se caracterizaron por abarcar grupos de vegetales restringidos ya sea taxonómica o geográficamente (Zucol, 1995). Este enfoque se continuó utilizando hasta la actualidad, y como consecuencia de ello es frecuente encontrar en la literatura fitolítica que un mismo tipo morfológico es denominado de diferentes modos, o que en las distintas clasificaciones un mismo tipo morfológico posee rangos de variabilidad disímiles.

Otras propuestas clasificatorias se presentan en los trabajos de Mulholland (1989), Fredlund y Tieszen (1994); Kondo et al. (1994); Alexandre et al. (1997); Gallego y Distel (2004); Carnelli et al. (2004), Bremond et al. (2005); Zucol y Brea, (2005), Barboni et al., (2006), entre otros.

Actualmente no hay consenso generalizado sobre el criterio a seguir para utilizar una sistemática de fitolitos, que permita el claro tratamiento y denominación de estos elementos en un sistema universal, como fuera enunciado por diversos autores, ya desde el pasado (Zucol, 1995; Zucol 1999a, Bowdery, et al., 1998; Hart, et al., 2000; Lentfer et al., 2000). Por lo que, en el año 2000 , se conformó una comisión de nomenclatura que recientemente enunció un protocolo para la nomenclatura fitolítica (Madella et al., 2002; 2005), en donde se plantearon lo lineamientos básicos para la nomenclatura de los morfotipos fitolíticos. Esta propuesta unificadora pretendía eliminar los casos de sinonimias existentes.

En síntesis, se hace necesario el establecimiento de pautas clasificatorias para instaurar una sistemática de fitolitos que permita un preciso tratamiento y delimitación de las categorías, de acuerdo a las normativas de la nomenclatura botánica como fuera propuesto por ZUcol y Brea (2005). En este trabajo se adoptó el criterio clasificatorio propuesto por Zucol y Brea (2005) con los aportes de otros autores, como se esquematiza en la tabla 4.2. Para la identificación y clasificación de los morfotipos fitolíticos observados en las diferentes muestras y atendiendo al problema nomenclatural existente en esta temática de estudio, se realizó una tabla comparativa (tabla 4.2.) con las equivalencias clasificatorias propuestas por los autores más reconocidos e incorporaciones del código internacional, donde también se muestra el nombre utilizado en las descripciones desarrolladas en este análisis, definido en la misma tabla, refiriéndolo a esquemas presentados en la figura 4.5. 


\subsection{DESCRIPCION DE LOS MORFOTIPOS UTILIZADOS PARA ESTE} ANÁLISIS

\section{Globulolithum}

Este nombre fue dado por Zucol y Brea (2005a) para referirse a aquellos fitolitos esféricos a elipsoidales, de tamaño variable y superficie lisa, rugulosa $u$ ornamentada (figuras 4.5 .1 y 4.5.2). En los ornamentados, su superficie puede estar cubierta por espinas de gran tamaño, espinas pequeñas o microespinas. Otros tipos de ornamentación que se observan en estos fitolitos son las papilas, de tamaño similar a las espinas pero con ápice romo, y en algunos casos la ornamentación toma aspecto de clava. El nombre deriva de la morfotribu Globulolita (Bertoldi de Pomar, 1971).

\section{Globulolithum sphaeroechinulathum}

Nombre dado por Zucol y Brea (2005a) a aquellos fitolitos esféricos con ornamentación espinosa (figura 4.5.1). Poseen numerosas espinas bien definidas. El nombre es derivado de la variante Globulolita esferoquinulata (Bertoldi de Pomar, 1971). El epíteto genérico hace referencia al carácter globular de estos fitolitos, mientras que el epíteto específico hace alusión a su contorno esferoidal y a su ornamentación equinulada (equinulate).

\section{Globulolithum sphaeropsilathum}

Este nombre fue dado por Zucol y Brea (2005a). Hace referencia a aquellos fitolitos esféricos con superficie lisa o suavemente rugosa (figura 4.5.2). La combinación del epíteto específico alude a la esfericidad del tipo fitolítico, conjuntamente con la característica de su superficie lisa (psilate).

\section{Aculeolithum}

Este nombre fue dado por Zucol y Brea (2005a) a aquellos fitolitos con un extremo aguzado y base ensanchada, irregular, ovalada o circular, sobre la que se desarrolla el ápice afilado o barba (figuras 4.5.17-21). Las principales variaciones de sus morfotipos se encuentran en la forma de la base y de la barba. En general los aguijones epidérmicos foliares de gramíneas presentan dos tendencias morfométricas (Zucol, 1996a): aguijones de mayor tamaño que 
se distribuyen en las zonas marginales foliares; y aguijones de menor tamaño que se distribuyen en las zonas costales o más raramente intercostales de las epidermis adaxiales y abaxiales foliares. Nombre derivado de la morfotribu Aculeolita (Bertoldi de Pomar, 1971). En general estos fitolitos son originados en macropelos, aguijones u otros tricomas, principalmente de gramíneas y ciperáceas; formados por una base ensanchada mediante la cual se incerta al tejido, un cuerpo delgado o globoso que remata en una barba.

\section{Aculeolithum rostrathum}

Este nombre fue dado por Zucol y Brea (2005a) para aquellos fitolitos de cuerpo con base ancha, y barba prominente, robusta, cuya base es difícilmente diferenciable del cuerpo (figura 4.5.18). Nombre derivado de la variante Aculeolita rostrata (Bertoldi de Pomar, 1971).

\section{Aculeolithum acuminathum}

Este nombre fue dado por Zucol y Brea (2005a) para aquellos fitolitos de base alargada de extremos aguzados, cuerpo delgado, barba corta (figura 4.5.20). Nombre derivado de la variante Aculeolita acuminata (Bertoldi de Pomar, 1971).

\section{Aculeolithum ancistrathum}

Nombre dado por Zucol y Brea (2005a) para referirse a aquellos fitolitos de área basal ovalada y corta a circular, cuerpo redondeado superficialmente que remata en una barba a modo de gancho (figura 4.5.19). Nombre derivado de la variante Aculeolita ancistrata (Bertoldi de Pomar, 1971).

\section{Aculeolithum aciculathum}

Nombre dado por Zucol y Brea (2005a) para los fitolitos de área basal muy alargada cuerpo delgado y barba acicular que prolonga el cuerpo en sentido longitudinal (figura4.5.21). Nombre derivado de la variante Aculeolita aciculata (Bertoldi de Pomar, 1971). 


\section{Flabelolithum}

Nombre dado por Zucol y Brea (2005a) a aquellos fitolitos de cuerpo aplanado, prismático, con uno o ambos extremos flabelados o en forma de abanico (figura 4.5.26-30). Cuando existe un único extremo con forma de flabelo, el extremo opuesto es más delgado y se lo denomina pie, las caras laterales del pie pueden ser rectas, cóncavas o irregulares, dispuestas en forma simétrica o asimétrica con respecto al eje longitudinal. Nombre derivado de la morfotribu Flabelolita (Bertoldi de Pomar, 1971). Se originan en su mayoría a partir de células bulliformes o motoras de gramíneas; por lo cual, la cara mayor de estos fitolitos prismáticos es perpendicular a la superficie epidérmica foliar. Estas células presentan una elevada varibilidad en forma y tamaño. (Zucol y Brea, 2005a).

\section{Flabelolithum euflabelathum}

Nombre dado por Zucol y Brea (2005a) a aquellos fitolitos de cuerpo prismático aplanado, compuesto por un flabelo y un pie con desarrollo simétrico con respecto al eje longitudinal; flabelo semicircular convexo, largo del pie no mayor a dos veces el largo del flabelo, pie de caras laterales cóncavas (figura 4.5.27). Nombre derivado de la variante Flabelolita euflabelata (Bertoldi de Pomar, 1971).

\section{Flabelolithum complanathum}

Nombre dado por Zucol y Brea (2005a) para aquellos fitolitos en forma de abanico, con contorno cuneiforme, lateralmente adelgazados; caras laterales del pie planas; pie ancho de lados rectos (figura 4.5.28). Nombre derivado de la variante Flabelolita complanata (Bertoldi de Pomar, 1971).

\section{Flabelolita elongata}

Nombre dado por Bertoldi de Pomar (1971) para aquellos fitolitos en forma de abanico con un flabelo semicircular convexo; pie adelgazado, tres veces más largo que la altura del flabelo (figura 4.5.29). 


\section{Flabelolita excavata}

Nombre dado por Bertoldi de Pomar (1971) para aquellos fitolitos con una testa con escotadura más o menos pronunciada, pie corto, del mismo largo que la altura de la testa (figura 4.5.30).

\section{Macroprismatolithum}

Nombre dado por Zucol y Brea (2005a) para aquellos fitolitos prismáticos aplanados, de cara superficial lisa o con protuberancias papilosas, con aristas laterales que pueden ser lisas, onduladas, denticuladas, serradas, de un largo superior a $40 \mu \mathrm{m}$; extremos planos o cóncavos (figuras 4.5.31-36). Nombre derivado de la morfotribu Prismatolita (Bertoldi de Pomar, 1971), el prefijo macro alude a que el tamaño promedio de estos fitolitos se encuentra en el rango de los macrosilicofitolitos propuesto por Bertoldi de Pomar, 1971.

\section{Macroprismatolithum psilaristathum}

Nombre dado por Zucol y Brea (2005a) para aquellos fitolitos prismáticos de aristas de las caras superficiales lisas; extremos lisos, irregulares o regulares (figura 4.5.32). Nombre derivado de la variante Euprismatolita psilaristata (Bertoldi de Pomar, 1971).

\section{Macroprismatolithum denticulathum}

Nombre dado por Zucol y Brea (2005a) para aquellos fitolitos prismáticos con aristas denticuladas en sus caras superficiales lisas; extremos lisos, irregulares o regulares (figura 4.5.35). Nombre derivado de la variante Euprismatolita denticulata (Bertoldi de Pomar, 1971).

\section{Macroprismatolithum ondulathum}

Nombre dado por Zucol y Brea (2005a) para aquellos fitolitos prismáticos de aristas de las caras superficiales onduladas; extremos lisos, irregulares 0 regulares (figura 4.5.31). Nombre derivado de la variante Euprismatolita ondulata (Bertoldi de Pomar, 1971). 


\section{Macroprismatolithum excavathum}

Nombre dado por Zucol y Brea (2005a) para aquellos fitolitos prismáticos de aristas de las caras superficiales lisas, denticuladas $u$ onduladas; con uno o ambos extremos marcadamente cóncavos (figura 4.5.36). Nombre derivado de la variante Euprismatolita excavata (Bertoldi de Pomar, 1971).

\section{Euprismatolita elongata}

Nombre dado por Bertoldi de Pomar (1971) para aquellos fitolitos de cuerpo prismático aplanado, aristas laterales lisas, muy alargada; relación largo-ancho mayor a 5:1 (figura 4.5.33). Corresponden a células epidérmicas largas de gramíneas.

\section{Euprismatolita anisocornisata}

Nombre dado por Bertoldi de Pomar (1971) para aquellos fitolitos de cuerpo prismático aplanado,con prominencias en las caras laterales, a modo de cornisas asimétricamente dispuestas.

\section{Euprismatolita serrata}

Nombre dado por Bertoldi de Pomar (1971) para aquellos fitolitos de cuerpo prismático aplanado, con aristas serradas (figura 4.5.34).

\section{Halteriolita}

Nombre dado por Bertoldi de Pomar (1971) para aquellos fitolitos de cuerpo en forma de halterio o barra de gimnasta. Con un istmo o cintura y dos lóbulos. El ancho y largo del istmo (centro) es variable, así como la forma de los extremos terminales, ensanchados a modo de cabeza o lóbulos. Visto por las caras laterales (derecha e izquierda), son aplanados, con el istmo muy delgado de modo que los lóbulos terminales toman el aspecto de tacos, ensanchados en la base. Los extremos pueden ser rectos, cóncavos o convexos (figura 4.5.4-14 y 4.5.16). Pueden presentar uno o más istmos o cinturas, lo que permite subdividirlos en dos subtribus con sus respectivas variantes (Bertoldi de Pomar, 1971). 
Euhalteriolita bitestata: fitolitos de cuerpo en forma de halterio o barra de gimnasta con lóbulos más o menos convexos o modo de cabezas o "testas" (figura 4.5.4) (Bertoldi de Pomar, 1971).

E. testilobata: fitolitos de cuerpo en forma de halterio o barra de gimnasta con extremos o lóbulos hendidos, de modo que aparecen bilobados (figura 4.5.10) (Bertoldi de Pomar, 1971).

E. botulata: fitolitos de cuerpo en forma de halterio o barra de gimnasta rollizo, botuliforme, pero con istmo marcado (figura 4.5.7) (Bertoldi de Pomar, 1971).

E. testicaudiculata: fitolitos de cuerpo en forma de halterio o barra de gimnasta con los extremos o lóbulos terminales rectos (figura 4.5.9) (Bertoldi de Pomar, 1971).

E. cruciformata: fitolitos de cuerpo en forma de halterio o barra de gimnasta con lóbulos profundamente hendidos e istmo muy adelgazado, de modo que resulta en figura de cruz (figura 4.5.16) (Bertoldi de Pomar, 1971).

E. faseolata: fitolitos de cuerpo en forma de halterio o barra de gimnasta de contorno reniforme o forma de poroto (figura 4.5.6) (Bertoldi de Pomar, 1971).

E. tipo Stipa: fitolitos de cuerpo en forma de halterio o barra de gimnasta con dos lóbulos marcados. Visto por las caras laterales (derecha e izquierda) no son aplanados sino que presentan una quilla (figura 4.5.8).

Plurhalteriolita: fitolitos con dos o más cinturas o istmos con contornos laterales simétricos o asimétricos (figuras 4.5.12-14) (Bertoldi de Pomar, 1971).

$\boldsymbol{P}$. trilobata: fitolitos con dos istmos o cinturas, dando el cuerpo el aspecto del fruto del maní, con lóbulos terminales convexos, bilobados o cotilados (figura 4.5.13) (Bertoldi de Pomar, 1971).

$P$. inequilobata: fitolitos con caras laterales asimétricamente acinturadas, de modo que una muestra tres lóbulos y la otra sólo dos (figura 4.5.12) (Bertoldi de Pomar, 1971).

$P$. catenulata: fitolitos con más de dos cinturas 0 istmos, y cuatro o más lóbulos dispuestos en cadena (figura 4.5.14) (Bertoldi de Pomar, 1971).

\section{Estrobilolita}

Nombre dado por Bertoldi de Pomar (1971) para aquellos fitolitos de cuerpo en forma de cono o estróbilo, truncado y lateralmente comprimido, 
secciones basales desde subcirculares hasta ovaladas y muy alargadas, relación base-altura variable (figura 4.5.22-25).

E. complanata: fitolito cónico verticalmente aplastado; relación alto-ancho 1:2 (figura 4.5.23) (Bertoldi de Pomar, 1971).

E. aplanada: fitolito cónico verticalmente aplastado con el cuerpo longitudinalmente alargado (figura 4.5.25).

E. equidimensionata: fitolito cónico equidimensional, relación base-altura 1:1 (figura 4.5.22) (Bertoldi de Pomar, 1971).

E. elongata: fitolito cónico con altura mayor que la base (relación alto-ancho 1>1) (figura 4.5.24) (Bertoldi de Pomar, 1971).

E. cotilata: fitolito cónico verticalmente comprimido, hasta tomar aspecto de palangana o cótila, relación alto -ancho 3:1 (Bertoldi de Pomar, 1971).

\section{Doliolita}

Nombre dado por Bertoldi de Pomar (1971) para aquellos fitolitos de cuerpo semejante a una silla de montar o tonel, con caras laterales convexas y caras superior e inferior cóncavas (figura 4.5.37-39).

D. oblata: fitolitos de cuerpo semejante a una silla de montar o tonel, relación ancho- alto 2:1 (comprimida verticalmente) (figura 4.5.38) (Bertoldi de Pomar, 1971).

D. elongata: fitolitos de cuerpo semejante a una silla de montar o tonel, relación ancho- alto 1:2 (lateralmente comprimida) (figura 4.5.39) (Bertoldi de Pomar, 1971).

D. equidimensionata: fitolitos de cuerpo semejante a una silla de montar o tonel, relación alto-ancho 1:1 (figura 4.5.37) (Bertoldi de Pomar, 1971).

\section{Otros:}

\section{Longolita}

Nombre dado por Bertoldi de Pomar (1971) para aquellos fitolitos de cuerpo fusiforme, clavado o elongado, con ornamentaciones que forman superficies de tipo corrugado, de hasta 200 micrones (figura 4.5.41). Corresponden a células subepidérmicas de Podostemanceae. 


\section{Pileolita}

Nombre dado por Bertoldi de Pomar (1971) para aquellos fitolitos de cuerpo pileiforme. Con o sin reborde anular liso y ornamentado (figura 4.5.41). Citada para Cyperaceae en general.

\subsection{RECUENTO DE FITOLITOS Y OBTENCIÓN DE LA MUESTRA}

\section{MÍNIMA}

Al no existir valores universales en lo que respecta al número de individuos fitolíticos a recontar en una muestra, de modo de asegurarse que esta muestra sea representativa del material procesado, hay que recurrir a la muestra minima, representativa de un conjunto de muestras de igual origen.

Una vez obtenidos los preparados se comienza con su observación al microscopio óptico, de esta manera se obtiene el valor de la muestra mínima, que resulta de establecer la variabilidad presente en el muestreo (que en este caso es la presencia de las diferentes clases morfológicas) a medida que se incrementa el número de fitolitos relevados. De esta forma si llevamos esto a un gráfico " $x$ " e "y" (variabilidad vs. tamaño muestral) (figura4.4.) observaremos que la variabilidad presente en las muestras se incrementará a medida que se incrementa el tamaño muestral. Tendencia que se manifiesta hasta un punto donde la curva se vuelve asintótica con un determinado valor de variabilidad, y es a partir de ese punto donde por más incrementos que realicemos en el tamaño de la muestra la variabilidad se va a mostrar constante o con leves diferencias, ese punto nos indica cual es el límite inferior de la representatividad de nuestras observaciones con respecto al tamaño muestral; la proyección de ese punto sobre el eje y, o tamaño muestral, nos indicará cual es el tamaño de la muestra mínima representativa. En este caso la muestra mínima fue obtenida en los 400 fitolitos por muestra. De esta manera el siguiente paso consta en observar cada una de las muestras y relevar los fitolitos colocando los datos en planillas de conteo. 


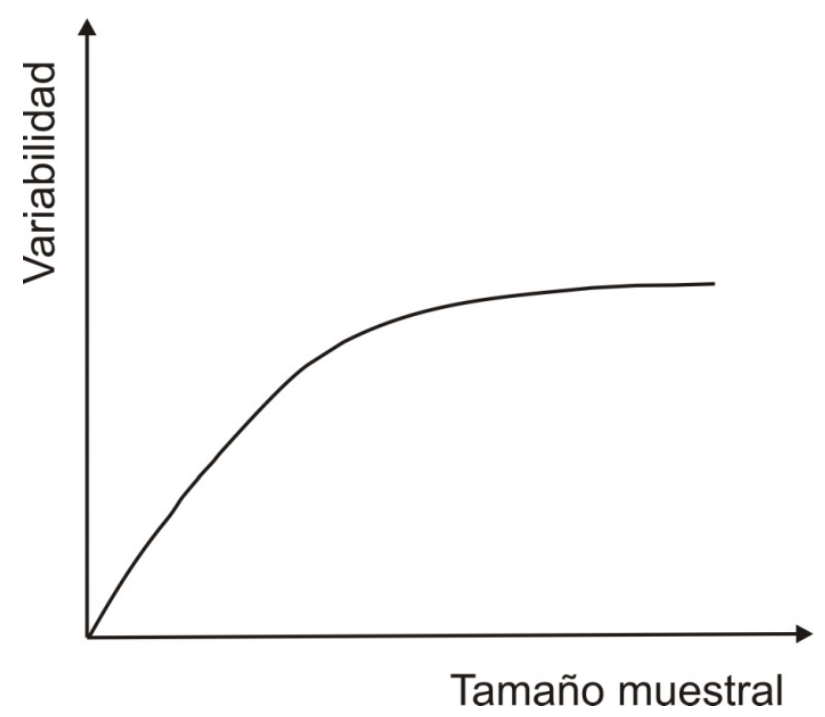

Figura 4.4. Gráfico x e y (tamaño muestral vs. variabilidad) utilizado para la obtención de la muestra mínima.

\subsection{ABUNDANCIA RELATIVA}

Los conteos realizados se volcaron en las planillas de cálculo. Una vez completas se realizó el análisis de la información, que se expresan en valores de abundancia, los cuales se expresaron en valores porcentuales (frecuencias relativas) y en categorías de abundancia. Las abundancias relativas (tabla 4.1.) se consideraron en clases de frecuencias distribuidas en una escala que abarca desde la ausencia de los fitolitos de una determinada clase morfológica, a su presencia en forma "Rara", "Escasa", "Frecuente" o "Muy Frecuente". Los límites de dichas clases se obtuvieron teniendo en cuenta que: La ausencia está representada por el $0 \%$ de la frecuencia relativa. El valor máximo de la escala (D) es igual al valor de la clase morfológica que posee la mayor frecuencia relativa de la asociación. Raros se han encontrado a los fitolitos cuyas clases morfológicas poseen valores de frecuencia relativas superiores al $0 \%$ y que no superen el límite $A$, siendo $A=0.1 \times D$. Escasos se han considerado a los fitolitos cuyas clases morfológicas poseen valores de frecuencias relativas iguales o superiores a $A$ y que no superen el limite $B$, siendo $B=0.3 \times D$. Frecuentes se han considerado a los fitolitos cuyas clases morfológicas poseen valores de frecuencias relativas iguales o superiores a $\mathrm{B}$ y que no superen el limite $C$, siendo $C=0.6 \times D$. Muy frecuentes se han 
considerado a los fitolitos cuyas clases morfológicas poseen valores de frecuencias relativas entre $C$ y $D$.

\begin{tabular}{|l|l|}
\hline frecuencia relativa del 0\% & Ausente (A) \\
\hline mayor al 0\% y menor al valor A $(\mathrm{A}=0.1 \times \mathrm{D})$ & Raro (R) \\
\hline mayor o igual al valor A y menor que B (B=0.3 $\mathrm{D}$ D) & Escaso (E) \\
\hline mayor o igual a B y menor que C $(\mathrm{C}=0.6 \times \mathrm{D})$ & Frecuente (F) \\
\hline si se encuentra entre C y D & Muy frecuente (Mf) \\
\hline $\begin{array}{l}\text { (D) es igual al valor de la clase morfológica que posee la mayor frecuencia } \\
\text { relativa de la asociación }\end{array}$ \\
\hline
\end{tabular}

Tabla 4.1. Valores de abundancia (los cuales se expresaron en valores porcentuales frecuencias relativas- y en categorías de abundancia).

Una vez obtenidos los valores de abundancia se creó una matriz básica de datos (MBD) sobre la que se efectuaron los análisis numéricos. El procesamiento de la información y su graficación en diagramas fitolíticos se realizaron con el programa POLPAL, Numerical Análisis (Walanus y Nalepka 1999a, 1999b, 2002; Nalepka y Walanus 2003). En el diagrama se representa la abundancia de cada taxón en cada muestra a lo largo del perfil. Lo que se indica como "Rarefacción" se refiere a la riqueza de los taxa, mientras que el "Diagrama de cluster" es la sumatoria de las especies (figuras 5.5., 5.9., 5.13., 5.17., 5.21., 5.25., 5.29., 5.37., 5.40., 5.44.)

Con la información obtenida se realizó el análisis de los porcentajes a lo largo de cada perfil, con el fin de establecer las zonaciones, y mediante métodos de análisis multivariado la comparación de los distintos perfiles con la intención de establecer vinculaciones entre las distintas asociaciones paleoflorísticas descriptas (figuras 6.1., 6.2., 6.3., 6.4.,6.5.).

El análisis de componentes principales (PCA) y el análisis cluster, dos técnicas de ordenamiento multivariado, proveyeron un manera útil de analizar la variabilidad entre muestras, y de mostrar gráficamente la forma en que estas se asocian. Para esta etapa se utilizó el programa PAST (ver. 1.76), con el índice Moristia. 


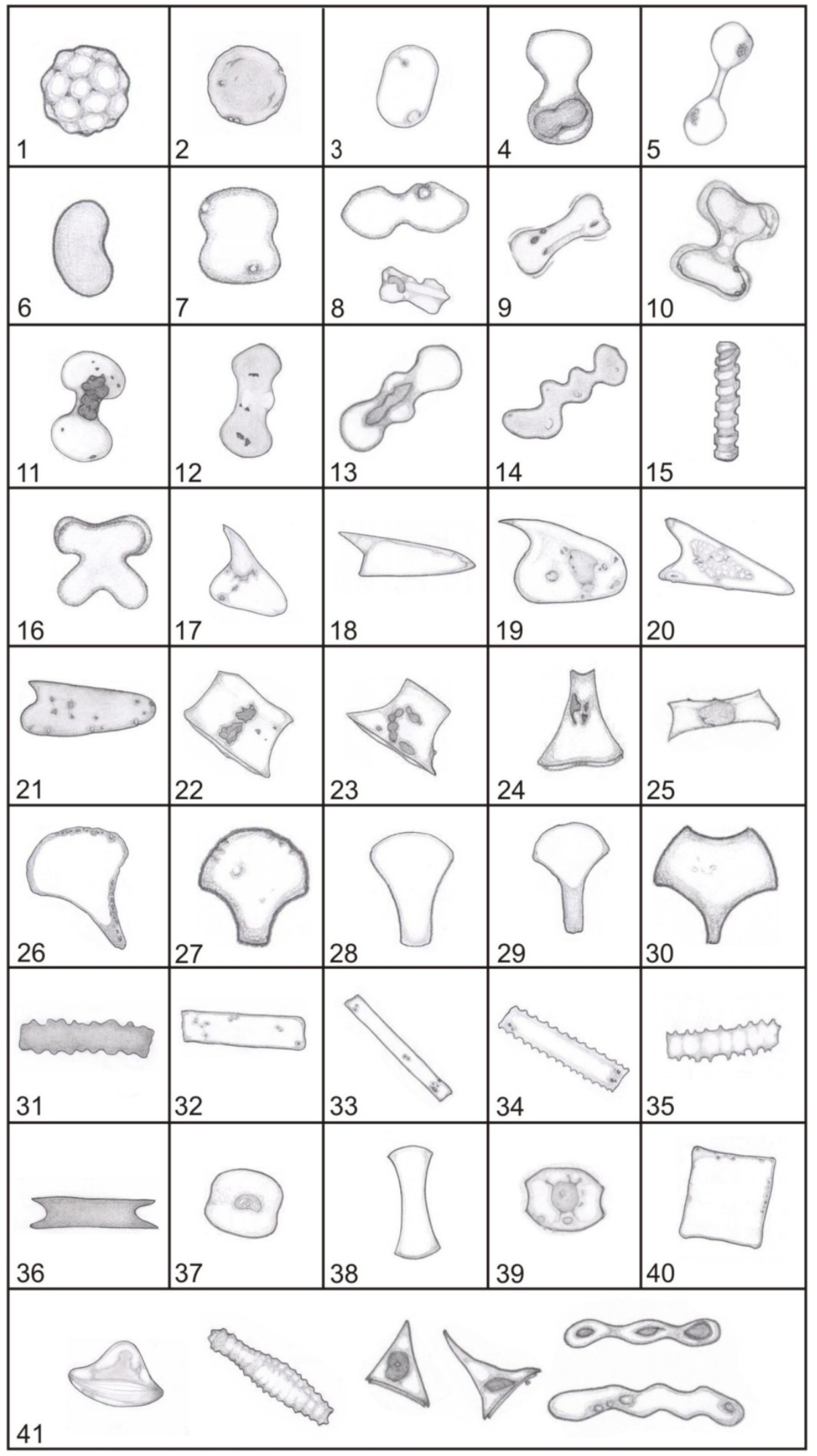

Figura 4.5. Esquemas de los morfotipos utilizados para este análisis. Nótese que los esquemas no están a escala y su función es mostrar la morfología a un tamaño apreciable. 


\begin{tabular}{|c|c|c|c|c|c|c|c|c|c|c|c|}
\hline $\mathbf{N}^{\circ}$ & $\begin{array}{l}\text { Twiss, et al., } \\
\text { 1969.Twiss, } 1992\end{array}$ & $\begin{array}{l}\text { Bertoldi de Pomar, } \\
1971\end{array}$ & $\begin{array}{l}\text { Kondo et al., } 1994 . \\
\text { Alexandre et al., } \\
\text { 1997. Bremond et al. } \\
2005\end{array}$ & $\begin{array}{l}\text { Fredlund y } \\
\text { Tieszen, , } 994 \\
\text { Mulholland, } 1989\end{array}$ & $\begin{array}{l}\text { Gallego y Distel, } \\
2004\end{array}$ & $\begin{array}{l}\text { Carnelli et al., } \\
2004\end{array}$ & $\begin{array}{l}\text { Zucol y Brea, } \\
2005\end{array}$ & $\begin{array}{l}\text { Madella et al., } \\
2005\end{array}$ & Barboni et al., 2006 & $\begin{array}{l}\text { Zucol y Bonomo, } \\
2008\end{array}$ & $\begin{array}{l}\text { Nombre utilizado } \\
\text { en este análisis }\end{array}$ \\
\hline 1 & & $\begin{array}{l}\text { Globulolita } \\
\text { esferoequinulata }\end{array}$ & $\begin{array}{l}\text { Spherical spinulose class, } \\
\text { Kondo et al., } 1994 \\
\text { spherical crenate, } \\
\text { Bremond et al. } 2005\end{array}$ & & & Sfherical rugose & $\begin{array}{l}{ }^{*} \text { *Globulolithum } \\
\text { spheeroechinulathum }\end{array}$ & $\begin{array}{l}\text { Globular echinate- } \\
\text { granulate }\end{array}$ & Globular granulate & $\begin{array}{l}\text { Globulolita } \\
\text { esferoequinulata }\end{array}$ & $\begin{array}{l}\text { Globulolithum } \\
\text { sphaero- } \\
\text { echinulathum }\end{array}$ \\
\hline 2 & Circular & Globulolita & $\begin{array}{l}\text { Spherical smooth class } \\
\text { p.p. Kondo et al., 1994 = } \\
\text { Bremond et al. 2005 }\end{array}$ & & & Sfherical smooth & $\begin{array}{l}\text { *Globulolithum } \\
\text { sphaeropsilathum }\end{array}$ & Globular smooth & Globular smooth & Redondeado sp 1 & $\begin{array}{l}\text { Globulolitum } \\
\text { sphaero- } \\
\text { psilathum }\end{array}$ \\
\hline 3 & Elliptical, Oblong & Globulolita & & & Elliiptical, Oblong & & & Ovate-oblong & & $\begin{array}{l}\text { Globulolita } \\
\text { elipsoequinulata/ } \\
\text { eliptico sp1 }\end{array}$ & Eliptico \\
\hline 4 & Dumbbell & ${ }^{*}$ Halteriolita & $\begin{array}{l}\text { Dumdbell } \\
\text { Alexandre et al., } \\
1997=\text { Bremond et al. } \\
2005\end{array}$ & Simple-lobate & Dumbbell & & & Bilobate & Bilobate & Halteriolita & Halteriolita \\
\hline 5 & $\begin{array}{l}\text { Dumbbell, long } \\
\text { shank }\end{array}$ & & idem & & $\begin{array}{l}\text { Dumbbell with long } \\
\text { central portion }\end{array}$ & & $\begin{array}{l}\text { (Halterio de centro largo } \\
\text { y extremos convexos } \\
\text { Zucol, 1996) }\end{array}$ & Bilobate & Bilobate & Halteriolita sp1 & $\begin{array}{l}\text { Euhalteriolita centro } \\
\text { largo }\end{array}$ \\
\hline 6 & & $\begin{array}{l}\text { *Euhalteriolita } \\
\text { faseolata }\end{array}$ & & & & & & & Bilobate & $\begin{array}{l}\text { Halteriolita } \\
\text { faseolata }\end{array}$ & $\begin{array}{l}\text { Euhalteriolita } \\
\text { faseolata }\end{array}$ \\
\hline 7 & $\begin{array}{l}\text { Dumbbell, short } \\
\text { shank }\end{array}$ & $\begin{array}{l}{ }^{*} \text { Euhalteriolita } \\
\text { botulata }\end{array}$ & ídem & & $\begin{array}{l}\text { Dumbbell with short } \\
\text { central portion }\end{array}$ & & & Bilobate & Bilobate & Halteriolita botulata & $\begin{array}{l}\text { Euhalteriolita } \\
\text { botulata }\end{array}$ \\
\hline 8 & & & idem & Stipa-type & Stipa type dumbbell & & & Bilobate & Bilobate & $\begin{array}{l}\text { Halteriolita stipa } \\
\text { type }\end{array}$ & $\begin{array}{l}\text { *Euhalteriolita tipo } \\
\text { Stipa }\end{array}$ \\
\hline 9 & $\begin{array}{l}\text { Dumbbell, short } \\
\text { shank, straight ends }\end{array}$ & $\begin{array}{l}\text { *Euhalteriolita } \\
\text { testicaudiculata } \\
\text { (para los de final } \\
\text { recto) }\end{array}$ & idem & Panicoid-type & $\begin{array}{l}\text { Dumbbell with long } \\
\text { central portion and } \\
\text { straight end }\end{array}$ & & & Bilobate & Bilobate & $\begin{array}{l}\text { Halteriolita } \\
\text { testicaudiculata }\end{array}$ & $\begin{array}{l}\text { Euhalteriolita } \\
\text { testicaudiculata }\end{array}$ \\
\hline 10 & $\begin{array}{l}\text { Dumbbell, short } \\
\text { shank, concave } \\
\text { ends }\end{array}$ & $\begin{array}{l}\text { *Euhalteriolita } \\
\text { testilibata (para los } \\
\text { de final cóncavo) }\end{array}$ & ídem & Panicoid-type & $\begin{array}{l}\text { Panicoid-type } \\
\text { dumbbell }\end{array}$ & & & Bilobate & Bilobate & $\begin{array}{l}\text { Halteriolita } \\
\text { testilobata }\end{array}$ & $\begin{array}{l}\text { Euhalteriolita } \\
\text { testilobata }\end{array}$ \\
\hline 11 & $\begin{array}{l}\text { Dumbbell, short } \\
\text { shank }\end{array}$ & $\begin{array}{l}\text { "Euhalteriolita } \\
\text { bitestata }\end{array}$ & idem & Simple- lobate & $\begin{array}{l}\text { Dumbbell with short } \\
\text { central portion and } \\
\text { convex end }\end{array}$ & & $\begin{array}{l}\text { (Halterio de centro corto } \\
\text { y extremo conveexo } \\
\text { Zucol, 1996) }\end{array}$ & Bilobate & Bilobate & $\begin{array}{l}\text { Halteriolita } \\
\text { bitestata }\end{array}$ & $\begin{array}{l}\text { Euhalteriolita } \\
\text { bitestata }\end{array}$ \\
\hline 12 & $\begin{array}{l}\text { Dumbbell, nodular- } \\
\text { spiny shank }\end{array}$ & $\begin{array}{l}\text { *Plurihalteriolita } \\
\text { inequilobata }\end{array}$ & idem & Other lobate & $\begin{array}{l}\text { Irregular, complex } \\
\text { dumbbell, straight or } \\
\text { convex end }\end{array}$ & & & Polylobate irregular & Trapeziform polylobate & $\begin{array}{l}\text { Halteriolita } \\
\text { inequilobata }\end{array}$ & $\begin{array}{l}\text { Plurihalteriolita } \\
\text { inequilobata }\end{array}$ \\
\hline 13 & $\begin{array}{l}\text { Regular, complex } \\
\text { dumbbell }\end{array}$ & $\begin{array}{l}\text { *Flurihalteriolita } \\
\text { trilobata }\end{array}$ & $\begin{array}{l}\text { Polylobate Bremond et al. } \\
2005\end{array}$ & Other lobate & $\begin{array}{l}\text { Regular, complex } \\
\text { dumbebll, straight or } \\
\text { convex end }\end{array}$ & & & Polylobate regular & Trapeziform polylobate & Halteriolita trilobata & $\begin{array}{l}\text { Plurihalteriolita } \\
\text { trilobata }\end{array}$ \\
\hline 14 & Crenate & $\begin{array}{l}\text { *Plurihalteriolita } \\
\text { catenulata }\end{array}$ & ídem & Crenate & $\begin{array}{l}\text { Crenate dumbbell, } \\
\text { straight or convex end }\end{array}$ & & & Polylobate & Trapeziform polylobate & $\begin{array}{l}\text { Halteriolita } \\
\text { catenulata }\end{array}$ & $\begin{array}{l}\text { Plurihalteriolita } \\
\text { catenulata }\end{array}$ \\
\hline 15 & & & & & & & & & & & $\begin{array}{l}\text { Elemento de } \\
\text { conducción }\end{array}$ \\
\hline 16 & Cross & $\begin{array}{l}\text { *Euhalteriolita } \\
\text { criciforrmata }\end{array}$ & $\begin{array}{l}\text { Cross Bremond et al. } \\
2005\end{array}$ & Cross & Cross & & & Cross & Cross & $\begin{array}{l}\text { Halteriolita } \\
\text { cruciformata }\end{array}$ & $\begin{array}{l}\text { Euhalteriolita } \\
\text { cruciformata }\end{array}$ \\
\hline 17 & $\begin{array}{l}\text { Point shaped } \\
\text { Twiss, } 1992\end{array}$ & Aculeolita & $\begin{array}{l}\text { Point shaped class Kondo } \\
\text { et al., 1994.= Bremond et } \\
\text { al. } 2005\end{array}$ & & $\begin{array}{l}\text { Hairs, prickles or } \\
\text { hooks. Point shaped } \\
\text { Class }\end{array}$ & Trichomas & $\begin{array}{l}\text { “Aculeolithum p.p. } \\
\text { (Aguijón y Gancho } \\
\text { Zucol, 1996) }\end{array}$ & $\begin{array}{l}\text { Hooks, prickles and } \\
\text { macrohairs }\end{array}$ & Acicular hair cell & Aculeolita & Aculeolithum \\
\hline 18 & Ídem & Aculeolita rostrata & idem & & Idem & Trichomas & ${ }^{*}$ Aculeolithum rostrathum & & Acicular hair cell & $\begin{array}{l}\text { Aculeolita } \\
\text { rostrata }\end{array}$ & $\begin{array}{l}\text { Aculeolithum } \\
\text { rostrathum }\end{array}$ \\
\hline 19 & Ídem & Aculeolita ancistrata & ídem & & Idem & Trichomas & $\begin{array}{l}{ }^{*} \text { Aculeolithum } \\
\text { ancistrathum }\end{array}$ & & Acicular hair cell & $\begin{array}{l}\text { Aculeolita } \\
\text { ancistrata }\end{array}$ & $\begin{array}{l}\text { Aculeolithum } \\
\text { ancistrathum }\end{array}$ \\
\hline 20 & Ídem & $\begin{array}{l}\text { Aculeolita } \\
\text { acuminata }\end{array}$ & idem & & Idem & Trichomas & $\begin{array}{l}\text { *Aculeolithum } \\
\text { acuminathum }\end{array}$ & & Acicular hair cell & $\begin{array}{l}\text { Aculeolita } \\
\text { acuminata }\end{array}$ & $\begin{array}{l}\text { Aculeolithum } \\
\text { acuminathum }\end{array}$ \\
\hline 21 & Ídem & Aculeolita aciculata & idem & & Idem & Trichomas & $\begin{array}{l}\text { *Aculeolithum } \\
\text { aciculathum }\end{array}$ & & Acicular hair cell & Aculeolita aciculata & $\begin{array}{l}\text { Aculeolithum } \\
\text { aciculathum }\end{array}$ \\
\hline 22 & & “Estrobilolita & $\begin{array}{l}\text { Conical Bremond et al. } \\
2005\end{array}$ & $\begin{array}{l}\text { Conical-pyramidal } \\
\text { F. y T., 1994. } \\
\text { Rondel } \\
\text { Mulholland. 1989 }\end{array}$ & $\begin{array}{l}\text { Panicoid type } \\
\text { dumbbell }\end{array}$ & Trapezoids & & Rondel & Rondel short cell & $\begin{array}{l}\text { Estrobilolita } \\
\text { equidimensionata }\end{array}$ & $\begin{array}{l}\text { Estrobilolita } \\
\text { equidimensionata }\end{array}$ \\
\hline 23 & & $\begin{array}{l}\text { EEstrobilolita } \\
\text { complanata }\end{array}$ & idem & $\begin{array}{l}\text { Mulholland, } 1989 \\
\text { Conical-pyramidal }\end{array}$ & Stipa type dumdbell & Long trapezoids & & Rondel & & $\begin{array}{l}\text { Estrobilolita } \\
\text { complanata }\end{array}$ & $\begin{array}{l}\text { Estrobilolita } \\
\text { complanata }\end{array}$ \\
\hline 24 & & *Estrobilolita & ídem & Conical-pyramidal & & Narrow, chimney-like & & Rondel & & Estrobilolita & Estrobilolita \\
\hline
\end{tabular}




\begin{tabular}{|c|c|c|c|c|c|c|c|c|c|c|c|}
\hline $\mathbf{N}^{\circ}$ & $\begin{array}{l}\text { Twiss, et al., } \\
\text { 1969.Twiss, } 1992\end{array}$ & $\begin{array}{l}\text { Bertoldi de Pomar, } \\
1971\end{array}$ & $\begin{array}{l}\text { Kondo et al., } 1994 . \\
\text { Alexandre et al., } \\
\text { 1997. Bremond et al. } \\
2005\end{array}$ & $\begin{array}{l}\text { Fredlund y } \\
\text { Tieszen, 1994 } \\
\text { Mulholland, } 1989\end{array}$ & $\begin{array}{l}\text { Gallego y Distel, } \\
2004\end{array}$ & $\begin{array}{l}\text { Carnelli et al., } \\
2004\end{array}$ & $\begin{array}{l}\text { Zucol y Brea, } \\
2005\end{array}$ & $\begin{array}{l}\text { Madella et al., } \\
2005\end{array}$ & Barboni et al., 2006 & $\begin{array}{l}\text { Zucol y Bonomo, } \\
2008\end{array}$ & $\begin{array}{l}\text { Nombre utilizado } \\
\text { en este análisis }\end{array}$ \\
\hline & & $\begin{array}{l}\text { elongata (con } \\
\text { cintura) }\end{array}$ & & & & trapezoids & & & & elongata & elongata \\
\hline 25 & & & ídem & Conical-pyramidal & & Long thin trapezoids & & Rondel & & Estrobilolita sp1 & $\begin{array}{l}\text { *Estrobilolita } \\
\text { aplanada }\end{array}$ \\
\hline 26 & $\begin{array}{l}\text { Fan-shaped. Twiss, } \\
1992\end{array}$ & Flabelolita & $\begin{array}{l}\text { Fan-shaped class Kondo } \\
\text { et al., 1994= Bremond et } \\
\text { a. 2005 }\end{array}$ & & Fan & Bulliform cells & ${ }^{*}$ Flabelolithum p.p. & $\begin{array}{l}\text { Cuneiform/parallepi- } \\
\text { pedal bulliform cell }\end{array}$ & Cuneiform bulliform & Flabelolita & Flabelolithum \\
\hline 27 & Ídem & $\begin{array}{l}\text { Flabelolita } \\
\text { euflabelata }\end{array}$ & idem & & Fan & Bulliform cells & $\begin{array}{l}\text { *Flabelolithum } \\
\text { euflabelathum }\end{array}$ & & Cuneiform bulliform & $\begin{array}{l}\text { Flabelolita } \\
\text { euflabelata }\end{array}$ & $\begin{array}{l}\text { Flabelolithum } \\
\text { euflabelathum }\end{array}$ \\
\hline 28 & Ídem & $\begin{array}{l}\text { Flabelolita } \\
\text { complanata }\end{array}$ & idem & & Fan & Bulliform cells & $\begin{array}{l}{ }^{*} \text { FFlabelolithum } \\
\text { complanathum }\end{array}$ & & Cuneiform bulliform & $\begin{array}{l}\text { Flabelolita } \\
\text { complanata }\end{array}$ & $\begin{array}{l}\text { Flabelolithum } \\
\text { complanathum }\end{array}$ \\
\hline 29 & Ídem & ${ }^{*}$ Flabelolita elongata & ídem & & Fan & Bulliform cells & & & Cuneiform bulliform & Flabelolita elongata & Flabelolita elongata \\
\hline 30 & İdem & $\begin{array}{l}\text { *Flabelolita } \\
\text { excavata }\end{array}$ & idem & & Fan & Bulliform cells & & & Cuneiform bulliform & $\begin{array}{l}\text { Flabelolita } \\
\text { excavata }\end{array}$ & Flabelolita excavata \\
\hline 31 & Elongate sinuous & $\begin{array}{l}\text { Euprismatolita } \\
\text { ondulata }\end{array}$ & ídem & & Elongate sinuous & Rod long coarse wavy & $\begin{array}{l}{ }^{*} \text { Macroprismatolithum } \\
\text { ondulathum }\end{array}$ & Elongate sinuate & Elongate & $\begin{array}{l}\text { Prismatolita } \\
\text { ondulata }\end{array}$ & $\begin{array}{l}\text { Macroprismatoli- } \\
\text { thum ondulathum }\end{array}$ \\
\hline 32 & Elongate smooth & $\begin{array}{l}\text { Euprismatolita } \\
\text { psilaristata }\end{array}$ & $\begin{array}{l}\text { Elongate class Kondo et } \\
\text { al., 1994= Bremond et al. } \\
2005\end{array}$ & & Elongate smooth & Rod long smooth & $\begin{array}{l}\text { *Macroprismatolithum } \\
\text { psilaristathum }\end{array}$ & Elongate psilate & Elongate & $\begin{array}{l}\text { Prismatolita } \\
\text { psilaristata }\end{array}$ & $\begin{array}{l}\text { Macroprismatoli- } \\
\text { thum psilaristathum }\end{array}$ \\
\hline 33 & Elongate & $\begin{array}{l}\text { Euprismatolita } \\
\text { elongata }\end{array}$ & ídem & & Elongate & Rod long thin smooth & & Elongate & Elongate & & $\begin{array}{l}\text { Euprismatolita } \\
\text { elongata }\end{array}$ \\
\hline 34 & Elongate & $\begin{array}{l}\text { Euprismatolita } \\
\text { serrata }\end{array}$ & idem & & Elongate & Rod long & & Elongate & Elongate & & $\begin{array}{l}\text { *Euprismatolita } \\
\text { serrata }\end{array}$ \\
\hline 35 & Elongate spiny & $\begin{array}{l}\text { Euprismatolita } \\
\text { denticulata }\end{array}$ & idem & & Elongate spiny & $\begin{array}{l}\text { Rod long smooth thin } \\
\text { wavy }\end{array}$ & $\begin{array}{l}\text { *Macroprismatolithum } \\
\text { denticulathum }\end{array}$ & Elongate crenate & Elongate & $\begin{array}{l}\text { Prismatolita } \\
\text { denticulata }\end{array}$ & $\begin{array}{l}\text { Macroprismatoli- } \\
\text { thum denticulathum }\end{array}$ \\
\hline 36 & Elongate & $\begin{array}{l}\text { Euprismatolita } \\
\text { excavata }\end{array}$ & ídem & & Elongate & Rod long & & Elongate & Elongate & & $\begin{array}{l}\text { *Euprismatolita } \\
\text { excavata }\end{array}$ \\
\hline 37 & Chloridoid & $\begin{array}{l}\text { "Doliolita } \\
\text { equidimensionata }\end{array}$ & $\begin{array}{l}\text { Saddle Bremond et al. } \\
2005\end{array}$ & Saddle & Normal saddle & & & & Saddle & $\begin{array}{l}\text { Doliolita } \\
\text { equidimensionata }\end{array}$ & $\begin{array}{l}\text { Doliolita } \\
\text { equidimensionata }\end{array}$ \\
\hline $\begin{array}{l}38 \\
39\end{array}$ & $\begin{array}{l}\text { Thin Chloridoid } \\
\text { Chloridoid }\end{array}$ & $\begin{array}{l}\text { *Doliolita elongata } \\
\text { "Doliolita oblata }\end{array}$ & idem & $\begin{array}{l}\text { Saddle } \\
\text { SSaddle }\end{array}$ & Thin saddle & & & & $\begin{array}{l}\text { Saddle } \\
\text { Sardle }\end{array}$ & Doliolita elongata & Doliolita elongata \\
\hline $\begin{array}{l}39 \\
40 \\
41\end{array}$ & $\begin{array}{l}\text { Chloridold } \\
\text { Rectangular }\end{array}$ & $\begin{array}{l}\text { Doliofita oblata } \\
\text { Braquiolita }\end{array}$ & Idem & Saddie & Rectangular & Otros & & Parallepipedal & Sadale & Poliédricos sp1 & $\begin{array}{l}\text { Dololitta oblata } \\
\text { Poliéricos } \\
\text { Otros }\end{array}$ \\
\hline
\end{tabular}

Tabla 4.2. Equivalencia nomenclatural de morfotipos fitolíticos entre los términos utilizados en los principales trabajos descriptivos y los empleados en este trabajo de Tesis. En las columnas se indica la fuente original y en las filas se indican los morfotipos. .Aquellos morfotipos marcados con un asterisco $\left(^{*}\right)$ fueron descriptos en materiales y métodos. 


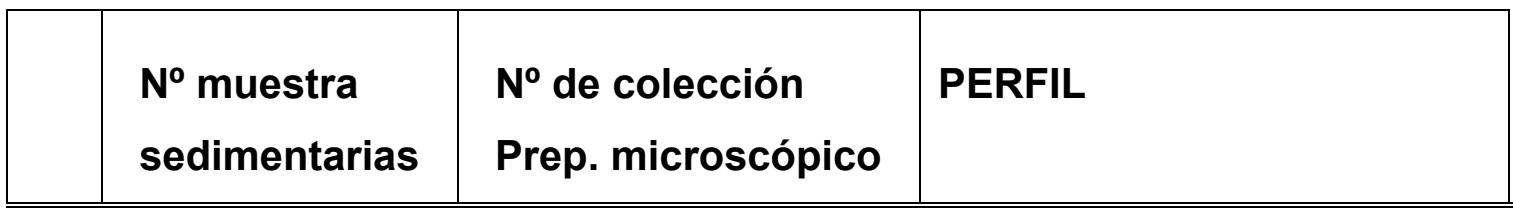

\begin{tabular}{|c|c|c|c|}
\hline 1 & 1099 & Palbomic 933 & PERFIL VIAL MAT \\
\hline 2 & 1100 & Palbomic 934 & PERFIL VIAL MAT \\
\hline 3 & 1101 & Palbomic 935 & PERFIL VIAL MAT \\
\hline 4 & 1102 & Palbomic 936 & PERFIL VIAL MAT \\
\hline 5 & 1103 & Palbomic 937 & PERFIL VIAL MAT \\
\hline$\overline{6}$ & 1105 & Palbomic 938 & PERFIL GAUCHITO GIL \\
\hline 7 & 1106 & Palbomic 939 & PERFIL GAUCHITO GIL \\
\hline 8 & 1107 & Palbomic 940 & PERFIL GAUCHITO GIL \\
\hline 9 & 1108 & Palbomic 941 & PERFIL GAUCHITO GIL \\
\hline 10 & 1109 & Palbomic 942 & PERFIL GAUCHITO GIL \\
\hline 11 & 1110 & Palbomic 943 & PERFIL GAUCHITO GIL \\
\hline 12 & 1111 & Palbomic 944 & PERFIL GAUCHITO GIL \\
\hline 13 & 1112 & Palbomic 945 & PERFIL GAUCHITO GIL \\
\hline 14 & 1113 & Palbomic 946 & PERFIL GAUCHITO GIL \\
\hline 15 & 1120 & Palbomic 947 & PERFIL RINCÓN DEL DOLL \\
\hline 16 & 1121 & Palbomic 948 & PERFIL RINCÓN DEL DOLL \\
\hline 17 & 1122 & Palbomic 949 & PERFIL RINCÓN DEL DOLL \\
\hline 18 & 1123 & Palbomic 950 & PERFIL RINCÓN DEL DOLL \\
\hline$\overline{19}$ & 1138 & Palbomic 951 & PERFIL DIAMANTE NORTE \\
\hline 20 & 1139 & Palbomic 952 & PERFIL DIAMANTE NORTE \\
\hline 21 & 1140 & Palbomic 953 & PERFIL DIAMANTE NORTE \\
\hline 22 & 1141 & Palbomic 954 & PERFIL DIAMANTE NORTE \\
\hline 23 & 1142 & Palbomic 955 & PERFIL DIAMANTE NORTE \\
\hline 24 & 1143 & Palbomic 956 & PERFIL DIAMANTE NORTE \\
\hline 25 & 1144 & Palbomic 957 & PERFIL DIAMANTE NORTE \\
\hline 26 & 1145 & Palbomic 958 & PERFIL DIAMANTE NORTE \\
\hline 27 & 1146 & Palbomic 959 & PERFIL DIAMANTE NORTE \\
\hline 28 & 1147 & Palbomic 960 & PERFIL DIAMANTE NORTE \\
\hline 29 & 1148 & Palbomic 961 & PERFIL DIAMANTE NORTE \\
\hline 30 & 1149 & Palbomic 962 & PERFIL DIAMANTE NORTE \\
\hline 31 & 1150 & Palbomic 963 & PERFIL DIAMANTE NORTE \\
\hline 32 & 1151 & Palbomic 964 & PERFIL DIAMANTE NORTE \\
\hline 33 & 1152 & Palbomic 965 & PERFIL DIAMANTE NORTE \\
\hline 34 & 1153 & Palbomic 966 & PERFIL DIAMANTE NORTE \\
\hline 35 & 1154 & Palbomic 967 & PERFIL DIAMANTE NORTE \\
\hline 36 & 1155 & Palbomic 968 & PERFIL DIAMANTE NORTE \\
\hline 37 & 1156 & Palbomic 969 & PERFIL DIAMANTE NORTE \\
\hline 38 & 1157 & Palbomic 970 & PERFIL DIAMANTE NORTE \\
\hline 39 & 1158 & Palbomic 971 & PERFIL DIAMANTE NORTE \\
\hline 40 & 1159 & Palbomic 972 & PERFIL DIAMANTE NORTE \\
\hline 41 & 1160 & Palbomic 973 & PERFIL DIAMANTE NORTE \\
\hline 42 & 371 & Palbomic 974 & PERFIL VILLA VALLE MARIA \\
\hline 43 & 372 & Palbomic 975 & PERFIL VILLA VALLE MARIA \\
\hline 44 & 373 & Palbomic 976 & PERFIL VILLA VALLE MARIA \\
\hline 45 & 374 & Palbomic 977 & PERFIL VILLA VALLE MARIA \\
\hline 46 & 375 & Palbomic 978 & PERFIL VILLA VALLE MARIA \\
\hline 47 & 376 & Palbomic 979 & PERFIL VILLA VALLE MARIA \\
\hline
\end{tabular}


Georgina Erral "Estudio fitolítico de la Formación Tezanos Pinto......"

\begin{tabular}{|c|c|c|c|}
\hline 48 & 377 & Palbomic 980 & PERFIL VILLA VALLE MARIA \\
\hline 49 & 378 & Palbomic 981 & PERFIL VILLA VALLE MARIA \\
\hline 50 & 379 & Palbomic 982 & PERFIL VILLA VALLE MARIA \\
\hline 51 & 380 & Palbomic 983 & PERFIL VILLA VALLE MARIA \\
\hline 52 & 381 & Palbomic 984 & PERFIL VILLA VALLE MARIA \\
\hline 53 & 1184 & Palbomic 985 & PERFIL ALVEAR \\
\hline 54 & 1185 & Palbomic 986 & PERFIL ALVEAR \\
\hline 55 & 1186 & Palbomic 987 & PERFIL ALVEAR \\
\hline 56 & 1187 & Palbomic 988 & PERFIL ALVEAR \\
\hline 57 & 1188 & Palbomic 989 & PERFIL ALVEAR \\
\hline 58 & 1189 & Palbomic 990 & PERFIL ALVEAR \\
\hline 59 & $\overline{1178}$ & Palbomic 991 & PERFIL LA JUANITA \\
\hline 60 & 1179 & Palbomic 992 & PERFIL LA JUANITA \\
\hline 61 & 1180 & Palbomic 993 & PERFIL LA JUANITA \\
\hline 62 & 1181 & Palbomic 994 & PERFIL LA JUANITA \\
\hline 63 & 1182 & Palbomic 995 & PERFIL LA JUANITA \\
\hline 64 & 1200 & Palbomic 996 & PERFIL LAS CUEVAS \\
\hline 65 & 1201 & Palbomic 997 & PERFIL LAS CUEVAS \\
\hline 66 & 1202 & Palbomic 998 & PERFIL LAS CUEVAS \\
\hline 67 & 1203 & Palbomic 999 & PERFIL LAS CUEVAS \\
\hline 68 & 1204 & Palbomic 1000 & PERFIL LAS CUEVAS \\
\hline 69 & 1205 & Palbomic 1001 & PERFIL LAS CUEVAS \\
\hline 70 & 1206 & Palbomic 1002 & PERFIL LAS CUEVAS \\
\hline 71 & 1328 & Palbomic 1003 & PERFIL TIPO TEZANOS PINTO \\
\hline 72 & 1329 & Palbomic 1004 & PERFIL TIPO TEZANOS PINTO \\
\hline 73 & 1330 & Palbomic 1005 & PERFIL TIPO TEZANOS PINTO \\
\hline 74 & 1331 & Palbomic 1006 & PERFIL TIPO TEZANOS PINTO \\
\hline 75 & 1332 & Palbomic 1007 & PERFIL TIPO TEZANOS PINTO \\
\hline 76 & 1333 & Palbomic 1008 & PERFIL TIPO TEZANOS PINTO \\
\hline 77 & 1334 & Palbomic 1009 & PERFIL TIPO TEZANOS PINTO \\
\hline 78 & 1335 & Palbomic 1010 & PERFIL TIPO TEZANOS PINTO \\
\hline 79 & 1336 & Palbomic 1011 & PERFIL TIPO TEZANOS PINTO \\
\hline 80 & 1337 & Palbomic 1012 & PERFIL TIPO TEZANOS PINTO \\
\hline 81 & 1338 & Palbomic 1013 & PERFIL TIPO TEZANOS PINTO \\
\hline 82 & 1339 & Palbomic 1014 & PERFIL TIPO TEZANOS PINTO \\
\hline 83 & 1340 & Palbomic 1015 & PERFIL TIPO TEZANOS PINTO \\
\hline 84 & 1341 & Palbomic 1016 & PERFIL TIPO TEZANOS PINTO \\
\hline 85 & 1342 & Palbomic 1017 & PERFIL TIPO TEZANOS PINTO \\
\hline 86 & 1343 & Palbomic 1018 & PERFIL TIPO TEZANOS PINTO \\
\hline 87 & 1344 & Palbomic 1019 & PERFIL TIPO TEZANOS PINTO \\
\hline 88 & 1345 & Palbomic 1020 & PERFIL TIPO TEZANOS PINTO \\
\hline 89 & 1346 & Palbomic 1021 & PERFIL TIPO TEZANOS PINTO \\
\hline 90 & 1347 & Palbomic 1022 & PERFIL TIPO TEZANOS PINTO \\
\hline 91 & 1348 & Palbomic 1023 & PERFIL TIPO TEZANOS PINTO \\
\hline 92 & 1349 & Palbomic 1024 & PERFIL TIPO TEZANOS PINTO \\
\hline 93 & 1350 & Palbomic 1025 & PERFIL TIPO TEZANOS PINTO \\
\hline 94 & $\overline{1384}$ & Palbomic 1026 & PERFIL PROTESTANTE \\
\hline 95 & 1385 & Palbomic 1027 & PERFIL PROTESTANTE \\
\hline 96 & 1386 & Palbomic 1028 & PERFIL PROTESTANTE \\
\hline 97 & 1387 & Palbomic 1029 & PERFIL PROTESTANTE \\
\hline 98 & 1388 & Palbomic 1030 & PERFIL PROTESTANTE \\
\hline 99 & 1389 & Palbomic 1031 & PERFIL PROTESTANTE \\
\hline
\end{tabular}


Georgina Erral "Estudio fitolítico de la Formación Tezanos Pinto......"

\begin{tabular}{|l|l|l|l|}
\hline 100 & 1390 & Palbomic 1032 & PERFIL PROTESTANTE \\
\hline 101 & 1391 & Palbomic 1033 & PERFIL PROTESTANTE \\
\hline 102 & 1392 & Palbomic 1034 & PERFIL PROTESTANTE \\
\hline 103 & 1393 & Palbomic 1035 & PERFIL PROTESTANTE \\
\hline 104 & 1394 & Palbomic 1036 & PERFIL PROTESTANTE \\
\hline 105 & 1395 & Palbomic 1037 & PERFIL PROTESTANTE \\
\hline 106 & 1396 & Palbomic 1038 & PERFIL PROTESTANTE \\
\hline \hline
\end{tabular}

Tabla 4.3. Número de muestra y su número correspondiente del acta de colección. 


\section{RESULTADOS}

\subsection{PERFIL VIAL MAT}

\subsubsection{Descripción del perfil}

El perfil muestreado se encuentra en las proximidades de la Localidad Rincón de Nogoyá. Su ubicación es S 32 46’ 05,2" - O 59 56' 26,2" (figuras 4.1. y 4.2.).

La facies eólica (sensu Iriondo, 1985) de la Formación Tezanos Pinto no tiene aquí demasiada potencia. El espesor que presenta es de aproximadamente $0,75 \mathrm{~m}(0,90-1,65 \mathrm{~m})$. Se trata de un perfil vertical (figuras 5.1. y 5.2.) que está compuesto por limo con escasa arena muy fina y arcilla. El conjunto es friable y masivo (sin estructuras sedimentarias). Hacia el techo del loess se desarrolla un suelo de 0,90 m de potencia (A: $20 \mathrm{~cm}, \mathrm{~B}, 50 \mathrm{~cm}$, y B/C $20 \mathrm{~cm}$ ), y por debajo se halla la Formación Alvear. Se tomaron 5 muestras para análisis de fitolitos con una equidistancia de 0,10 m (1099, 1100, 1101, 1102, 1103).

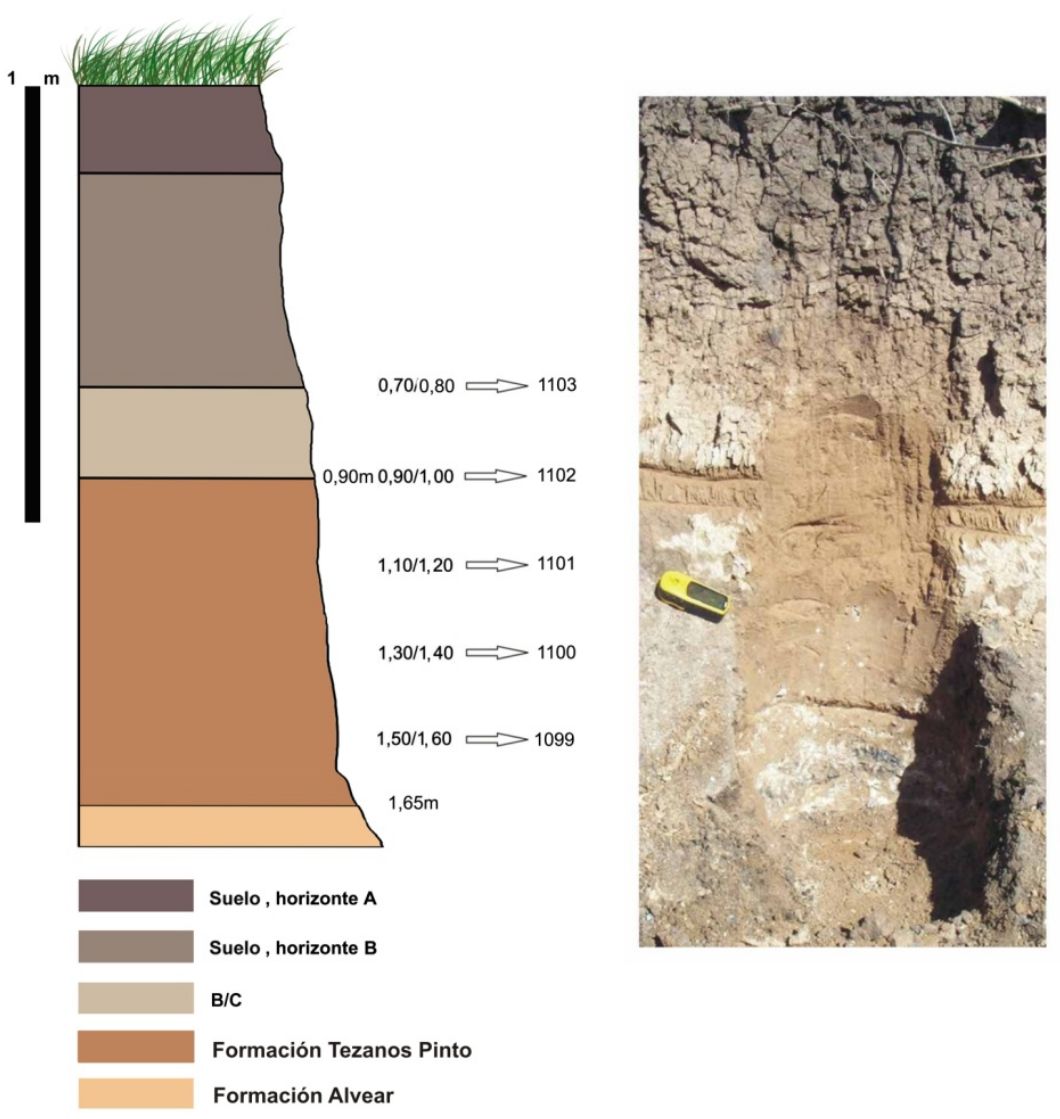

Figura 5.1.

Fotografía y esquema del perfil Vial Mat indicando la procedencia de las muestras. 


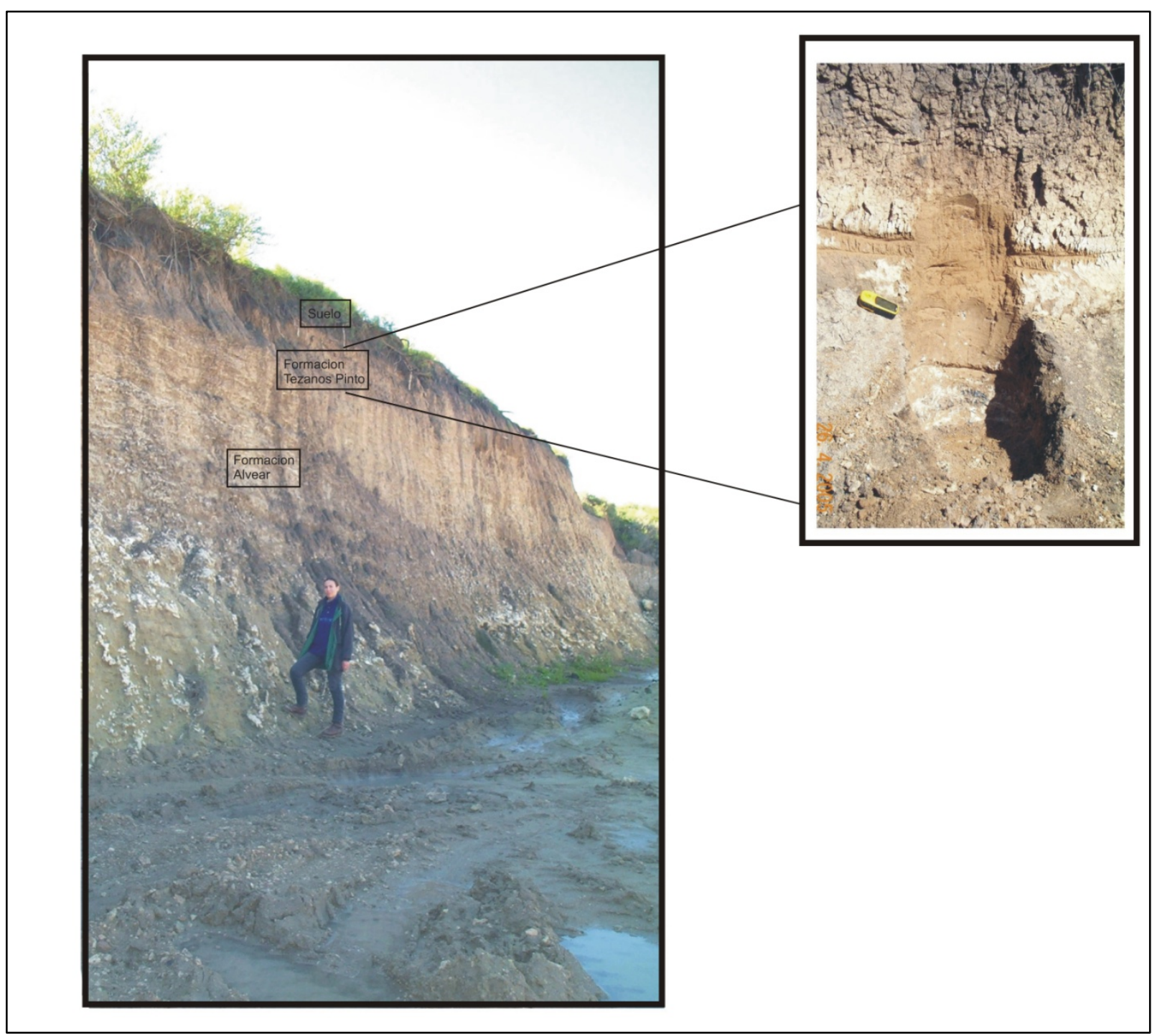

Figura 5.2. Fotografía del perfil Vial Mat y detalle de la procedencia de las muestras. 
5.1.2. Caracterización fitolítica de las muestras (las descripciones en extenso se presentan en el Apéndice)

\section{Muestra 1099}

En esta muestra se encontraron de manera muy frecuente $(>25,17 \%)$ los fitolitos prismáticos rectangulares Macroprismatolithum. De manera frecuente $(12,58-25,17 \%)$ los esféricos Globulolithum. Fueron escasos (4,19-12,58\%) Aculeolithum, los bilobados Halteriolita, fitolitos con forma de flabelo o abanico Flabelolithum, y el que incluye a aquellos en forma de cono truncado o rondel (Estrobilolita). De manera rara (0-4,19\%) aquellos en forma de silla de montar o saddle (Doliolita), elementos de conducción, Longolita, formas esféricas de gran tamaño, prismáticos menores a $40 \mu \mathrm{m}$, Euhalteriolita tipo Stipa, Pileolita, Plurihalteriolita, y poliédricos (figuras 5.3. y 5.4.).

\section{Muestra 1100}

En esta muestra se encontraron de manera muy frecuente $(>26,99 \%)$ los fitolitos prismáticos (Macroprismatolithum) y el grupo que incluye a aquellos en forma de cono truncado o rondel (Estrobilolita). De manera frecuente $(13,49-$ $26,99 \%$ ) los fitolitos esféricos (Globulolithum). De manera rara (0-4,49\%) los pelos, ganchos y aguijones (Aculeolithum), los bilobados o en forma de halterio (Halteriolita), fitolitos con forma de flabelo o abanico (Flabelolithum), aquellos en forma de silla de montar o saddle (Doliolita), Elementos de conducción, Longolita, prismáticos menores a $40 \mu \mathrm{m}$, Euhalteriolita tipo Stipa, Pileolita, Plurihalteriolita, y poliédricos (figuras 5.3. y 5.4.).

\section{Muestra 1101}

En esta muestra fueron muy frecuentes $(>25,84 \%)$ los Macroprismatolithum. Frecuentes (12,92-25,84\%) los esféricos (Globulolithum) y aquellos en forma de cono truncado (Estrobilolita). Escasos (4,30-12,92\%) los poliédricos. $Y$ raros (0-4,30\%) los pelos, ganchos y aguijones (Aculeolithum), las cruces, aquellos en forma de silla de montar o saddle (Doliolita), los bilobados o en forma de halterio (Halteriolita), fitolitos con forma de flabelo o abanico (Flabelolithum), elementos de conducción, Longolita, formas esféricas 
de gran tamaño, Euhalteriolita tipo Stipa y prismáticos menores a $40 \mu \mathrm{m}$ (figuras 5.3. y 5.4.).

\section{Muestra 1102}

En esta muestra se encontraron de manera muy frecuente $(>22,40 \%)$ los prismáticos rectangulares (Macroprismatolithum) y el grupo que incluye a aquellos en forma de cono truncado o rondel (Estrobilolita). De manera frecuente $(11,20-22,40 \%)$ los fitolitos esféricos (Globulolithum). De manera rara $(0-3,73 \%)$ los pelos, ganchos, y aguijones (Aculeolithum), las cruces, los bilobados (Halteriolita), fitolitos con forma de flabelo (Flabelolithum), aquellos en forma de silla de montar o saddle (Doliolita), elementos de conducción, prismáticos menores a $40 \mu \mathrm{m}$, Euhalteriolita tipo Stipa, Plurihalteriolita, y poliédricos (figuras 5.3. y 5.4.).

\section{$\underline{\text { Muestra } 1103}$}

En esta muestra se encontraron de manera muy frecuente $(>18,80 \%)$ los fitolitos prismáticos (Macroprismatolithum), los esféricos (Globulolithum) y el grupo que incluye a aquellos en forma de cono truncado o rondel (Estrobilolita). De manera Escasa (3,13-9,40\%) los pelos, ganchos y aguijones (Aculeolithum) y los poliédricos. De manera rara $(0-3,13 \%)$ aquellos en forma de silla de montar o saddle (Doliolita), los bilobados (Halteriolita), fitolitos con forma de flabelo (Flabelolithum), Longolita, formas macroglobosas, prismáticos menores a $40 \mu \mathrm{m}$, Euhalteriolita tipo Stipa, Plurihalteriolita y Pileolita (figuras 5.3. y 5.4.). 


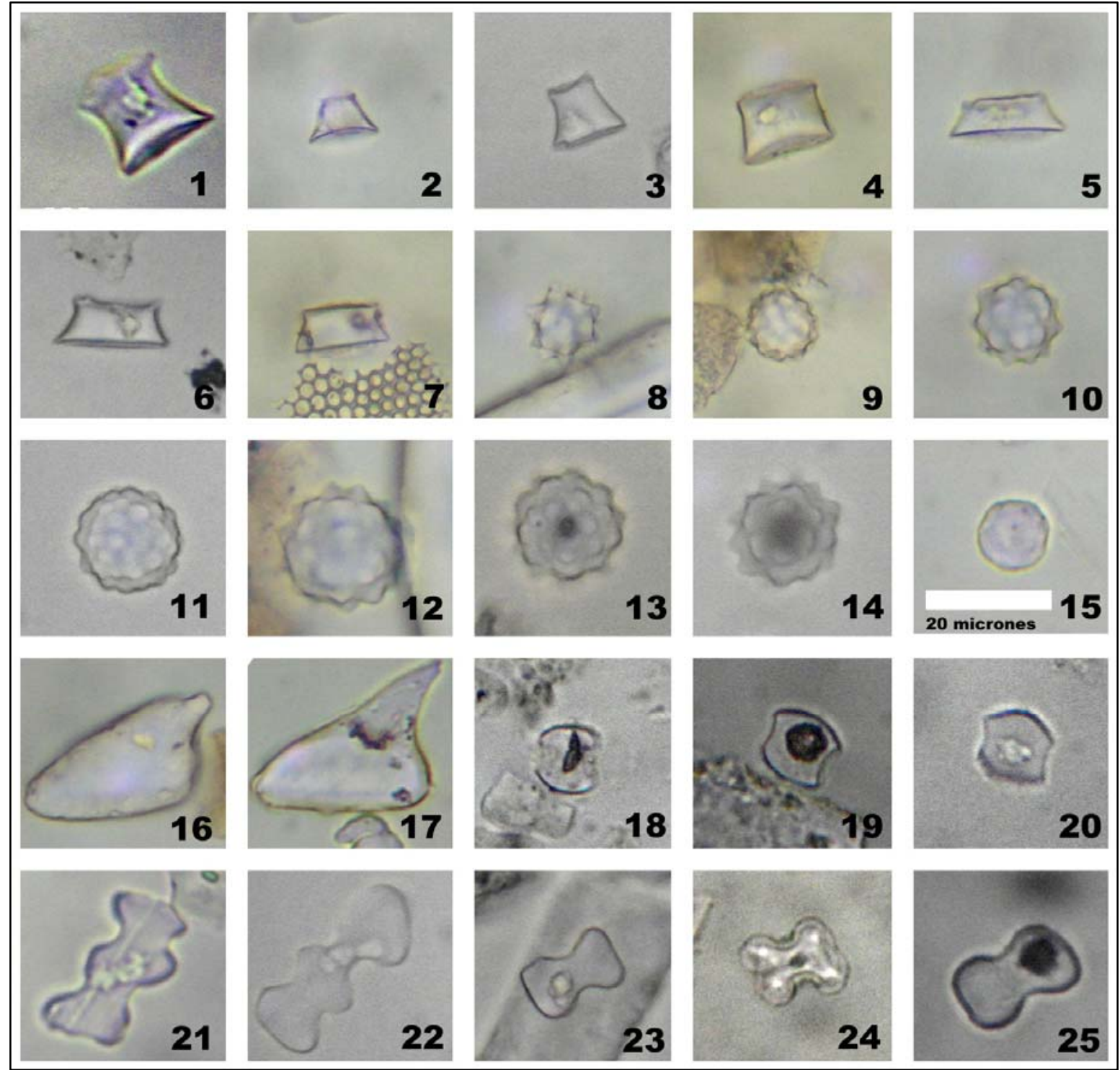

Figura 5.3. Lámina microfitolitos. Escala gráfica en $15=20$ micrones (válida para todas las imágenes).1-7: Fitolitos provenientes de células cortas en forma de conos truncados,

Estrobilolita ("rondel"). 8-14: Fitolitos esféricos espinosos, Globulolithum sphaeroequinulathum 15: Fitolito esférico liso, Globulolithum sphaeropsilathum.16-17: Fitolitos originados a partir de aguijones, Aculeolithum. 18-20: Fitolitos originados en células cortas en forma de silla de montar, Doliolita ("saddle"). 21-22: Fitolitos polilobados regulares, Plurihalteriolita trilobata. 2325: Fitolitos bilobados originados en células cortas en forma de pesa de gimnasia Halteriolita. 


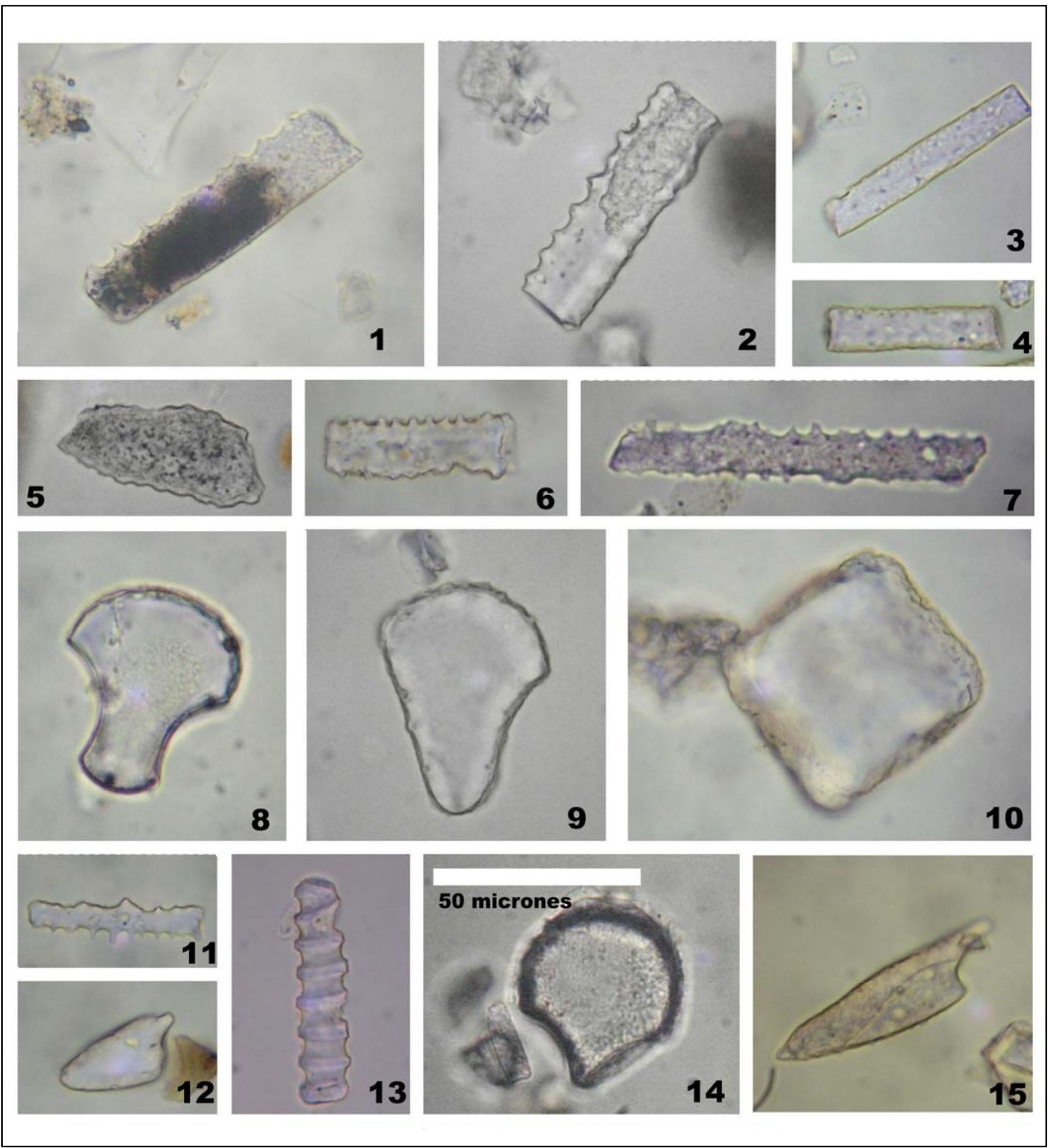

Figura 5.4. Lámina macrofitolitos. Escala gráfica en $14=50$ micrones (válida para todas las imágenes). 1-4,6-7,11: Fitolitos prismáticos elongados Macroprismatolithum. 5: Fitolito de Podostemaceae, Longolita. 8,9,14: Fitolitos originados en células bulliformes en forma de abanico, Flabelolithum. 10: Fitolito poliédrico. 12,15: Fitolitos originados a partir de aguijones, Aculeolithum. 13: Fitolito originado en elementos de conducción 


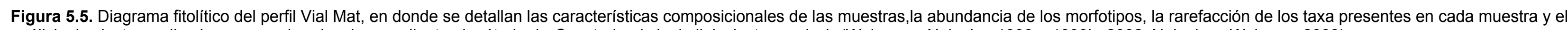

análisis de cluster realizado con sus abundancias, mediante el método de Constrained single link cluster analysis (Walanus y Nalepka, 1999a, 1999b, 2002; Nalepka y Walanus, 2003).

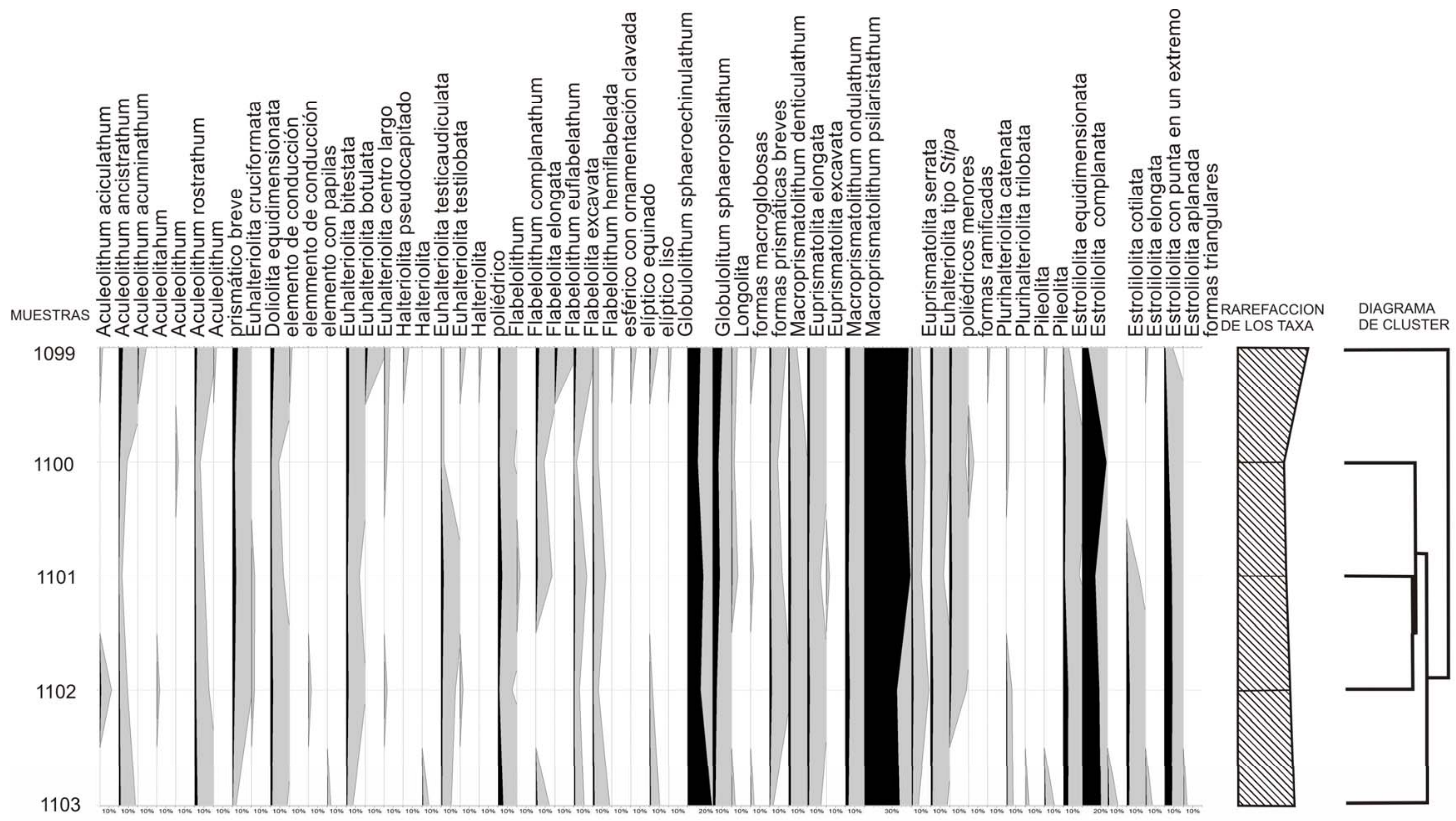




\subsection{PERFIL GAUCHITO GIL}

\subsubsection{Descripción del perfil}

El perfil muestreado se encuentra en las proximidades de la ciudad de Victoria, con ubicación $S 32^{\circ} 36^{\prime} 37,3^{\prime \prime}$ - O $60^{\circ} 08^{\prime} 34,3^{\prime \prime}$ (figuras 4.1. y 4.2.). En esta columna la Formación Tezanos Pinto (figura 5.6.) se presenta con un espesor de 2,20 m. Los sedimentos correspondientes a dicha formación se encuentran por debajo del suelo actual que posee $50 \mathrm{~cm}$ de potencia, compuesto por los horizontes A y B. En los centímetros inferiores de la Formación Tezanos Pinto, se reconocen abundantes concreciones carbonáticas ubicadas sobre una lente de cenizas de aproximadamente $30 \mathrm{~cm}$ (el espesor es variable), y por debajo de la lente, en discordancia erosiva, se identifica la Formación Alvear. Se tomaron 9 muestras para estudios de fitolitos con $10 \mathrm{~cm}$ de equidistancia entre ellas en la Formación Tezanos Pinto (1105, $1106,1107,1108,1109,1110,1111,1112,1113)$ numeración dada de base a techo del perfil.
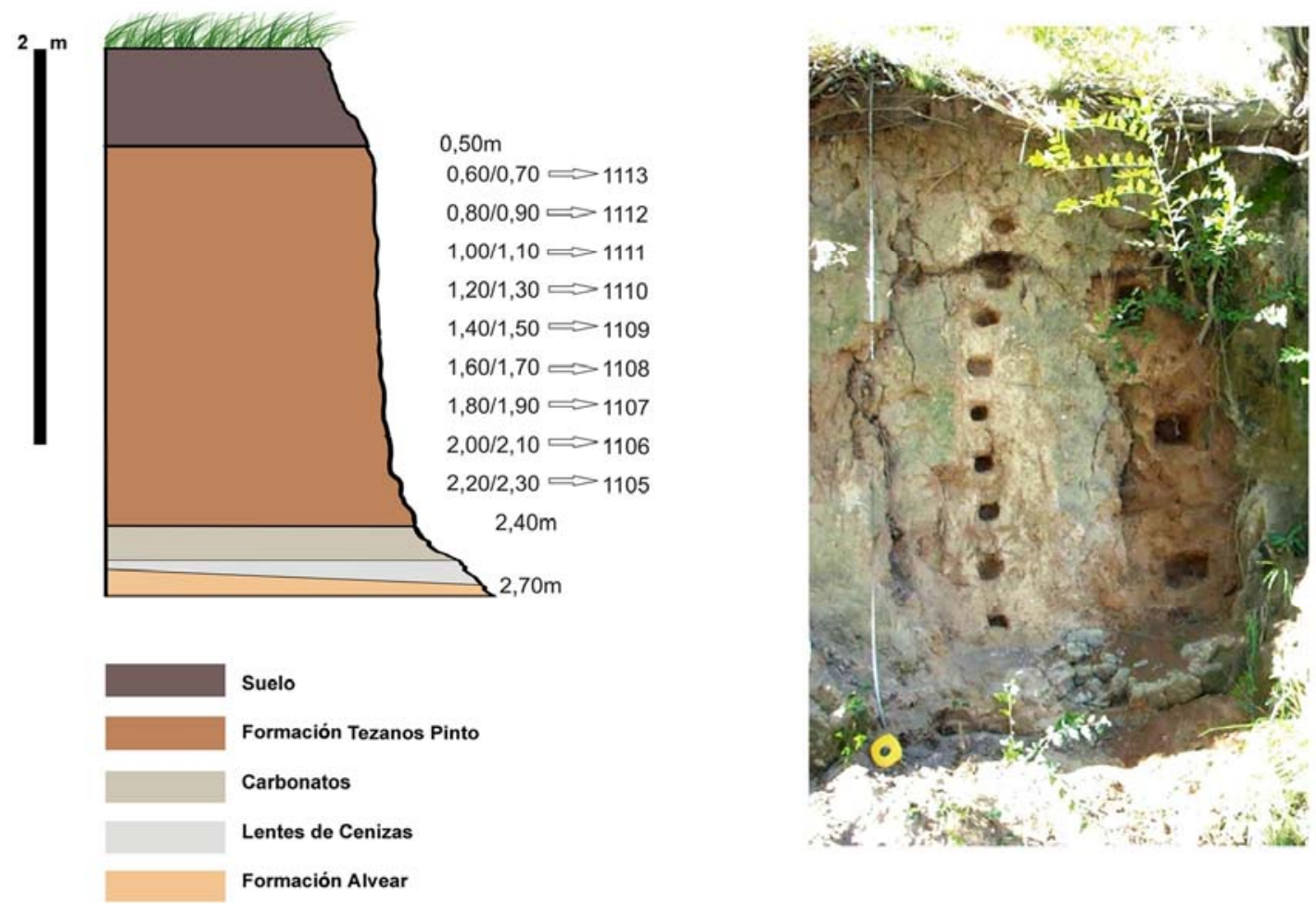

Figura 5.6. Fotografía del perfil Gauchito Gil y esquema indicando la procedencia de las muestras 
5.2.2. Caracterización fitolítica de las muestras (las descripciones en extenso se presentan en el Apéndice)

\section{Muestra 1105}

Fueron muy frecuentes $(>23,49 \%)$ los prismáticos rectangulares Macroprismatolithum y los fitolitos en cono truncado Estrobilolita. Los esféricos Globulolithum y los bilobados Halteriolita fueron escasos (3,91-11,74\%). Raros $(0-3,91 \%)$ los halterios Euhalteriolita tipo Stipa, los polilobados Plurihalteriolita, las cruces, los pelos, ganchos y aguijones Aculeolithum, Doliolita, los elementos de conducción, Longolita, los flabelos Flabelolithum, y los poliédricos (figuras 5.7. y 5.8.).

\section{Muestra 1106}

En esta muestra fueron muy frecuentes $(>25,56 \%)$ los prismáticos rectangulares Macroprismatolithum y los estróbilos (fitolitos en cono truncado) Estrobilolita. Los esféricos Globulolithum y los bilobados Halteriolita fueron frecuentes (12,78-25,56\%). Escasos (4,26-12,78\%) tanto los pelos, ganchos y aguijones Aculeolithum, como los poliédricos. Raros (0-4,26\%) aquellos en forma de silla de montar o saddle (Doliolita), elementos de conducción, las cruces, Flabelolithum, los fitolitos de Podostemaceae Longolita, los prismáticos menores a $40 \mu \mathrm{m}$, los halterios Euhalteriolita tipo Stipa, y los polilobados Plurihalteriolita (figuras 5.7. y 5.8.).

\section{Muestra 1107}

Se presentaron de manera muy frecuente $(>25,39 \%)$ los prismáticos rectangulares Macroprismatolithum y los estróbilos Estrobilolita. Los esféricos Globulolithum y los bilobados Halteriolita fueron escasos (4,23-12,69\%). Raros $(0-4,23 \%)$ los halterios Euhalteriolita tipo Stipa, los pelos, ganchos y aguijones (Aculeolithum), aquellos en forma de silla de montar o saddle (Doliolita), los prismáticos lisos menores a $40 \mu \mathrm{m}$, los elementos de conducción, Longolita, Flabelolithum, y poliédricos (figuras 5.7. y 5.8.). 


\section{Muestra 1108}

Se presentaron de manera muy frecuente $(>22,40 \%)$ los prismáticos rectangulares Macroprismatolithum y los Estrobilolita. Globulolithum y los bilobados Halteriolita fueron escasos (3,73-11,20\%). Raros (0-3,73\%) los halterios Euhalteriolita tipo Stipa, Aculeolithum, Doliolita, los prismáticos menores a $40 \mu \mathrm{m}$, los elementos de conducción, Longolita, Flabelolithum, y los poliédricos (figuras 5.7. y 5.8.).

\section{Muestra 1109}

Fueron muy frecuentes $(>23,25 \%)$ los prismáticos rectangulares Macroprismatolithum y los fitolitos en cono truncado Estrobilolita. Los esféricos (Globulolithum) fueron frecuentes $(11,62-23,25 \%)$. Los bilobados Halteriolita escasos $(3,87-11,62 \%)$. Raros $(0-3,87 \%)$ los halterios Euhalteriolita tipo Stipa, los polilobados Plurihalteriolita, las cruces, los pelos, ganchos y aguijones Aculeolithum, aquellos en forma de silla de montar o saddle (Doliolita), los elementos de conducción, Longolita, los flabelos (Flabelolithum), formas multilobadas, poliédricos y prismáticos menores a $40 \mu \mathrm{m}$ (figuras 5.7. y 5.8.).

\section{$\underline{\text { Muestra } 1110}$}

Se presentaron de manera muy frecuente (>24,05\%) los Macroprismatolithum y Estrobilolita. Los Globulolithum fueron escasos $(4,00-$ 12,02\%). Mientras Aculeolithum, Doliolita, Halteriolita, Flabelolithum, Longolita, Euhalteriolita tipo Stipa, prismáticos menores a $40 \mu \mathrm{m}$ y poliédricos fueron raros $(0-4,00 \%)$ (figuras 5.7. y 5.8.).

\section{Muestra 1111}

Se presentaron de manera muy frecuente $(>23,14 \%)$ Macroprismatolithum y Estrobilolita. Los esféricos Globulolithum fueron frecuentes $(11,57-23,14 \%)$. Fueron raros $(0-3,85 \%)$ los pelos, ganchos y aguijones Aculeolithum, aquellos en forma de silla de montar (Doliolita), los bilobados Halteriolita, Flabelolithum, Longolita, los polilobados Plurihalteriolita, Euhalteriolita tipo Stipa, prismáticos menores a $40 \mu \mathrm{m}$ y poliédricos (figuras 5.7 . y 5.8.). 


\section{Muestra 1112}

Se presentaron de manera muy frecuente $(>24,87 \%)$ los prismáticos rectangulares Macroprismatolithum y los fitolitos en cono truncado Estrobilolita. Los esféricos Globulolithum fueron escasos $(4,14-12,43 \%)$. Raros $(0-4,14 \%)$ los Aculeolithum, Doliolita, los bilobados Halteriolita, los flabelos Flabelolithum, Longolita, los polilobados Plurihalteriolita, Euhalteriolita tipo Stipa, prismáticos menores a $40 \mu \mathrm{m}$ y poliédricos (figuras 5.7. y 5.8.).

\section{$\underline{\text { Muestra } 1113}$}

Fueron muy frecuentes $(>22,48 \%)$ los prismáticos rectangulares Macroprismatolithum. Los estróbilos Estrobilolita y los esféricos Globulolithum fueron frecuentes $(11,24-22,48 \%)$. Escasos $(3,74-11,24 \%)$, los pelos, ganchos y aguijones (Aculeolithum), los bilobados Halteriolita y los poliédricos. Raros (0$3,74 \%$ ), aquellos en forma de silla de montar (Doliolita), formas estrelladas, las cruces (Halteriolita cruciformata), Flabelolithum, Longolita, formas multilobadas, prismáticos menores a $40 \mu \mathrm{m}$, Euhalteriolita tipo Stipa, y los plurihalteriolita (figuras 5.7. y 5.8.). 

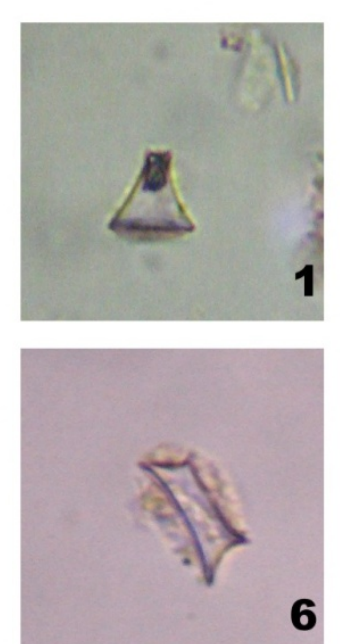

6
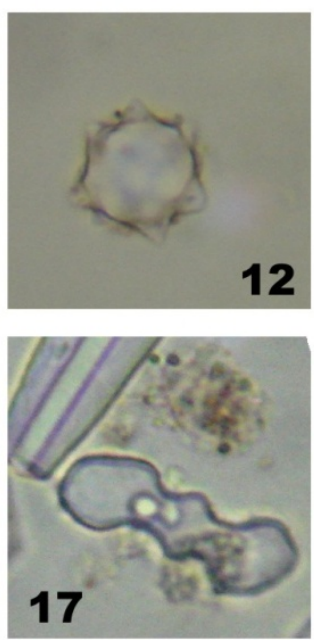
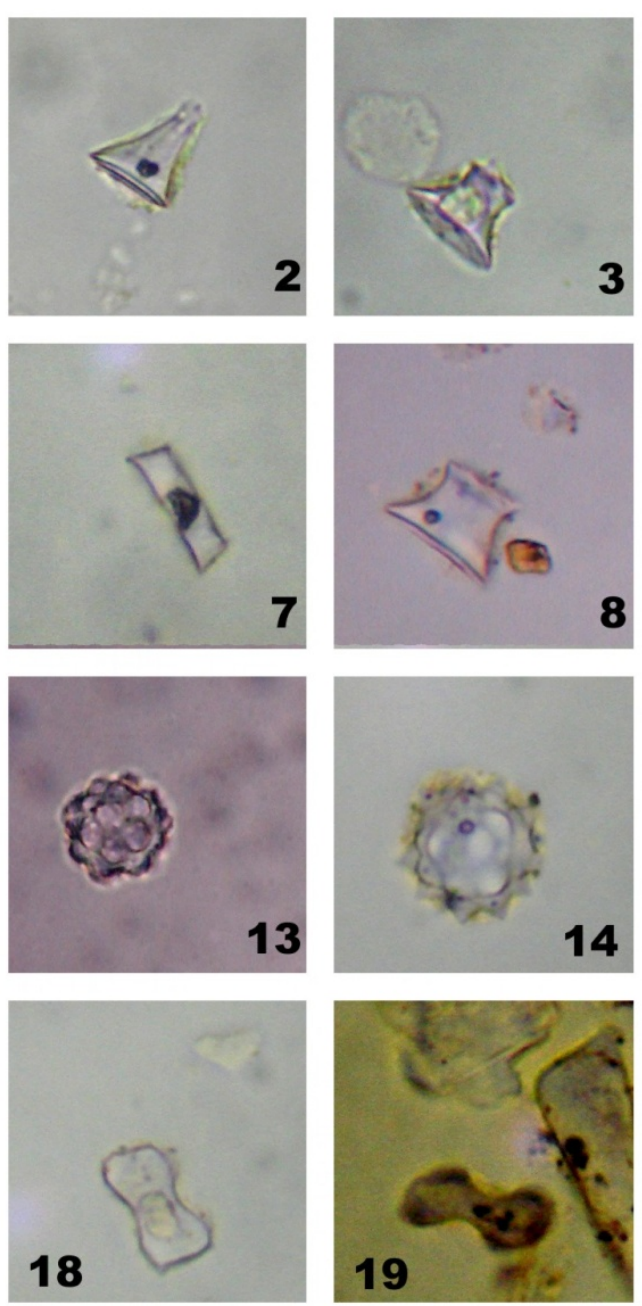
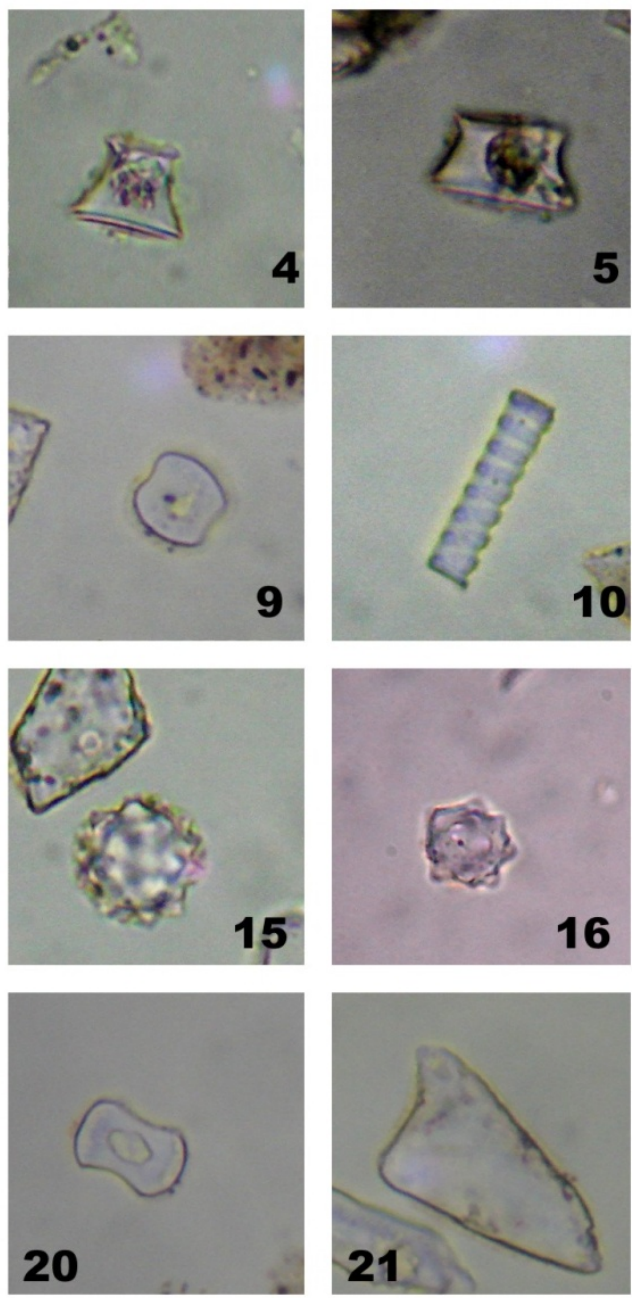

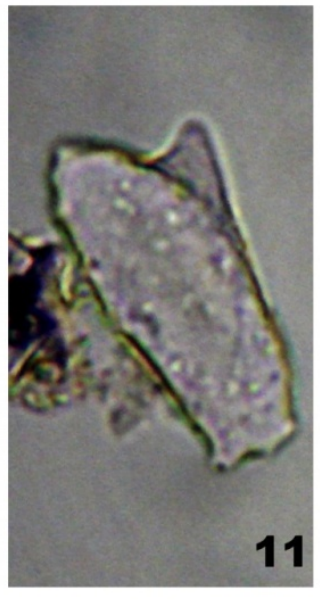

11

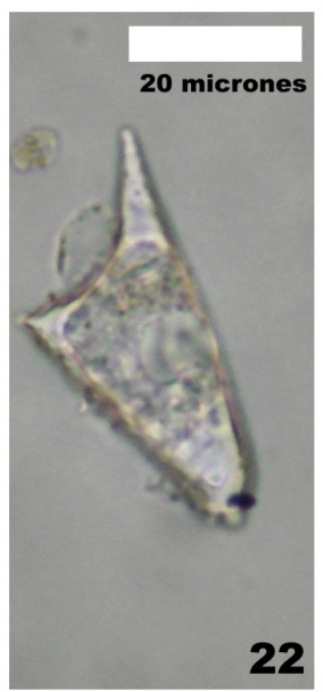

Figura 5.7. Lámina microfitolitos. Escala gráfica en $22=20$ micrones (válida para todas las imágenes).1-8: Fitolitos provenientes de células cortas en forma de conos truncados, Estrobilolita ("rondel"). 9,20: Fitolitos originados en células cortas en forma de silla de montar, Doliolita ("saddle"). 10: Fitolito originado en elementos de conducción. 11,21,22: Fitolitos originados a partir de aguijones, Aculeolithum. 12-16: Fitolitos esféricos espinosos,

Globulolithum sphaeroequinulathum.17: Fitolito polilobado regular, Plurihalteriolita trilobata. 18,19: Fitolitos bilobados originados en células cortas en forma de pesa de gimnasia Halteriolita. 

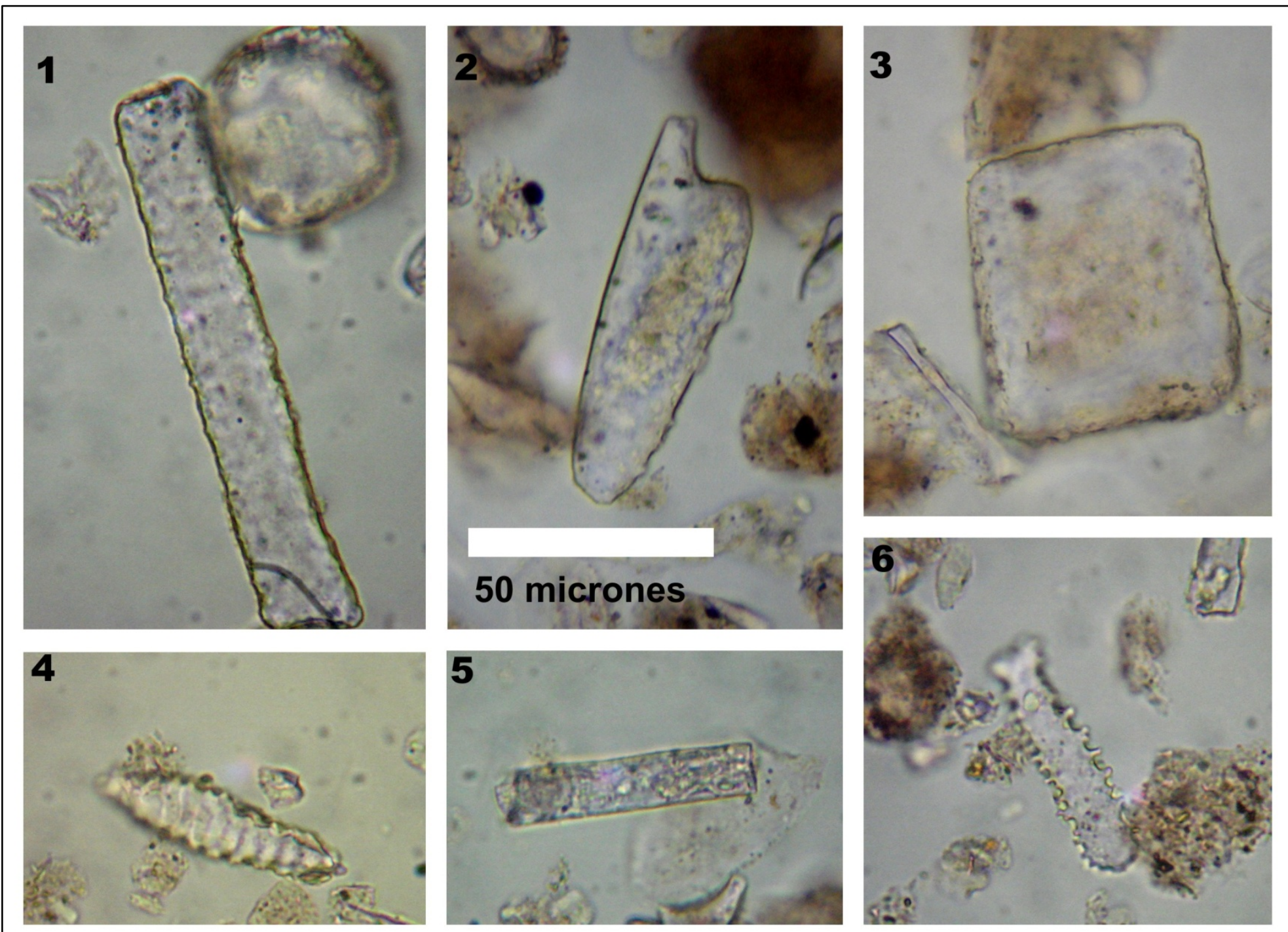

Figura 5.8. Lámina macrofitolitos. Escala gráfica en $2=50$ micrones (válida para todas las imágenes).1,5,6: Fitolitos prismáticos elongados Macroprismatolithum. 2: Fitolitos originados a partir de aguijones, Aculeolithum. 3: Fitolito poliédrico. 4: Fitolito de Podostemaceae, Longolita. 


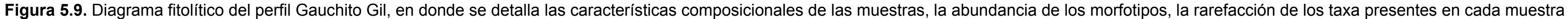
y el análisis de cluster realizado con sus abundancias, mediante el método de Constrained single link cluster analysis (Walanus y Nalepka, 1999a, 1999b, 2002; Nalepka y Walanus, 2003).

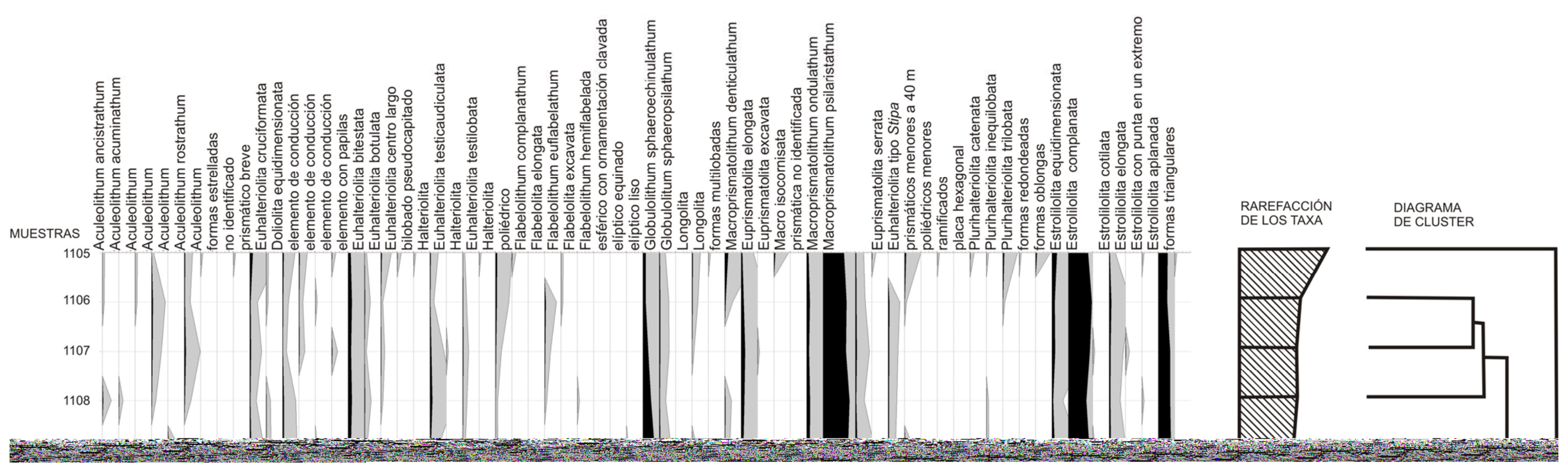










5.4.2. Caracterización fitolítica de las muestras (las descripciones en extenso se presentan en el Apéndice)

\section{Muestra 1138}

Se presentaron de manera muy frecuente $(>27,38 \%$ ) los estróbilos (fitolitos en cono truncado) Estrobilolita. Los bilobados Halteriolita fueron frecuentes $(27,38-13,69 \%)$. Escasos (13,69-4,56\%) aquellos en forma de silla de montar o saddle Doliolita, los halterios Euhalteriolita tipo Stipa, los esféricos Globulolithum y los prismáticos rectangulares Macroprismatolithum. Raros (0-4,56\%) los ganchos, pelos y aguijones Aculeolithum, las cruces, los elementos de conducción, Longolita, los flabelos Flabelolithum, los prismáticos menores a $40 \mu \mathrm{m}$, los polilobados Plurihalteriolita y los poliédricos (figuras 5.15. y 5.16.).

\section{Muestra 1139}

Se presentaron de manera muy frecuente $(>29,70 \%)$ los estróbilos (fitolitos en cono truncado) Estrobilolita. Escasos (14,85-4,95\%) Doliolita, los bilobados Halteriolita, los esféricos Globulolithum y los prismáticos rectangulares Macroprismatolithum. Raros (0-4,95\%) los pelos, ganchos y aguijones Aculeolithum, los elementos de conducción, Longolita, Flabelolithum, prismáticos menores a $40 \mu \mathrm{m}$, los halterios Euhalteriolita tipo Stipa, los polilobados Plurihalteriolita y los poliédricos (figuras 5.15. y 5.16.).

\section{Muestra 1140}

Se presentaron de manera muy frecuente $(>30,96 \%)$ los estróbilos Estrobilolita. Escasos (15,48-5,16\%) los bilobados Halteriolita, Globulolithum y Macroprismatolithum. Raros (0-5,16\%) Doliolita, Aculeolithum, los elementos de conducción, Flabelolithum, prismáticos menores a $40 \mu \mathrm{m}$, los halterios Euhalteriolita tipo Stipa, los polilobados Plurihalteriolita y los poliédricos (figuras 5.15. у 5.16.).

\section{Muestra 1141}

Se presentaron de manera muy frecuente $(>33,94 \%)$ los fitolitos en cono truncado Estrobilolita. Fueron escasos (5,65-16,97\%) Doliolita, Halteriolita, los esféricos Globulolithum y Macroprismatolithum. Raros (0-5,65\%) Aculeolithum, las 
cruces, los flabelos Flabelolithum, Longolita, prismáticos menores a $40 \mu \mathrm{m}$, formas multilobadas, Euhalteriolita tipo Stipa, los polilobados Plurihalteriolita y los poliédricos (figuras 5.15. y 5.16.).

\section{Muestra 1142}

Se presentaron de manera muy frecuente $(>25,63 \%)$ los Estrobilolita. Mientras que Macroprismatolithum fue frecuente (12,81-25,63\%). Otros escasos $(4,27-12,81 \%)$ como Aculeolithum, Doliolita, los Halteriolita, Globulolithum y raros (0-4,27\%), Flabelolithum, elementos de conducción, prismáticos menores a 40 $\mu \mathrm{m}$, Euhalteriolita tipo Stipa, Plurihalteriolita y los poliédricos (figuras 5.15. y 5.16.).

\section{Muestra 1143}

Los estróbilos (fitolitos en cono truncado) Estrobilolita se presentaron de manera muy frecuente $(>26,85 \%)$. Frecuente $(13,42-26,85 \%)$, los prismáticos rectangulares Macroprismatolithum. Escasos (4,47-13,42\%) aquellos en forma de silla de montar o saddle Doliolita, los bilobados en forma de halterio Halteriolita, los esféricos Globulolithum y raros (0-4,47\%) los ganchos y aguijones Aculeolithum, las cruces, los flabelos Flabelolithum, prismáticos menores a $40 \mu \mathrm{m}$, los halterios Euhalteriolita tipo Stipa y los polilobados Plurihalteriolita (figuras 5.15. y 5.16.).

\section{Muestra 1144}

De manera muy frecuente $(>17,63 \%)$ se presentaron los estróbilos (fitolitos en cono truncado) Estrobilolita y los prismáticos rectangulares Macroprismatolithum. Frecuentes (8,50-17,63\%) fueron los flabelos Flabelolithum y los esféricos Globulolithum. Escasos (2,83-8,50\%) los ganchos y aguijones Aculeolithum, aquellos en forma de silla de montar o saddle Doliolita, los bilobados en forma de halterio Halteriolita, prismáticos menores a $40 \mu \mathrm{m}$ y los poliédricos. Raros $(0-2,83 \%)$ los halterios Euhalteriolita tipo Stipa, los polilobados Plurihalteriolita y los Pileolita (figuras 5.15. y 5.16.). 


\section{Muestra 1145}

Se presentaron de manera muy frecuente $(>21,46 \%)$ los prismáticos rectangulares Macroprismatolithum y los estróbilos (fitolitos en cono truncado) Estrobilolita. Fueron escasos (3,57-10,73\%) Aculeolithum, los bilobados en forma de halterio Halteriolita, los flabelos Flabelolithum, los esféricos Globulolithum y los halterios Euhalteriolita tipo Stipa. Raros (0-3,57\%) aquellos en forma de silla de montar o saddle Doliolita, las cruces, Longolita, prismáticos menores a $40 \mu \mathrm{m}$, Pileolita y los Poliédricos (figuras 5.15. y 5.16.).

\section{Muestra 1146}

Se presentaron de manera muy frecuente $(>19,76 \%)$ los prismáticos rectangulares Macroprismatolithum y los estróbilos (fitolitos en cono truncado) Estrobilolita. Fueron frecuentes $(9,88-19,76 \%)$ los esféricos Globulolithum. Escasos (3,29-9,88\%) los ganchos y aguijones Aculeolithum, los flabelos Flabelolithum, los poliédricos y los bilobados en forma de halterio Halteriolita. Raros $(0-3,29 \%)$ las cruces, aquellos en forma de silla de montar o saddle Doliolita, Longolita, prismáticos menores a $40 \mu \mathrm{m}$, los halterios Euhalteriolita tipo Stipa, Plurihalteriolita y Pileolita (figuras 5.15. y 5.16.).

\section{$\underline{\text { Muestra } 1147}$}

Se presentaron de manera muy frecuente $(>20,66 \%)$ Macroprismatolithum y Estrobilolita. Fueron frecuentes (10,33-20,66\%) Aculeolithum. Escasos (3,44$10,33 \%)$ Globulolithum, los poliédricos y Halteriolita. Raros (0-3,44\%) las cruces, Doliolita, los elementos de conducción, los flabelos Flabelolithum, Longolita, prismáticos menores a $40 \mu \mathrm{m}$, los halterios Euhalteriolita tipo Stipa, Plurihalteriolita y los Pileolita (figuras 5.15. y 5.16.).

\section{$\underline{\text { Muestra } 1148}$}

Se presentaron de manera muy frecuente $(>24,64 \%)$ los estróbilos Estrobilolita. De manera frecuente (12,32-24,64\%) Macroprismatolithum. Escasos (4,10-12,32\%) los Aculeolithum, Doliolita, Halteriolita y Globulolithum. Raros (0$4,10 \%)$ los elementos de conducción, Flabelolithum, Euhalteriolita tipo Stipa, 
Longolita, prismáticos menores a $40 \mu \mathrm{m}$, Plurihalteriolita y los poliédricos (figuras 5.15. y 5.16.).

\section{$\underline{\text { Muestra } 1149}$}

Se presentaron de manera muy frecuente (>20,38\%) los estróbilos (fitolitos en cono truncado) Estrobilolita y los prismáticos rectangulares Macroprismatolithum. Frecuente $(10,19-20,38 \%)$ los esféricos Globulolithum. Fueron escasos (3,39-10,19\%) Aculeolithum y Halteriolita. Raros (0-3,39\%) Doliolita, Flabelolithum, Longolita, prismáticos menores a $40 \mu \mathrm{m}$, Euhalteriolita tipo Stipa, Plurihalteriolita, Pileolita, y poliédricos (figuras 5.15. y 5.16.).

\section{Muestra 1150}

Se presentaron de manera muy frecuente $(>27,92 \%)$ Estrobilolita. Frecuente (13,96-27,92\%) Macroprismatolithum. Escasos (4,65-13,96\%) Halteriolita y Globulolithum. Raros (0-4,65\%) Aculeolithum, Doliolita, las cruces, los flabelos Flabelolithum, Longolita, prismáticos menores a $40 \mu \mathrm{m}$, Euhalteriolita tipo Stipa, Plurihalteriolita, Pileolita, y los poliédricos (figuras 5.15. y 5.16.).

\section{Muestra 1151}

Se presentaron de manera muy frecuente $(>21,97 \%)$ los prismáticos rectangulares Macroprismatolithum y los estróbilos (fitolitos en cono truncado) Estrobilolita. Escasos (3,66-10,98\%) los pelos, ganchos y aguijones Aculeolithum y los esféricos Globulolithum. Los poliédricos y los bilobados en forma de halterio Halteriolita, raros (0-3,66\%) igual que Doliolita, los elementos de conducción, los flabelos Flabelolithum, Longolita, prismáticos menores a $40 \mu \mathrm{m}$, los halterios Euhalteriolita tipo Stipa y los polilobados Plurihalteriolita (figuras 5.15. y 5.16.).

\section{Muestra 1152}

Se presentaron de manera muy frecuente $(>18,90 \%)$ los Estrobilolita y los rectangulares Macroprismatolithum. De manera frecuente (9,45-18,90\%) Globulolithum. Escasos (3,15-9,45\%) Aculeolithum, Halteriolita, Euhalteriolita tipo Stipa, y raros $(0-3,15 \%)$ Doliolita, Flabelolithum, Longolita, los polilobados Plurihalteriolita, Pileolita y los poliédricos (figuras 5.15. y 5.16.). 


\section{Muestra 1153}

Se presentaron de manera muy frecuente $(>23,15 \%)$ Macroprismatolithum y Estrobilolita. Escasos (3,85-11,57\%) Halteriolita, y Globulolithum. Raros (0$3,85 \%)$ Aculeolithum, Doliolita, Flabelolithum, Longolita, Euhalteriolita tipo Stipa, los polilobados Plurihalteriolita, Pileolita, y los poliédricos (figuras 5.15. y 5.16.).

\section{Muestra 1154}

Se presentaron de manera muy frecuente $(>24,85 \%)$ Estrobilolita y los prismáticos rectangulares Macroprismatolithum. Escasos (12,42-4,14\%) los bilobados Halteriolita y los esféricos Globulolithum. Raros (0-4,14\%) Doliolita, Aculeolithum, las cruces, los flabelos Flabelolithum, Longolita, prismáticos menores a $40 \mu \mathrm{m}$, los Euhalteriolita tipo Stipa, Pileolita, los polilobados Plurihalteriolita y los poliédricos (figuras 5.15. y 5.16.).

\section{Muestra 1155}

Se presentaron de manera muy frecuente $(>22,55 \%)$ los fitolitos en cono truncado Estrobilolita y los prismáticos rectangulares Macroprismatolithum. Frecuente $(11,27-22,55 \%)$ los esféricos Globulolithum. Escasos (11,27-3,75\%) los bilobados Halteriolita y los poliédricos. Raros (0-3,75\%) Doliolita, Aculeolithum, las cruces, los elementos de conducción, Flabelolithum, Longolita, prismáticos menores a $40 \mu \mathrm{m}$ y Euhalteriolita tipo Stipa (figuras 5.15. y 5.16.).

\section{Muestra 1156}

Fueron muy frecuentes $(>22,85 \%)$ los estróbilos Estrobilolita y los Macroprismatolithum. Escasos (11,29-3,76\%) Aculeolithum, Doliolita, Halteriolita y Globulolithum. Raros (0-3,76\%) cruces, elementos de conducción, Flabelolithum, Longolita, prismáticos menores a $40 \mu \mathrm{m}$, Pileolita, los halterios Euhalteriolita tipo Stipa y poliédricos (figuras 5.15. y 5.16.).

\section{Muestra 1157}

Fueron muy frecuentes $(>30,98 \%$ ) los fitolitos en cono truncado Estrobilolita. Frecuentes (30,98-15,49\%) los prismáticos rectangulares Macroprismatolithum. Escasos (15,49-5,16\%) los esféricos Globulolithum. Raros 
$(0-5,16 \%)$ los pelos, ganchos y aguijones Aculeolithum, aquellos en forma de silla de montar o saddle Doliolita, los bilobados en forma de halterio Halteriolita, los flabelos Flabelolithum, formas macroglobosas, formas prismáticas menores a 40 $\mu \mathrm{m}$, los polilobados Plurihalteriolita, Pileolita, los halterios Euhalteriolita tipo Stipa y los poliédricos (figuras 5.15. y 5.16.).

\section{Muestra 1158}

Se presentaron de manera muy frecuente $(>26,44 \%)$ los Estrobilolita y los Macroprismatolithum. Escasos (13,22-4,40\%) Doliolita y los esféricos Globulolithum. Raros (0-4,40\%) los bilobados Halteriolita, Euhalteriolita tipo Stipa, los pelos, ganchos y aguijones Aculeolithum, las cruces, los elementos de conducción, Longolita, los flabelos Flabelolithum, prismáticos menores a $40 \mu \mathrm{m}$, Pileolita y los poliédricos (figuras 5.15. y 5.16.).

\section{$\underline{\text { Muestra } 1159}$}

Se presentaron de manera muy frecuente $(>29,36 \%)$ los Estrobilolita. Fueron frecuentes $(27,38-13,69 \%)$ los Macroprismatolithum. Escasos (14,68$4,89 \%)$ Halteriolita, Globulolithum y Euhalteriolita tipo Stipa. Raros $(0-4,89 \%)$ Aculeolithum, Doliolita, Longolita, Flabelolithum, prismáticos menores a $40 \mu \mathrm{m}$, Plurihalteriolita y poliédricos (figuras 5.15. y 5.16.).

\section{Muestra 1160}

Se presentaron de manera muy frecuente (>24,23\%) los estróbilos Estrobilolita. Los bilobados Halteriolita y los Macroprismatolithum fueron frecuentes $(24,23-12,11 \%)$. Escasos (12,11-4,03\%) Aculeolithum y Globulolithum. Raros (0-4,03\%) Doliolita, Longolita, los flabelos Flabelolithum, prismáticos menores a $40 \mu \mathrm{m}$, Macroglobulolithum, los halterios Euhalteriolita tipo Stipa, Pileolita, los polilobados Plurihalteriolita y los poliédricos (figuras 5.15. y 5.16.). 


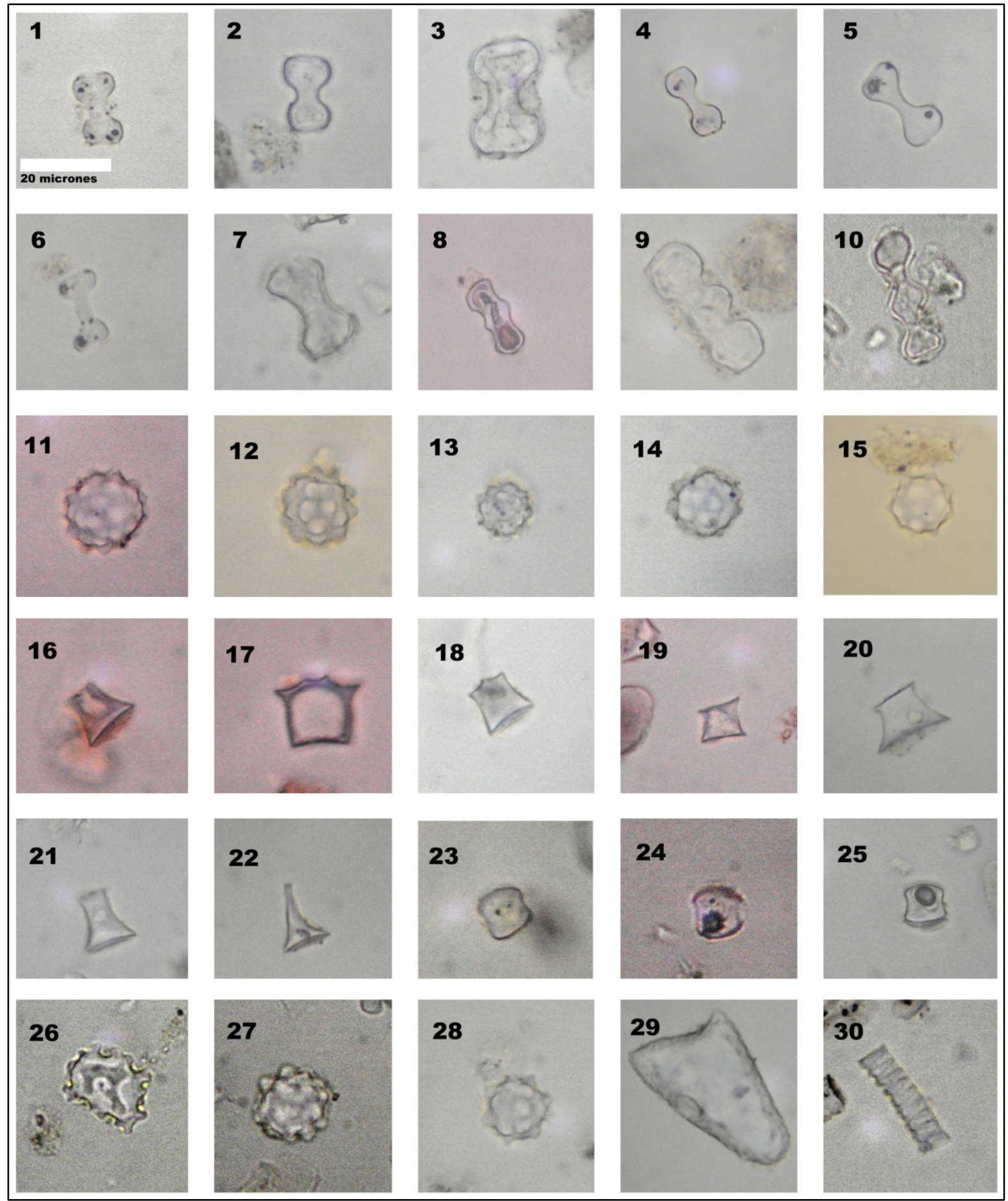

Figura 5.15. Lámina microfitolitos. Escala gráfica en 1 = 20 micrones (válida para todas las imágenes).1-7: Fitolitos bilobados originados en células cortas en forma de pesa de gimnasia, Halteriolita. 8-10: Fitolitos polilobados regulares, Plurihalteriolita trilobata. 11-15,27,28: Fitolitos esféricos equinados, Globulolithum sphaeroequinulathum. 16-22: Fitolitos provenientes de células cortas en forma de conos truncados, Estrobilolita ("rondel"). 23-25: Fitolitos originados en células cortas en forma de silla de montar, Doliolita ("saddle"). 26: Fitolito no identificado. 29: Fitolito originado a partir de aguijones, Aculeolithum 30: Fitolito originado en elementos de conducción. 

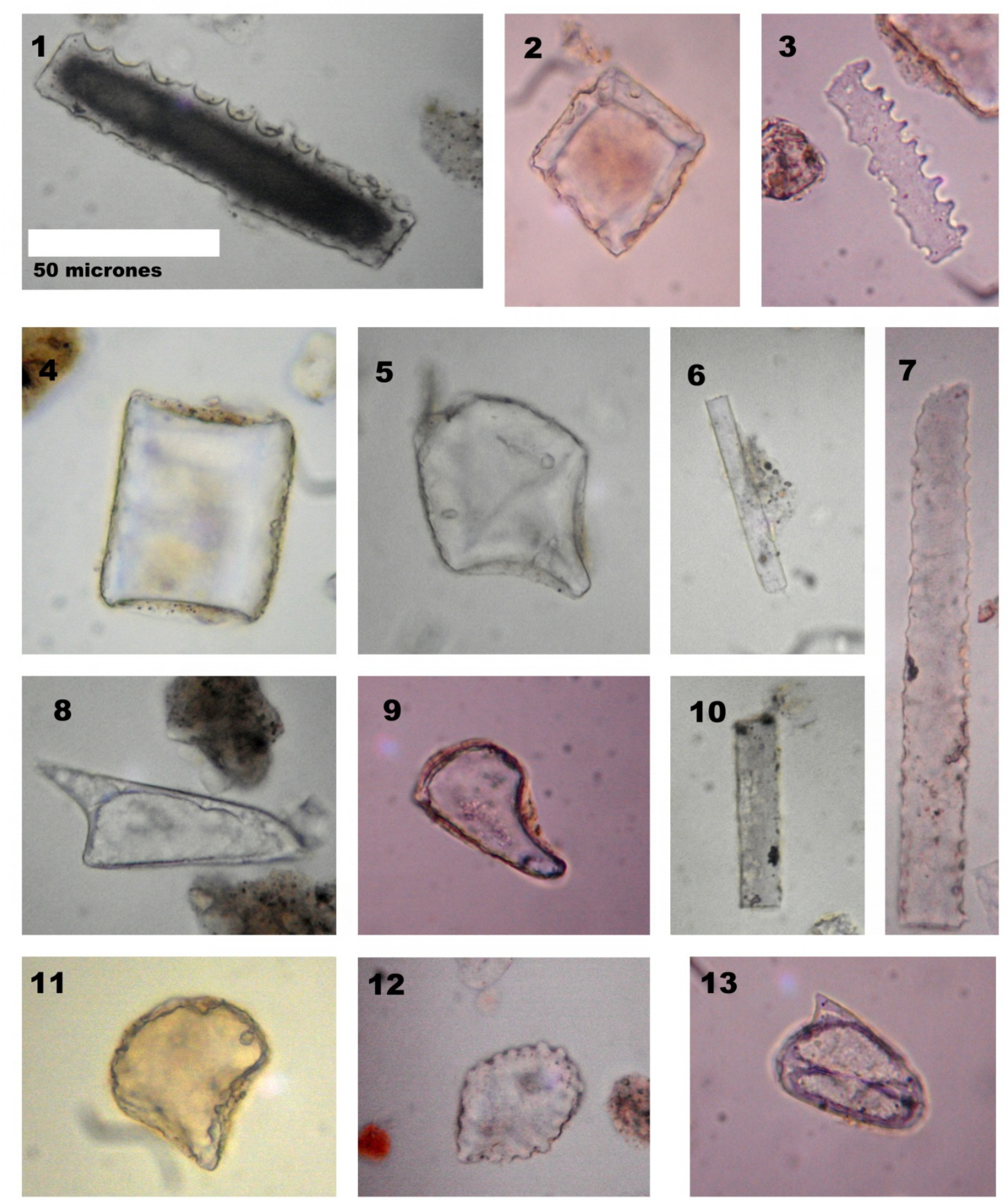

Figura 5.16. Lámina macrofitolitos. Escala gráfica en $1=50$ micrones (válida para todas las imágenes).1,3,6,7,10: Fitolitos prismáticos elongados Macroprismatolithum. 2,4: Fitolitos poliédricos. 5,9,11: Fitolitos originados en células bulliformes en forma de abanico, Flabelolithum. 8,13: Fitolitos originados a partir de aguijones, Aculeolithum. 12:Longolita 


\subsection{PERFIL ALVEAR}

\subsubsection{Descripción del perfil}

Este perfil fue muestreado al sur de la localidad General Alvear, con ubicación S $31^{\circ} 58^{\prime} 09,2$ " - O 6040'38,5"' (figuras 4.1. y 4.2.).

Se trata de una sección vertical, donde el suelo actual posee 1,20 m de potencia (figura 5.18.). Por debajo del suelo se halla el loess típico, correspondiente a la Formación Tezanos Pinto de poca potencia (1,40 m de espesor). Es un depósito masivo (sin estructuras sedimentarias visibles), friable, eólico, de color castaño pálido, primario, en su mayor parte está formado por limo con escasa arena muy fina y arcilla. No hay $\mathrm{CaCO}_{3}$ segregado. En esta sección, la Formación Tezanos Pinto se halla por encima de la Formación Alvear, en marcada discordancia erosiva, la que presenta $3 \mathrm{~m}$ de potencia. Se tomaron 6 muestras para análisis de fitolitos numeradas 1184 , 1185, 1186, 1187, 1188, 1189.
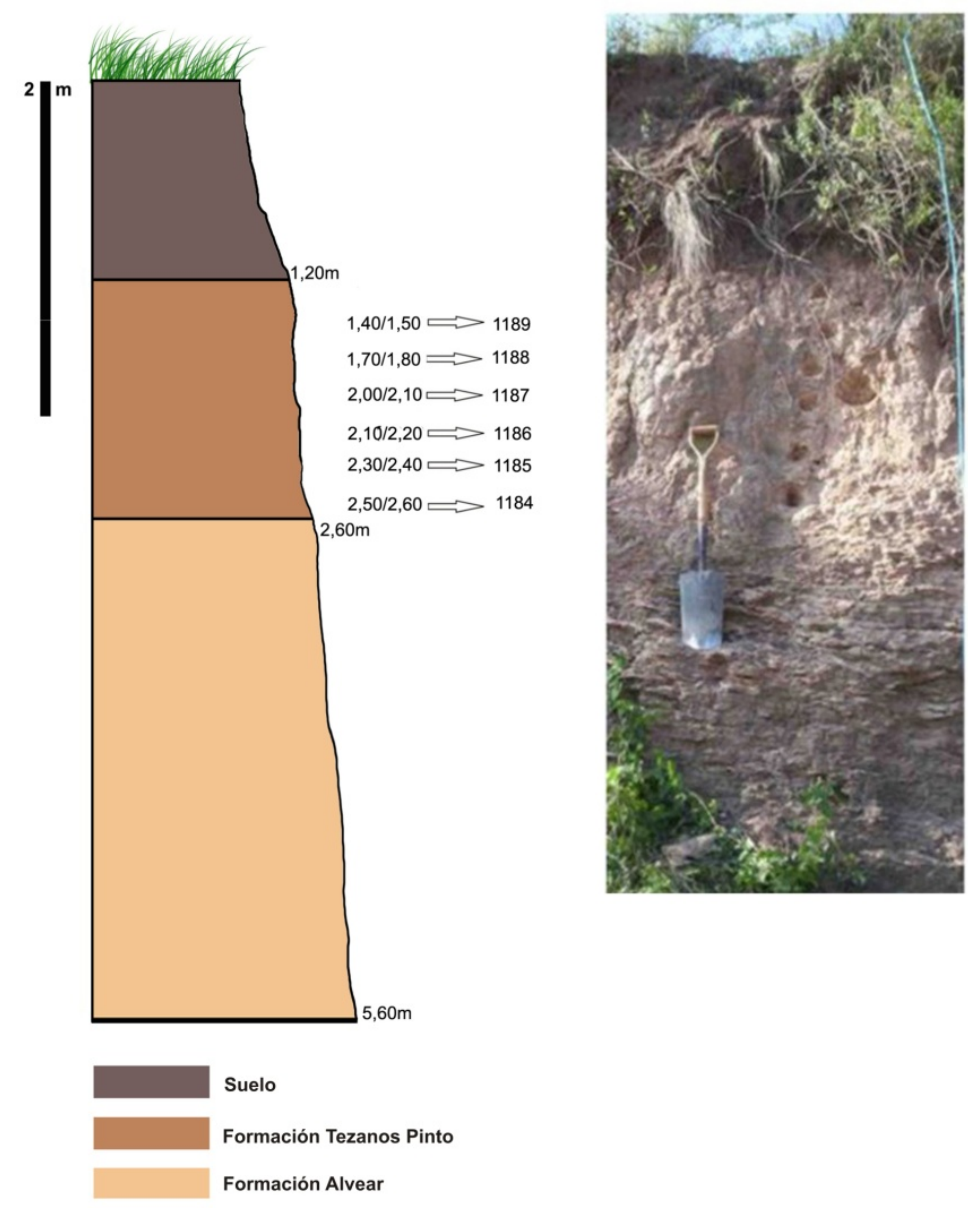

Figura 5.18. Fotografía del perfil Alvear y esquema indicando la procedencia de las muestras. 
5.5.2. Caracterización fitolítica de las muestras (las descripciones en extenso se presentan en el Apéndice)

\section{Muestra 1184}

En esta muestra se encontraron de manera muy frecuente $(>15,95 \%)$ el gran grupo correspondiente a los fitolitos prismáticos rectangulares Macroprismatolithum, el de aquellos en forma de cono truncado o rondel Estrobilolita y el de los fitolitos esféricos Globulolithum. De manera frecuente (7,97-15,95\%) los bilobados Halteriolita. De manera Escasa (2,65-7,97\%) aquellos en forma de silla de montar o saddle (Doliolita). De manera rara (02,65\%) los correspondientes a pelos, ganchos, y aguijones Aculeolithum, Euhalteriolita tipo Stipa, Pileolita, elementos de conducción, fitolitos con forma de flabelo o abanico Flabelolithum, Longolita, Plurihalteriolita, y poliédricos (figuras 5.19. y 5.20.).

\section{Muestra 1185}

En esta muestra se encontraron de manera muy frecuente $(>18,05 \%)$ los grandes grupos correspondientes a los fitolitos en forma de cono truncado (Estrobilolita), los fitolitos esféricos (Globulolithum), y los prismáticos rectangulares (Macroprismatolithum). De manera Escasa (3,0-9,02\%) los bilobados (Halteriolita). De manera rara (0-3,0\%) los Euhalteriolita tipo Stipa, Aculeolithum, elementos de conducción, Doliolita, Flabelolithum, Longolita, cruces, Pileolita y poliédricos (figuras 5.19. y 5.20.).

\section{$\underline{\text { Muestra } 1186}$}

En esta muestra se presentaron de manera muy frecuente $(>20,48 \%)$ los fitolitos prismáticos Macroprismatolithum y aquellos en forma de cono truncado Estrobilolita. De manera frecuente (10,24-20,48\%) solo el grupo de los fitolitos esféricos Globulolithum. De manera Escasa (3,41- 10,24 \%) aquellos en forma de silla de montar o saddle (Doliolita) y los bilobados Halteriolita. De manera rara $(0-3,41 \%)$ los correspondientes a pelos, ganchos y aguijones (Aculeolithum), las cruces, Euhalteriolita tipo Stipa, fitolitos con forma de abanico o "fan-shaped" (Flabelolithum), Longolita, Plurihalteriolita y poliédricos (figuras 5.19. y 5.20.). 


\section{Muestra 1187}

En esta muestra se encontraron de manera muy frecuente (>20,09\%) los fitolitos prismáticos Macroprismatolithum, los esféricos Globulolithum, y aquellos en forma de cono truncado Estrobilolita. De manera Escasa $(3,34-$ $10,04 \%)$ los bilobados Halteriolita. De manera rara (0-3,34\%) Aculeolithum, aquellos en forma de silla de montar Doliolita, formas esféricas de gran tamaño, prismáticos menores a $40 \mu \mathrm{m}$, elementos de conducción, Flabelolithum, Longolita, Euhalteriolita tipo Stipa, Plurihalteriolita, Pileolita y poliédricos (figuras 5.19. y 5.20.).

\section{$\underline{\text { Muestra } 1188}$}

En esta muestra se encontraron de manera muy frecuente $(>18,58 \%)$ los fitolitos esféricos Globulolithum y los prismáticos rectangulares Macroprismatolithum. De manera frecuente $(9,29-18,58 \%)$ el que incluye a aquellos en forma de cono truncado Estrobilolita. De manera Escasa $(3,09-$ $9,29 \%)$ los bilobados Halteriolita y los poliédricos. De manera rara $(0-3,09 \%)$ los correspondientes a aguijones (Aculeolithum), aquellos en forma de silla de montar o saddle (Doliolita), elementos de conducción, fitolitos con forma de flabelo (Flabelolithum), Longolita, formas multilobadas, Euhalteriolita tipo Stipa y prismáticos menores a $40 \mu \mathrm{m}$ (figuras 5.19. y 5.20.).

\section{Muestra 1189}

En esta muestra se encontraron de manera muy frecuente $(>16,82 \%)$ el gran grupo correspondiente a los fitolitos prismáticos rectangulares (Macroprismatolithum), el que incluye a aquellos en forma de cono truncado Estrobilolita, y aquel de los fitolitos esféricos (Globulolithum). De manera frecuente $(8,41-16,82 \%)$ no se presentó ningún grupo. De manera Escasa $(2,80-8,41 \%)$ los bilobados Halteriolita y los poliédricos. De manera rara (0$2,80 \%$ ) los correspondientes a aguijones (Aculeolithum), aquellos en forma de silla de montar o saddle (Doliolita), elementos de conducción, prismáticos breves, placas hexagonales, Longolita, Euhalteriolita tipo Stipa y Plurihalteriolita (figuras 5.19. y 5.20.). 


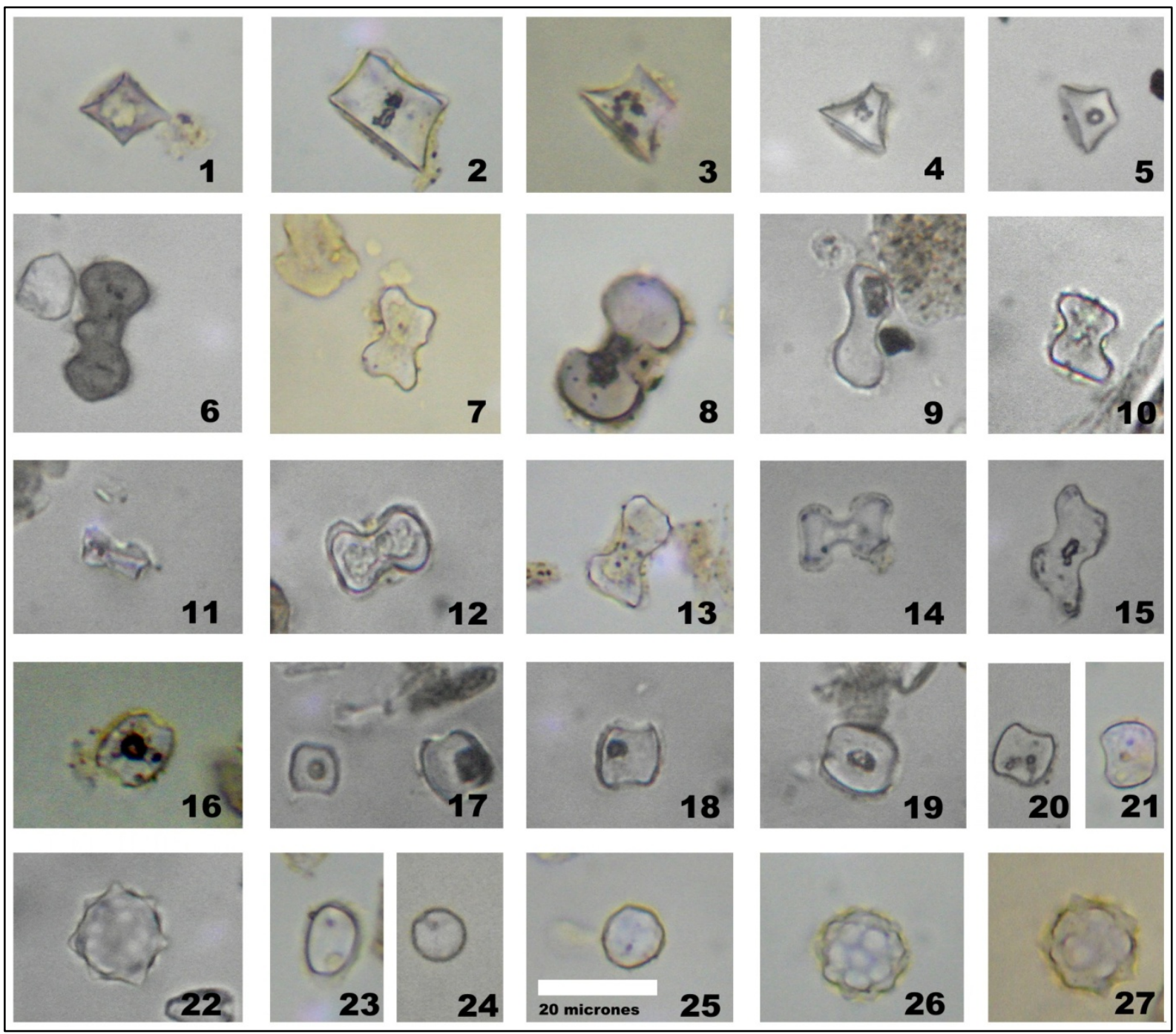

Figura 5.19. Lámina microfitolitos. Escala gráfica en $25=20$ micrones (válida para todas las imágenes).1-5: Fitolitos provenientes de células cortas en forma de conos truncados, Estrobilolita ("rondel"). 6: Fitolito polilobado irregular, Plurihalteriolita inequilobata. 7-15: Fitolitos bilobados originados en células cortas en forma de pesa de gimnasia Halteriolita. 16-21: Fitolitos originados en células cortas en forma de silla de montar, Doliolita ("saddle"). 22,26,27: Fitolitos esféricos espinosos, Globulolithum sphaeroequinulathum. 23:Fitolito elíptico liso. 2425: Fitolitos esféricos lisos, Globulolithum sphaeropsilathum. 


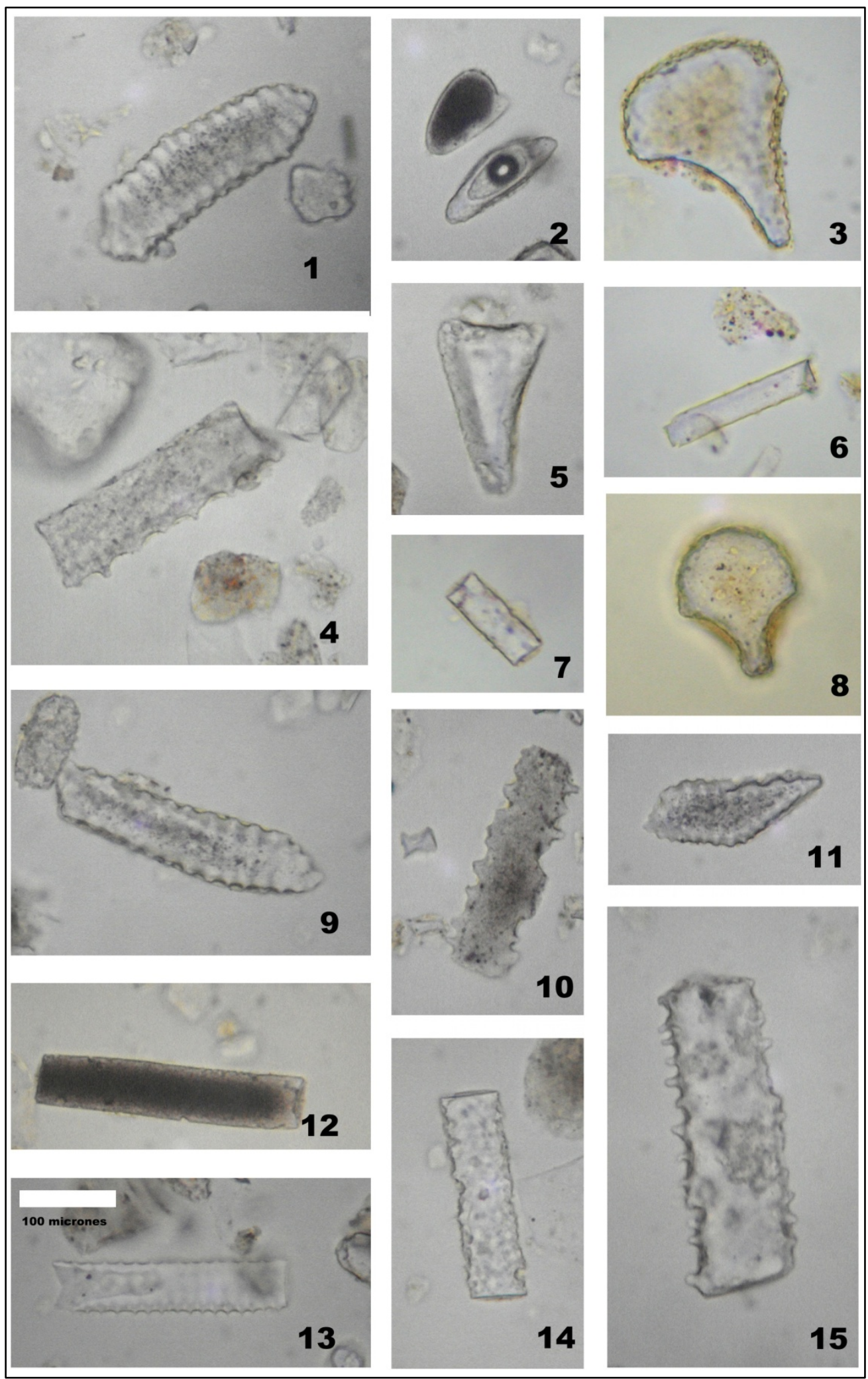

Figura 5.20. Lámina macrofitolitos. Escala gráfica en $13=100$ micrones (válida para todas las imágenes).1,9,11:Fitolito de Podostemaceae, Longolita.2:Fitolito originado a partir de aguijones, Aculeolithum. 3,5,8: Fitolitos originados en células bulliformes en forma de abanico, Flabelolithum. 4,6,7,10,12-15:Fitolitos prismáticos elongados Macroprismatolithum. 


\subsection{PERFIL PROTESTANTE}

\subsubsection{Descripción del perfil}

Este perfil fue muestreado en las proximidades de la localidad Aldea Protestante, con ubicación S $32^{\circ} 01^{\prime} 19.4^{\prime \prime}$ - O 60 30' 38.2" (figuras 4.1. y 4.2.).

La sección sedimentaria (figura 5.22.) se compone de arriba hacia abajo del suelo actual, parcialmente erosionado de 0,30 m de espesor. Por debajo de este suelo se encuentra la Formación Tezanos Pinto que se extiende desde los $0,30 \mathrm{~m}$ hasta los 2,80 m (2,50 m de potencia), teniendo en los últimos $0,20 \mathrm{~m}$ abundantes concreciones carbonáticas, correspondientes a la facies torrencial de la Formación, el resto se trata de la facies eólica, primaria, típica, masiva, friable. Esta formación descansa en marcada discordancia erosiva sobre la Formación Paraná (Mioceno). Se tomaron 13 muestras. Con numeración 1384, la de la base $(2,50-2,40 \mathrm{~m}$ de profundidad) $1385,1386,1387,1388,1389$, $1390,1391,1392,1393,1394,1395,1396$, la que corresponde al techo de la formación. Las muestras fueron tomadas con una equidistancia de $10 \mathrm{~cm}$. 


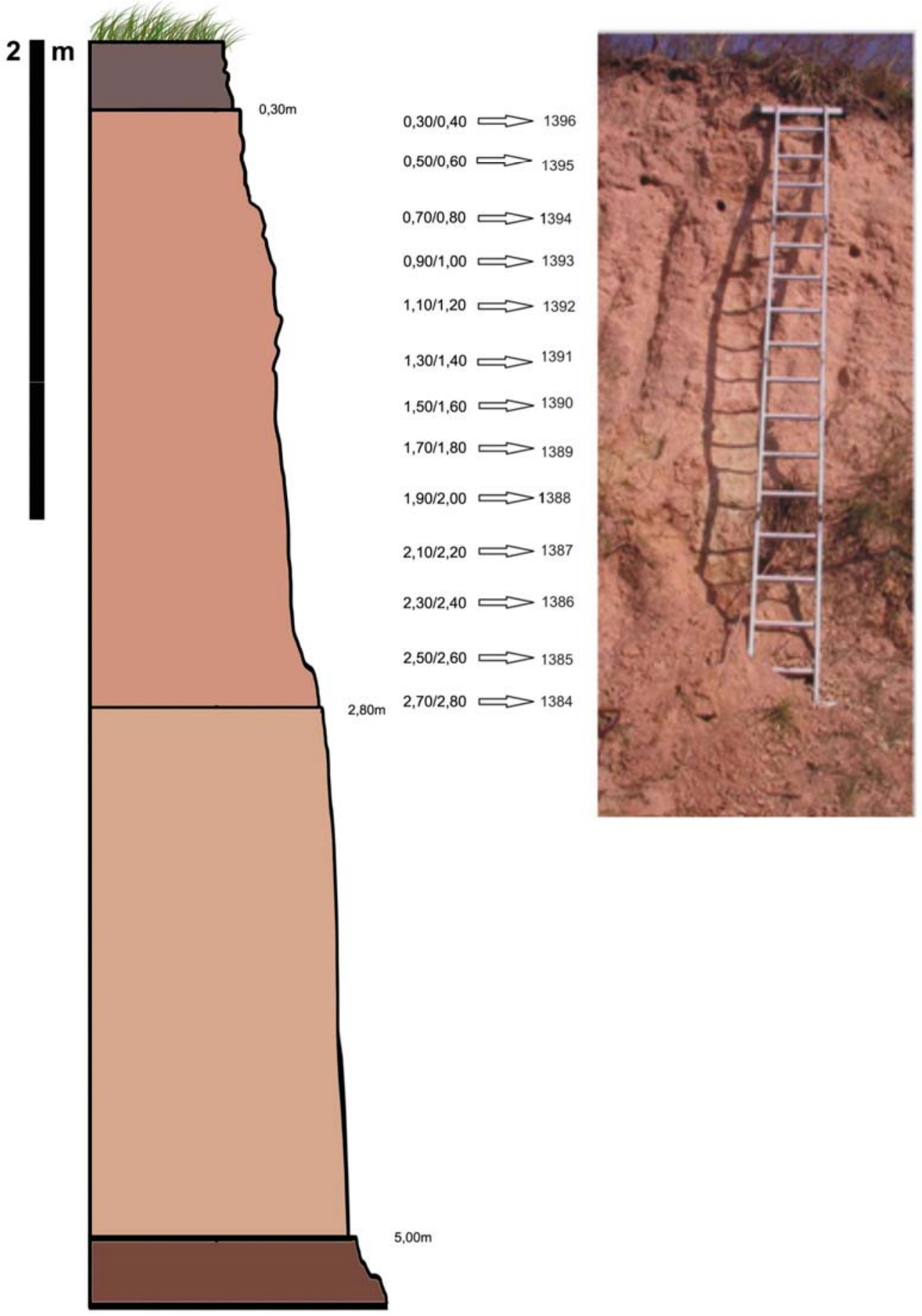

Suelo

Formación Tezanos Pinto

Depósitos torrenciales

Formación Parana

Figura 5.22. Fotografía del perfil Protestante y esquema indicando la procedencia de las muestras. 
5.6.2. Caracterización fitolítica de las muestras (las descripciones en extenso se presentan en el Apéndice)

\section{Muestra 1384}

En esta muestra se encontraron de manera muy frecuente $(>21,50 \%)$ el grupo correspondiente aquellos fitolitos en forma de cono truncado o rondel (Estrobilolita). De manera frecuente $(10,75-21,50 \%)$ los fitolitos esféricos (Globulolithum). De manera Escasa $(3,58-10,75 \%)$ los correspondientes a aguijones (Aculeolithum), aquellos en forma de silla de montar o saddle (Doliolita), los bilobados (Halteriolita), los fitolitos con forma de flabelo o abanico (Flabelolithum) y los prismáticos (Macroprismatolithum). De manera rara $(0-3,58 \%)$ los Euhalteriolita tipo Stipa, elementos de conducción, los polilobados Plurihalteriolita, y los poliédricos (figuras 5.23. y 5.24.).

\section{Muestra 1385}

En esta muestra se encontraron de manera muy frecuente $(>16,95 \%)$ Estrobilolita y Globulolithum. De manera frecuente (8,47-16,95\%) Macroprismatolithum. De manera Escasa (2,82-8,47\%) Flabelolithum, Halteriolita, Doliolita, y Aculeolithum. De manera rara (0-2,82\%) Euhalteriolita tipo Stipa, los prismáticos rectangulares de tamaño inferior a $40 \mu \mathrm{m}$, elementos de conducción, Plurihalteriolita, y poliédricos (figuras 5.23. y 5.24.).

\section{Muestra 1386}

En esta muestra se encontraron de manera muy frecuente $(>25,52 \%)$ aquellos fitolitos en forma de cono truncado (Estrobilolita). De manera frecuente $(12,76-25,52 \%)$ los esféricos (Globulolithum). De manera Escasa (4,25$12,76 \%$ ) los prismáticos rectangulares (Macroprismatolithum), aquellos en forma de silla de montar (Doliolita), y los aguijones (Aculeolithum). De manera rara $(0-4,25 \%)$ los fitolitos con forma de flabelo o abanico (Flabelolithum), los bilobados (Halteriolita), los Euhalteriolita tipo Stipa, los prismáticos 
rectangulares de tamaño inferior a $40 \mu \mathrm{m}$, elementos de conducción, los polilobados Plurihalteriolita, y los poliédricos (figuras 5.23. y 5.24.).

\section{Muestra 1387}

En esta muestra se encontraron de manera muy frecuente $(>28,70 \%)$ Estrobilolita. De manera frecuente $(14,35-28,70 \%)$ los esféricos (Globulolithum). De manera Escasa $(4,78-14,35 \%)$ los prismáticos rectangulares (Macroprismatolithum), aquellos en forma de silla de montar (Doliolita) y los bilobados (Halteriolita). De manera rara (0-4,78\%) los pelos, ganchos y aguijones (Aculeolithum). los fitolitos con forma de flabelo o abanico (Flabelolithum), los Euhalteriolita tipo Stipa, los prismáticos rectangulares de inferiores a $40 \mu \mathrm{m}$, elementos de conducción, los polilobados Plurihalteriolita, y los poliédricos (figuras 5.23. y 5.24.).

\section{Muestra 1388}

Se presentaron de manera muy frecuente $(>21,31 \%)$ Estrobilolita y Globulolithum. De manera Escasa $(3,55-10,65 \%)$ los pelos, ganchos y aguijones (Aculeolithum), aquellos en forma de silla de montar (Doliolita), los bilobados (Halteriolita), los prismáticos rectangulares (Macroprismatolithum), y Ios Euhalteriolita tipo Stipa. De manera rara (0-3,55\%) los fitolitos con forma de flabelo o abanico (Flabelolithum), los prismáticos rectangulares de tamaño inferior a $40 \mu \mathrm{m}$, los polilobados Plurihalteriolita, y los poliédricos (figuras 5.23. y 5.24.).

\section{Muestra 1389}

En esta muestra se encontraron de manera muy frecuente $(>21,85 \%)$ los fitolitos en forma de cono truncado (Estrobilolita). De manera frecuente $(10,92-21,85 \%)$ los fitolitos esféricos (Globulolithum). De manera Escasa $(3,64-$ $10,92 \%)$ los prismáticos rectangulares (Macroprismatolithum), los bilobados (Halteriolita), aquellos en forma de silla de montar o saddle (Doliolita), los Euhalteriolita tipo Stipa, y los correspondientes a pelos, ganchos y aguijones (Aculeolithum). De manera rara (0-3,64\%) los prismáticos rectangulares de tamaño inferior a $40 \mu \mathrm{m}$, elementos de conducción, los fitolitos con forma de 
abanico (Flabelolithum), Longolita, las cruces, los polilobados Plurihalteriolita, y los poliédricos (figuras 5.23. y 5.24.).

\section{Muestra 1390}

En esta muestra se encontraron de manera muy frecuente $(>18,29 \%)$ aquellos fitolitos en forma de cono truncado (Estrobilolita). De manera frecuente $(9,14-18,29 \%)$ los esféricos (Globulolithum) y los prismáticos rectangulares (Macroprismatolithum). De manera Escasa (3,04-9,14\%) aquellos en forma de silla de montar (Doliolita), los bilobados (Halteriolita), fitolitos con forma de flabelo (Flabelolithum), Euhalteriolita tipo Stipa y los aguijones (Aculeolithum). De manera rara (0-3,04\%), Longolita, los prismáticos rectangulares de tamaño inferior a $40 \mu \mathrm{m}$, los polilobados Plurihalteriolita, y los poliédricos (figuras 5.23. y 5.24.).

\section{Muestra 1391}

En esta muestra se encontraron de manera muy frecuente $(>25,88 \%)$ aquellos fitolitos en forma de cono truncado (Estrobilolita). De manera frecuente $(12,94-25,88 \%)$ los esféricos (Globulolithum). De manera Escasa $(4,31-12,94 \%)$ aquellos en forma de silla de montar (Doliolita), los bilobados (Halteriolita), y los Euhalteriolita tipo Stipa. De manera rara $(0-4,31 \%)$ los pelos, ganchos y aguijones (Aculeolithum), los prismáticos rectangulares (Macroprismatolithum), los fitolitos con forma de flabelo o abanico (Flabelolithum), , los prismáticos rectangulares de tamaño inferior a $40 \mu \mathrm{m}$, los polilobados Plurihalteriolita, y los poliédricos (figuras 5.23. y 5.24.).

\section{Muestra 1392}

En esta muestra se encontraron de manera muy frecuente $(>25,52 \%)$ aquellos fitolitos en forma de cono truncado (Estrobilolita). De manera frecuente $(12,76-25,52 \%)$ los esféricos (Globulolithum). De manera Escasa $(4,25-12,76 \%)$ los prismáticos rectangulares (Macroprismatolithum), aquellos en forma de silla de montar (Doliolita), y los aguijones (Aculeolithum). De manera rara $(0-4,25 \%)$ los fitolitos con forma de flabelo o abanico (Flabelolithum), los bilobados (Halteriolita), los Euhalteriolita tipo Stipa, los prismáticos rectangulares de tamaño inferior a $40 \mu \mathrm{m}$, elementos de 
conducción, los polilobados Plurihalteriolita, y los poliédricos (figuras 5.23. y 5.24.).

\section{Muestra 1393}

En esta muestra se encontraron de manera muy frecuente $(>25,52 \%)$ aquellos fitolitos en forma de cono truncado (Estrobilolita). De manera frecuente $(12,76-25,52 \%)$ los esféricos (Globulolithum). De manera Escasa $(4,25-12,76 \%)$ los prismáticos rectangulares (Macroprismatolithum), aquellos en forma de silla de montar (Doliolita), y los aguijones (Aculeolithum). De manera rara $(0-4,25 \%)$ los fitolitos con forma de flabelo o abanico (Flabelolithum), los bilobados (Halteriolita), los Euhalteriolita tipo Stipa, los prismáticos rectangulares de tamaño inferior a $40 \mu \mathrm{m}$, elementos de conducción, los polilobados Plurihalteriolita, y los poliédricos (figuras 5.23. y 5.24.).

\section{Muestra 1394}

En esta muestra se encontraron de manera muy frecuente $(>19,95 \%)$ Estrobilolita. De manera frecuente (9,97-19,95\%) los esféricos Globulolithum y aquellos en forma de silla de montar (Doliolita). De manera Escasa (3,32$9,97 \%$ ) aquellos con forma de abanico (Flabelolithum), los prismáticos rectangulares (Macroprismatolithum), los bilobados (Halteriolita), los correspondientes a pelos, ganchos y aguijones (Aculeolithum) y los poliédricos. De manera rara (0-3,32\%) los prismáticos rectangulares de tamaño inferior a $40 \mu \mathrm{m}$, los halterios bilobados tipo Stipa y elementos de conducción (figuras 5.23. y 5.24.).

\section{Muestra 1395}

En esta muestra se encontraron de manera muy frecuente $(>18,13 \%)$ aquellos fitolitos en forma de cono truncado (Estrobilolita). De manera frecuente $(9,06-18,13 \%)$ los esféricos (Globulolithum), los prismáticos rectangulares (Macroprismatolithum) y los fitolitos con forma de flabelo o abanico (Flabelolithum). De manera Escasa (3,02-9,06\%) aquellos en forma de silla de montar (Doliolita), los bilobados (Halteriolita), los aguijones (Aculeolithum) y los poliédricos. De manera rara $(0-3,02 \%)$ Longolita, los 
Euhalteriolita tipo Stipa, los prismáticos rectangulares de tamaño inferior a 40 $\mu \mathrm{m}$, los polilobados Plurihalteriolita (figuras 5.23. y 5.24.).

\section{Muestra 1396}

Se encontraron de manera muy frecuente (>18,07\%) los fitolitos en forma de cono truncado (Estrobilolita). De manera frecuente (9,03-18,07\%) aquellos en forma de silla de montar (Doliolita), los prismáticos rectangulares (Macroprismatolithum) y los bilobados (Halteriolita). De manera Escasa (3,019,03\%) los correspondientes a pelos, ganchos y aguijones (Aculeolithum), los fitolitos con forma de flabelo o abanico (Flabelolithum), los fitolitos esféricos (Globulolithum) y los Euhalteriolita tipo Stipa. De manera rara (0-3,01\%) los prismáticos rectangulares de tamaño inferior a $40 \mu \mathrm{m}$, los polilobados Plurihalteriolita, y los poliédricos (figuras 5.23. y 5.24.). 


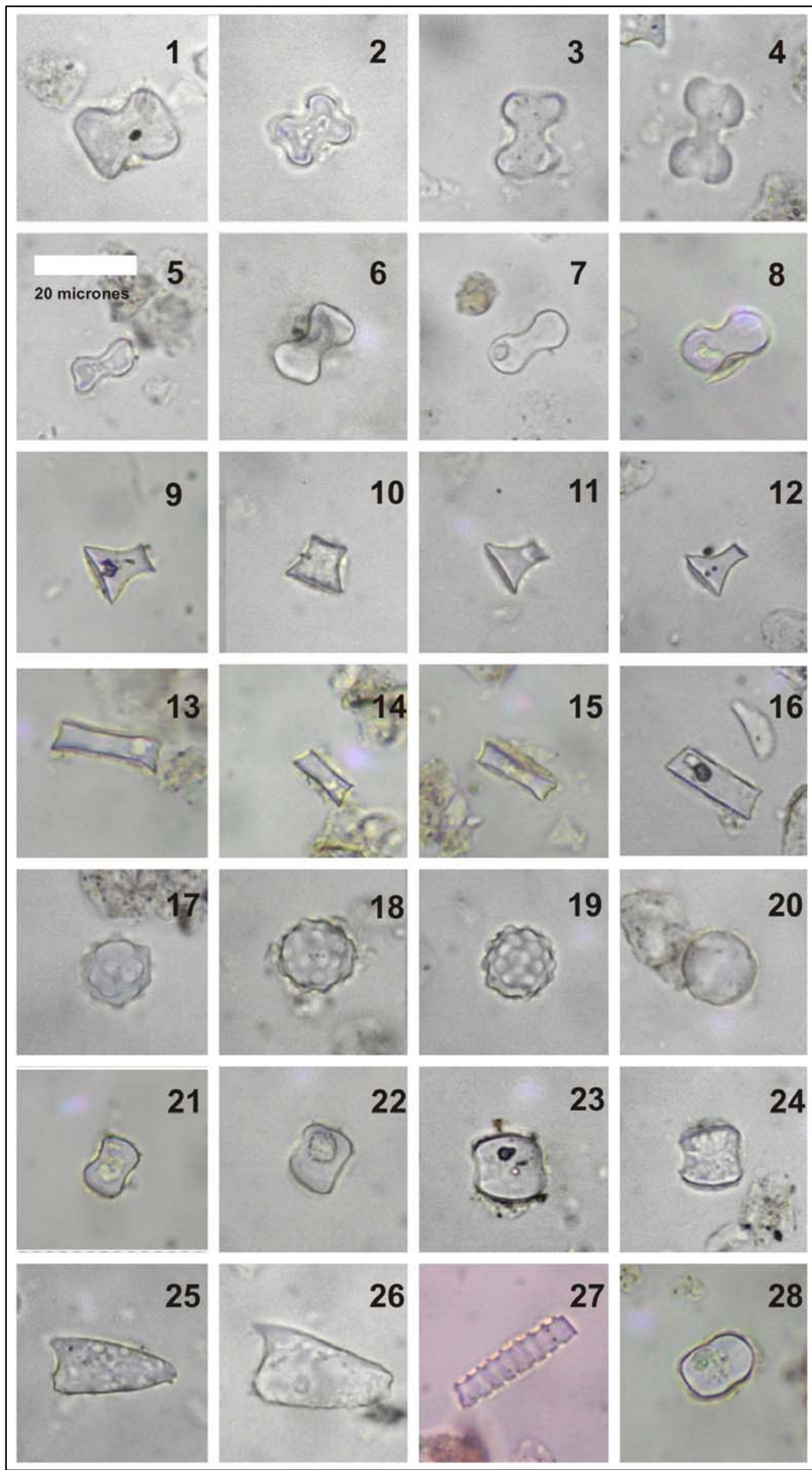


Figura 5.23. Lámina microfitolitos. Escala gráfica en $5=20$ micrones (válida para todas las imágenes). 1-8: Fitolitos bilobados originados en células cortas en forma de pesa de gimnasia Halteriolita. 9-16: Fitolitos provenientes de células cortas en forma de conos truncados, Estrobilolita ("rondel"). 17-19: Fitolitos esféricos equinados, Globulolithum sphaeroequinulathum. 20: Fitolito esférico liso, Globulolithum sphaeropsilathum. 21-24: Fitolito originado en células cortas en forma de silla de montar, Doliolita ("saddle"). 25-26: Fitolitos originados a partir de aguijones, Aculeolithum. 27: Fitolito originado en elementos de conducción.28: Fitolito oblongo. 

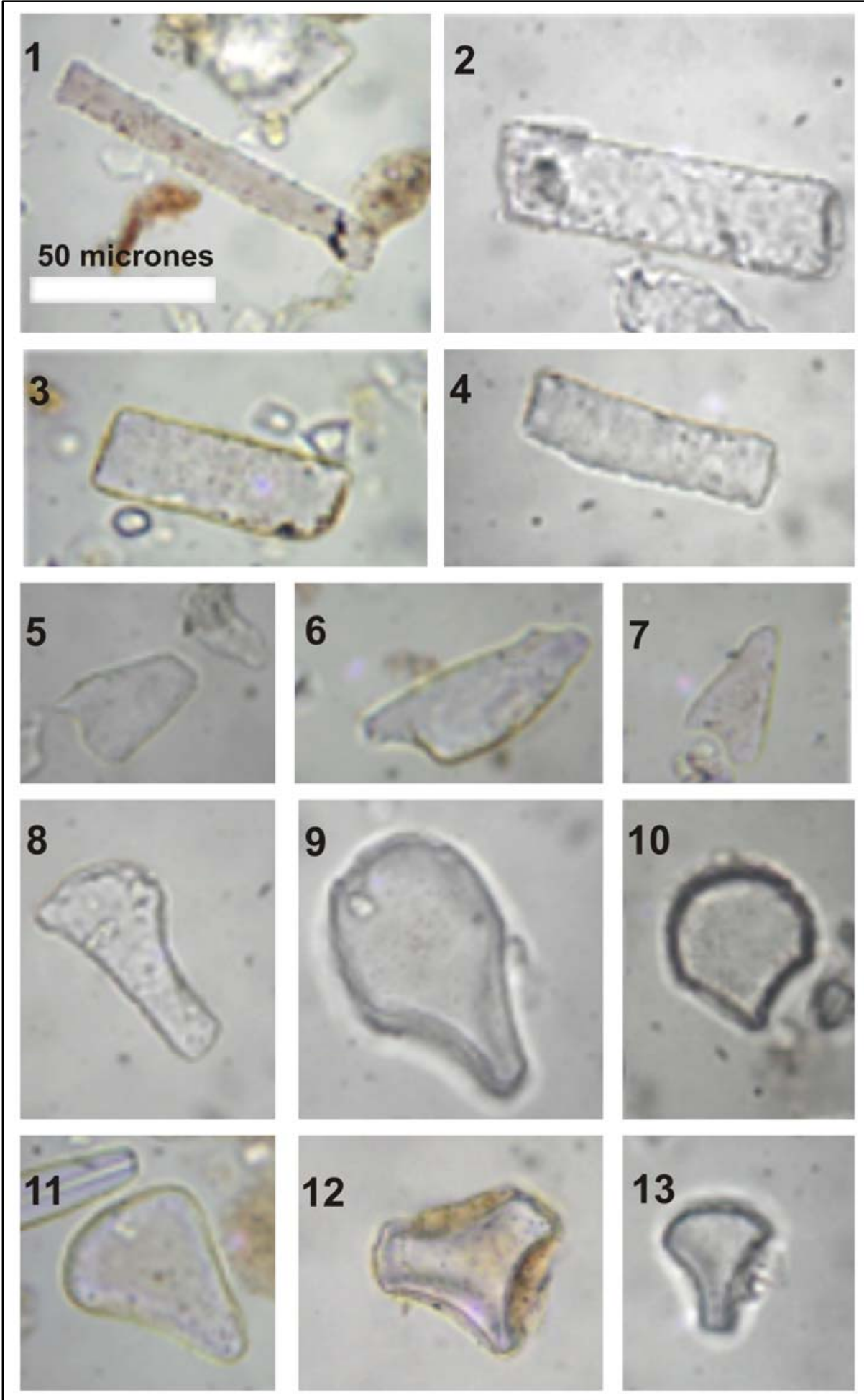

Figura 5.24. Lámina macrofitolitos. Escala gráfica en $1=50$ micrones (válida para todas las imágenes).1-4: Fitolitos prismáticos Macroprismatolithum. 5-7: Fitolitos originados a partir de aguijones, Aculeolithum. 8-13:.Fitolitos originados en células bulliformes en forma de abanico, Flabelolithum.. 


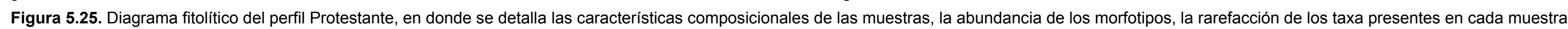
Figura 5.25. Diagrama fitolitico del perfil Protestante, en donde se detalla las características composicionales de las muestras, la abundancia de los morfotipos, la rarefacción de los taxa prese
y el análisis de cluster realizado con sus abundancias, mediante el método de Constrained single link cluster analysis (Walanus y Nalepka, 1999a, 1999b, 2002; Nalepka y Walanus, 2003).

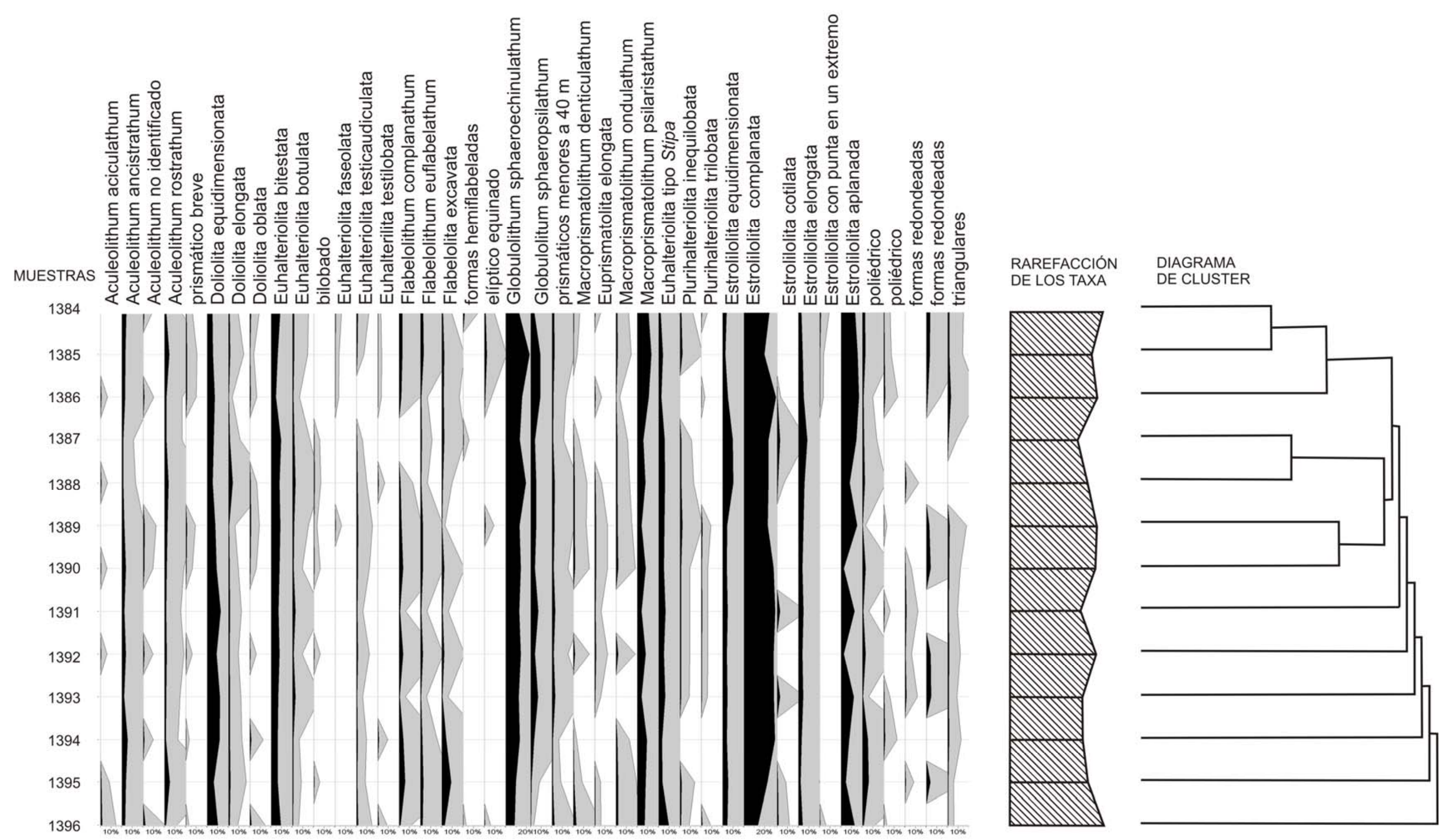




\subsection{PERFIL LA JUANITA}

\subsubsection{Descripción del perfil}

Esta secuencia sedimentaria fue muestreada al NO de la Unidad Geomorfológica Colinas Loéssicas de Crespo (Iriondo, 1998), en las proximidades de la localidad La Juanita, a los S $31^{\circ} 51^{\prime} 43,3^{\prime \prime}$ - O $60^{\circ} 38^{\prime} 53,2^{\prime \prime}$ (figuras 4.1. y 4.2.). Perfil norte de la cantera vieja, ubicada sobre la margen derecha del nuevo acceso a las canteras recientes.

Se compone de un nivel de loess, correspondiente a la Formación Tezanos Pinto (figura 5.26.), con $1 \mathrm{~m}$ de espesor. Se trata de un perfil vertical, de color castaño pálido en seco. Es un depósito masivo (sin estructuras sedimentarias visibles), friable, en su mayor parte está formado por limo con escasa arena muy fina y arcilla. Está débilmente organizado en agregados prismáticos gruesos (poco definidos en el perfil). No hay $\mathrm{CaCO}_{3}$ segregado, excepto en el sector inferior del perfil del loess, en proximidades del contacto con el paleosuelo infrayacente (desarrollado en el techo de la Formación La Juanita, que sigue por debajo del perfil aflorante). Los $20 \mathrm{~cm}$ inferiores de la sección presentan alta reacción al ácido $\mathrm{ClH}$, el resto es no calcáreo.

La parte superior del perfil descripto presenta mayor contenido de humedad (otorgándole un color más amarillento). Hay abundantes macroporos muy finos y finos. La parte superior del perfil está atravesada por raicillas actuales. No hay nódulos ni motas. Sobre el loess se ha desarrollado un suelo de $1 \mathrm{~m}$ de potencia (no se puede discriminar el suelo enterrado ni la Formación San Guillermo) interpretado como suelo actual (con una secuencia típica A + B).

Se realizaron muestreos para estudio de fitolitos (5 muestras en el loess), sedimentológicas y para estudio de moluscos. Las muestras de fitolitos se tomaron en la Formación. Tezanos Pinto, desde los 2,00 m de profundidad la 1ra. hasta los $1,00 \mathrm{~m}$ la última, con muestreos equidistantes cada $10 \mathrm{~cm}$ (1,00 $\mathrm{m}$ de potencia total). 

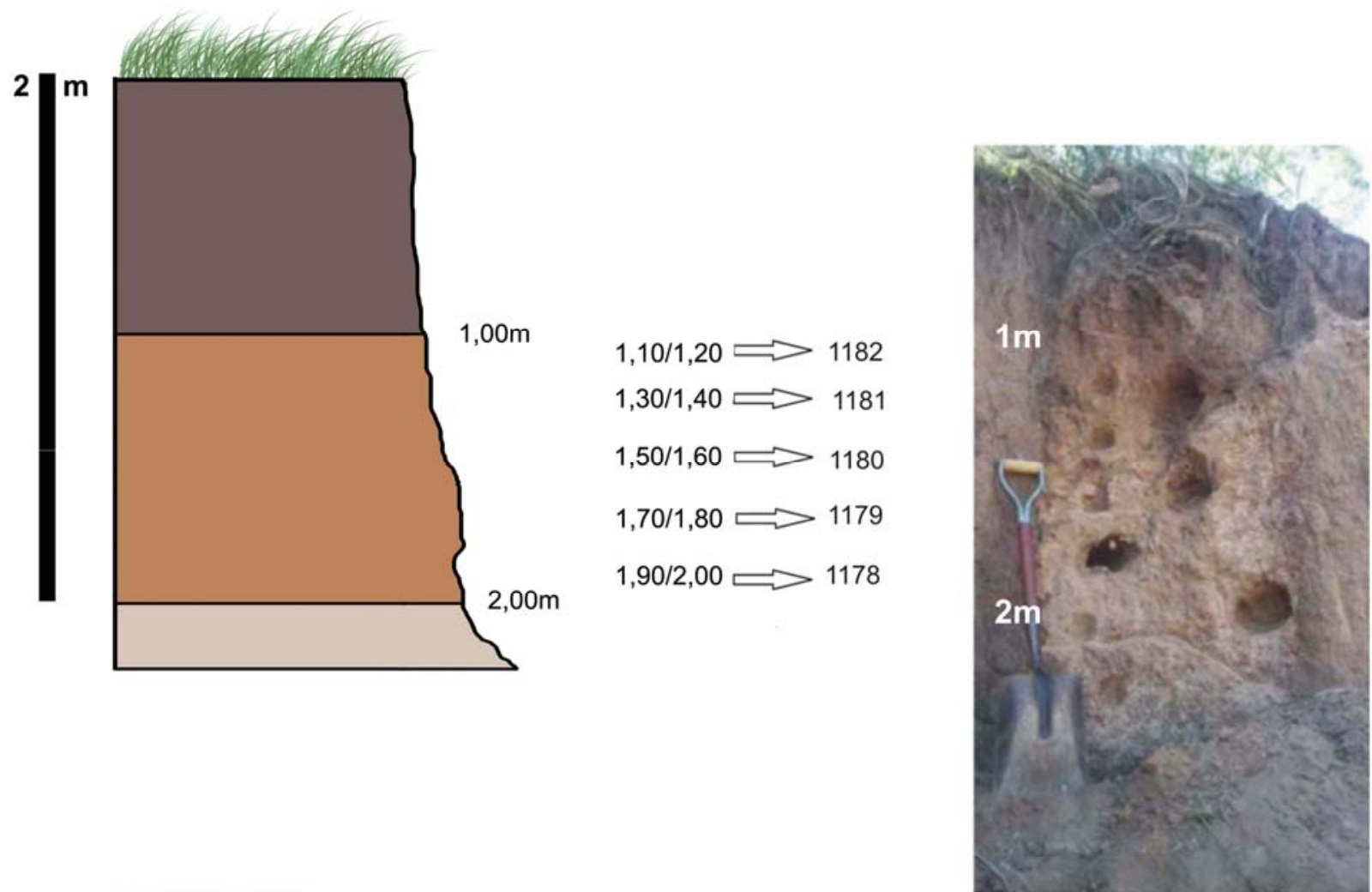

Suelo

Formación Tezanos Pinto

Paleosuelo

Figura 5.26. Fotografía del perfil La Juanita y esquema indicando la procedencia de las muestras. 
5.7.2. Caracterización fitolítica de las muestras (las descripciones en extenso se presentan en el Apéndice)

\section{Muestra 1178}

Se presentaron de manera muy frecuente $(>28,20 \%)$ los fitolitos en cono truncado (Estrobilolita). Los prismáticos rectangulares (Macroprismatolithum) fueron frecuentes $(28,20-14,10 \%)$. Escasos (14,10-4,70\%) aquellos en forma de silla de montar o saddle (Doliolita), los bilobados (Halteriolita) y los halterios Euhalteriolita tipo Stipa. Raros (0-4,70\%) los pelos, ganchos y aguijones (Aculeolithum), los elementos de conducción, Longolita, los flabelos (Flabelolithum), los esféricos (Globulolithum), los prismáticos menores a $40 \mu \mathrm{m}$ y los poliédricos (figuras 5.27. y 5.28.).

\section{$\underline{\text { Muestra } 1179}$}

En esta muestra se presentaron de manera muy frecuente $(>25,35 \%)$ los estróbilos (fitolitos en cono truncado) (Estrobilolita). Fueron escasos (12,67$4,22 \%)$ los pelos, ganchos y aguijones (Aculeolithum), aquellos en forma de silla de montar o saddle (Doliolita), los bilobados (Halteriolita), los esféricos (Globulolithum), los prismáticos rectangulares (Macroprismatolithum) y los halterios Euhalteriolita tipo Stipa. Raros $(0-4,22 \%)$ los elementos de conducción, Longolita, las bulliformes flabeladas (Flabelolithum), formas multilobadas, prismáticos menores a $40 \mu \mathrm{m}$, los polilobados Plurihalteriolithum y los poliédricos (figuras 5.27. y 5.28.).

\section{Muestra 1180}

Se presentaron de manera muy frecuente $(>24,53 \%)$ los estróbilos (fitolitos en cono truncado) (Estrobilolita). Los esféricos (Globulolithum) fueron frecuentes (24,53-12,26\%). Escasos (12,26-4,08\%) aquellos en forma de silla de montar o saddle (Doliolita), los bilobados (Halteriolita), los prismáticos rectangulares (Macroprismatolithum) y los halterios Euhalteriolita tipo Stipa. Raros (0-4,08\%) los ganchos, pelos y aguijones (Aculeolithum), Longolita, los flabelos (Flabelolithum), prismáticos menores a $40 \mu \mathrm{m}$, Plurihalteriolita y los poliédricos (figuras 5.27. y 5.28.). 


\section{Muestra 1181}

Se presentaron de manera muy frecuente $(>16,82 \%)$ Estrobilolita y Globulolithum. Fueron frecuentes (16,82-8,41\%) Macroprismatolithum y Doliolita. Escasos (8,41-2,80\%) Aculeolithum y Euhalteriolita tipo Stipa. Raros $(0-2,80 \%)$ los elementos de conducción, Halteriolita, Longolita, Flabelolithum, prismáticos menores a $40 \mu \mathrm{m}$, Plurihalteriolita y poliédricos (figuras 5.27. y 5.28.).

\section{Muestra 1182}

Se presentaron de manera muy frecuente $(>17,12 \%)$ los fitolitos en cono truncado (Estrobilolita), los prismáticos rectangulares (Macroprismatolithum) y los esféricos (Globulolithum). Fueron escasos (8,56$2,85 \%$ ) aquellos en forma de silla de montar (Doliolita), los pelos, ganchos y aguijones (Aculeolithum), los bilobados (Halteriolita), las bulliformes (Flabelolithum), los halterios Euhalteriolita tipo Stipa y los poliédricos. Raros (0$2,85 \%)$ Longolita, formas multilobadas, prismáticos menores a $40 \mu \mathrm{m}$ y los polilobados Plurihalteriolita (figuras 5.27. y 5.28.). 


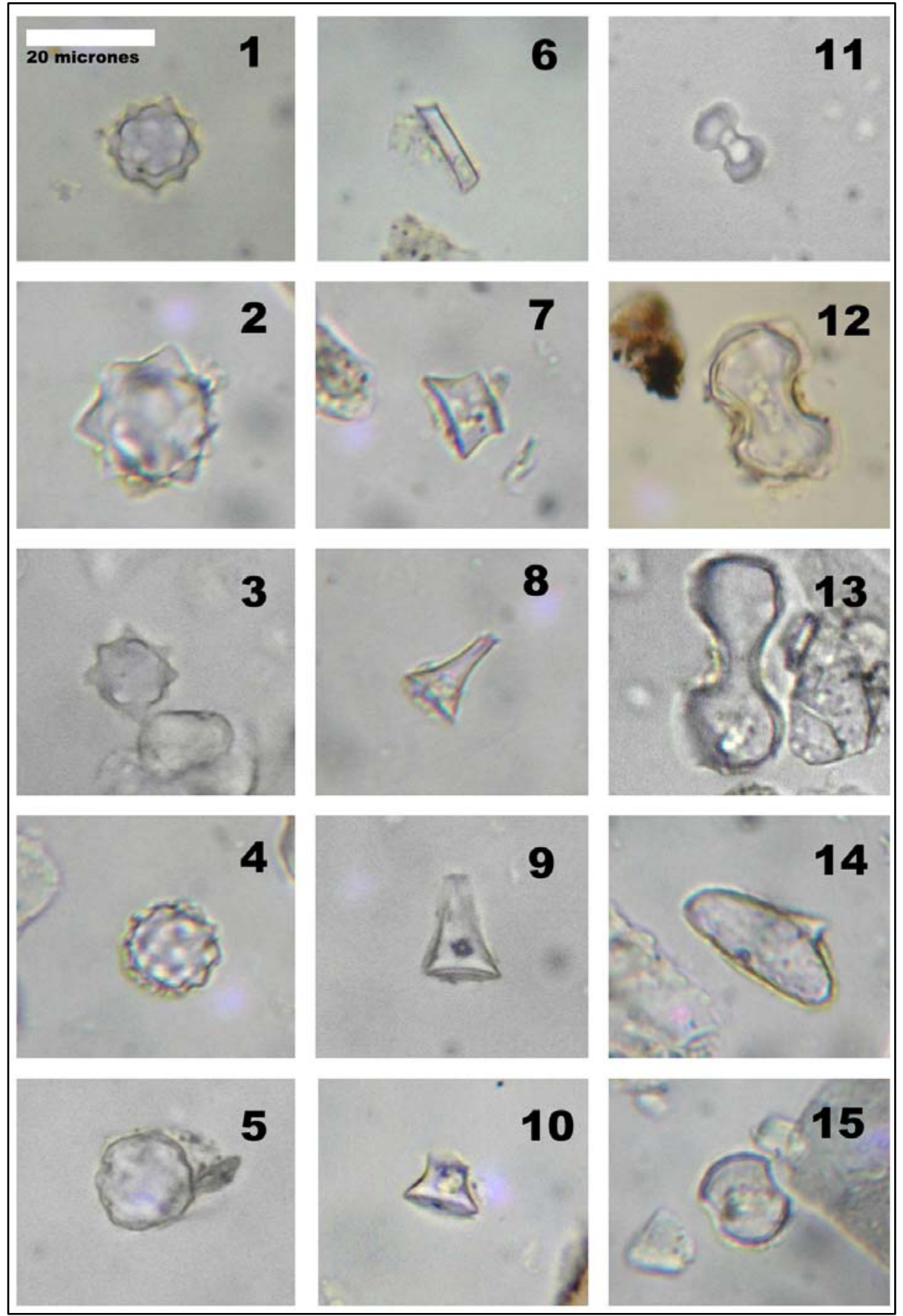

Figura 5.27. Lámina microfitolitos. Escala gráfica en $1=20$ micrones (válida para todas las imágenes). 1-4: Fitolitos esféricos equinados, Globulolithum sphaeroequinulathum. 5: Fitolito esférico liso, Globulolithum sphaeropsilathum.6-10: Fitolitos provenientes de células cortas en forma de conos truncados, Estrobilolita ("rondel"). 11-13: Fitolitos bilobados originados en células cortas en forma de pesa de gimnasia Halteriolita. 14: Fitolito originado a partir de aguijones, Aculeolithum. 15: Fitolito originado en células cortas en forma de silla de montar, Doliolita ("saddle"). 


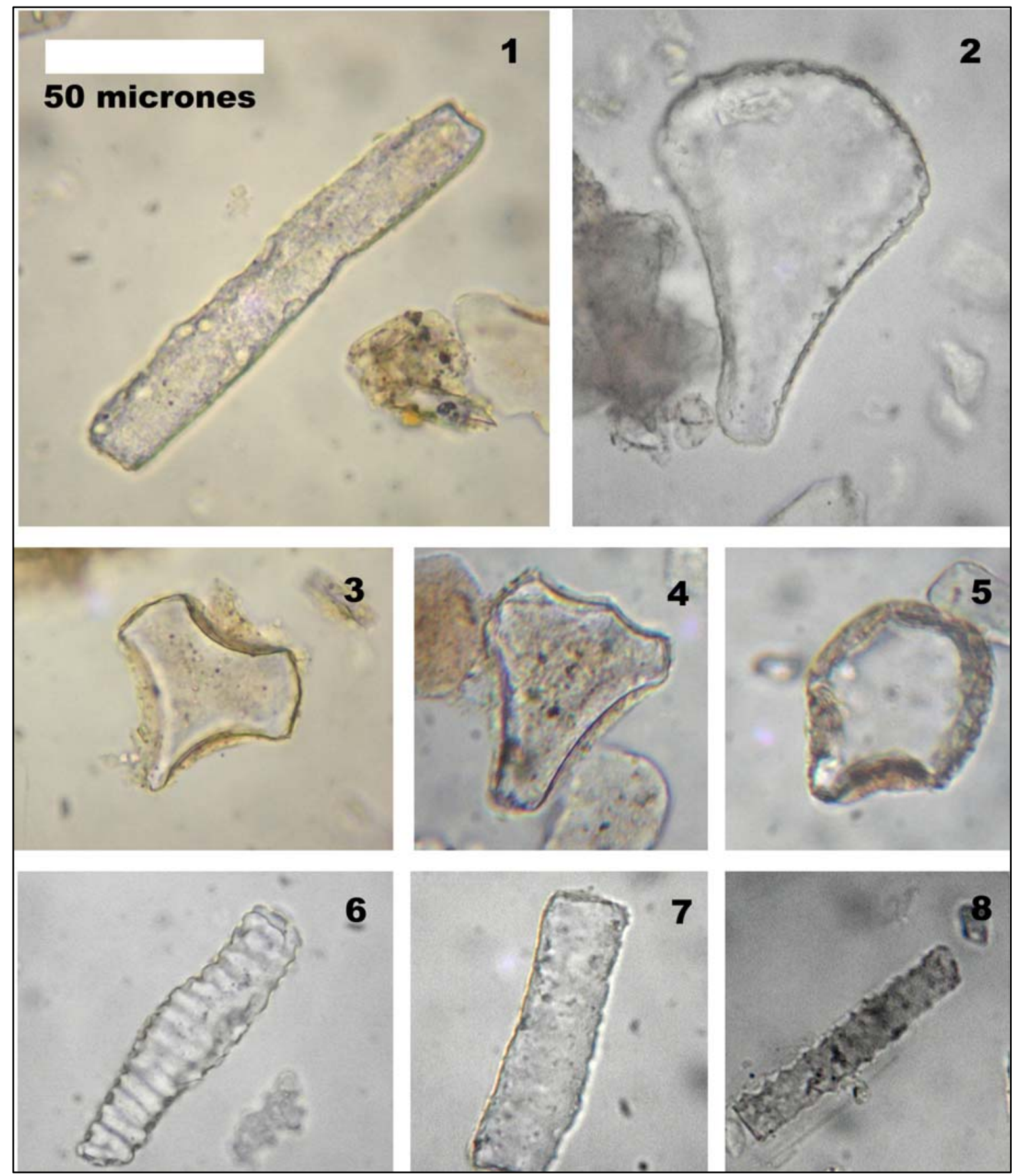

Figura 5.28. Lámina macrofitolitos. Escala gráfica en $1=50$ micrones (válida para todas las imágenes). 1,7,8: Fitolitos prismáticos elongados Macroprismatolithum 2-5:Fitolitos originados en células bulliformes en forma de abanico, Flabelolithum. 6: Fitolito de Podostemaceae, Longolita 


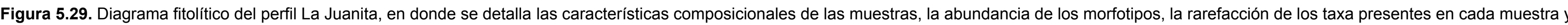
el análisis de cluster realizado con sus abundancias, mediante el método de Constrained single link cluster analysis (Walanus y Nalepka, 1999a, 1999b, 2002; Nalepka y Walanus, 2003).

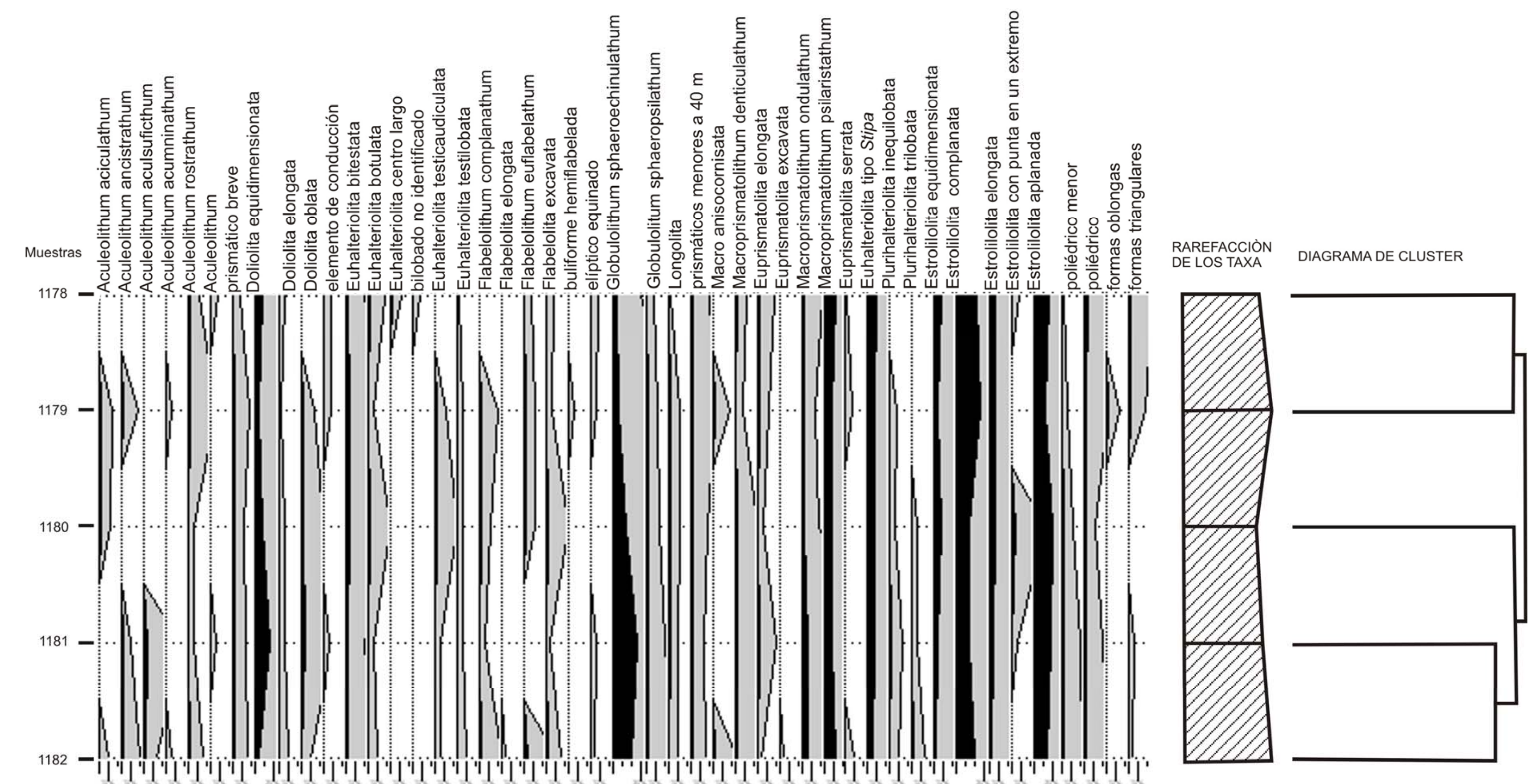




\subsection{PERFIL TIPO TEZANOS PINTO}

\subsubsection{Descripción del perfil}

El perfil muestreado se ubica $S 31^{\circ} 53^{\prime} 20,5^{\prime \prime}$ - O $60^{\circ} 32^{\prime} 27,8^{\prime \prime}$ (figuras 4.1. y 4.2.) en las proximidades de la localidad de Tezanos Pinto. Se trata de la localidad Tipo, en la que fue definida la Formación por Iriondo (1980).

La secuencia sedimentaria consta de un suelo actual de $2 \mathrm{~m}$ de espesor (figuras 5.30.y 5.31.), desarrollado sobre la Formación Tezanos Pinto, con 2,3 $\mathrm{m}$ de potencia aflorante. En dicha unidad se evidencian varias facies sedimentarias.

En la parte superior del perfil aflorante (figuras 5.30., 5.31. y 5.34.) se diferencia la facies "eólica", masiva, friable, con alta proporción de limo, escasa arcilla y arena muy fina. Es un loess primario, típico, con alta reacción al $\mathrm{HCl}$, conteniendo rizoconcreciones de $\mathrm{CaCO}_{3}$. El color de esta facies es $10 \mathrm{Y} / \mathrm{R}$ 6/3 (castaño pálido). Se tomaron 12 muestras (1350, 1349, 1348, 1347, 1346, $1345,1344,1343,1342,1341,1340,1339)$.

Inmediatamente por debajo se encuentra la facies "endurecida" (figura 5.30.y 5.31.). Es una facies loéssica mas dura que la primaria típica, que presenta baja reacción al $\mathrm{HCl}$. Es similar a la eólica típica de la formación, pero se la diferencia por su mayor grado de consolidación y bajo contenido de $\mathrm{CaCO}_{3}$ diseminado en la masa sedimentaria. El color es $10 \mathrm{Y} / \mathrm{R} 7 / 3$ en seco (castaño muy pálido). De aquí se tomaron las muestras 1338, 1337, 1336, y 1335.

Las siguientes muestras $(1334,1333,1332,1331,1330,1329$, y 1328$)$ se tomaron desde los 3,6 a los 4,3 m de profundidad, donde se encuentra una facies "palustre" (representativa de ambiente de pantanos temporarios). Esta facies es laminada, y se encuentra estructurada en prismas. Localmente contiene lentes con abundantes rizoconcreciones. En general presenta baja reacción al $\mathrm{HCl}$. El color es $10 \mathrm{Y} / \mathrm{R} 7 / 3$, castaño muy pálido, con variaciones difusas al 6/3.

Por debajo, (entre los $4,3 \mathrm{~m}$ y hasta los $5,3 \mathrm{~m}$ ) con $1 \mathrm{~m}$ de espesor se evidencia una facies "torrencial" (figura 5.33.), un concentrado por retrabajo fluvial de concreciones carbonáticas rodadas, representando un ambiente de alta energía hídrica. Presenta 2 colores en seco, 10 Y/R 6/4 (castaño amarillo 
claro) en las lentes de pelitas, y 5 Y/R 5/4 (castaño rojizo) en las lentes gruesas. de donde fueron tomadas las muestras 1371, 1372, 1373, 1374, 1375, 1376, 1377, 1378, 1379.

En el área también se hizo evidente la presencia de otra facies de la Formación Tezanos Pinto, una facies "de relleno de canal abandonado" (figura 5.32.), la que presenta estructura laminada. El color del sedimento limoarenoso que la compone es castaño amarillento claro (10 Y/R 6/4) de esta facies no se tomaron muestras.

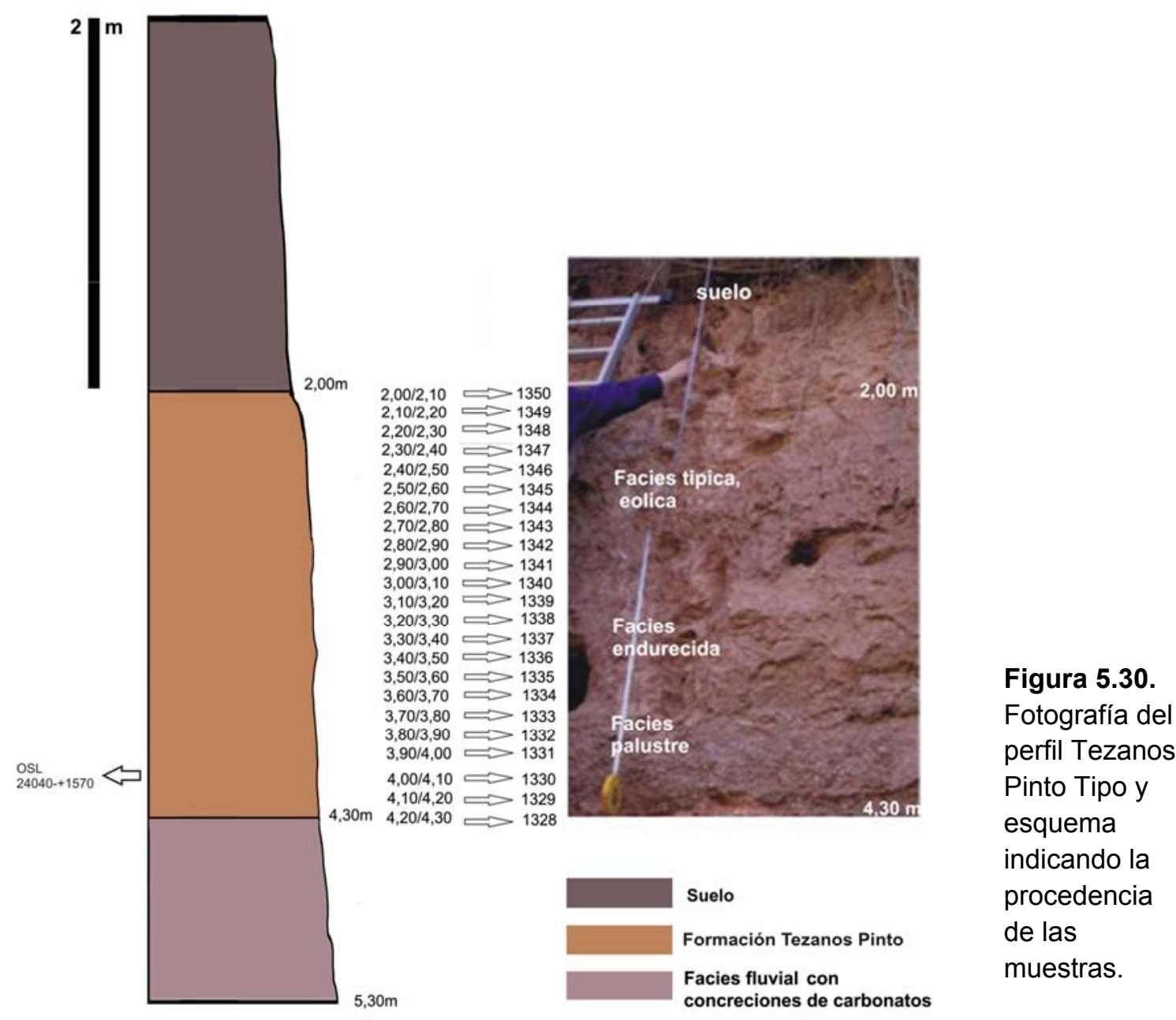




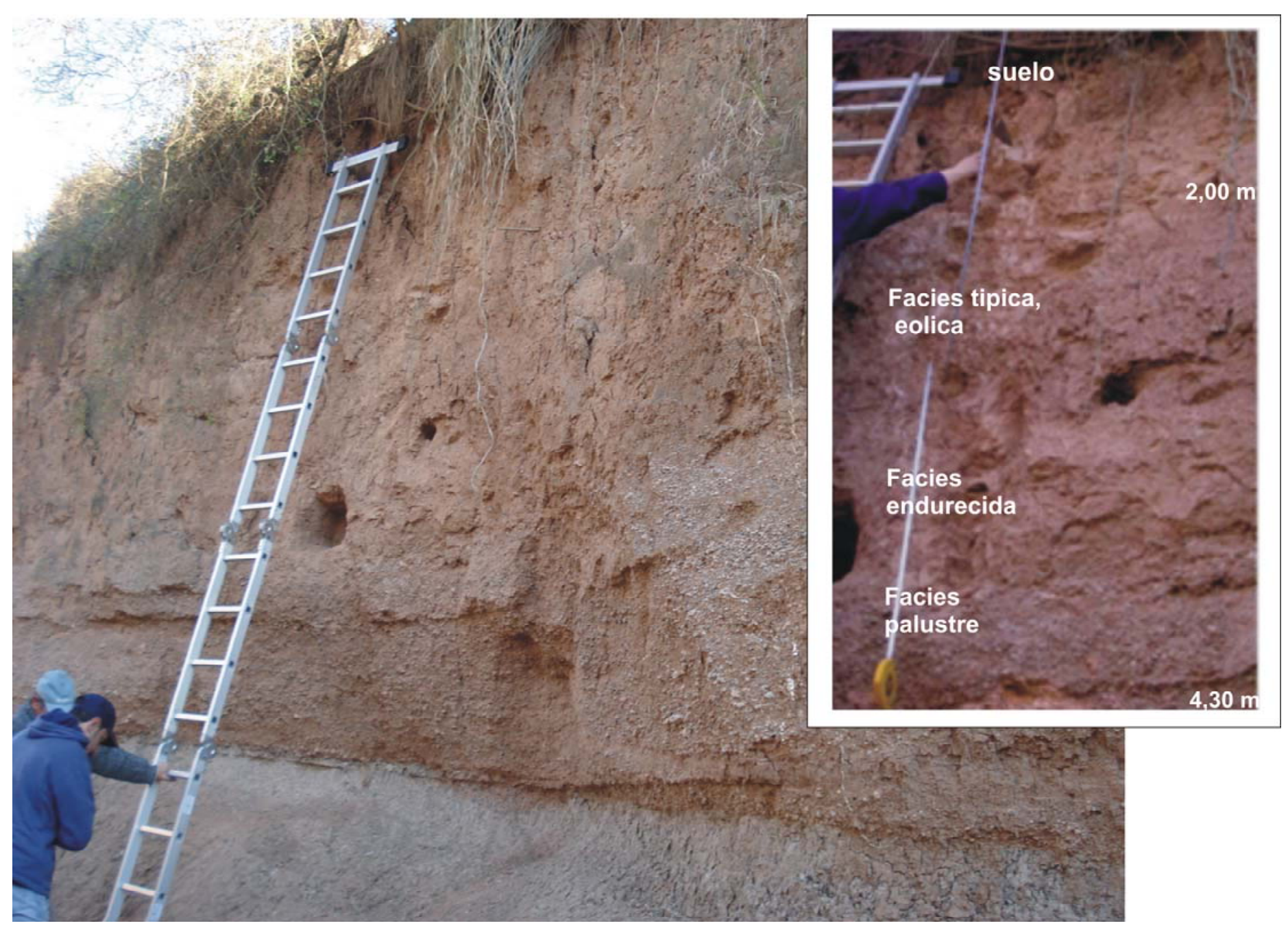

Figura 5.31. Vista del perfil en el campo.

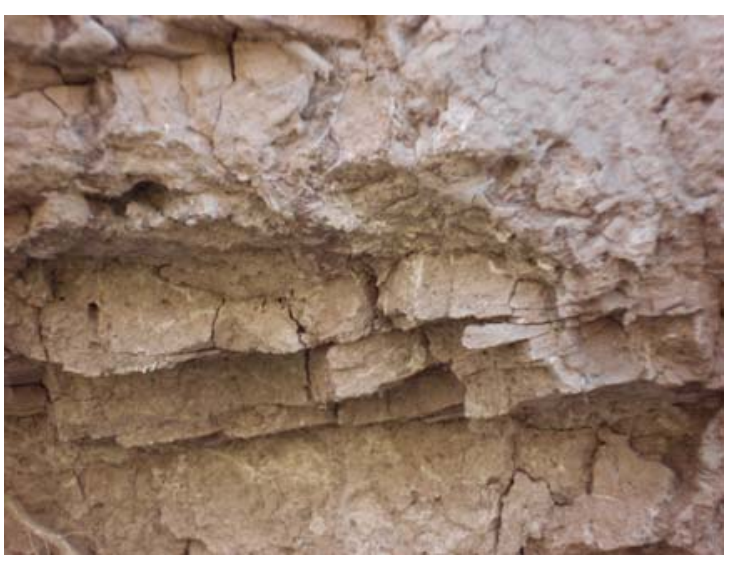

Figura 5.32. Facies de relleno canal abandonado

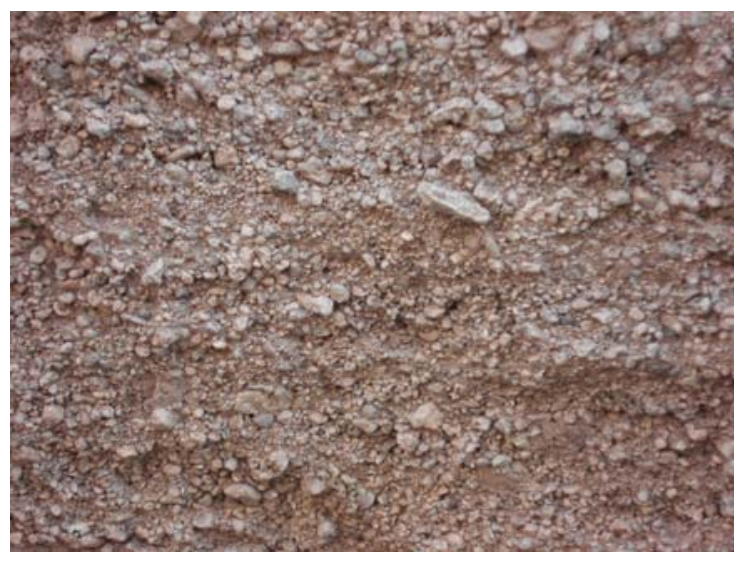

Figura 5.33. Facies torrencial 


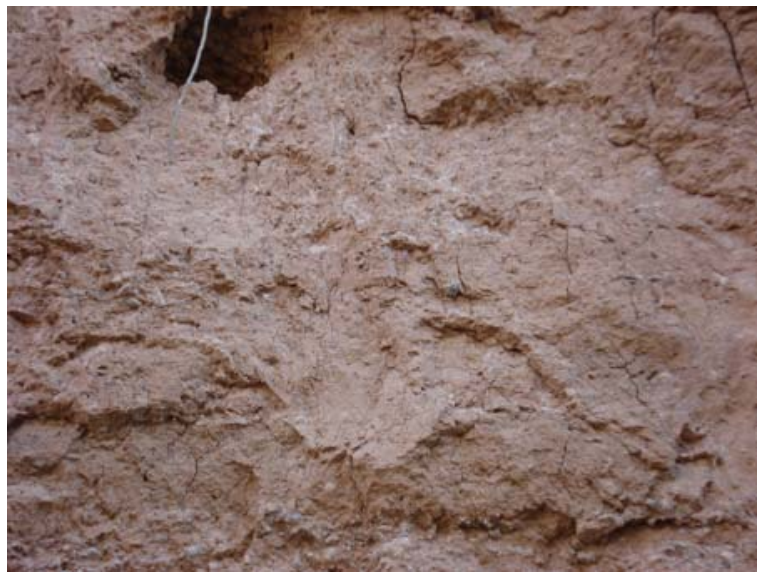

Figura 5.34. Facies eólica primaria

5.8.2. Caracterización fitolítica de las muestras (las descripciones en extenso se presentan en el Apéndice)

\section{Muestra 1328}

En esta muestra se presentaron de manera muy frecuente $(>27,17 \%)$ los fitolitos Estrobilolita. Los bilobados Halteriolita fueron frecuentes $(27,17-$ 13,58\%). Escasos (13,58-4,52\%) Doliolita, Globulolithum, y los prismáticos rectangulares Macroprismatolithum. Raros (0-4,52\%) Aculeolithum, Flabelolithum, Euhalteriolita tipo Stipa, las cruces, Longolita, los prismáticos rectangulares de tamaño inferior a $40 \mu \mathrm{m}$, Plurhalteriolita y los Poliédricos (figuras 5.35. y 5.36.).

\section{Muestra 1329}

Se presentaron de manera muy frecuente $(>26,25 \%)$ los fitolitos en cono truncado Estrobilolita. Fueron escasos (13,12-4,37\%) Aculeolithum, los bilobados Halteriolita, Doliolita, Flabelolithum, los esféricos Globulolithum, y los rectangulares Macroprismatolithum. Raros (0-4,37\%) las cruces, Euhalteriolita 
tipo Stipa, los naviculados Longolita, los prismáticos rectangulares de tamaño inferior a $40 \mu \mathrm{m}$, Plurhalteriolita y los Poliédricos (figuras 5.35. y 5.36.).

\section{$\underline{\text { Muestra } 1330}$}

Se presentaron de manera muy frecuente $(>26,52 \%)$ los fitolitos en cono truncado Estrobilolita. Fueron escasos (13,26-4,42\%) los bilobados Halteriolita, Doliolita, Flabelolithum, Globulolithum, y Macroprismatolithum. Raros $(0-4,42 \%)$ Aculeolithum, las cruces, Longolita, los Euhalteriolita tipo Stipa, los prismáticos rectangulares de tamaño inferior a $40 \mu \mathrm{m}$, Plurhalteriolita y los Poliédricos (figuras 5.35. y 5.36.).

\section{Muestra 1331}

Se presentaron de manera muy frecuente $(>21,29 \%)$ los fitolitos en cono truncado Estrobilolita. Los bilobados Halteriolita y Doliolita fueron frecuentes (21,29-10,64\%). Escasos (10,64-3,54\%) Aculeolithum, Globulolithum, Euhalteriolita tipo Stipa, y Macroprismatolithum. Raros (0-3,54\%), Flabelolithum, Longolita, los prismáticos rectangulares de tamaño inferior a 40 $\mu \mathrm{m}$, Plurihalteriolita y los Poliédricos (figuras 5.35. y 5.36.).

\section{Muestra 1332}

Se presentaron de manera muy frecuente $(>29,71 \%)$ los fitolitos en cono truncado Estrobilolita. Fueron escasos $(14,85-4,95 \%)$ los bilobados Halteriolita, Ios Doliolita, Globulolithum, y Macroprismatolithum. Raros (0-4,95\%) Aculeolithum, Flabelolithum, Euhalteriolita tipo Stipa, los prismáticos rectangulares de tamaño inferior a $40 \mu \mathrm{m}$, Plurihalteriolita y los Poliédricos (figuras 5.35. y 5.36.).

\section{$\underline{\text { Muestra } 1333}$}

Se presentaron de manera muy frecuente $(>20,09 \%)$ los fitolitos en cono truncado Estrobilolita. Flabelolithum y Macroprismatolithum fueron frecuentes $(20,09-10,04 \%)$. Escasos $(10,04-3,34 \%)$ los bilobados Halteriolita y Doliolita Aculeolithum, Globulolithum, Euhalteriolita tipo Stipa y los Poliédricos. Raros (0$3,34 \%)$, formas multilobadas, Longolita, los prismáticos rectangulares de tamaño inferior a $40 \mu \mathrm{m}$, y Plurihalteriolita (figuras 5.35. y 5.36.). 


\section{Muestra 1334}

Se presentaron de manera muy frecuente $(>27,05 \%)$ los fitolitos en cono truncado Estrobilolita. Fueron escasos (13,52-4,50\%) Aculeolithum, Doliolita, los bilobados Halteriolita, Flabelolithum, Globulolithum, y Macroprismatolithum. Raros (0-4,50\%), Longolita, los prismáticos rectangulares de tamaño inferior a $40 \mu \mathrm{m}$, Euhalteriolita tipo Stipa y los Poliédricos (figuras 5.35. y 5.36.).

\section{Muestra 1335}

Estrobilolita se presentó de manera muy frecuente $(>23,42 \%)$. Fueron escasos (11,71-3,90\%) Aculeolithum, Doliolita, los bilobados Halteriolita, Globulolithum, Macroprismatolithum, y Euhalteriolita tipo Stipa. Raros (0-3,90\%) Flabelolithum, formas multilobadas, prismáticos rectangulares de tamaño inferior a $40 \mu \mathrm{m}$, Plurihalteriolita, Poliédricos y Pileolitas (figuras 5.35. y 5.36.).

\section{Muestra 1336}

Se presentaron de manera muy frecuente $(>17,16 \%)$ los fitolitos en cono truncado Estrobilolita y los prismáticos rectangulares Macroprismatolithum. Mientras las flabeladas Flabelolithum, Aculeolithum, y Globulolithum fueron frecuentes $(17,16-8,58 \%)$. Escasos $(8,58-2,86 \%)$ los bilobados Halteriolita y los Poliédricos. Raros (0- 2,86\%), Doliolita, Euhalteriolita tipo Stipa, y Pileolita (figuras 5.35. y 5.36.).

\section{Muestra 1337}

Se presentaron de manera muy frecuente $(>22,46 \%)$ los fitolitos en cono truncado Estrobilolita. De manera frecuente (22,46-11,23\%) los Macroprismatolithum y Flabelolithum. Fueron escasos (11,23-3,74\%) Aculeolithum, Doliolita, Globulolithum, los Euhalteriolita tipo Stipa, y los Poliédricos. Raros $(0-3,74 \%)$, los bilobados Halteriolita, Longolita, los prismáticos rectangulares de tamaño inferior a $40 \mu \mathrm{m}$ y Pileolitas (figuras 5.35 . y 5.36.). 


\section{Muestra 1338}

Se presentaron de manera muy frecuente $(>24,26 \%)$ los fitolitos en cono truncado Estrobilolita. Fueron escasos (12,13-4,04\%) Aculeolithum, Doliolita, los bilobados Halteriolita, Flabelolithum, Globulolithum y Macroprismatolithum. Raros $(0-4,04 \%)$, los Poliédricos, Euhalteriolita tipo Stipa, y los prismáticos rectangulares de tamaño inferior a $40 \mu \mathrm{m}$ (figuras 5.35. y 5.36.).

\section{Muestra 1339}

Se presentaron de manera muy frecuente $(>21,29 \%)$ los fitolitos en cono truncado Estrobilolita. De manera frecuente (21,29-10,64\%) Doliolita, y Flabelolithum. Fueron escasos (10,64-3,54\%) Aculeolithum, Macroprismatolithum, los esféricos Globulolithum y los Poliédricos. Raros (0$3,54 \%$ ) los bilobados Halteriolita, Euhalteriolita tipo Stipa, los prismáticos rectangulares de tamaño inferior a $40 \mu \mathrm{m}$, y Plurihalteriolita (figuras 5.35. y 5.36.).

\section{Muestra 1340}

Se presentaron de manera muy frecuente $(>15,51 \%)$ Estrobilolita y Flabelolithum. De manera frecuente (15,51-7,75\%) Aculeolithum, Macroprismatolithum y los Poliédricos. Fueron escasos (7,75-2,58\%) Doliolita, los bilobados Halteriolita, los esféricos Globulolithum y los prismáticos rectangulares de tamaño inferior a $40 \mu \mathrm{m}$; y raros (0-2,58\%) Euhalteriolita tipo Stipa (figuras 5.35. y 5.36.).

\section{$\underline{\text { Muestra } 1341}$}

Se presentaron de manera muy frecuente $(>17,18 \%)$ los fitolitos en cono truncado Estrobilolita. De manera frecuente (17,18-8,59\%) Macroprismatolithum y los esféricos Globulolithum. Fueron escasos (8,59$2,86 \%)$ Aculeolithum, Doliolita, los bilobados Halteriolita, Flabelolithum y los Poliédricos. Raros (0-2,86\%) Longolita, Euhalteriolita tipo Stipa, los prismáticos rectangulares de tamaño inferior a $40 \mu \mathrm{m}$, y Plurihalteriolita (figuras 5.35. y 5.36.). 


\section{Muestra 1342}

Se presentaron de manera muy frecuente $(>18,98 \%)$ los fitolitos en cono truncado Estrobilolita. De manera frecuente (18,98-9,49\%) Doliolita, Macroprismatolithum y Flabelolithum. Fueron escasos (9,49-3,16\%) Aculeolithum, los bilobados Halteriolita y los esféricos Globulolithum. Raros (0$3,16 \%)$ Longolita, Euhalteriolita tipo Stipa, Plurihalteriolita y Poliédricos.

\section{Muestra 1343}

Se presentaron de manera muy frecuente $(>13,34 \%)$ los fitolitos en cono truncado Estrobilolita, Macroprismatolithum y Flabelolithum. De manera frecuente $(13,34-6,67 \%)$ Aculeolithum y los Poliédricos. Fueron escasos (6,67$2,22 \%)$ Doliolita, los bilobados Halteriolita y los esféricos Globulolithum. Raros (0-2,22\%) Longolita, Euhalteriolita tipo Stipa, los prismáticos rectangulares de tamaño inferior a $40 \mu \mathrm{m}$, formas macroglobosas y Plurihalteriolita(figuras 5.35 . y 5.36.).

\section{$\underline{\text { Muestra } 1344}$}

Se presentaron de manera muy frecuente $(>14,64 \%)$ Estrobilolita, Macroprismatolithum y Flabelolithum. De manera frecuente $(14,64-7,32 \%)$ Aculeolithum, Doliolita y los esféricos Globulolithum. Fueron escasos (7,32$2,44 \%)$ Halteriolita y los Poliédricos. Raros (0-2,44\%) Euhalteriolita tipo Stipa, los prismáticos rectangulares de tamaño inferior a $40 \mu \mathrm{m}$ y Longolita (figuras 5.35. y 5.36.).

\section{Muestra 1345}

Se presentaron de manera muy frecuente $(>14,96 \%)$ los fitolitos en cono truncado Estrobilolita, Macroprismatolithum y Flabelolithum. De manera frecuente $(14,96-7,48 \%)$ los bilobados Halteriolita. Fueron escasos $(7,48-$ 2,94\%) Aculeolithum, Doliolita, los esféricos Globulolithum, Euhalteriolita tipo Stipa, y los Poliédricos. Raros (0-2,94\%) Longolita, los prismáticos rectangulares de tamaño inferior a $40 \mu \mathrm{m}$, formas macroglobosas $\mathrm{y}$ Plurihalteriolita (figuras 5.35. y 5.36.). 


\section{Muestra 1346}

Se presentaron de manera muy frecuente $(>19,80 \%)$ los fitolitos en cono truncado Estrobilolita. De manera frecuente (19,80-9,90\%) Macroprismatolithum, Flabelolithum y Aculeolithum. Fueron escasos $(9,90-$ $3,30 \%$ ) los bilobados Halteriolita y los esféricos Globulolithum. Raros (0$3,30 \%$ ), Doliolita, los prismáticos rectangulares de tamaño inferior a $40 \mu \mathrm{m}$, Euhalteriolita tipo Stipa, y los Poliédricos (figuras 5.35. y 5.36.).

\section{$\underline{\text { Muestra } 1347}$}

Se presentaron de manera muy frecuente $(>17,52 \%)$ Macroprismatolithum y Flabelolithum. De manera frecuente $(17,52-8,76 \%)$ los fitolitos en cono truncado Estrobilolita y los Poliédricos. Fueron escasos (8,762,92\%) Aculeolithum y los bilobados Halteriolita. Raros (0-2,92\%), Doliolita, Globulolithum, los Euhalteriolita tipo Stipa, Longolita, los prismáticos rectangulares de tamaño inferior a $40 \mu \mathrm{m}$ y Plurihalteriolita (figuras 5.35. y 5.36.).

\section{Muestra 1348}

Se presentaron de manera muy frecuente $(>21,33 \%)$ los fitolitos prismáticos rectangulares Macroprismatolithum y los flabelados Flabelolithum. Fueron escasos (10,66-3,55\%) Aculeolithum, Globulolithum, Estrobilolita y los Poliédricos. Raros $(0-3,55 \%)$, Doliolita, los bilobados Halteriolita, los Euhalteriolita tipo Stipa y Longolita (figuras 5.35. y 5.36.).

\section{Muestra 1349}

Se presentaron de manera muy frecuente $(>27,24 \%)$ los fitolitos en cono truncado Estrobilolita. Los bilobados Halteriolita fueron escasos (13,62-4,54\%), al igual que Aculeolithum, Globulolithum, y Macroprismatolithum. Raros (0$4,54 \%)$ Doliolita, Euhalteriolita tipo Stipa, las cruces, Flabelolithum, las naviculadas Longolita, los prismáticos rectangulares de tamaño inferior a 40 $\mu \mathrm{m}$, los halterios polilobados Plurhalteriolita y los Poliédricos (figuras 5.35. y 5.36.). 


\section{Muestra 1350}

Se presentaron de manera muy frecuente (>25,65\%) los Estrobilolita. Macroprismatolithum fue frecuente (25,65-12,82\%). Halteriolita Escaso (12,82$4,27 \%$ ), al igual que Doliolita, Globulolithum, y Euhalteriolita tipo Stipa. Raros (0-4,27\%) Aculeolithum, Flabelolithum, Longolita, los prismáticos rectangulares de tamaño inferior a $40 \mu \mathrm{m}$, Plurihalteriolita y los Poliédricos (figuras 5.35. y 5.36.). 


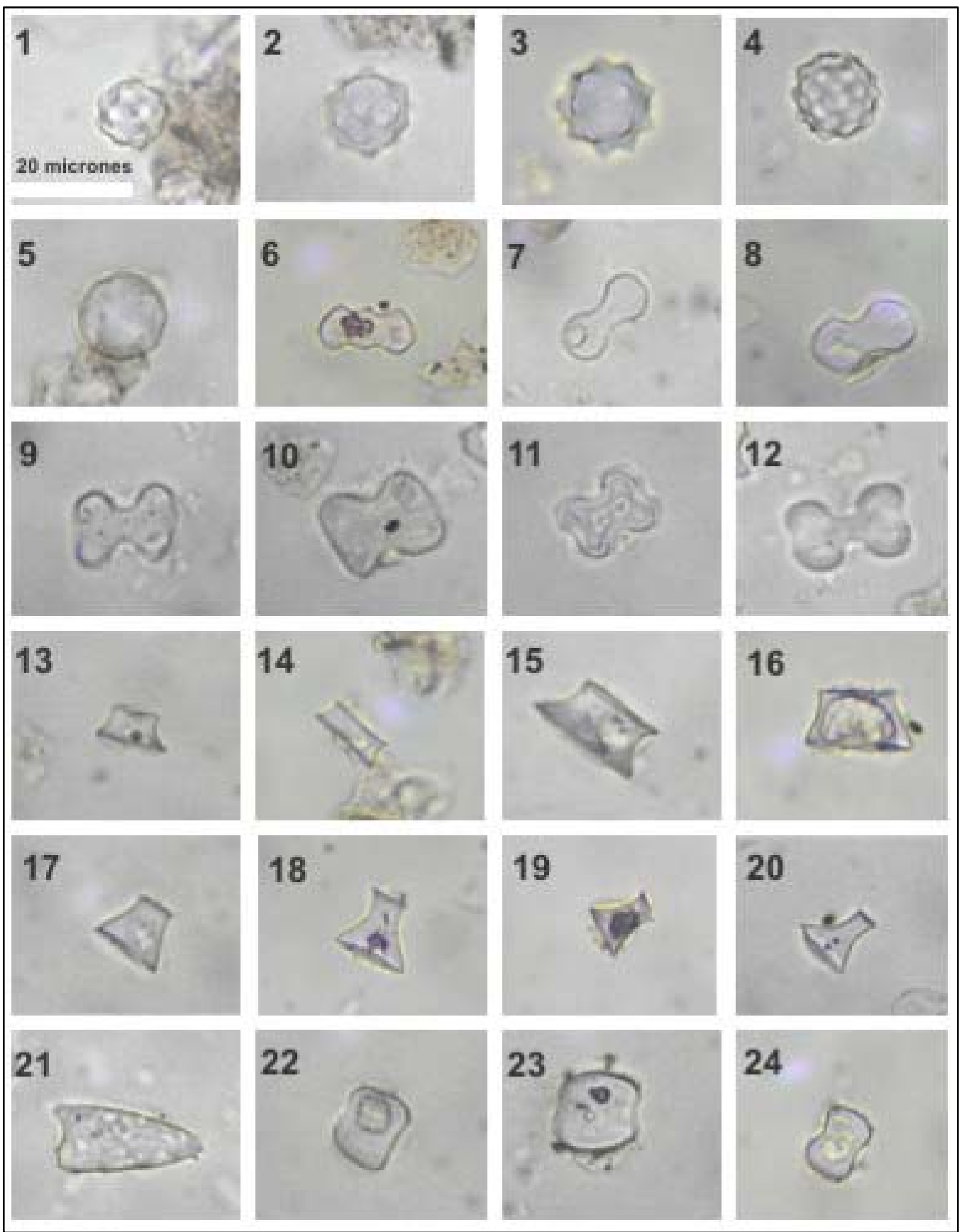

Figura 5.35. Lámina microfitolitos. Escala gráfica en $1=20$ micrones (válida para todas las imágenes). 1-4: Fitolitos esféricos equinados, Globulolithum sphaeroequinulathum. 5: Fitolito esférico liso, Globulolithum sphaeropsilathum.6: Plurihalteriolita trilobata. 7-12: Fitolitos bilobados originados en células cortas en forma de pesa de gimnasia Halteriolita. 13-20: Fitolitos provenientes de células cortas en forma de conos truncados, Estrobilolita ("rondel"). 21: Fitolito originado a partir de aguijones, Aculeolithum. 22-24: Fitolitos originados en células cortas en forma de silla de montar, Doliolita ("saddle"). 


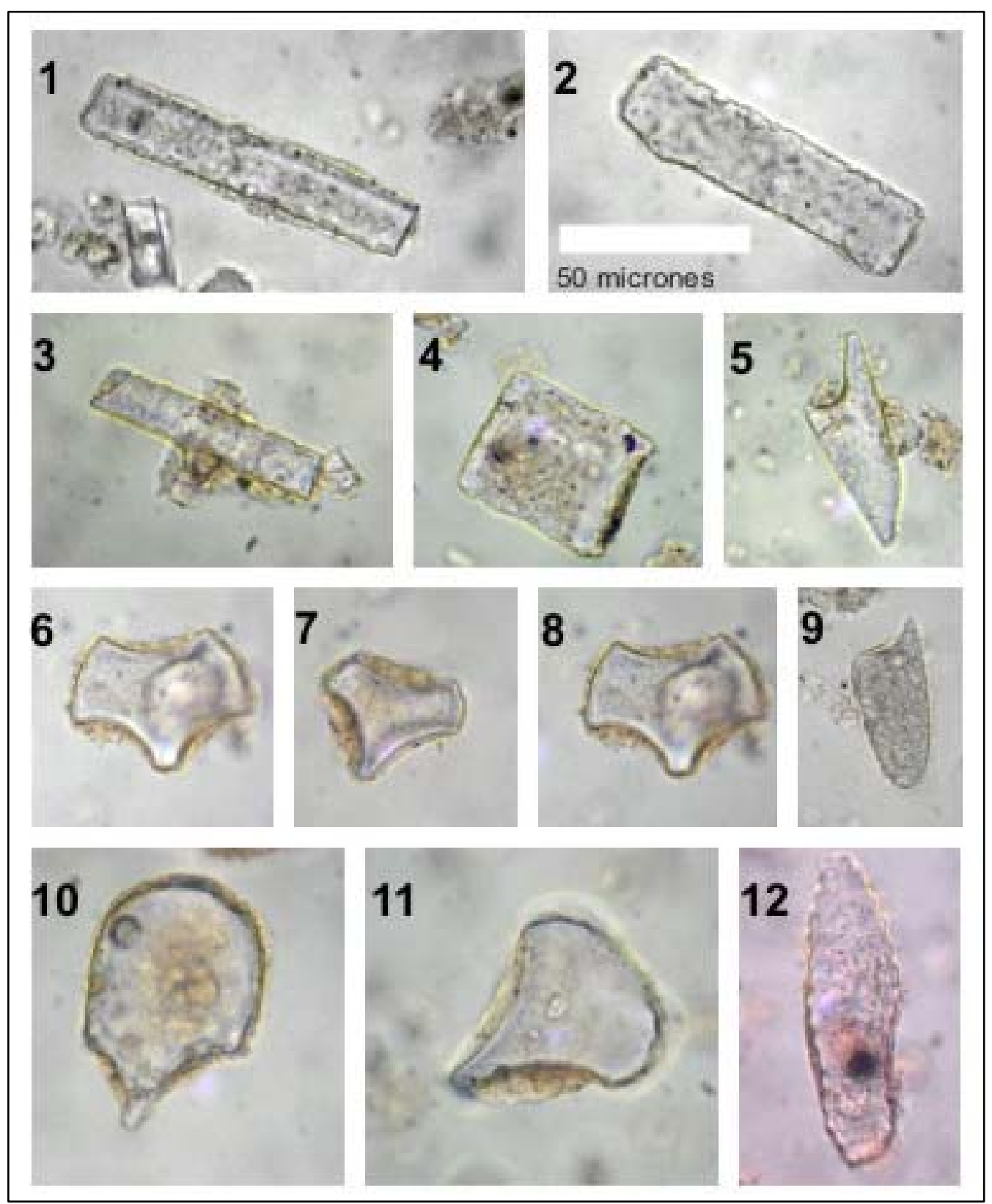

Figura 5.36. Lámina macrofitolitos. Escala gráfica en $2=50$ micrones (válida para todas las imágenes).1-3: Fitolitos prismáticos Macroprismatolithum. 4: Fitolito poliédrico. 5,9: Fitolitos originados a partir de aguijones, Aculeolithum. 6-8, 10-11: Fitolitos originados en células bulliformes en forma de abanico, Flabelolithum. 12: Fitolito de Podostemaceae, Longolita. 


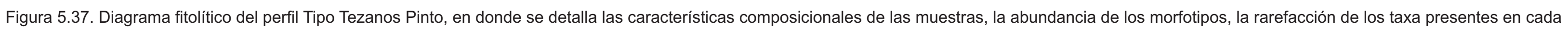

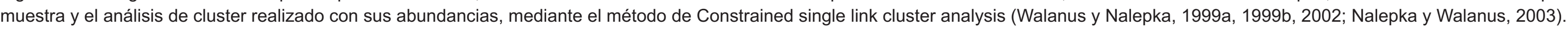

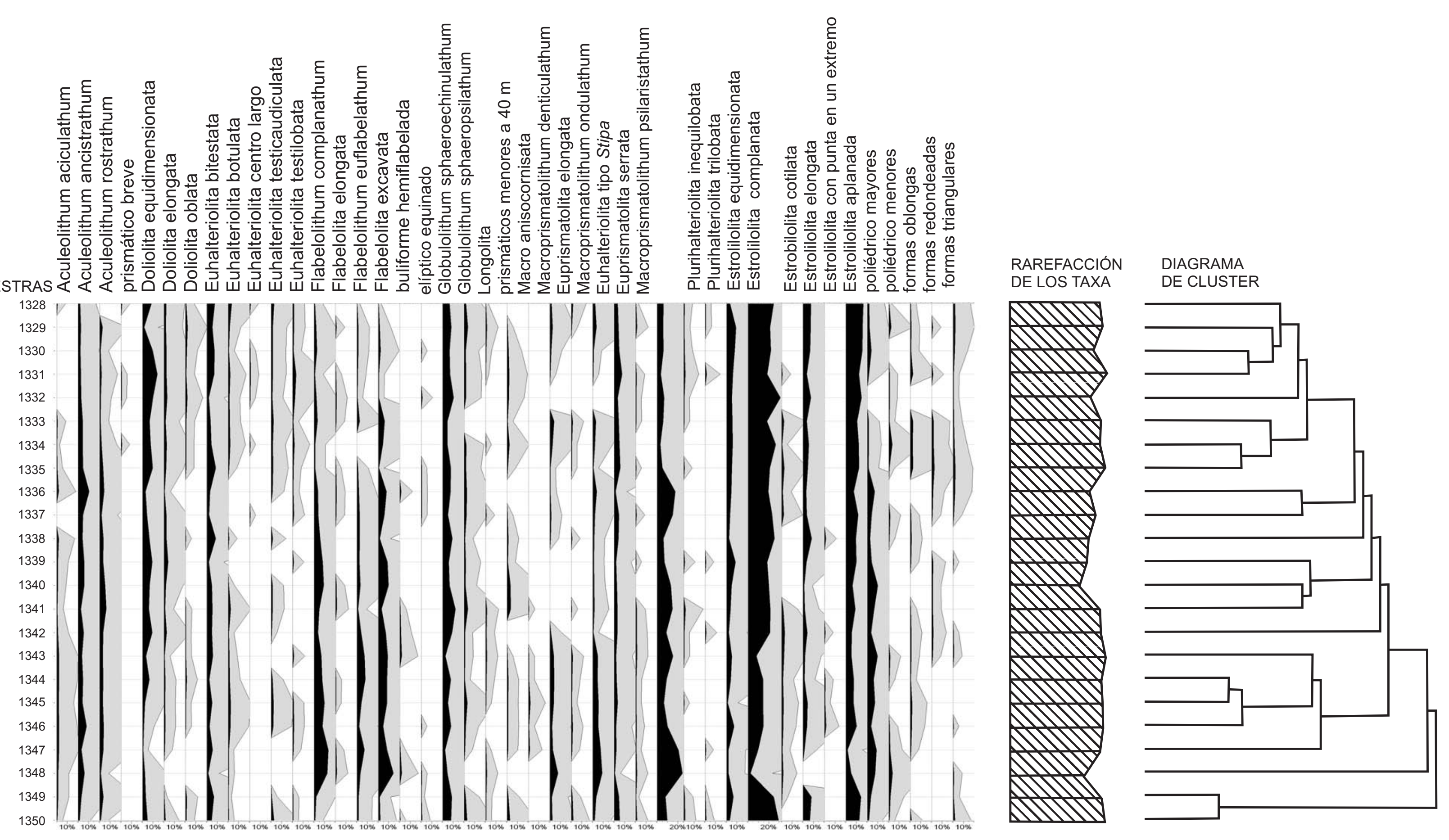




\section{PERFIL ACCESORIO}

\subsection{PERFIL RINCÓN DEL DOLL}

\subsubsection{Descripción del perfil}

El perfil muestreado se encuentra en las proximidades de la localidad de Rincón del Doll, con ubicación S32 ${ }^{\circ}$ 25' 22,2" - O 60²3' 52,9" (figuras 4.1. y 4.2.). En él la formación muestreada (figura 5.38.) tiene un espesor de 0,75 m, no corresponde a la Formación Tezanos Pinto, sino muy probablemente a la Formación La Picada (Iriondo, 1980), una unidad holocena típica de los valles de la provincia de Entre Ríos.

Se tomaron 4 muestras para hacer estudios de fitolitos, numeradas 1120 , 1121,1122 y 1123 , tomadas a $1,15 \mathrm{~m}$ de profundidad la $1 \mathrm{ra}$., $0,90 \mathrm{~m}$ la 2 da., $0.65 \mathrm{~m}$ la 3ra. y $0,40 \mathrm{~m}$ la 4 ta.

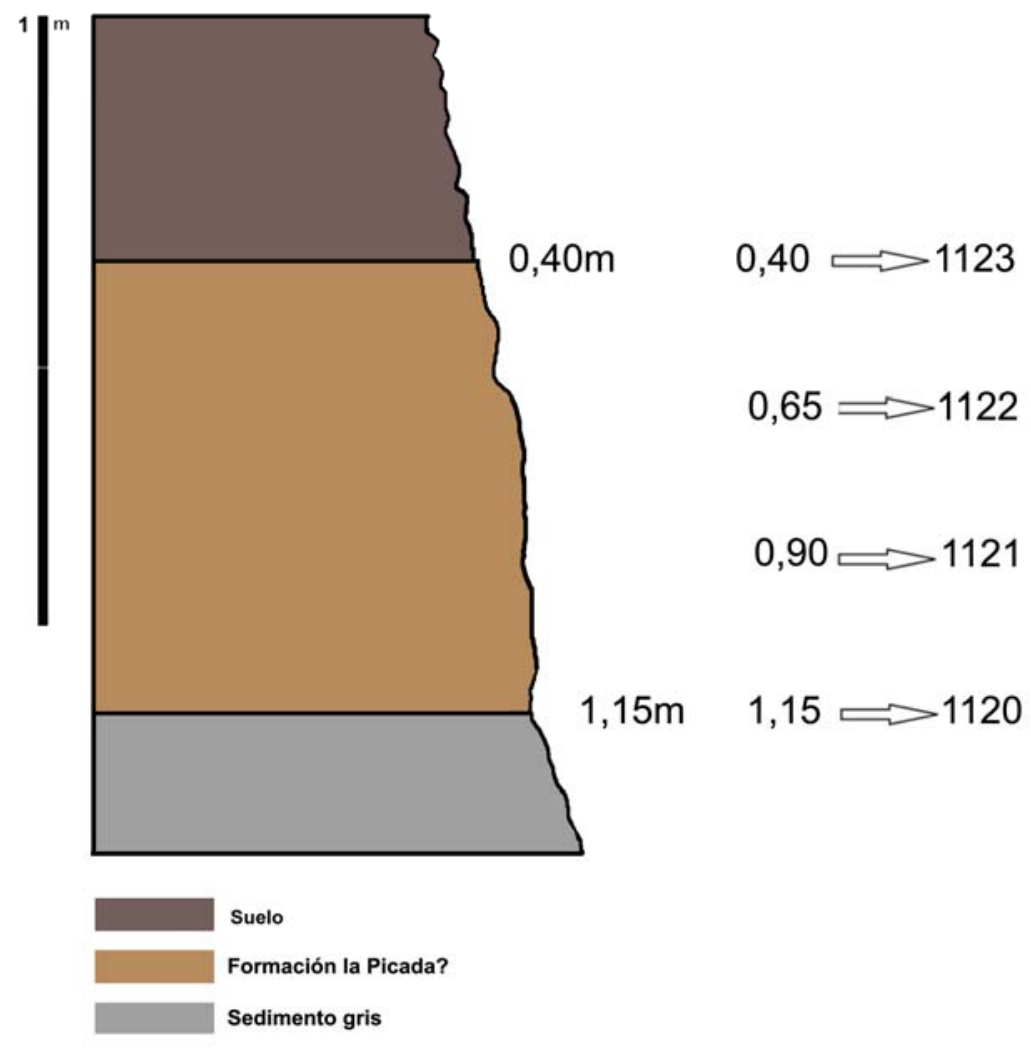

Figura 5.38. Esquema del perfil Rincón del Doll indicando la procedencia de las muestras. 
5.9.2. Caracterización fitolítica de las muestras (las descripciones en extenso se presentan en el Apéndice)

\section{Muestra 1120}

Se presentaron de manera muy frecuente $(>37,37 \%)$ los prismáticos rectangulares (Macroprismatolithum). Fueron escasos $(6,22-18,68 \%)$ los estróbilos (fitolitos en cono truncado) (Estrobilolita). Raros (0-6,22\%) los pelos, ganchos y aguijones (Aculeolithum), aquellos en forma de silla de montar o saddle (Doliolita), los bilobados (Halteriolita), aquellos en forma de abanico (Flabelolithum), los fitolitos esféricos (Globulolithum), los prismáticos rectangulares de tamaño inferior a $40 \mu \mathrm{m}$, fitolitos poliédricos, Longolita, y los polilobados Plurihalteriolita (figura 5.39.).

\section{Muestra 1121}

Se presentaron de manera muy frecuente $(>36,92 \%)$ los prismáticos rectangulares (Macroprismatolithum). Fueron escasos $(6,15-18,46 \%)$ los estróbilos (fitolitos en cono truncado) (Estrobilolita). Raros (0- 6,15\%) los pelos, ganchos y aguijones (Aculeolithum), aquellos en forma de silla de montar o saddle (Doliolita), los elementos de conducción, los bilobados o en forma de halterio (Halteriolita), aquellos en forma de abanico (Flabelolithum), los fitolitos esféricos (Globulolithum), los prismáticos rectangulares de tamaño inferior a $40 \mu \mathrm{m}$, los poliédricos (figura 5.39.).

\section{Muestra 1122}

Se presentaron de manera muy frecuente $(>27,23 \%)$ los prismáticos rectangulares (Macroprismatolithum). Frecuente $(27,23-13,61 \%)$ los estróbilos (fitolitos en cono truncado) (Estrobilolita). Fueron escasos (4,53-13,61\%) los pelos, ganchos y aguijones (Aculeolithum), aquellos en forma de abanico (Flabelolithum) y los poliédricos. Raros (0-4,53\%) aquellos en forma de silla de montar o saddle (Doliolita), en forma estrellada, bilobados (Halteriolita), los fitolitos esféricos (Globulolithum), prismáticos rectangulares de tamaño inferior a $40 \mu \mathrm{m}$, Pileolita y los halterios polilobados Plurihalteriolita (figura 5.39.). 


\section{Muestra 1123}

Se presentaron de manera muy frecuente $(>25,36 \%)$ los prismáticos rectangulares (Macroprismatolithum) y los estróbilos (fitolitos en cono truncado) (Estrobilolita). Fueron escasos (4,22-12,68\%) los pelos, ganchos y aguijones (Aculeolithum), los fitolitos esféricos (Globulolithum) y los fitolitos poliédricos. Raros (0-4,22\%) aquellos en forma de silla de montar o saddle (Doliolita), los elementos de conducción, los bilobados o en forma de halterio (Halteriolita), aquellos en forma de abanico (Flabelolithum), y los halterios polilobados Plurihalteriolita (figura 5.39.). 


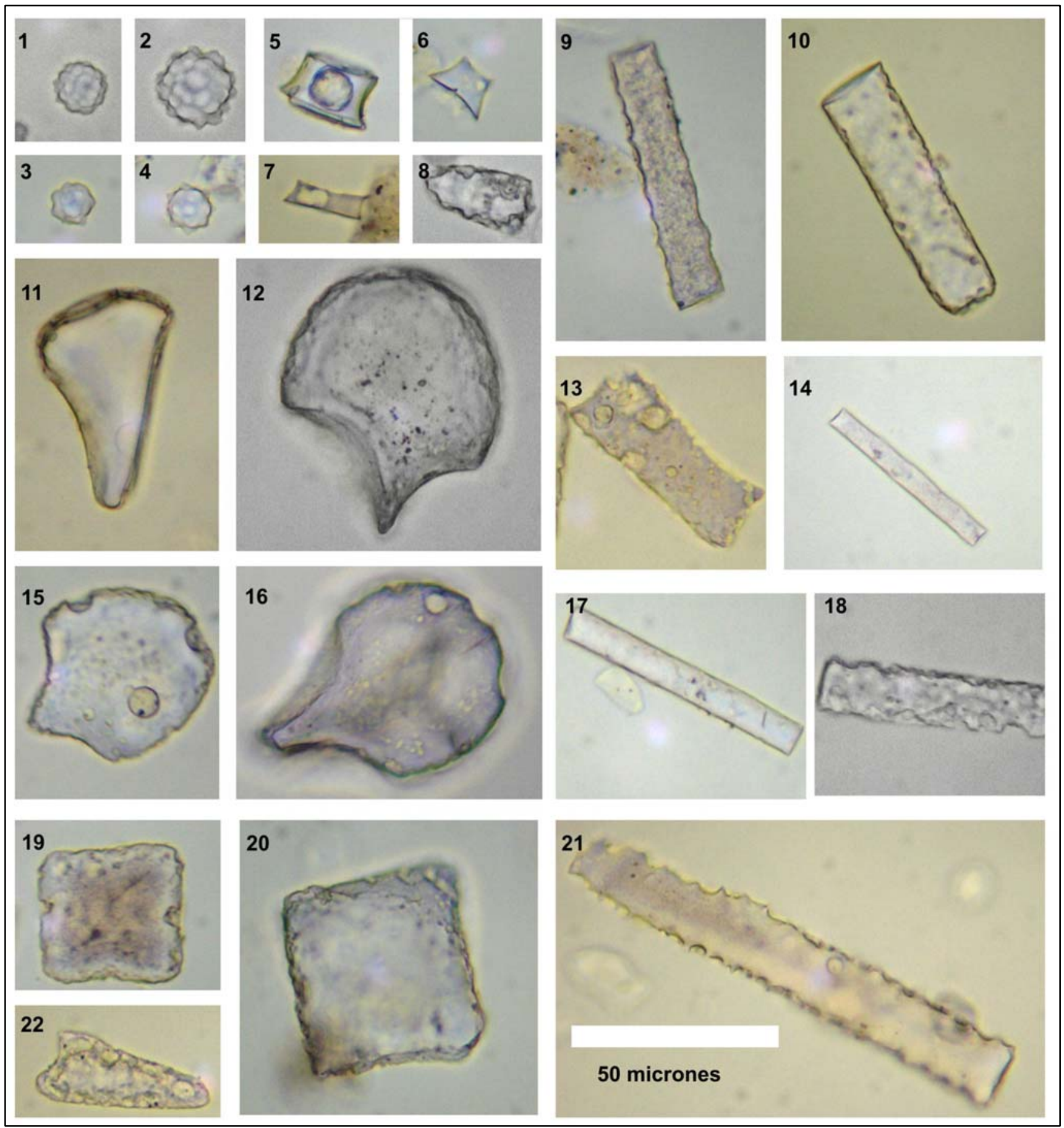

Figura 5.39. Lámina macro y microfitolitos. Escala gráfica en $21=50$ micrones (válida para todas las imágenes). 1-4: Fitolitos esféricos espinosos, Globulolithum sphaeroequinulathum. 5-7: Fitolitos provenientes de células cortas en forma de conos truncados, Estrobilolita ("rondel"). 8,22: Fitolitos originados a partir de aguijones, Aculeolithum. 9,10,13-18,21: Fitolitos prismáticos elongados Euprismatolita elongata. 11-12, 15-16: Fitolitos originados en células bulliformes en forma de abanico, Flabelolithum. 19,20: Fitolitos poliédricos. 


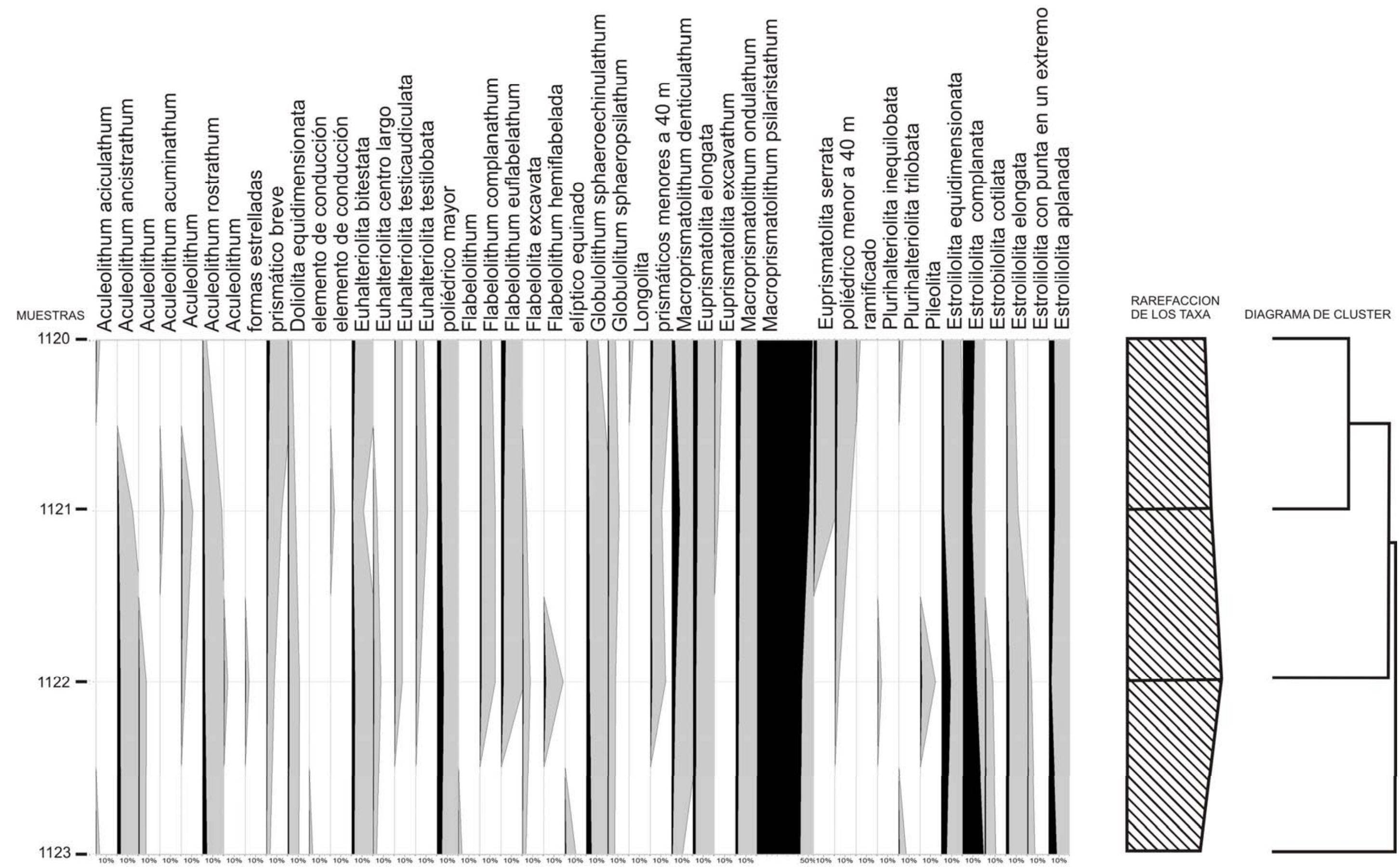

Figura 5.40. Diagrama fitolítico del perfil Rincón del Doll, en donde se detalla

las características composicionales de las muestras, la abundancia de los morfotipos, la rarefacción de los taxa presentes en cada muestra y el análisis de cluster realizado con sus abundancias, mediante el método de Constrained single link cluster analysis

(Walanus y Nalepka, 1999a, 1999b, 2002; Nalepka y Walanus, 2003). 


\section{PERFIL ACCESORIO}

\subsection{PERFIL VILLA VALLE MARIA}

\subsubsection{Descripción del perfil}

El perfil muestreado se encuentra en las proximidades de la ciudad de Diamante, en el acceso al balneario de Aldea Valle María con ubicación $S 32^{\circ}$ 00 '35,2" - O $60^{\circ} 38^{\prime} 14,9 "$ (figuras 4.1. y 4.2.). Se trata de unidad de importancia local (González et al., 2008), generada por el retrabajo eólico del material que compone la Formación Tezanos Pinto, posteriormente depositada en una depresión de un paleopaisaje labrado en la Formación Alvear. Esta unidad (figura 5.41.) posee $2 \mathrm{~m}$ de potencia, se encuentra por debajo del suelo actual (de 0,40 m. de espesor) y por encima, en discordancia erosiva, de la Formación Alvear, con 2,80 m de espesor aflorante. Se tomaron muestras para estudios fitolíticos en dicha formación, que corresponde a un retrabajo de la Formación Tezanos Pinto (conteniendo además una importante cantidad de malacofauna (González et al., 2008). Se tomaron 11 muestras, con una equidistancia de $15 \mathrm{~cm}$, y número de ingreso al laboratorio, 371, 372, 373, 374, $375,376,377,378,379,380,381$.
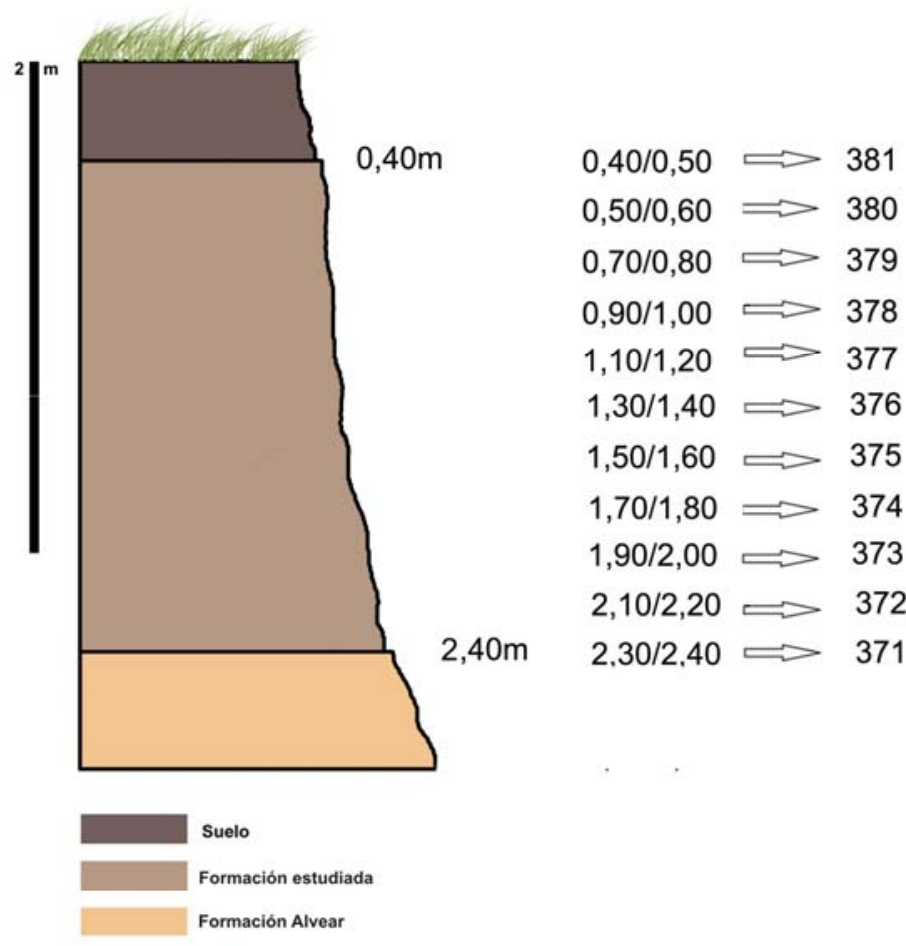

Figura 5.41. Esquema del perfil Villa Valle María indicando la procedencia de las muestras. 
5.10.2. Caracterización fitolítica de las muestras (las descripciones en extenso se presentan en el Apéndice)

\section{Muestra 371}

Se presentaron de manera muy frecuente (>20,91\%) los prismáticos rectangulares (Macroprismatolithum). Los fitolitos esféricos (Globulolithum) fueron frecuentes $(10,45-20,91 \%)$. Los pelos, ganchos y aguijones (Aculeolithum), los bilobados (Halteriolita), los estróbilos (fitolitos en cono truncado) (Estrobilolita), los poliédricos, Nasoprismatolithum y aquellos en forma de abanico (Flabelolithum) fueron escasos (3,48-10,45\%). Fueron raros $(0-3,48 \%)$ los prismáticos breves, las cruces Euhalteriolita cruciformata, aquellos en forma de silla de montar (Doliolita), elementos de conducción, Longolita, formas multilobadas, prismáticos rectangulares de tamaño inferior a $40 \mu \mathrm{m}$, los halterios Euhalteriolita tipo Stipa, y los halterios polilobados Plurihalteriolita (figuras 5.43. y 5.42.).

\section{Muestra 372}

Se presentaron de manera muy frecuente $(>28,11 \%)$ los prismáticos rectangulares (Macroprismatolithum). Los fitolitos esféricos (Globulolithum) fueron frecuentes $(14,05-28,11 \%)$. Escasos (4,68-14,05\%) aquellos en forma de abanico (Flabelolithum), los fitolitos en cono truncado (Estrobilolita) y los poliédricos. Fueron raros (0-4,68\%) Aculeolithum, Doliolita, elementos de conducción, Halteriolita, Longolita, formas macroglobosas, prismáticos rectangulares de menores a $40 \mu \mathrm{m}$, formas con protuberancias a modo de mamelón y Pileolita (figuras 5.43. y 5.42.).

\section{Muestra 373}

Se presentaron de manera muy frecuente (>18,74\%) Globulolithum, Estrobilolita, y Macroprismatolithum. Mientras Aculeolithum, prismáticos menores a $40 \mu \mathrm{m}$, y Halteriolita fueron escasos (3,12-9,37\%). Raros $(0-3,12 \%)$ Flabelolithum, Longolita, cuerpos ramificados y los poliédricos (figuras 5.43. y 5.42.). 


\section{Muestra 374}

Se presentaron de manera muy frecuente $(>20,34 \%)$ los fitolitos esféricos (Globulolithum), los fitolitos en cono truncado (Estrobilolita), y los prismáticos rectangulares (Macroprismatolithum). Los pelos, ganchos y aguijones (Aculeolithum) y los bilobados (Halteriolita) fueron escasos (3,39$10,17 \%)$. Raros $(0-3,39 \%)$ los prismáticos menores a $40 \mu \mathrm{m}$, las cruces Euhalteriolita cruciformata, los elementos de conducción, aquellos en forma de abanico (Flabelolithum), Longolita, cuerpos con proyecciones tales como mamelones o papilas, polilobados (Plurihalteriolita) y poliédricos (figuras 5.43. y 5.42.).

\section{Muestra 375}

Se presentaron de manera muy frecuente $(>19,00 \%)$ los fitolitos esféricos (Globulolithum), los estróbilos (fitolitos en cono truncado) (Estrobilolita), y los prismáticos rectangulares (Macroprismatolithum). Los pelos, ganchos y aguijones (Aculeolithum) y los bilobados (Halteriolita) fueron escasos $(3,16-$ $9,50 \%)$. Raros $(0-3,16 \%)$ los prismáticos menores a $40 \mu \mathrm{m}$, las cruces, Euhalteriolita cruciformata, aquellos en forma de silla de montar o saddle (Doliolita), los elementos de conducción, las bulliformes en forma de abanico (Flabelolithum), cuerpos ramificados con mamelón o papila, los polilobados (Plurihalteriolita) y los poliédricos (figuras 5.43. y 5.42.).

\section{Muestra 376}

Se presentaron de manera muy frecuente $(>18,49 \%)$ los prismáticos rectangulares (Macroprismatolithum), los fitolitos esféricos (Globulolithum) y los estróbilos (fitolitos en cono truncado) (Estrobilolita). Fueron frecuentes $(9,24-$ $18,49 \%)$ los bilobados o en forma de halterio (Halteriolita). Raros $(0-3,08 \%)$ los pelos, ganchos y aguijones (Aculeolithum), las cruces Euhalteriolita cruciformata, aquellos en forma de silla de montar o saddle (Doliolita), y en forma de abanico (Flabelolithum), los prismáticos rectangulares de tamaño inferior a $40 \mu \mathrm{m}$, los halterios polilobados Plurihalteriolita, los poliédricos (figuras 5.43. y 5.42.). 


\section{Muestra 377}

Se presentaron de manera muy frecuente $(>18,55 \%)$ los prismáticos rectangulares (Macroprismatolithum), los fitolitos esféricos (Globulolithum) y los estróbilos (fitolitos en cono truncado) (Estrobilolita). Fueron frecuentes $(9,27-$ $18,55 \%)$ los bilobados (Halteriolita). Raros (0-3,09\%) los pelos, ganchos y aguijones (Aculeolithum), las cruces Euhalteriolita cruciformata, aquellos en forma de silla de montar o saddle (Doliolita), y en forma de abanico (Flabelolithum), los elementos de conducción, formas macroglobosas, formas multilobadas, los halterios polilobados Plurihalteriolita y los poliédricos (figuras 5.43. y 5.42.).

\section{Muestra 378}

Se presentaron de manera muy frecuente $(>20,04 \%)$ los prismáticos rectangulares (Macroprismatolithum) y los fitolitos esféricos (Globulolithum). Fueron frecuentes $(10,02-20,04 \%)$ los fitolitos en cono truncado (Estrobilolita). Los pelos, ganchos y aguijones (Aculeolithum) y los bilobados (Halteriolita) fueron escasos $(3,34-10,02 \%)$. Raros $(0-3,34 \%)$ los poliédricos, cuerpos ramificados con mamelón o papila, formas macroglobosas, aquellos en forma de abanico (Flabelolithum), los en forma de silla de montar o saddle (Doliolita), elementos de conducción, y los halterios polilobados Plurihalteriolita (figuras 5.43. y 5.42.).

\section{Muestra 379}

Se presentaron de manera muy frecuente $(>19,45 \%)$ los prismáticos rectangulares (Macroprismatolithum) y los fitolitos esféricos (Globulolithum). Fueron frecuentes $(9,72-19,45 \%)$ los bilobados (Halteriolita) y los estróbilos (fitolitos en cono truncado) (Estrobilolita). Raros (0-3,24\%) los pelos, ganchos y aguijones (Aculeolithum), formas estrelladas, aquellos en forma de silla de montar o saddle (Doliolita), y en forma de abanico (Flabelolithum), los elementos de conducción, prismáticos rectangulares de tamaño inferior a 40 $\mu \mathrm{m}$, los halterios polilobados Plurihalteriolita y los poliédricos (figuras 5.43. y 5.42.). 


\section{Muestra 380}

Se presentaron de manera muy frecuente $(>21,79 \%)$ los prismáticos rectangulares (Macroprismatolithum) y los fitolitos esféricos (Globulolithum). Fueron frecuentes $(10,89-21,79 \%)$ los bilobados o en forma de halterio (Halteriolita) y los estróbilos (fitolitos en cono truncado) (Estrobilolita). Raros (0$3,63 \%$ ) los pelos, ganchos y aguijones (Aculeolithum), aquellos en forma de silla de montar o saddle (Doliolita), y en forma de abanico (Flabelolithum), los elementos de conducción, prismáticos rectangulares de tamaño inferior a 40 $\mu \mathrm{m}$, los halterios polilobados Plurihalteriolita y los poliédricos (figuras 5.43. y 5.42.).

\section{Muestra 381}

Se presentaron de manera muy frecuente $(>21,68 \%)$ los fitolitos esféricos (Globulolithum). Fueron frecuentes (10,84-21,68\%) los prismáticos rectangulares (Macroprismatolithum). Escasos (10,84-3,61\%) los pelos, ganchos y aguijones (Aculeolithum), los bilobados (Halteriolita) y los estróbilos (fitolitos en cono truncado) (Estrobilolita). Raros (0-3,61\%) los prismáticos breves, las cruces Euhalteriolita cruciformata, aquellos en forma de silla de montar o saddle (Doliolita), y en forma de abanico (Flabelolithum), los elementos de conducción, prismáticos rectangulares de tamaño inferior a 40 $\mu \mathrm{m}$, formas macroglobosas, los halterios polilobados Plurihalteriolita y los poliédricos (figuras 5.43. y 5.42.). 

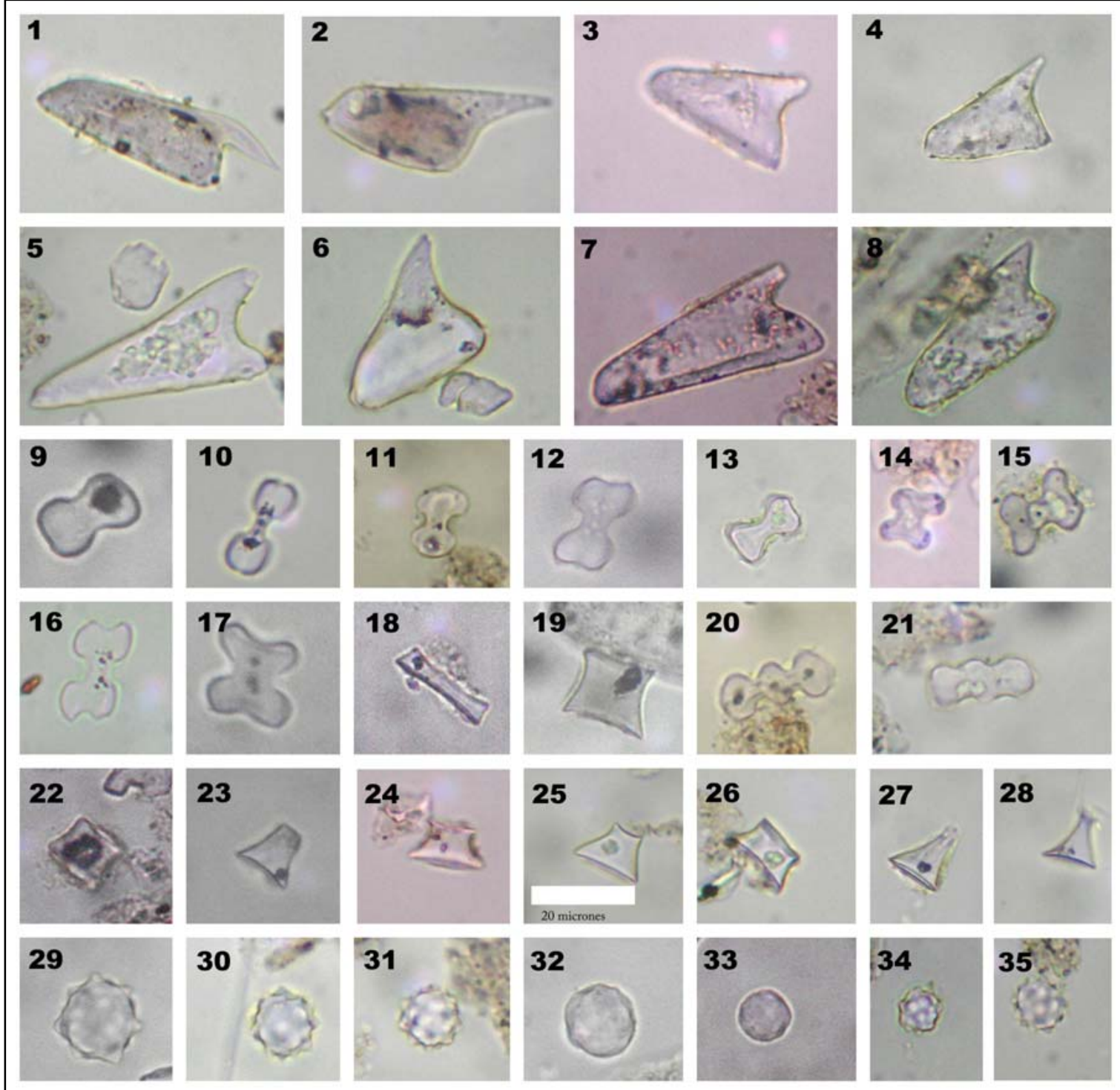

Figura 5.42. Lámina macro y microfitolitos. Escala gráfica en $25=20 \mu \mathrm{m}$ (válida para todas las imágenes). 1-8: Fitolitos originados a partir de aguijones, Aculeolithum. 9-17: Fitolitos bilobados originados en células cortas en forma de pesa de gimnasia, Halteriolita. 18-19, 22-28: Fitolitos provenientes de células cortas en forma de conos truncados, Estrobilolita ("rondel"). 20,21: Fitolitos polilobados regulares, Polilobado trilobado. 29-31,34,35: Fitolitos esféricos espinosos, Globulolithum sphaeroequinulathum. 32,33: Fitolitos esféricos lisos, Globulolithum sphaeropsilathum. 


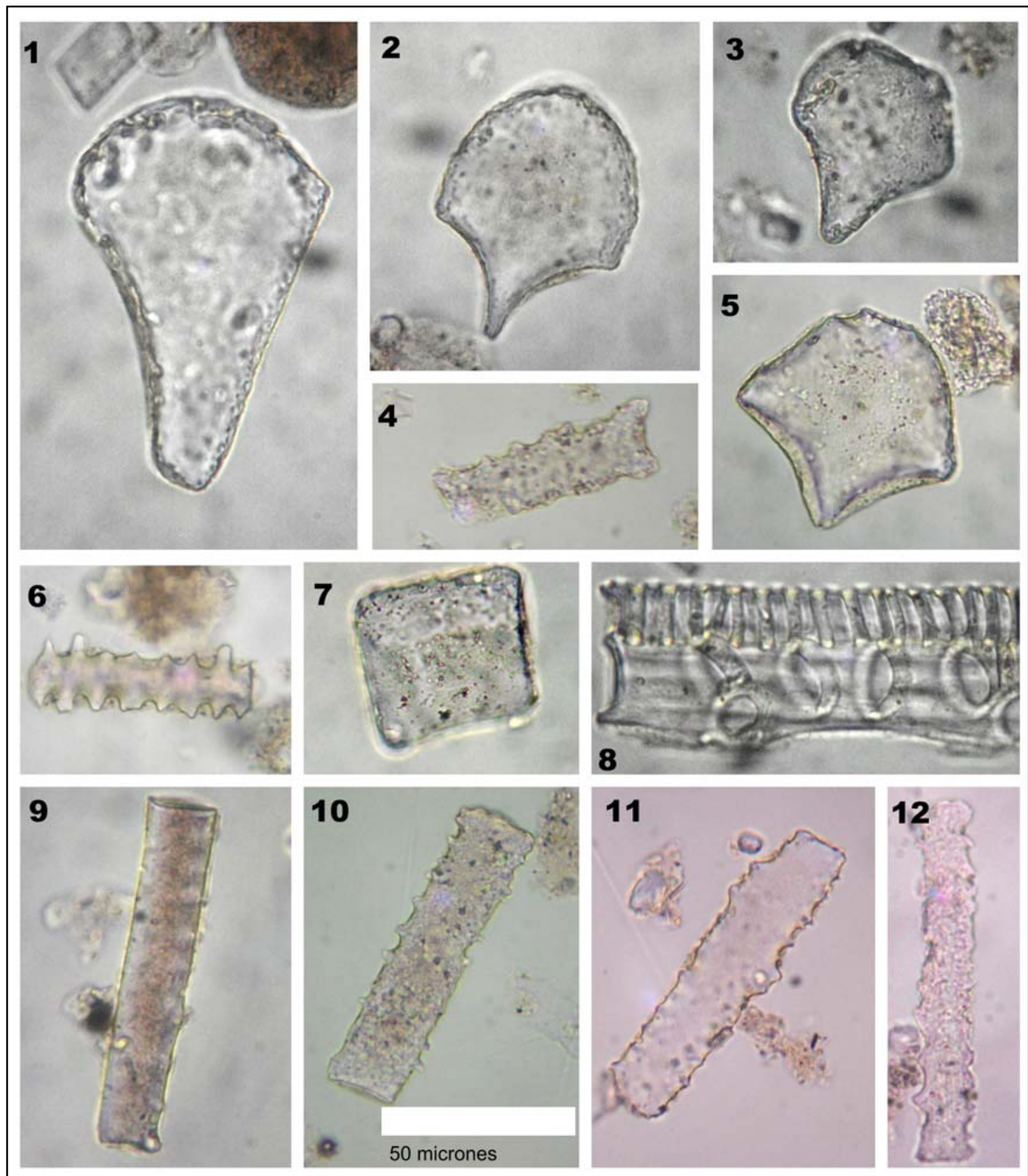

Figura 5.43. Lámina macrofitolitos. Escala gráfica en $10=50 \mu \mathrm{m}$ (válida para todas las imágenes). 1,2,3,5: Fitolitos originados en células bulliformes en forma de abanico, Flabelolithum. 4,6,9-12: Fitolitos prismáticos elongados Macroprismatolithum. 7: Fitolito poliédrico. 8: Fitolito originado en elementos de conducción. 


\section{INTEGRACIÓN DE LOS PERFILES Y ANÁLISIS DE LA INFORMACIÓN}

Teniendo en cuenta que era necesario determinar si las diferencias entre las asociaciones fitolíticas correspondían a cambios ocurridos a través del tiempo o si se relacionaban con variaciones geográficas controladas por el clima u otros factores regionales, se realizó la comparación de las muestras obtenidas en un mismo perfil y con los restantes utilizando técnicas de análisis multivariado. Las dos tecnicas utilizadas: análisis de componentes principales (PCA) y el análisis de agrupamiento se llevaron a cabo con el programa PAST ( ver.1.76; Hammer, Harper y Ryan, 2007). El análisis de componentes principales es un procedimiento que permite encontrar variables hipotéticas nuevas (componentes) que resumen gran parte de la varianza acumulada en las variables usadas como caracteres. Los análisis de agrupamiento permitieron construir fenogramas que agrupan muestras permitiendo visualizar las relaciones entre las asociaciones fitoliticas. En ambos casos, las matrices básicas de datos (MBD) confeccionadas utilizaron como Otus a las muestras (asociaciones fitolíticas) obtenidas en los perfiles y como variables a los porcentajes de morfotipos presentes en cada muestra (datos continuos discretos).

En primera instancia, se realizó la comparación entre las muestras de los perfiles centrales de la transecta que son los de mayores potencia: Diamante Norte y Tezanos Tipo, esperables de ser poseedores de la mayor representatividad paleoflorística, evidenciada por las asociaciones fitolíticas presentes en ellos. Además, cabe recordar la importancia del perfil Tezanos Tipo, ya que es el perfil Tipo, donde se define la formación de estudio (Formación Tezanos Pinto) para la provincia de Entre Ríos.

Como se ve en las figuras 6.1. y 6.2., en el perfil Tezanos Tipo (TT) las muestras que aparecen en prácticamente la totalidad de la secuencia sedimentaria se correlacionan con muestras que aparecen solo en el tope y en la base del Diamante Norte (DN), excluyendo a las muestras agrupadas en el sector medio de la columna, o sea, sin equivalentes en el perfil Tezanos Tipo. Así, TT presenta asociaciones fitolíticas compuestas por Estrobilolita, de manera muy frecuente, Halteriolita de manera frecuente, Doliolita, Globulolithum, y Macroprismatolithum de manera escasa, y de manera rara 
Aculeolithum, Flabelolithum, Euhalteriolita tipo Stipa, cruces, Longolita, prismáticos rectangulares de tamaño inferior a $40 \mu \mathrm{m}$, Plurhalteriolita y poliédricos (figuras 5.35. y 5.36.). Las muestras del sector medio del perfil Diamante Norte estarían conformadas de manera muy frecuente tanto por Estrobilolita como de Macroprismatolithum, de manera frecuente por Globulolithum, escasa por Aculeolithum, Halteriolita, Euhalteriolita tipo Stipa, y rara por Doliolita, Flabelolithum, Longolita, Plurihalteriolita, Pileolita y poliédricos (figuras 5.15. y 5.16.). Al no poder definir una estrecha correlación entre estos dos perfiles, en segunda instancia, se sumaron otros dos perfiles, de distintos espesores como son el Protestante y el Gauchito Gil (figuras 6.3., 6.4. y 6.10.).

Al analizarlos en conjunto, se observó una tendencia a complementarse con los perfiles anteriormente examinados (TT y DN), en sectores acotados de la columna (figuras 6.3., 6.4. y 6.10.). Por ejemplo, muestras que aparecen hacia el tope del perfil Gauchito Gil, se corresponden con sus pares ubicadas tanto en el tope como en el sector medio de la columna del perfil Diamante Norte, pero no presentan vinculación alguna con los perfiles Protestante ni Tezanos Tipo. Sin embargo el perfil Protestante guarda estrecha relación con el Diamante Norte, ya que toda su columna está vinculada con sectores limitados del tope, medio, y base de este último (figura 6.4.).

Del mismo modo se sumaron además, los perfiles ubicados en los sectores periféricos de la transecta, La Juanita (extremo NO), y Vial Mat (extremo SE). De esta forma, y con todos los perfiles evaluados en el mismo análisis comprensivo, se pudo observar la tendencia a la complementación de las asociaciones, de manera gradual en dirección NO-SE (figura 6.4.).

Por lo tanto con los datos obtenidos de las muestras estudiadas no se pudo lograr una diferenciación que permita zonificar toda el área estudiada. Sin embargo lo que sí se evidencia claramente es una diferenciación geográfica marcada en cuanto a la composición fitolítica entre los perfiles del área NO de la transecta respecto de aquellos ubicados al SE de la misma (figuras 6.3. y 6.9.).

A pesar de que los espesores sedimentarios de la Formación Tezanos Pinto disminuyen en sentido NO-SE, las secciones del SE no tendrían que ser 
necesariamente secuencias parciales de aquellas presentes al NO, sino que podría tratarse de asociaciones diferentes, debidas, quizás, a la variación geográfica, o que conjuntamente completarían la columna total integrada.

Las secciones sedimentarias correspondientes a los perfiles Vial Mat y La Juanita (ubicados en los extremos de la transecta estudiada) (figura 6.9.) pudieron haber actuado como sectores de depositación durante más tiempo, aunque acumulando menores cantidades de sedimento. Estas diferencias composicionales podrían corresponderse con variaciones paleoclimáticas 0 paleocológicas muy locales, que merecerían un extenso estudios que excede el presente trabajo de Tesis.

Los resultados obtenidos resaltan la potencialidad de la metodología empleada y abre la posibilidad de continuar con la investigación, no sólo dentro de esta especialidad, sino también de otras disciplinas. Así, un análisis más detallado, por ejemplo microsedimentario local en cada perfil, podría asistir a un entendimiento más acabado de los causales de estas variaciones geográficas que no han sido, hasta el momento, comprensivamente interpretadas. 
Asociación
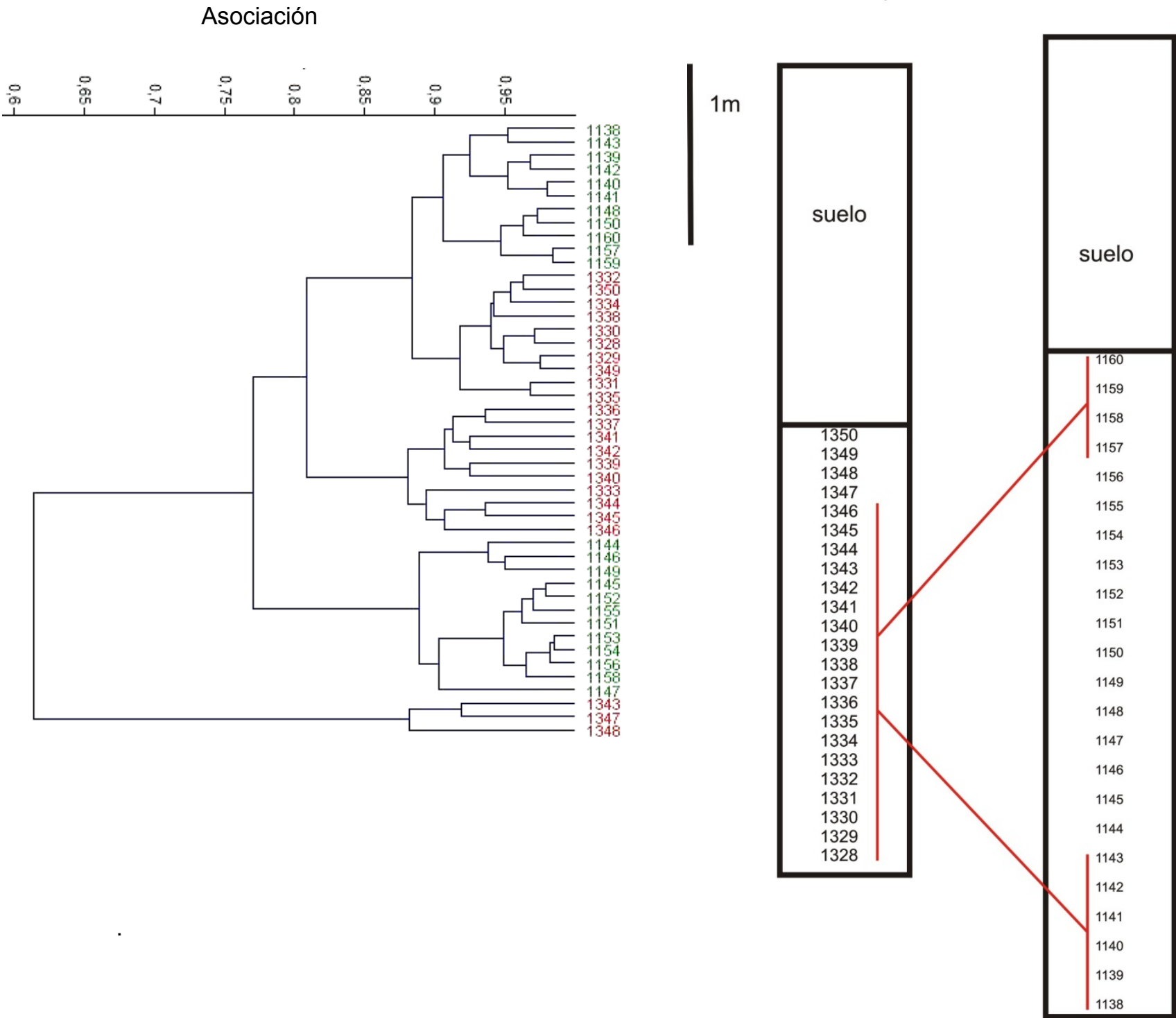

Figura 6.1. Dendrograma mostrando la asociación entre las muestras de los perfiles Tezanos Tipo y Diamante Norte y esquema donde se representa esta asociación en la columna de los perfiles. El índice utilizado para medir el grado de asociación entre las muestras fue el de Moristia. 


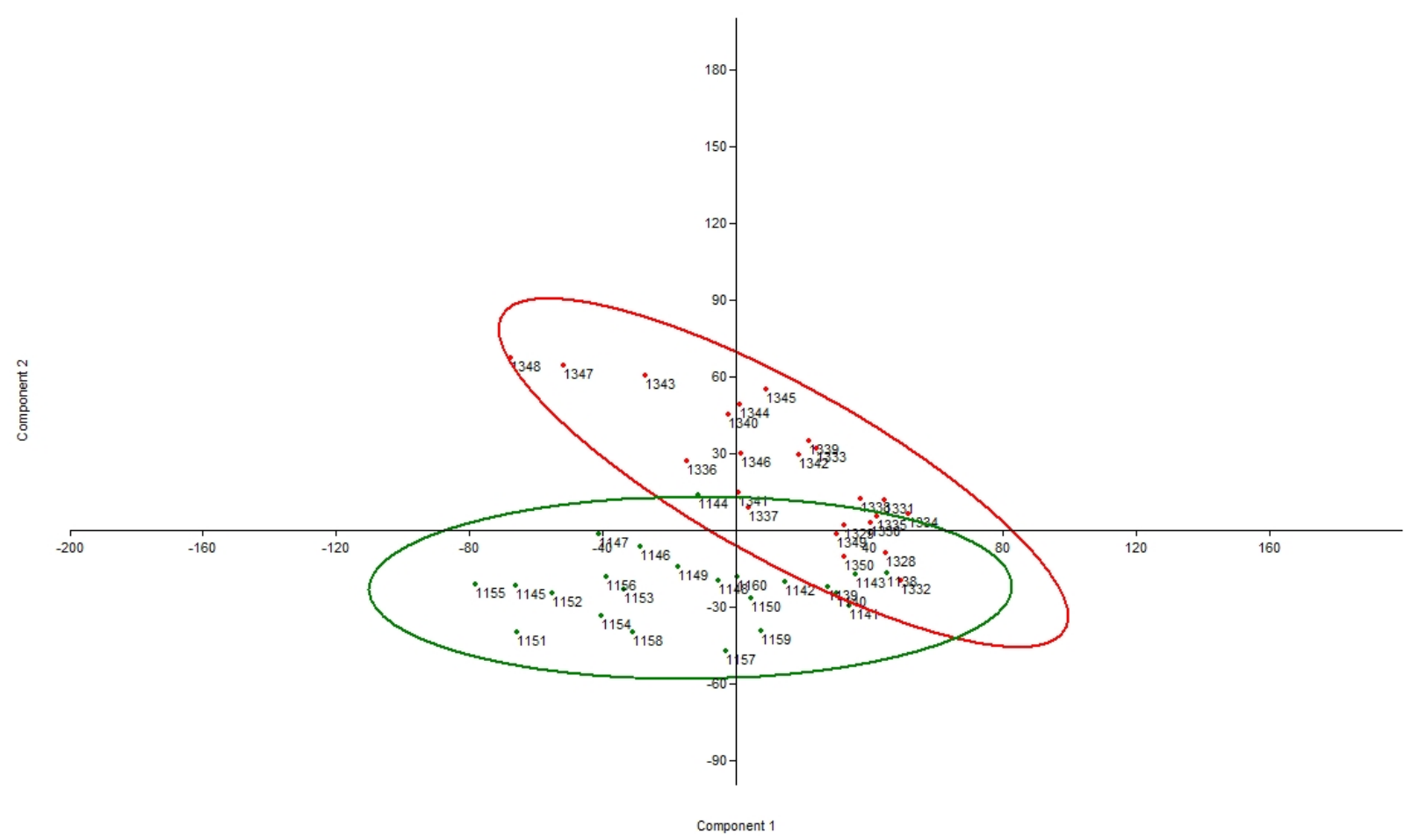

Figura 6.2. Análisis de componentes principales de las muestras de los perfiles Tezanos Tipo y Diamante Norte. 
Tezanos Tipo Protestante Diamante Norte Gauchito Gil

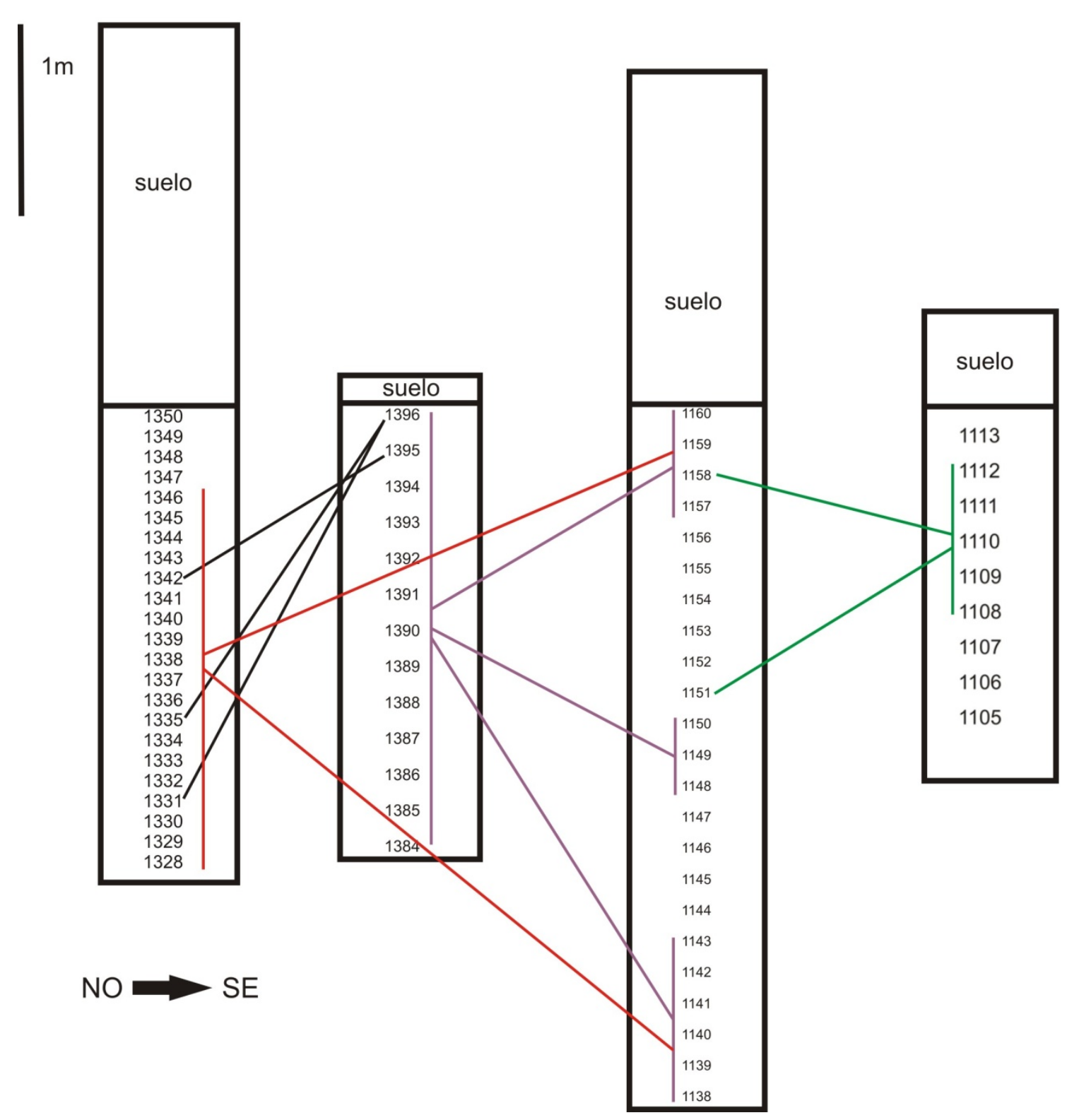

Figura 6.3. Representación esquemática de la vinculación entre las muestras en los perfiles, Gauchito Gil, Protestante, Tezanos Tipo y Diamante Norte. 


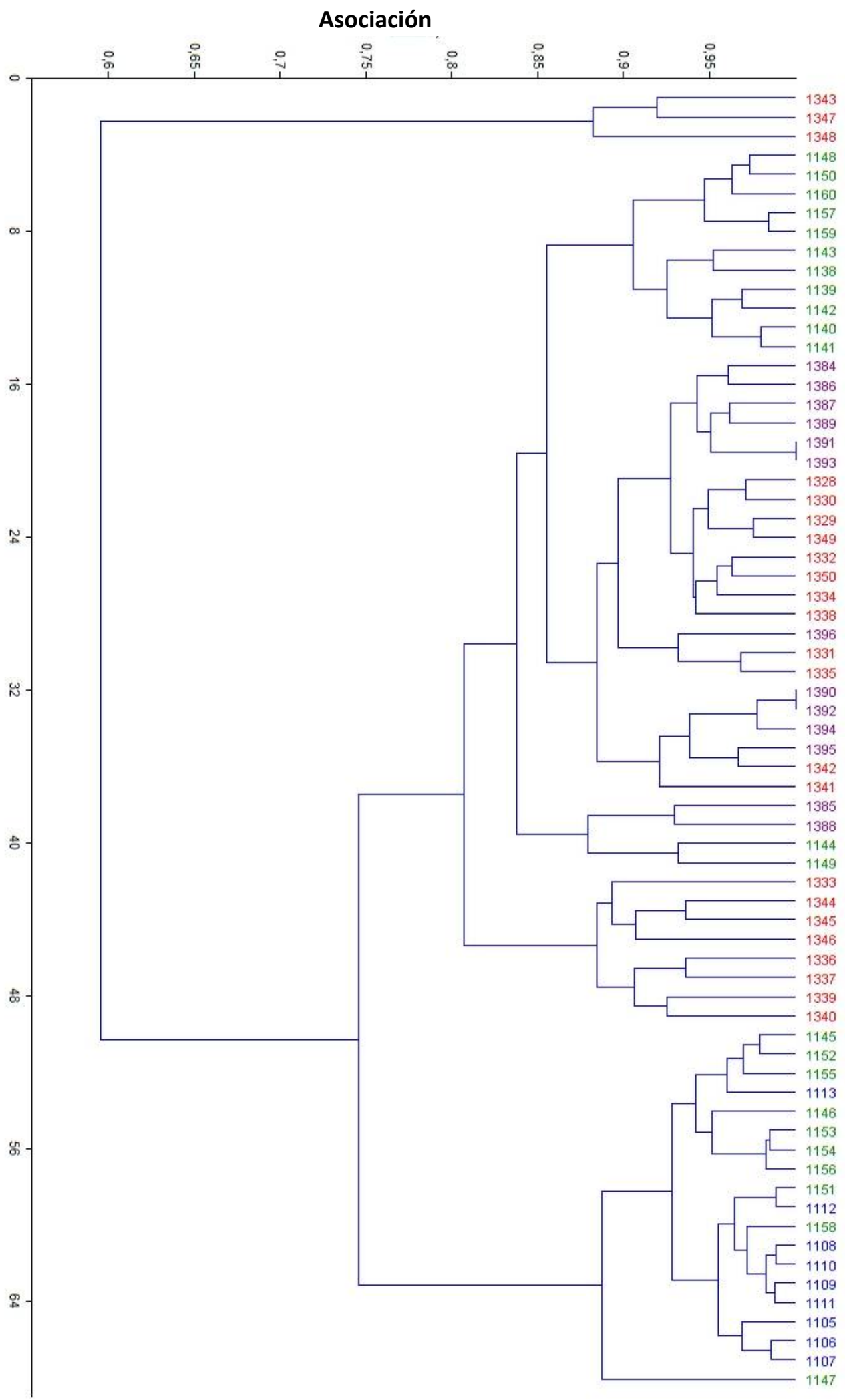

Figura 6.4. Dendrograma mostrando la asociación entre las muestras de los perfiles Tezanos Tipo, Gauchito Gil, Diamante Norte y Protestante. El índice utilizado para medir el grado de asociación entre las muestras fue el de Moristia. 


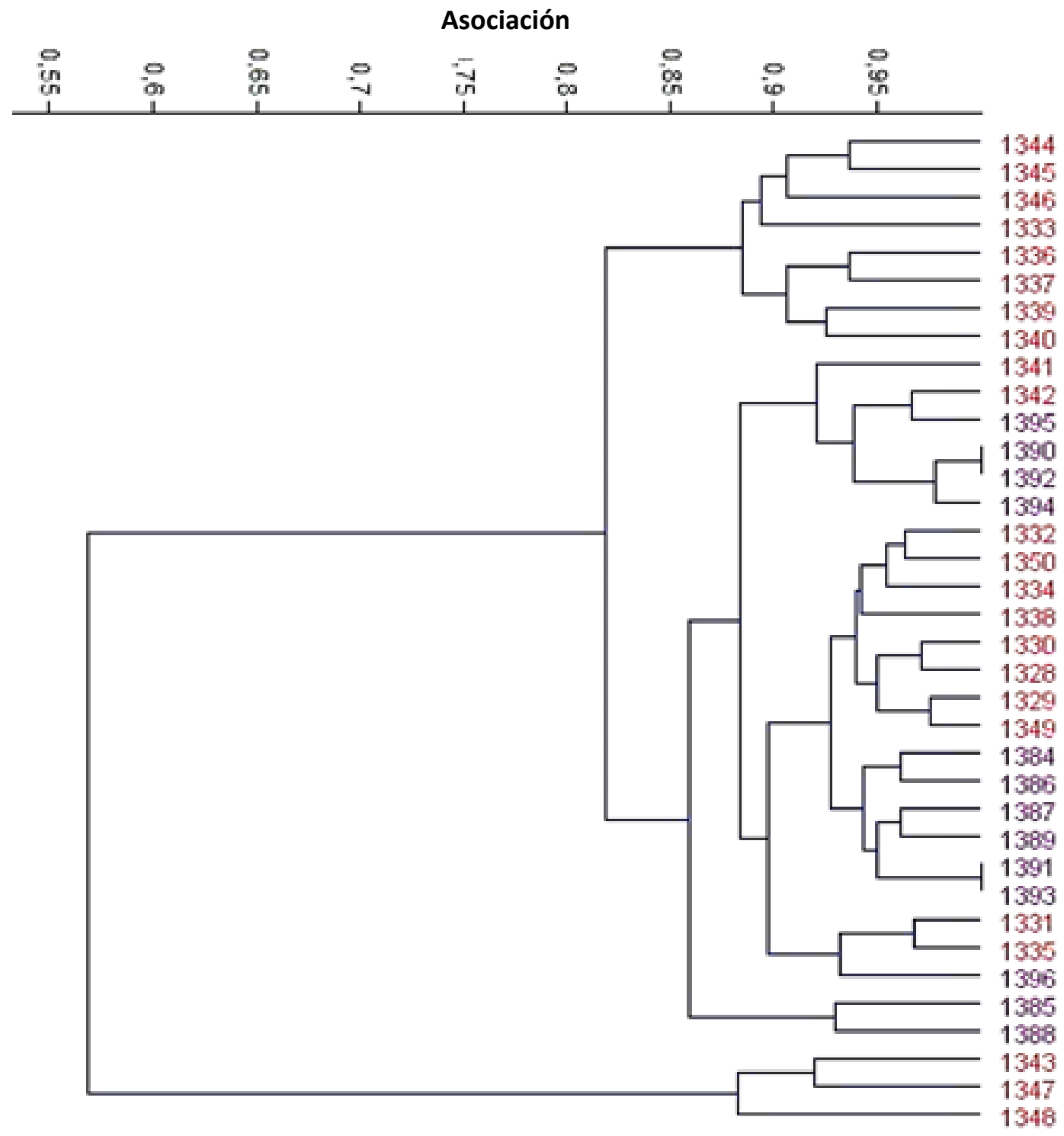

Figura 6.5. Dendrograma mostrando la asociación entre las muestras de los perfiles Tipo y Protestante (índice Moristia). 


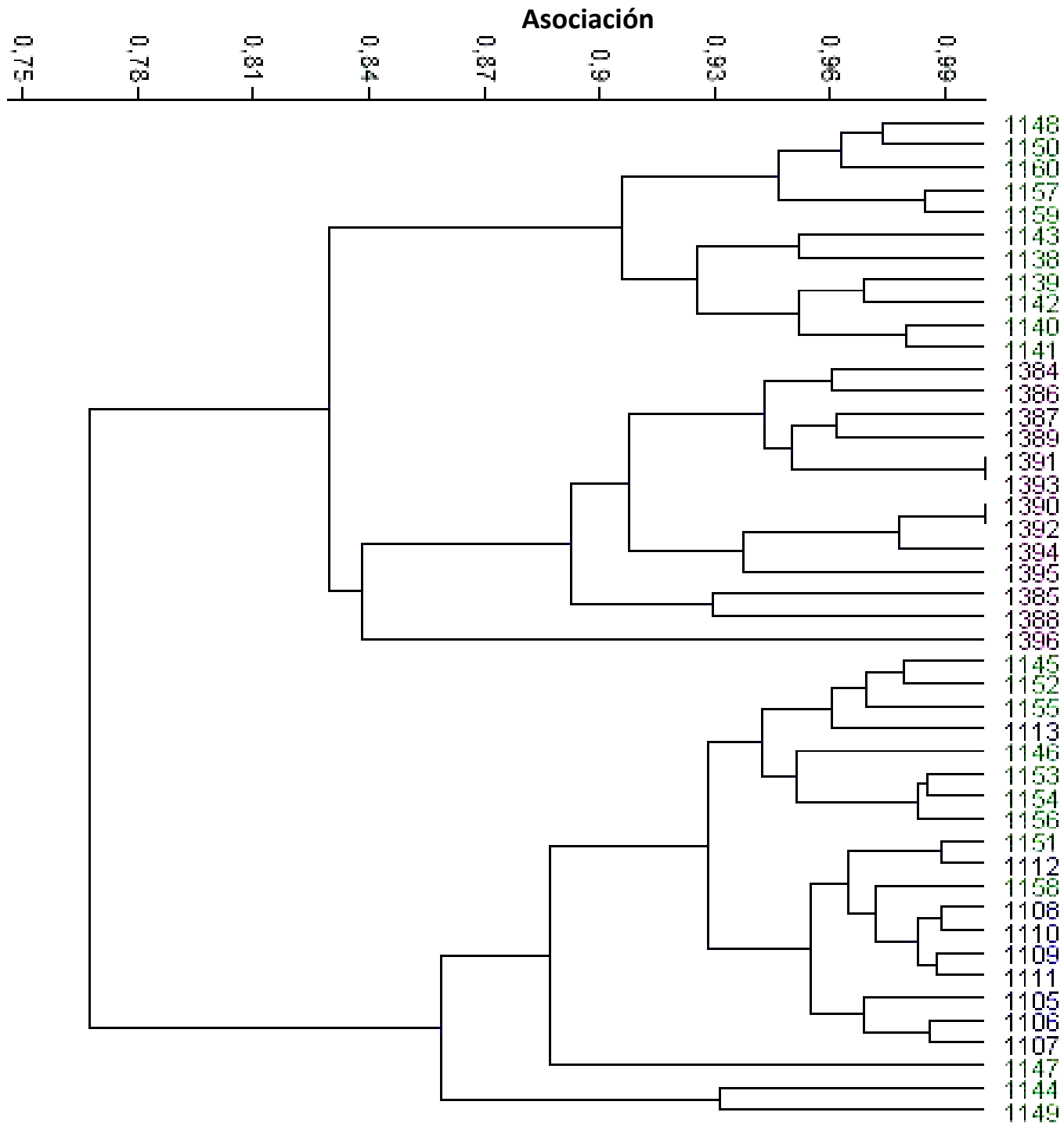

Figura 6. 6. Dendrograma mostrando la asociación entre las muestras de los perfiles Diamante Norte, Protestante y Gauchito Gil. (índice Moristia) 


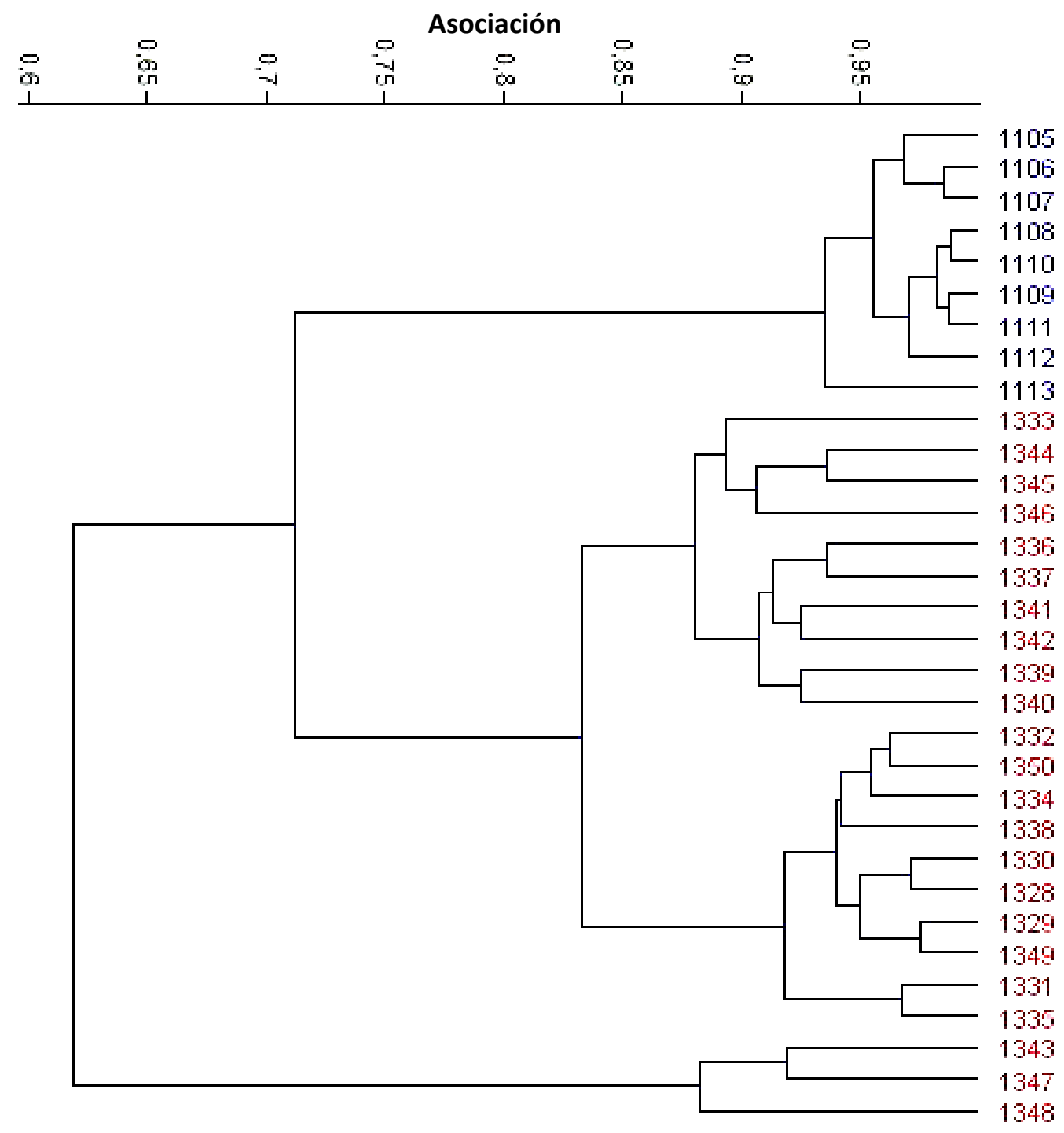

Figura 6.7. Dendrograma mostrando la asociación entre las muestras de los perfiles Tipo y Gauchito Gil. El índice utilizado para medir el grado de asociación entre las muestras fue el de Moristia. 

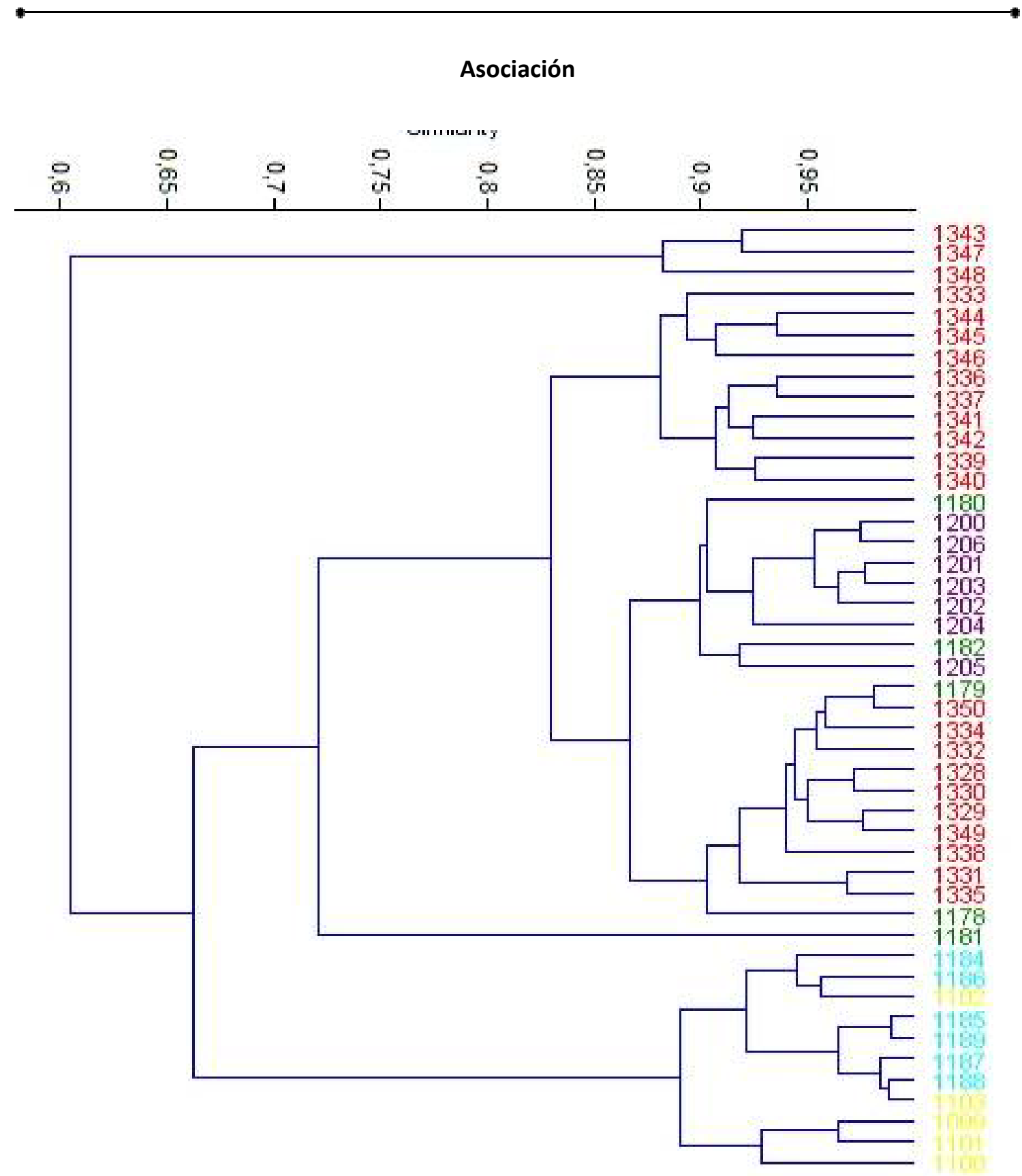

Figura 6.8. Cluster cruzando muestras de los perfiles Tipo, Vial Mat, La Juanita, Las Cuevas, y Alvear. El índice utilizado para medir el grado de asociación entre las muestras fue el de Moristia. 
La Juanita

Tezanos Tipo

Protestante

Diamante Norte

Gauchito Gil

Vial Mat

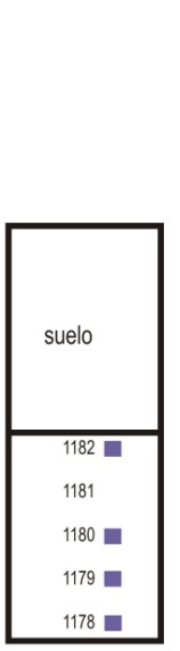

\begin{tabular}{|l|}
\hline \\
suelo \\
\\
\\
\hline 1103 \\
1102 \\
1101 \\
1100 \\
1099 \\
\hline
\end{tabular}

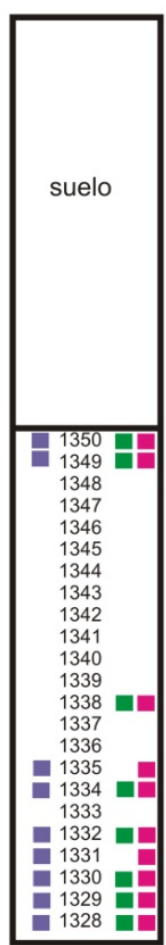

\begin{tabular}{|c|}
\hline suelo \\
\hline 1396 \\
1395 \\
1394 \\
$\mathbf{\square} 1393$ \\
1392 \\
$\square 1391$ \\
1390 \\
$\mathbf{\square} 1389$ \\
1388 \\
$\mathbf{\square} 1387$ \\
$\mathbf{\square} 1386$ \\
1385 \\
1384 \\
\hline
\end{tabular}

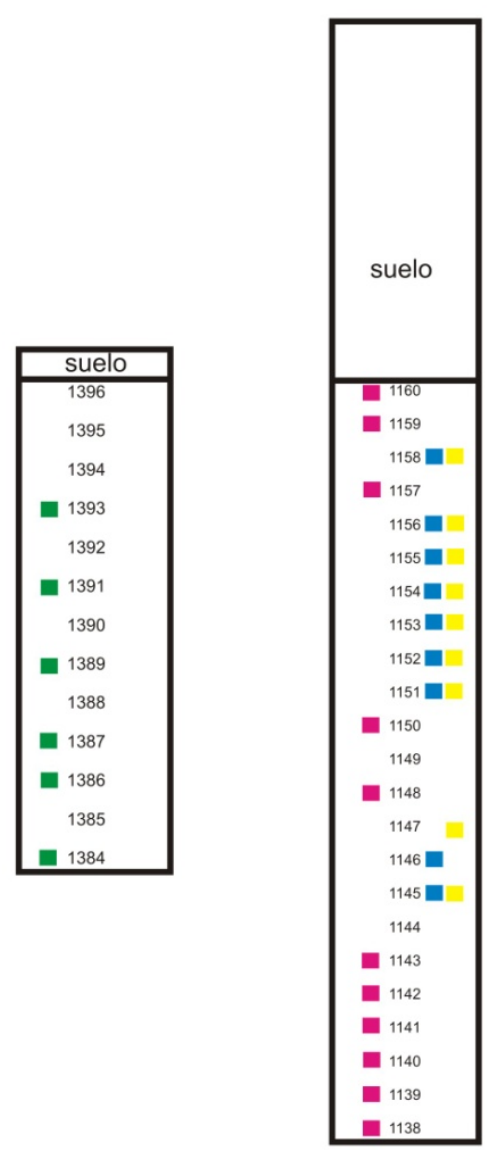

$\mathrm{NO}$

SE

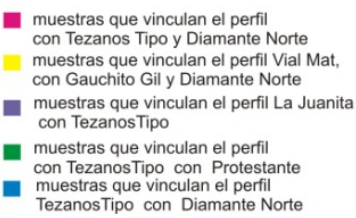

Figura 6.9. Representación esquemática de la vinculación entre las muestras en los perfiles, Gauchito Gil, Protestante, Tezanos Tipo y Diamante Norte. 


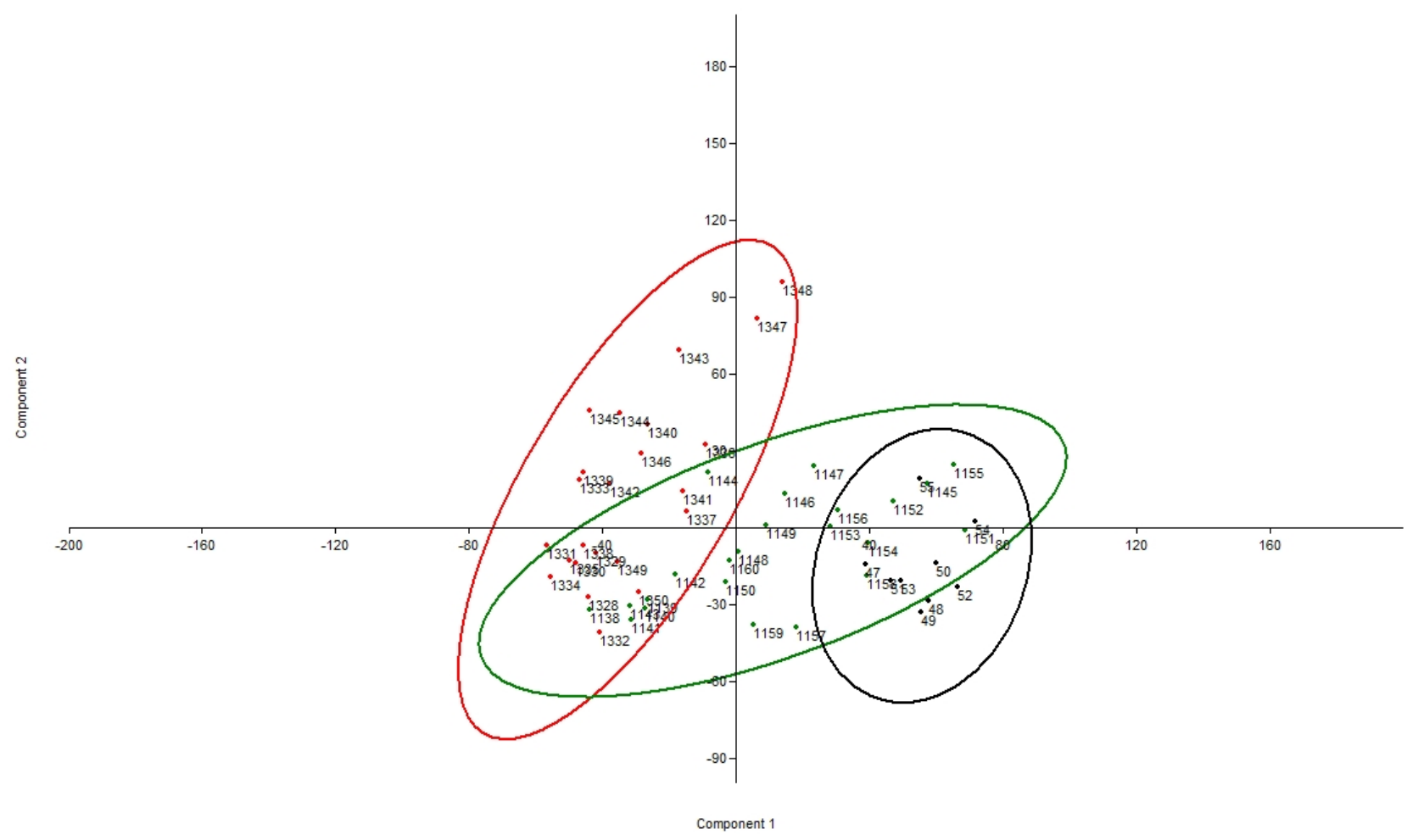

Figura 6.10. Análisis de componentes principales de las muestras de los perfiles Tezanos Tipo, Gauchito Gil y Diamante Norte. 


\section{Problemas planteados que se discutieron en los capítulos anteriores}

\section{-Origen del loess}

El modelo sobre el origen del sistema morfosedimentario desarrollado en la llanura pampeana durante el Ultimo Máximo Glacial (UMG), que se adopto en este trabajo de tesis, fue el propuesto por Iriondo y Kröhling $(1995,2007)$ basado en estudios geomorfológicos, granulométricos y mineralógicos. La discusión se encuentra desarrollada en el apartado correspondiente a "Antecedentes geológicos".

\section{-Tratamiento metodológico de los fitolitos}

La aproximación metodológica utilizada fue el de la asociación fitolítica. Donde cada taxón está representado por un conjunto de morfotipos fitolíticos que lo caracterizan y por la frecuencia relativa que cada uno de ellos presentó. Es decir, no se trabajó con una sola forma, sino con el conjunto de morfotipos.

La discusión se encuentra desarrollada en el apartado correspondiente a "Materiales y métodos".

\section{-Problema nomenclatural}

Ante la ausencia de pautas clasificatorias para una sistemática de fitolitos que permita un preciso tratamiento y delimitación de las categorías, en un sistema universal, en este trabajo se adoptó el criterio clasificatorio propuesto por Zucol y Brea (2005) con los aportes de otros autores, como se esquematiza en la tabla 4.2. de la página 62. La necesidad de una sistemática de fitolitos, que permita su claro tratamiento y denominación, sigue siendo de urgente debate.

La discusión se encuentra desarrollada en el apartado correspondiente a "Materiales y métodos". 


\subsection{CONSIDERACIONES FINALES}

\subsubsection{En lo referente a la cuestión paleoambiental}

En la literatura geológica, los depósitos de origen eólico del Pleistoceno y Holoceno, que se extienden en gran parte de la región pampeana de la Argentina, fueron considerados como depositados bajo "condiciones correspondientes a ambientes áridos o semiáridos" (Tonni y Fidalgo 1978, Fidalgo y Tonni, 1981, Iriondo 1995, 1999). Según Iriondo (1987) las Ilanuras de loess, están originadas por la acumulación de polvo transportado en suspensión por el viento y sedimentado en forma de manto en "regiones peridesérticas de clima semiárido".

Por otro lado, relacionando estos conceptos netamente geológicos, con aquellos de tipo ambiental, Tsoar y Pye (1987) consideran que las áreas de acumulación de loess se dan donde las suspensiones eólicas de corto término pueden ser atrapadas por irregularidades topogáficas, superficies húmedas y superficies vegetadas. Embleton y King (1968), y Tsoar y Pye (1987) indicaron que "las áreas vegetadas son las trampas más adecuadas para los depósitos de envergadura desarrollados en las márgenes de los desiertos y regiones glaciales". A su vez, Spalletti (1992) plantea que "las regiones de sabana, estepa y pradera parecen ser sitios más que apropiados para la generación de los depósitos loéssicos".

Iriondo y García (1993), Kröhling e Iriondo (1999), Iriondo (1999), Tonni et al. (1999), y Cione y Tonni (2001) coinciden en afirmar la ocurrencia de un aumento de condiciones áridas, semiáridas y frías desde la parte más superior del Sanandresense (Plioceno Tardío- Pleistoceno Temprano) hasta el Lujanense tardío (Pleistoceno Tardío), resultando en ambientes caracterizados por el desarrollo de espacios abiertos con pastizales (Prado et al., 1987; Deschamps y Tonni, 1992). Esta situación es avalada a partir del estudio de los mamíferos del Pleistoceno, ya que indican que las condiciones ambientales debieron ser para la región pampeana, "más frías y áridas o semiáridas, con un marcado predominio de ambientes abiertos" (Carlini et al. 2003). A pesar de que a lo largo del Pleistoceno en la región pampeana predominaban las condiciones áridas y semiáridas y frías, existieron intervalos mucho más breves de condiciones húmedas y cálidas. Por lo que no todo el pleistoceno fue 
progresivamente más árido y frío sino que alternó con condiciones interglaciales.

Por su parte, Ferrero (2009), observó que la fauna recuperada de la Formación Tezanos Pinto puede asociarse con la fauna Lujanense propiamente dicha de la provincia de Buenos Aires, que se desarrolló fundamentalmente durante el EIO 2. Ferrero identificó una marcada sucesión faunística, expresada por un cambio en la composición de taxones de mamíferos desde el Lujanense temprano (base del Pleistoceno superior) al Lujanense tardío (Pleistoceno más Tardío-Holoceno más Temprano). Este cambio presentó tres rasgos fundamentales (observados en el Lujanense tardío): la desaparición de taxones tropicales-subtropicales, la aparición de taxones vinculados a condiciones climáticas más frías y áridas y el incremento de megamamíferos pastadores. La misma autora reconoce para la Formación Tezanos Pinto los primeros registros de especies "que habitan biomas abiertos" y "están adaptadas a condiciones climáticas frías y secas" como lo son por ejemplo Dusicyon gymnocercus y Lama guanicoe (Ferrero, 2009)

\subsubsection{En lo referente a la asignación sistemática y a la comunidad representada por la asociación fitolítica}

Los análisis paleopalinológicos son ampliamente utilizados para hacer la reconstrucción de comunidades vegetales e inferir paleoambientes desarrollados en distintas regiones del mundo. Sin embargo cuando se intenta interpretar los paleopastizales los análisis paleopalinológicos presentan ciertas limitaciones ya que estas comunidades están dominadas por especies de la familia Poaceae. Esta familia constituye un grupo estenopolínico (no existe variación en los granos de polen por debajo de la categoría de familia, por lo que no se puede diferenciar entre subfamilia y géneros a través de su estudio). Es así, que los análisis fitolíticos toman importancia y constituyen una herramienta de creciente aplicación en el mundo que permite abordar de manera satisfactoria, y más precisa, el estudio de los paleopastizales.

La familia Poaceae es uno de los grupos con mayor abundancia y diversidad en la producción de fitolitos, los que permiten una clara identificación de la familia y sus subfamilias, y por lo tanto, las comunidades vegetales que 
ellos representan (Twiss et al., 1969; Rovner, 1971; Bertoldi de Pomar, 1975; Piperno, 1988; Fredlund y Tieszen, 1994, 1997; Alexandre et al., 1997; Barboni et al., 1999; Osterrieth, 2000; Strömberg, 2004; Thorn, 2004a; Bremond et al., 2005; Lu et al., 2006).

Burkart (1975), dividió los ecosistemas de América del Sur dominados por gramíneas en tres grandes grupos o "dominios de pastizales": el de los vegetales microtérrmicos, el de los mesotérmicos, y el de los megatérmicos. Teniendo en cuenta la influencia de la temperatura en su desarrollo y los requerimientos hídricos de cada una. Define a los pastizales microtérmicos como aquellos compuestos principalmente por vegetales $C_{3}$, que se desarrollan en comunidades herbáceas de regiones templadas a templado-frías de elevadas latitudes y altitudes; a los mesotérmicos como los conformados por especies $\mathrm{C}_{3}$ y $\mathrm{C}_{4}$, y que habitan principalmente regiones templado-cálidas que en muchos casos se encuentran caracterizadas por una marcada aridez, y finalmente a los megatérmicos, como los que están formados predominantemente por especies $\mathrm{C}_{4}$, siendo ellos los pastizales y sabanas de regiones cálidas tropicales (Zucol y Brea, 2005).

Los fitolitos presentan formas generalmente regulares, ya que copian la forma de caja de la célula que le dio origen. Dentro de los diferentes grupos vegetales, hay formas, que según los diferentes autores, son características de determinados grupos taxonómicos. En este análisis, las formas encontradas fueron: las cruces, los bilobulados, y los polilobados, que son morfotipos encontrados predominantemente en la subfamilia Panicoideae (Twiss et al., 1969; Mulholland, 1989; Fredlund y Tieszen, 1994; Kondo et al., 1994), representando gramíneas $\mathrm{C}_{4}$, adaptadas a climas cálidos y húmedos, con alta disponibilidad de agua en el suelo (Teeri y Stowe, 1976; Tieszen et al., 1979; Cabido et al., 1997; Scott, 2002); sin embargo, algunas especies de gramíneas Panicoideae son $\mathrm{C}_{3}$. El tipo saddle (Doliolita) es producido en alta proporción por especies de la subfamilia Chloridoideae (Twiss et al., 1969; Mulholland, 1989; Fredlund y Tieszen, 1994; Kondo et al., 1994), y representan gramíneas $\mathrm{C}_{4}$ adaptadas a condiciones de climas cálidos y secos, con suelos secos (Tieszen et al., 1979; Livingstone y Clayton, 1980). El tipo cónico o rondel (Estrobilolita) es producido principalmente por la subfamilia Pooideae, (Twiss et al., 1969), integrado por gramíneas $C_{3}$, que son abundantes en zonas 
templado-frías o de altas elevaciones (Tieszen et al., 1979; Livingstone y Clayton, 1980; Tieszen et al., 1997; Scott, 2002; Winslow et al., 2003). Los provenientes de pelos, espinas y ganchos (Aculeolithum), de células bulliformes (Flabelolithum), y de células largas (Macroprismatolithum), son todos tipos celulares de origen epidérmico de gramíneas sin capacidad diagnóstica para diferenciar subfamilias o rutas metabólicas del proceso fotosintético. Otros fitolitos hallados en el sedimento pero producidos por taxones no graminoides fueron los esféricos equinados, provenientes de la familia Aracaceae (Kondo et al., 1994; Runge, 1999, Runge y Fimbel, 1999; Vrydaghs y Dourelepont, 2000, Zucol) (en Bremond et al., 2005).

\subsubsection{En lo referente a los perfiles accesorios}

Durante el Holoceno Tardío en la llanura chaco-pampeana de la Argentina y regiones periféricas se estableció un clima semiárido (Iriondo, 1990). Basado en las dataciones radiocarbónicas existentes en ese momento, Iriondo (1990), concluye que el "...dry climate event occurred between 3500 and 1000 years B.P". En trabajos posteriores (Iriondo, 1993; 1999), acota este período seco entre 3500 y 1400 años BP, siguiendo a Servant (1981). La Formación San Guillermo, con la que "...en general culmina la secuencia sedimentaria de la región" (Iriondo y Kröhling, 1996) es una unidad de origen eólico compuesta por "...limo grueso con escasas proporciones de arena muy fina y arcilla...gris pardusco (10YR5/1)".

Considerando un fechado radiocarbónico Tonni et al. (2001) asignan los $0,20 \mathrm{mts}$ superiores del perfil aflorante en el acceso al camping de Aldea Valle María (en el área de estudio de este trabajo) como pertenecientes a la Formación San Guillermo y postulan, en consecuencia, la extensión del período árido del Holoceno Tardío propuesto por Iriondo (1980) hasta por lo menos el lapso 950 a 1.200 A.D. para el sudoeste de Entre Ríos. Por otra parte, González et al. (2008), obtienen un fechado radiocarbónico de $2.490 \pm 45$ años ${ }^{14} \mathrm{C}$ A.P (similar al obtenido por Tonni et al. 2001, de 2990-+ 80 años ${ }^{4} \mathrm{C}$, corregido por efecto reservorio, para el lapso mencionado en el párrafo anterior) de la malacofauna recuperada en la unidad fosilífera aflorante en el perfil de Valle María. Considerando este resultado, la unidad portadora fue 
generada durante el Holoceno Tardío con anterioridad a los 1000 años A.P. La unidad fosilífera en cuestión es solo correlacionable temporalmente con la Formación San Guillermo y no asignable a la misma, si bien ambas unidades litoestratigráficas son el producto de la deflación de materiales superficiales (entre ellas, la Formación Tezanos Pinto y el suelo enterrado desarrollado en el techo de dicha unidad) y su posterior redepósito (Kröhling, com. pers.).

No se detectaron evidencias que indiquen si las condiciones áridas de este lapso son debidas a un déficit hídrico producido por disminución de precipitaciones o por aumento de temperaturas. (Tonni, com. Pers.)

\begin{tabular}{|lcc|}
\hline Unidad & Ambiente & Edad/años \\
\hline Fm San Guillermo & Semiárido & $3.500-1.400$ \\
\hline Fm Tezanos Pinto (miembro superior) & Semiárido & $14.000-8.500$ \\
\hline Fm Tezanos Pinto (miembro inferior) & Árido & $36.000-16.000$ \\
\hline
\end{tabular}

Figura 7.1. Estratigrafía simplificada del Cuaternario Tardío en las provincias de Santa Fe y Córdoba. Según Kröhling 1999. La cronología está basada en una combinación de termolumuniscencia y estimaciones de edad de radiocarbono calibradas 


\subsection{CONCLUSIONES}

Atendiendo al problema nomenclatural existente en esta temática de estudio, los morfotipos fitolíticos observados se clasificaron según los criterios propuestos por Zucol y Brea (2005), con los aportes de Bertoldi de Pomar (1971), y con modificaciones propias expresadas en la tabla 4.2. del apartado "Materiales y Métodos" (pg 62). En cuanto al grado autoctonía de los fitolitos objeto de este estudio, el análisis de las asociaciones fitolíticas de las muestras en los perfiles correspondientes a la Formación Tezanos Pinto puso de manifiesto, desde varios aspectos, que se trataría de material autóctono. Las evidencias a favor de esta interpretación son el amplio rango de tamaños observado, el buen estado de preservación de los fitolitos, la presencia de estructuras frágiles preservadas y de elementos articulados. En todas las muestras se observa la presencia conjunta de tamaños variados de fitolitos, estando presentes tanto macrofitolitos (denominado de este modo a aquellos fitolitos con tamaños mayores a $40 \mu \mathrm{m}$ ) como microfitolitos (menores a $40 \mu \mathrm{m}$ ), por lo que tampoco hubo una selección granulométrica importante propia de transporte. Los ejemplares tampoco presentan signos de erosión y desgaste por transporte. Estos signos se hacen evidentes sólo en los perfiles accesorios donde la Formación Tezanos Pinto es reemplazada por unidades fluviales o eólicas que incluyen un retrabajo del loess (por ej.: Rincón del Doll y Valle María. A su vez, algunos morfotipos conservan sus estructuras frágiles, como las espinas en las globulolitas, ambos lóbulos en los halterios, la morfología completa en los estróbilos. Por otra parte, los datos obtenidos desde otras fuentes, como la paleontología de vertebrados y la sedimentología, confirman la autoctonía de estos depósitos. En el primer caso, los estudios de paleontología de vertebrados, específicamente de fauna herbívora para la misma área y el mismo lapso temporal, sustentan la existencia de pastizales abiertos (Ferrero, 2008; Zurita, 2007). En el segundo caso, hay un consenso generalizado en cuanto a las condiciones necesarias para la formación de depósitos loéssicos, como por ejemplo la presencia de vegetación "trampa" que capture y retenga el sedimento fino transportado, siendo el sitio más propicio los pastizales (Spalletti, 1992);y condiciones climáticas áridassemiáridas (Iriondo, 1987; Ferrero, 2008). Como el viento dominante en ese 
momento (PleistocenoTardío-Holoceno) provenía del SO (Iriondo, 1994), deberían encontrarse en el loess bajo estudio fitolitos correspondientes a vegetación propia de cordillera, y no exclusivamente de vegetación propia de pastizales. En consecuencia, se infiere que el material fitolítico recuperado no estuvo sometido a transporte eólico manifiesto. Los resultados obtenidos en este trabajo, confirmaron la homogeneidad en cuanto a la composición y variabilidad fitolítica del loess cuaternario estudiado del SO de Entre Ríos y la identidad de la Formación Tezanos Pinto cuando se la contrasta con otras unidades del Cuaternario Superior del área. En general la representatividad de las asociaciones fitolíticas halladas fue constante en todas las muestras, tanto la representación temporal (o vertical), como la representación espacial (en la horizontal geográfica). Lo que sí se evidencia, a partir de datos obtenidos de los análisis multivariados aplicados, es una diferenciación geográfica marcada en cuanto a las proporciones de las morfotipos presentes en las asociaciones fitolíticas, entre los perfiles del área NO de la transecta respecto de aquellos ubicados al SE de la misma (figuras 6.3. y 6.9.). A pesar de que los espesores de la Formación Tezanos Pinto disminuyen en sentido SE, no significaría que sean secuencias parciales de aquellas presentes al NO, sino que se trataría de asociaciones diferentes, que en su conjunto podrían completar la columna de manera integral o ser variaciones geográficas.

Por lo tanto con los datos obtenidos de las muestras estudiadas no se pudo lograr una diferenciación que permita zonificar toda el área estudiada. Sin embargo lo que sí se evidencia claramente es una diferenciación geográfica marcada en cuanto a la composición fitolítica entre los perfiles del área NO de la transecta respecto de aquellos ubicados al SE de la misma (figuras 6.3. y 6.9.). Estas diferencias composicionales podrían corresponderse con variaciones paleoclimáticas o paleocológicas muy locales, que merecerían un extenso estudios que excede el presente trabajo de Tesis.

Los fitolitos más abundantes que se hallaron en las diferentes muestras fueron los esféricos equinados, Globulolithum sphaeroechinulathum, estando presentes también, aunque de manera no muy abundante, los esféricos lisos y los elípticos lisos y elípticos equinados. Las Estrobilolitas fueron muy abundantes también en todas sus formas, con Estrobilolita complanata y Estrobilolita aplanada en mayor medida, pero de manera también muy 
abundante Estrobilolita elongata y Estrobilolita equidimensionata. Se encontraron también los bilobulados, tanto los de centro corto y largo, de finales rectos, cóncavos y convexos, y los de contracara en forma de quilla; las doliolitas, principalmente las Doliolita equidimensionata, y en menor medida Doliolita elongata y Doliolita oblata. Otros fitolitos presentes fueron los Aculeolithum, con Aculeolithum rostrathum, Aculeolithum ancistrathum de manera dominante, y los prismáticos rectangulares menores a 40 micrones. Los fitolitos de mayor tamaño corresponden a las Flabelolithum, con Flabelolithum euflabelathum, Flabelolithum complanathum, Flabelolita elongata y Flabelolita excavata. Entre los macrofitolitos también se detectaron los prismáticos rectangulares Macroprismatolithum (Macroprismatolithum psilaristathum, el más importante, pero también estuvieron presentes los Macroprismatolithum ondulathum, Euprismatolita elongata, Macroprismatolithum denticulathum) y los Poliédricos.

La paleocomunidad que se infiere y define a base del análisis de los fitolitos reconocidos, está compuesta por gramíneas del tipo Panicoide $\left(C_{3}\right.$ y $\mathrm{C}_{4}$ ), Chloridoide $\left(\mathrm{C}_{4}\right)$, Pooide $\left(\mathrm{C}_{3}\right)$ y Stypoide $\left(\mathrm{C}_{3}\right)$ conformando una comunidad Mesotérmica (Burkart, 1975) con presencia de componentes tanto $C_{3}$ como $C_{4}$, también habría palmeras asociadas y ciperáceas. Se trata de un pastizal abierto con palmares asociados y cuerpos de agua de poca importancia. El ambiente inferido se desarrolló bajo condiciones áridas y semiáridas, debidas más a la sequedad del clima que a las bajas temperaturas, las que se corresponden a temperaturas templadas. Con variaciones menores locales (apartado 6.).

Este escenario es coincidente con las interpretaciones realizadas desde la geología, ya que se indican condiciones áridas y semiáridas para el momento de depositación de la formación estudiada (Iriondo, 1980, 1994; Iriondo y Kröhling, 2007, Kemp et al. 2006). 


\section{BIBLIOGRAFÍA CITADA}

ACEÑOLAZA, F.G. 2007. Geología y Recursos Geológicos de la Mesopotamia Argentina. Serie de Correlación Geológica 22:149 pp.

ALBERT, R. M.; Bamford, M. K. y Cabanes, D. 2006. Taphonomy of phytoliths and macroplants in different soils from Olduvai Gorge (Tanzania) and the application to Plio - Pleistocene palaeoanthropological samples. Quaternary International, 148: 78-94.

ALEXANDRE, A.; Meunier, J.; Lezine, A.; Vincens, A. y Schwartz, D. 1997. Phytoliths: indicators of grasslands dynamics during the late Holocene in intertropical Africa. Palaeogeography, Palaeoclimatology, Palaeoecology, 136: 213-229.

ALVAREZ, M. F. 2003. Biominerales de sílice en suelos y paleosuelos presentes en secuencias del Cuaternario Tardío en el sudeste bonaerense. Tesis de grado, Facultad de Ciencias Exactas y Naturales, Universidad Nacional de Mar del Plata.

ALVAREZ, M. F. y Osterrieth, M. 2004. Biominerales de sílice indicadores de la evolución de suelos y paleosuelos del SE bonaerense. Resúmenes XIX Congreso Argentino de la Ciencia del Suelo, Paraná: 372.

ALVAREZ, F.; Borrelli, N.; Fernández Honaine, M.; Monti, L.; Osterrieth, M.; Oyarbide, F. y Rossi, V. 2005. Silicofitolitos en médanos e intermédanos costeros de Mar Chiquita, Buenos Aires, Argentina. En: Zucol, A.F.; Osterrieth, M. y Brea, M. (Eds.) Fitolitos. Estado actual de sus conocimientos en América del Sur: 9 pp. (en prensa).

AMEGHINO, F. 1881. Mamíferos fósiles del terreno pampeano. En: Masson-Igon Hermanos (Eds.): La antigüedad del hombre en el Plata. Buenos AiresParis:309pp.

AMEGHINO, F. 1889. Contribución al conocimiento de los mamíferos fósiles de la República Argentina. Academia Nacional de Ciencias de la República Argentina (Córdoba). Buenos Aires. 6: 1-1027.

BABOT, M. P. y E. Bru de Labanda. 2005. Análisis of three factors that have an influence on the preservation of microfossils in archaeological artefacts. The Phytolitharien 17 (2): 4-5.

BAILEY, J. W.1856. On the non existente of polarizing silica in the organic Kingdom. American Journal Society a Arts. 2:21.

BAKER, G. D.C. 1959a Fossil opal phytolith and phytolith nomenclature. Australian Journal of Science 2 (9): 305-306.

BAKER, G. D.C. 1960. Phytolitarien. Australian Journal of Botany 22 (9): 392G-393.

BARBONI, D.; Bonnefille, R.; Alexandre, A. y Meunier, J. D. 1999. Phytoliths as paleoenvironmental indicators, West Side Middle Awash Valley, Ethiopia. Palaeogeography, Palaeoclimatology, Palaeoecology, 152: 87-100.

BehRENSMeYER, A. K., Damuth, J. D., DiMichele, W. A., Potts, R., Sues, H. D. y S. L. Wing (eds). 1992. Terrestrial ecosystems through time. Evolutionary Paleoecology of terrestrial plants and animals. Univ. Chicago Press. $568 \mathrm{p}$.

BERTOLDI DE POMAR, H. 1969a. La micropaleontología continental en los estudios edafológicos. V Reunión Argentina de Ciencias del Suelo, Actas: 727-730.

BERTOLDI DE POMAR, H. 1969b. Partículas de sílice organizadas en sedimentos pampeanos de la llanura santafecina. IV Jornada Geológica Argentina, Actas. Mendoza. 
BERTOLDI DE POMAR, H. 1970a. Fitolitos y zoolitos, su significado geológico en sedimentos continentales. Boletín de la Asociación Geológica de Córdoba 1(1): 2131.

BERTOLDI DE POMAR, H. 1970b. Caracterización micropaleontológica de sedimentos y suelos aluviales del Paraná Medio. II Jornadas de la Cuenca del Plata, Santa Fe.

BERTOLDI DE POMAR, H. 1971. Ensayo de clasificación morfológica de los silicofitolitos. Ameghiniana, 7(3-4): 317-328.

BERTOLDI DE POMAR, H. 1972. Ópalo Organógeno en Sedimentos Superficiales de la Llanura Santafesina. Ameghiniana. Revista de la Asociación Paleontológica Argentina. Tomo IX.

BERTOLDI DE POMAR, H. 1973. Crisostomatáceas en sedimentos de fondo de la laguna Guadalupe. Asociación de Ciencias Naturales del Litoral, Revista 4: 73-86.

BERTOLDI DE POMAR, H. 1974. Silicobiolitos en sedimentos de cauce fluviales correntinos. I Congreso Argentino de Paleontología y Bioestratigrafía, Actas: 633639.

BERTOLDI DE POMAR, H. 1975. Los silicofitolitos: Sinopsis de su conocimiento. Darwiniana 19: 173-206.

BERTOLDI DE POMAR, H. 1976. Métodos de preparación de sedimentos clásticos para su estudio microscópico. I. Tratamientos previos. Asociación de Ciencias Naturales del Litoral, Revista 7: 1-55.

BERTOLDI DE POMAR, H. 1980. Análisis comparativo de silicobiolitos de diversos sedimentos continentales argentinos. Asociación Geológica Argentina, Revista 35(4): 547-557.

BERTOLDI DE POMAR, H. 1983 Silicobiolitos en sedimentos del cauce del Río Paraguay. Asociación de Ciencias Naturales del Litoral, Revista 14 (1): 53-62.

BERTOLDI DE POMAR, H. 1999. Propuesta de nomenclatura para nuevos morfotipos de silicofitolitos (Insertae Sedis). Ameghiniana 36 (4) Suplemento, Resúmenes: 40R.

BERTOLDI DE POMAR, H. 2006 Propuesta de nomenclatura para nuevos morfotipos de silicofitolitos (Insertae Sedis). En: Fitolitos en suelos, sedimentos y sitios arqueológicos: Estado actual de sus conocimientos en América del Sur, editado por A. F. Zucol, M. L. Osterrieth y M. Brea. Mar del Plata (en prensa).

BERTOLDI DE POMAR, H. y N. M. Tur 1970. Células silicificadas en gramíneas acuáticas. Asociación de Ciencias Naturales del Litoral, Revista 1: 17-18.

BIDEGAIN, J. C. Y Rico, Y. 2004. Mineralogía magnética y registros de susceptibilidad en sedimentos cuaternarios de polaridad normal (Brunhes) y reversa (Matuyama) de la cantera de Juárez, provincia de Buenos Aires. Revista de la Asociación Geológica Argentina. 59 (3): 451-461.

BIDEGAIN, J. C., Van Velezen, A. J. Y Rico, Y. 2001. Parámetros magnéticos en una secuencia de loess y paleosuelos del Cenozoico Tardío en la cantera de Gorina, La Plata: Su relevancia en el estudio de los cambios paleoclimáticos y paleoambientales. Revista de la Asociación Geológica Argentina, 56 (4): 503-516.

BIDEGAIN, J. C., Van Velezen, A. J. Y Rico, Y. 2007. The Brunhes/Matuyama boundary and magnetic parameters related to climatic changes in Quaternary sediments of Argentina. Journal of South American Earth Sciences, 23: 17-29.

BLACKMAN, E. 1971. Opaline silica bodies in the range grasses of southern Alberta. Canadian Journal of Botany, 49: 769-781. 
BLARASÍN, M. y Sánchez, M. 1987. Secuencia Evolutiva de Dunas Cuaternarias en el Sector de Laguna Oscura, Dpto. Río Cuarto, Prov. de Córdoba. $10^{\circ}$ Congreso Geológico Argentino, San Miguel de Tucumán.Actas 3: 297-300.

BLINNIKOV, M. S. 2005. Phytoliths in plants and soils of the interior Pacific Northwest, USA. Review of Palaeobotany and Palynology, 135: 71- 98.

BLINNIKOV, M., Busacca, A., Whitlock, C., 2002. Reconstruction of the Late Pleistocene Columbia basin grassland, Washington, USA, based on phytolith records in Loess. Palaeogeography, Palaeoclimatology, Palaeoecology 177: 77-101.

BORRELLI, N. 2001. Minerales, biominerales y su relación con las propiedades físico químicas de Argiudoles típicos afectados por prácticas agrícolas en Laguna de los Padres, Buenos Aires. Tesis de grado, Facultad de Ciencias Exactas y Naturales, Universidad Nacional de Mar del Plata.

BORRELLI, N. y Osterrieth, M. 2001. Sílice amorfo de origen orgánico e inorgánico en suelos de agroecosistemas y campos naturales de Laguna de los Padres, Buenos Aires. Evaluación preliminar. Natura Neotropicalis: 27-32.

BORRELLI, N. y Osterrieth, M. 2002. Ciclo biogeoquímico de la sílice en Argiudoles típicos (Laguna de los Padres, Buenos Aires). Resúmenes XVIII Congreso Argentino de la Ciencia del Suelo, Puerto Madryn: 6.

BORRELLI, N.; Osterrieth, M. y Miretzky, P. 2004. Influencia de la cobertura vegetal en el ciclobiogeoquímico de la sílice en Arguidoles típicos. Resúmenes XIX Congreso Argentino de la Ciencia del Suelo, Paraná: 370.

BOWDERY, D., Hart, D.M., Lentfer, C. y Wallis, L.A. 1998. A universal phytolith key. 2nd International Meeting on phytolith Research ( Aix en Provence, Francia) Volume of Abstract : 17.

BRAVARD, A. 1857. Observaciones geológicas sobre diferentes terrenos de transporte, en la Hoya del Plata. Biblioteca del Diario la Prensa, Imprenta y Linotipia de J.Bernheim: 1-80.

BREA , M. y Zucol, A. F., 2007. Guadua zuloagae nov. sp., the first petrified bamboo bulm record from Ituzaingó Formation (Middle Pliocene), Paraná Basin, Argentina. Annals of Botany. 100:711-723.

BREMOND, L.; Alexandre, A.; Hély, C. y Guiot, J. 2005. A phytolith index as a proxy of tree cover density in tropical areas: Calibration with Leaf Area Index along a forestsavanna transect in southeastern Cameroon. Global and Planetary Change 45: 277-293.

BROWN, D. A. 1984. Prospects and limits of a phytolith key for grasses in the Central United State. Journal of Archaeological Science, 11: 345-368.

BURKART, A. 1975.Evolution of Grasses and Grasslands in South America. Taxon. Vol. 24(1) 53-66.

CABIDO, M., Ateca, N., Astegiano, M.E., Anton, A.M., I.M.B.I.V., U.-C., 1997. Distribution of C3 and C4 grasses along an altitudinal gradient in Central Argentina. Journal of Biogeography 24:197-204.

CABRERA, A. L. 1976. Regiones fitogeográficas Argentinas $2^{\circ}$ ed. Enc. Arg. Agricultura y Jardinería. Ed. ACME S.A.I.C. Buenos Aires. 85 pp.

CABRERA , A. y A. Willink. 1973. Biogeografía de América Latina. Monografía 13, Serie de Biología.

CARLINI, A. A., Zurita A. E., Gasparini G. y Noriega J.I. 2003. Los mamíferos del Pleistoceno de la Mesopotamia argentina y su relación tanto con aquéllos del Centro Norte de la Argentina, Paraguay y Sur de Bolivia, como con los del Sur de 
Brasil y Oeste de Uruguay: Paleobiogeografía y Paleoambientes. Temas de la Biodiversidad del Litoral fluvial argentino. INSUGEO, Miscelánea. 12: 5 - 12.

CARNELLI, A. L.; Theurillatb, J. P. y Madella, M. 2004. Phytolith types and typefrequencies in grasses. Annals of Botany, 28: 169-185.Church, G. E. 1898. Argentine Geography and the Ancient Pampean Sea. The Geographical Journal. 12 (4): 386-401.

CIONE, A. L. y Tonni, E. P. 2001. Correlation of pliocene to Holocene southern South American and European vertebrate-bearing units. Bolletino della Società Palentologica Italiana, 40 (2): 167-173.

COIL, J., M. A. Korstanje, S. Archer y C. A. Hastorf. 2003. Laboratory goals and considerations for multiple microfossil extraction in archaeology. Journal of Archaeological Science 30: 991-1008.

DARWIN, C. 1846. Geological observations on South America. Smith, Elder and Co.:279 p. London.

DAVY, H. 1814. Elements of agricultural chemistry. 2a Ed.

DELHON, C., Alexandre, A., Berger, J., Thiebault, S., Brochier, J., Meunier, J., 2003. Phytoliths assemblages as a promising tool for reconstructing. Quaternary research.59 (1):48-60.

DESCHAMPS, C.M.; Tonni, E.P. 1992. Los vertebrados del Pleistoceno Tardío del arroyo Napostá Grande, Provincia de Buenos Aires. Aspectos paleoambientales. Ameghiniana, Vol. 29, No. 3, p. 201-210.

D'ORBIGNY, A.D. 1842. Voyage dans I'Amerique meridionale. Palaeontology et Geologie 3: 1-152.

DUNBAR, C. y Rodgers, J. 1957. Principles of Stratigraphy. Wiley. 356pp. New York.

EHRENBERG , C. G. 1841 Über verbreitung und Einfluss des mikroskopischen lebend in Süd und Nordamerika. Monastsber Preuss Akad. Wiss. Berlin: 139-144.

EHRENBERG, C. G. 1854 Mikrogeologie. Leopold Voss, Leipzig. 354 pp.

ELLIS, R. P. 1979. A procedure for standardizing comparative leaf anatomy in the Poaceae. II. The epidermis as seen in surface view. Bothalia, 12: 641-671.

ELLIS, R. P. 1987. A review of comparative leaf blade anatomy in the systematics of the Poaceae: The past twenty-five years. En: Soderstrom T.R.; Hilu K.W.; Campbell C.S. y Barkworth M.E. (Eds.), Grass systematics and evolution. Smithsonian Institution Press, Washington, 3-10.

EMBLETON, C. y King, C.1968. Glacial and priglacial geomorphology. Arnold:608pp. Edimburgh.

EPSTEIN, E. 1994. The anomaly of silicon in plant biology. Proceedings of the National Academy of Science, 91: 11-17.

ERRA, G. y A. F. Zucol. 2007. Diversidad fitolítica en sedimentos Cuaternarios de la provincia de Entre Ríos. Reunión Anual de Comunicaciones de la Asociación Paleontológica Argentina, Resúmenes: 11.

ERRA, G., A. F. Zucol, D. Kröhling y M. Brea. 2006. Análisis fitolíticos en el loess del Pleistoceno Tardío-Holoceno Temprano en la provincia de Entre Ríos: resultados preliminares. III Congreso Argentino de Cuaternario y Geomorfología, Actas de trabajo, tomo II: 691-699:13.

ERRA, G., A. F. Zucol y D. Kröhling. 2008. Phytolithic composition of the Tezanos Pinto Formation (Late Pleistocene loess) at the Southwest of the Entre Ríos province, Argentina. 7mo. Encuentro Internacional de Investigaciones Fitolíticas y 4to. Encuentro Sudamericano de Investigaciones Fitoliticas. Mar del Plata, Argentina. 
FERNÁNDEZ HONAINE, M. 2007. Análisis fitolítico del pastizal de Paspalum quadrifarium y su relación con la evolución pedológica en el sudeste de la provincia de Buenos Aires. Tesis Doctoral. Facultad de Ciencias Exactas y Naturales. Universidad Nacional de Mar del Plata.

FERNÁNDEZ HONAINE, M; Zucol, A. F. y Osterrieth, M. 2005. Biomineralizaciones de sílice en Celtis tala (Celtidaceae). Boletín de la Sociedad Argentina de Botánica, 40 (3-4): 229-239.

FERNÁNDEZ HONAINE, M.; Osterriethm M. I.;y Zucol, A. F. 2009. Plant communities and soil phytolith assemblages relationship in native grasslands from southeastern Buenos Aires province, Argentina. Catena. 76: 89-96.

FERRERO, B. S. 2009. Mamíferos del Cuaternario de la provincia de Entre Ríos, Argentina: Diversidad y evolución. Aspectos bioestratigráficos y paleozoogeográficos de una fauna particular. Tesis Doctoral. Facultad de Ciencias Naturales y Museo. Universidad Nacional de La Plata.

FIDALGO F. y Tonni E. P. 1981. Sedimentos eólicos del pleistoceno Tardío y Reciente en el área interserrana Bonaerense. VIII Congreso Geológico Argentino, San Luis Actas III.33:39.

FLÓREZ, M. T. y N. L. Parra.1999. Atlas de fitolitos de la vegetación altoandina, páramos de Belmira y Frontino, departamento de Antioquia. En: Silicofósiles altoandinos. Conciencias, Universidad Nacional de Colombia, editado por M. T. Flórez y G. C. Lozano. pp. 3-41.

FREDLUND, G. G. y Tieszen, L. T. 1994. Modern phytolith assemblages from the North American Great Plains. Journal of Biogeography, 21: 312-335.

FREDLUND, G. G. y Tieszen, L. T. 1997. Phytolith carbon isotope evidence for late Quaternary vegetation and climate change in the southern Black Hills, South Dakota. Quaternary Research, 47: 206-217.

FRENGUELLI J. 1920. Contribución al conocimiento de la Geología de Entre Ríos. Bol. Acad. Nac. Cs. Córdoba, 24: 55-256.

FRENGUELLI, J. 1925. Loess y limos pampeanos. Sociedad Argentina de Estudios Geográficos, Anales. GAEA 1: 1-88.

FRENGUELLI, J., 1930. Partículas de sílice organizadas en el loess y en limos pampeanos. Células silíceas de Gramíneas. Anales de la Sociedad Científica de Santa Fé. 2: 64-109.

FRENGUELLI, J. 1950. Rasgos generales de la morfología y la geología de la provincia de Buenos Aires. LEMIT, serie II: 33: 1-72.

FRENGUELLI, J. 1955. Loess y limos pampeanos. Ministerio de Educación de la Nación, Universidad Nacional de La Plata, Facultad de Ciencias Naturales y Museo, Serie técnica y didáctica 7: 3-88.

GALLEGO, L. y Distel, R. A. 2004. Phytolith assemblages in grasses native to Central Argentina. Annals of Botany, 94: 865-874.

GALLEGO, L.; Distel, R. A.; Camina, R. y Rodriguez Iglesias, R. M. 2004. Soil phytoliths as evidence for species replacement in grazed rangelands of Central Argentina. Ecography, 27: 1-8.

GONZÁLEZ, G. y Osterrieth, M. 1996. Silicobiolitos en suelos, paleosuelos y sus materiales parentales, Buenos Aires, Argentina. Resúmenes $2^{\circ}$ Encuentro Europeo de estudio de fitolitos, España. I: 83-92. 
GoNZÁLEZ, C. A.; Aguirre, M. L.; Miquel, S. E.; Kröhling, D.; Zucol A. F. y Brea M. 2008. Malacofauna continental holocena y paleoambientes en Villa Valle María (Dpto. Diamante, Entre Ríos, Argentina). 4th Congress RCANS. Abstracts. 26.

GROB, A. 1896. Beiträge zur Anatomie der Epidermis der Gramineenblätter. Bibliotheca Botanica 7: 1-122.

HAMMER, O., D.A.T. Harper \& P.D. Ryan. 2007. PAST Palaeontological Statistics, Version: 1.76. http://folk.uio.no/ohammer/past

HART, D.M., Lentfer, C., Wallis, L.A. y Bowdery, D. 2000. A universal phytolith key: Point class. 3th International Meeting on phytolith Research (Tervuren, Bélgica), Abstract : 13-14.

HART, D. M. y Humphreys, G. S. 2003. Phytolith depth functions in surface regolith materials. En: Roach I.C. (Ed.) Advances in Regolith, CRC LEME: 159-163.

HELBAEK, H. 1961. Studying the diet of ancient man. Archaeology 14: 95-101.

HODSON, M. J.; White, P.J.; Mead, A. y Broadley, M. R. 2005. Phylogenetic variation in the silicon composition of plants. Annals of Botany, 96: 1027-1046.

ICPN Working group, Madella, M., Alexandre, A., Ball, T.B., 2005.International code for phytolith nomenclature 1.0. Annals of Botany. 96:253-260.

INTA. 1991. Carta de suelos de la Republica Argentina, Departamento Diamante, Provincia de Entre Ríos.

IRIARTE, J. 2006. Vegetation and climate change since 14,810 14C yr B.P. in southeastern Uruguay and implications for the rise of early Formative societies. Quaternary Research 65 (1), 20-32.

IRIONDO, M. 1980. El cuaternario de Entre Ríos. Revista de la Asociación de Ciencias Naturales del Litoral.11: 125-141.

IRIONDO, M. 1985. Geología y geomorfología. Su importancia y relación con la edafología. Publicación Miscelanea. INTA. 30: 145-185.

IRIONDO, M. 1987. Geomorfología y Cuaternario de la provincia de Santa Fé (Argentina). D’Orbignyana. Corrientes. 4:1-54.

IRIONDO, M. 1990a. Map of the South American plains - Its present state. In: Rabassa, J. (Ed.), Quaternary of South America and Antarctic Peninsula, A.A. Balkema Publishers, Rotterdam, 6:297-308.

IRIONDO, M. 1990b. A late Holocene dry period in the Argentine plains. In: Rabassa, J. (Ed.), Quaternary of South America and Antarctic Peninsula, A.A. Balkema Publishers, Rotterdam, 7:197-218.

IRIONDO, M. 1993. Cambios climáticos en el Noroeste durante los últimos 15.000 años en El Holoceno de la Argentina (Iriondo ed.), Paraná. 35-44.

IRIONDO M. 1994. Los climas cuaternarios de la región pampeana. Subsecretaría de Cultura. Com. Mueso Provincial de Ciencias Naturales. Santa Fe. 4:(2)1-46.

IRIONDO, M. 1998. Loess in Argentina: Temperate and Tropical. Excursión Guide №3. Province of Entre Ríos. Internacional Union for Quaternary Reserch. Internacional Join Field Meeting 1-12pp.

IRIONDO, M. 1999. Climatic changes in the South American plains: Records of a continent-scale oscillation. Quaternary International 57/58:93-112.

IRIONDO, M. y Mannavella, C., 1990. Facies sedimentarias de la Formación Tezanos Pinto en el centro de la provincia de Santa Fe. In: Zarate, M. (Ed.), International Symposium on Loess, Properties, Chronology and Palaeoclimatic signiphicance of loess, INQUA, Mar del Plata, Expanded Abstracts. 74-77. 
IRIONDO, M. y Garcia, N., 1993. Climatic variations in the Argentine plains during the last 18,000 yr. Palaeogeography, Paleoclimatology, Palaeoecology 101, 209-220.

IRIONDO, M. y Kröhling D. 1995. El Sistema Eólico Pampeano. Subsecretaría de Cultura. Com. Museo Provincial de Ciencias Naturales "Florentino Ameghino". Santa Fé. 5:(1) 1-68.

IRIONDO, M. y Kröhling, D. 1996. Los sedimentos eólicos del noreste de la llanura pampeana (Cuaternario superior). XIII Congreso Geológico Argentino y III Congreso de Exploración de Hidrocarburos, Buenos Aires, Actas IV, 27-48.

IRIONDO, M.H. y Kröhling, D. 2003. A neoformed kaolinitic mineral in the upper Pleistocene of northeastern Argentina. En: (Eds.) Domínguez E.A, Mas G. y Cravero F, A clay Odyssey 109-116.

IRIONDO, M. y D Kröhling. 2007. Geomorfología y sedimentología de la Cuenca superior del río Salado (sur de Santa Fe y Noroeste de Buenos Aires, Argentina). Latin Aamerican Journal of Sedimentology and Basin Análisis. 14 (1): 1-23.

IRIONDO, M. y Kröhling, D. 2008. Cambios ambientales en la cuenca del Uruguay (desde el Presente hasta dos millones de años atrás). Colección Ciencia y Técnica, Universidad Nacional del Litoral, pp.358.

IRIONDO, M.; Kröhling, D. y J. C. Bidegain. 2000. The Quaternary of SW Entre Ríos, Argentina. 31 International Geological Congress, Abs, Río de Janeiro.

ISC 2007 IUGS 2007. Request for IUGS Ratification to Establish the Quaternary as a System/Period of the Cenozoic and revise the associated base of the Pleistocene Series. http://www.iugs.org/.

JONES, L. H. P. y Handreck, K. A. 1967. Silica in soils, plants and animals. Advances in Agronomy, 19: 107-149.

KEMP, R. A., Zárate, M., Toms, P., King, M., Sanabria, J. Y Arguello, G. 2006. Late Quaternary paleosols, stratigraphy and landscape evolution in the Northern Pampa, Argentina. Quaternary Research, 66: 119-132.

KONDO, R.; Sase, T. y Kato, Y. 1987. Opal phytolith analysis of andisols with regard to interpretation of paleovegetation. En: Kinloch, D.I. (ed.) Proceedings of the Ninth International Soil Classification Workshop: 520-534.

KONDO, R.; Childs, C. W. y Atkinson, I. A. E. 1994. Opal phytoliths of New Zealand. Lincoln, Manaaki Whenua Press.

KRAPOVICKAS, S. y A. Di Giacomo. 1998. Conservation of pampas and campos grasslands in Argentina. Parks. 8: 53.

KRÖHLING, D.1998. International Union for Quaternary Research. Loess in Argentina: temperate and tropical. Excursion guía №2: north Pampa (Carcaraña river basin, Santa Fe province). International Joint Field Meeting: Loess in Argentina: Temperate and Tropical. INQUAPASH- CLIP-UNER-CECOAL, 33 pp.

KRÖHLING, D., 1998a. Geomorfología y Geología del Cuaternario de la cuenca del río Carcarañá, desde la confluencia de los ríos Tercero y Cuarto, provincias de Santa Fe y Córdoba. Doctoral Thesis. Facultad de Ciencias Exactas, Físicas y Naturales, Universidad Nacional de Córdoba (unpublished).

KRÖHLING, D., 1998b. Silt content of outcropping loessic units of North Pampa. In: Iriondo, M., Kröhling, D., Orfeo, O., Carignano, C. y Cioccale,M (Eds.), Abstracts International Joint Field Meeting: Loess in Argentina: Temperate and Tropical. Parana H. INQUAPASH-CLIP-UNER-CECOAL. 
KRÖHLING, D. y Orfeo O. 2002. Sedimentología de unidades leoéssicas (Pleistoceno Holeoceno) del centro sur de Santa Fé. Asociación Argentina de Sedimentología. AAS Revista. 9:(2)135-154.

KRÖHLING, D. M. e Iriondo M. 1999. Upper Quaternary Paleoclimates of the Mar Chiquita Area (North Pampa, Argentina). En: T. Prartridge, P. Kershaw y M. Iriondo (Eds.): "Paleoclimates of the Southern Hemisphere". Quaternary Internatonal. 57/58:149164.

KRÖHLING, D. M. e Iriondo M. 2003. El loess de la Pampa Norte en el Bloque San Guillermo. Asociación Argentina de Sedimentología. AAS Revista.10:(2)137-150.

KRÖHLING, D., Zucol, A.F., Brea, M., Aguirre, M.L. y Passeggi, E., 2005. Resultados preliminares de estudios sedimentológicos y paleobiológicos de la Formación Tezanos Pinto (Cuaternario) en el SO de Entre Ríos. IV Taller de Sedimentologia y Medio Ambiente. AAS, CECOAL (CONICET), UNNE: 6-8. Corrientes.

KUKLA, G. 1975. Loess stratigraphy in Central Europe. En: Butzer, K. W. y G. LI. Isaac (Eds) "After the Australopithecines". The Hague. Mouton. 99-188.

KUKLA, G. 1989. Loess stratigraphy in Central China. Palaeogeog. Paleaeoclim. Palaeoecol., 72:203-225.

LEÓN, R., 1991. Vegetation, en: Soriano, A. y R. Coupland (eds.), Natural Grasslands: Introduction and Western Hemisphere, Ámsterdam, Elsevier.pp. 380-387.

LENTFER, C., Wallis, L.A., Bowdery, D. y Hart, D.M. 2000. A universal phytolith key: Prismatic/ellipsoid/trapezoid (PET) class. 3th International Meeting on phytolith Research, Tervuren, Bélgica, Abstract : 14.

LIVINGSTONE, D.A., Clayton, W.D., 1980. An altitudinal cline in tropical African grass floras and its paleoecological significance. Quaternary Research 13:392-402.

LOWENSTAM, H. A. 1981. Minerals formed by organisms. Science 211:1126-1131.

LU, H.Y.; Wu, N. Q.; Yang, X. D.; Jiang, H.; Liu, K. B. y Liu, T. S. 2006. Phytoliths as quantitative indicators for the reconstruction of past environmental conditions in China I: phytolith-based transfer functions. Quaternary Science Review, 25: 945959.

MADELLA, M., Alexandre, A. y Ball, T. 2002. Internacional Code for Phytolith Nomenclature. 4th International Meeting on Phytolith Research (Cambridge, Inglaterra), Abstract : 8.

MADELLA , M, Alexandre A, Ball T. 2005. International Code for Phytolith Nomenclature 1-0. Annals of Botany 96: 253-260.

MARSHALL, L. G., Berta, A., Hoffstetter, R., Pascual, R., Reig, O. A., Bombin, M. Y Mones, A. 1984. Mammals and stratigraphy: geochronology of the continental mammal-bearing quaternary of South America. Palaeovertebrata. Mém. Extr.:1-76.

MCNAUGHTON, S. J.; Tarrants, J. L.; McNaughton, M. M. y Davis, R. H. 1985. Silica as a defense against herbivory and a growth promotor in African grasses. Ecology, 66: 528-535.

METCALFE, C. R. 1960. Anatomy of monocotyledons I. Gramineae. Claredon Press. Oxford.

METCALFE, C, R. 1963. Comparative anatomy as a modern discipline to recent advances in the systematic anatomy of Monocotyledons. Adv. Bot. Res. 1:101-147.

MORRONE ,J. J. 2001. Biogeografía de América Latina y el Caribe. M\&T Manuales y Tesis SEA, 3:25-29.

MULHOLLAND, S. C. 1989. Phytolith shape frequencies in North Dakota grasses: a comparison to general patterns. Journal of Archaeological Science, 16: 489-511. 
NALEPKA, D. y A. Walanus. 2003. Data processing in pollen analysis. Acta Paleobotanica 43 (1): 125-134.

NETOLITZKY, F. 1900 Mikroskopische Untersuchung gänzlich verkohlter vrgeschichtlicher Nahrungsmittel aus Tidol. Zeitschrift fur Untersuchungen Nahrungsund Genussmittel 12: 401-407.

OLLENDORF, A. L. 1992. Toward a classification scheme of sedge (Cyperaceae) phytoliths. En: Rapp G. y Mulholland S.C. (Eds.), Phytolith Systematics, Plenum Press, Nueva York: 91-111.

OSTERRIETH, M. 2000. Silicofitolitos una herramienta para la comprensión de procesos pedológicos del Cuaternario. Actas XVII Congreso Argentino de la Ciencia del Suelo. CD: 4 pp.

OSTERRIETH, M. 2001a. Silicofitolitos en sedimentos loéssicos de la llanura inter. y periserrana de Tandilla, Buenos Aires, Argentina. Ameghiniana 38 (4) Suplemento, resúmenes: 47R-48R.

OSTERRIETH, M. 2001b. Silicobiolitos/silicofitolitos: su rol en la matriz de suelos y paleosuelos de ambientes costeros de Buenos Aires, Argentina. Ameghiniana 38 (4) Suplemento, resúmenes: 47R.

OSTERRIETH, M. 2005. Silicofitolitos en sedimentos loéssicos de la llanura inter y periserrana de Tandilia, Buenos Aires, Argentina. En: Zucol, A. F.; Osterrieth, M. y Brea, M. (eds.) Fitolitos.Estado actual de sus conocimientos en América del Sur: 19pp. (en prensa)

OSTERRIETH, M., 2006. Silicofitolitos en suelos, paleosuelos y sedimentos. Actas III Congreso Argentino de Cuaternario y Geomorfología, I, pp. 351-365.

OSTERRIETH, M., 2007a. Biomineralizaciones en Suelos y sedimentos. Curso del Dpto. de Postgrado la Facultad de Ciencias Naturales y Museo Universidad Nacional de La Plata mayo de 2007.

OSTERRIETH, M., 2007b. Silicofitolitos en Sedimentos loéssicos de la llanura inter y periserrana de Tandilia, Buenos Aires, Argentina. In: Zucol, A.F., Osterrieth, M., Brea, M. (Eds.), Fitolitos. Estado actual de sus conocimientos en América del Sur: 19pp. (en prensa).

OSTERRIETH, M. L., 2008. Inputs and limitations of the phytoliths studies in soils, sediments and paleosols, in the Pampean Region. Conferencia. 7th IMPR-4EIFSPR-CGCyC. Mar del Plata, Argentina, 2008. Actas de Resumenes p17.

OSTERRIETH, M. y Tassara, G. 2005. Silicofitolitos en artefactos de molienda de sitios arqueológicos del Área Interserrana, Buenos Aires. Actas III Encuentro de Investigaciones del Cono Sur, Tafí del Valle, Tucumán: 13-15.

OSTERRIETH, M. L. y M. Fernández Honaine. 2007. Micromorphology and phytoliths study in coastal dunes of the Southeastern Pampean Plains, Buenos Aires province, Argentina. En: Plants, People and Places: Recent Studies in Phytolithic Analysis. Proceeding of 4th International Meeting on Phytolith Research, editado por M. Madella, MK Jones y D. Zurro. Oxbow Books, Cambridge, UK. (en prensa).

OSTERRIETH, M.; Zucol, A. F. y Lopez de Armentia, A. 1998a. Presencia de restos vegetales carbonizados en secuencias sedimentarias costeras del Holoceno Tardío de Mar Chiquita, Buenos Aires, Argentina. V Jornadas Geológicas Bonaerenses, 2: 251-255.

OSTERRIETH, M.; Alvarez, M.F. y Madella, M. 2004. Paleosuelos loéssicos en secuencias sedimentarias del Cuaternario Tardío de la planicie fluvioeólica bonaerense. Actas X Reunión Argentina de Sedimentología: 123-124. 
OSTERRIETH, M.; Morrás, H. y Alvarez, M. F. 2005b. Silicobiolitos en suelos y sedimentos loéssicos de la Pampa ondulada, Buenos Aires. Actas III Encuentro de Investigaciones del Cono Sur, Tafí del Valle, Tucumán: 44-45.

OSTERRIETH, M. L., Madella, M Y D. Zurro, 2009. Taphonomical Aspects of Silica Phytoliths in the Loess Sediments of the Argentinean Pampas. In Quaternary International. Quaternary International, 193: 70-79.

OSTERRIETH, M.; Martínez, G.; Gutiérrez., M. y Alvarez, M. F. 2005a. Biomorfos de sílice en secuencias pedoarqueológicas del sitio Paso Otero 5, Buenos Aires. Actas III Encuentro de Investigaciones del Cono Sur, Tafí del Valle, Tucumán: 29-31.

OSTERRIETH, M.; Violante, R.; Borrelli, N y Bernava Laborde, V. 2005c. Silicofitolitos en sedimentos de testigos marinos de la plataforma submarina del litoral atlántico bonaerense. Actas III Encuentro de Investigaciones del Cono Sur, Tafí del Valle, Tucumán: 46-47.

OSTERRIETH, M.; Madella, M.; Zurro, D. y Alvarez, F. 2006. Taphonomical aspects of silica phytoliths in loess sediments of the Argentinean Pampas. Abstracts VI International Meeting for Phytolith Research, Barcelona, España: 1pp.

OSTERRIETH, M.; Martínez, G.; Zurro, D.; Zucol, A.; Brea, M. y Mazzanti, D. 2002a. Procesos de formación del sitio 2 de la localidad arqueológica Amalia: evolución paleoambiental. En: Mazzanti, D.; Berón, M. y Oliva, F. (Eds.) Del Mar a los salitrales: Diez mil años de historia pampeana en el umbral del tercer milenio, UNMdP, Sociedad Argentina de Arqueología: 343-354.

PARRA, L.N.S. y Flórez, M.T.M. 2001. Propuesta de clasificación morfológica para los Fitolitos altoandinos colombianos. Crónica forestal y del medio ambiente 16: 35-66.

PARRY, D.W. y Smithson, F. 1958 a. Silicification of bulliform cells in grasses. Nature 181: 1549-1550.Parry, D. W. y Smithson, F. 1964. Types of opaline silica depositions in the leaves of British grasses. Annals of Botany, 28: 169-185.

PATTERER, N. I. 2008. Análisis fitolíticos de suelos del SO de la provincia de Entre Ríos como una herramienta para el conocimiento de su génesis. Tesis de grado, Facultad de Ciencia y Tecnología. Uader.

PEARSALL, D. M. 2000. Paleoethnobotany: A handbook of procedures. Academic Press, San Diego.

PIPERNO, D. R. 1988. Phytolith analysis: an archaeological and geological perspective. San Diego: Academic Press. 280p.

PIPERNO, D. R. 1995. Plant microfossils and their application in the New World Tropics. En: Archaeology in the Lowland American Tropics, editado por P. W. Stahl, pp. 130-153. Cambridge Univesity Press.

PIPERNO, D., 2006. Phytoliths. A Comprehensive Guide for Archaeologist and Paleoecologist. Altamira Press, 248pp.

PIPERNO, D. R. y D. M. Pearsall. 1993. The Nature and Status of Phytolith Analysis. En: Current Research in Phytolith Analysis applications in Archaeology and Paleoecology, editado por D. M.Pearsall y D. M. Piperno, pp. 9-18. Philadelphia (MASCA, University Museum of Archaeology and Anthropology).

PIPERNO, D. R. y D. M. Pearsall. 1998. The silica bodies of tropical American grasses: Morphology, taxonomy, and implications for grass systematics and fossil phytolith identification. Smithsonian Contributions to Botany 85: 1-40.

PRADO, J. L., Menegaz, A. N., Tonni, E. P., and Salemme, M. C.1987. Los mamíferos de la fauna local Paso Otero (Pleistoceno Tardío), Provincia de Buenos Aires. Aspectos paleoambientales y bioestratigráficos. Ameghiniana 24(3-4), 217-233. 
PRASAD, V., C. A. E. Stromberg, Habib Alimohammadian, Ashok Sahni. 2005. Dinosaur Coprolites and the Early Evolution of Grassees and Grazers. Science. 310:(18) 1177-1178.

PRATT, H. 1932. L'épidermis des graminées. Etude anatomique et systematique. An. Sci. Nat. (Bot). 10(14):117-325.

PRIETO, A. R. 2000. Vegetational history of the Late glacial-Holocene transition in the grasslands of eastern Argentina. Palaeogeography, Palaeoclimatology, Palaeoecology, 157: 167-188.

RABASSA, J., Coronato, A. M. Y Salemme, M. 2005. Chronology of the Late Cenozoic Patagonian glaciations and their correlation with biostratigraphic units of the Pampean region (Argentina). Journal of South American Earth Sciences, 20 (1-2): 81-103.

RAPP, G. y Mulholland, S. C. 1992. Phytolith Sysytematics, Plenum Press, New York.

REAL, R., A. Barbosa, D. Porras, M. Kin, A. Márquez,J. Guerrero, L. Palomo, E. Justo y J. Vargas. 2003. Relative importance of environment, human activityandspatial situation in determining the distribution ofterrestrial mammaldiversity in Argentina. Journal of Biogeography. 30: pp. 939-947.

RETALLACK, G. J. 1982. Paleopedological perspectives on the development of grasslands during the Tertiary. 3 th. North American Paleontological Convention, Proceedings. 2-417:421.

ROVNER, I. 1971. Potential of opal phytolith for use in paleoecological reconstruction. Quaternary Research, 1: 343-359.

ROVNER, I. 1988. Fitolitos en las plantas: un factor probable en los orígenes de la agricultura. Coloquio 5. Gordon Childe. Estudios sobre la revolución neolítica y la revolución urbana . Universidad Nacional Autónoma de México, DF: 113-131.

RUNGE, F.1999. The opal phytolith inventory of soils in central Africa-quantities, shapes, classification, and spectra. Review of Palaeobotany and Palynology 107 (1-2) 2353.

RUNGE, F., Fimbel, R. 1999. Opal phytoliths as evidence for the formation of savanna islands in the rain forest of Southeast Cameroon. In: Heine, K., Runge, G.E.J. (Eds.), International Union for Quaternary Research. Proceeding of the VXth INQUA Conference (15th:1999:Durban South Africa)— Palaeoecology of Africa and the surrounding islands, Tokyo, pp. 171- 189.

SANGSTER, A. G. y Parry, D. W. 1971. Silica deposition in the grass leaf in relation to transpiration and the effect of dinitrophenol. Annals of Botany, 35: 667-677.

SAUSSURE, 1804. Recherches sur la vegetation. Citado en Frenguelli , 1930.

SAYAGO, J., Collantes, M., Karlson, A., Sanabria, J., 2001. Genesis and distribution of the Late Pleistocene and Holocene loess of Argentina: a regional approximation. Quaternary International 76-77, 247-257.

SCASSO, R y Limarino C. 1997. Petrología y diagénesis de rocas clásticas. Publicación Especial Nro. 1 de la Asociación Argentina de Sedimentología. 258p.

SCOTT, L. 2002. Grassland development under glacial and interglacial conditions in southern Africa: review of pollen, phytolith and isotope evidence. Palaeogeography, Palaeoclimatology, Palaeoecology 177 (1-2), 47- 57.

SCHELLENBERG, H. C. 1908. The remains of plants from the North Kurgan, Anau. En Explorations in Turkestan: Expedition of 1904 2, editado por R. Pumpelly. pp. 471473. Washington, DC, Carnegie Institute. 
SENDULSKY, T. y L. G. Labouriau 1966 Corpos silicosos de gramineas dos Cerrados. I. Ann. da Acad. Brasileira de Ciencias, 38 (supl.): 159-170.

SORIANO, A. 1991. Río de la Plata Grasslands. En: Coupland, R. T. (Ed.), Natural Grasslands: Introduction and Western Hemisphere, Ecosystems of the world 8A, Amsterdam: 367-407.

SORIANO, A., León, R. J. C., Sala, O. E., Lavado, R. S., Deregibus, V.A., Cauhépé, M.A., Scaglia, O.A., Velázquez, C.A., Lemcoff, J.H., 1991. Río de la Plata grasslands. In: Coupland, R.T. (Ed.),Natural Grasslands: Introduction and Western Hemisphere, Ecosystems of the world. Elsevier, New York. 367-407.

SPALLETTI, L. A. 1992. El loess y el problema de la identificación de las loessitas. Extracto de la Revista del Museo de La Plata (nueva serie). Sección Geología, tomo XI: 45-56.

STRÖMBERG, C. A. E. 2004. Using phytolith assemblages to reconstruct the origin and spread of grass-dominated habitats in the great plains of North America during the late Eocene to early Miocene. Palaeogeography, Palaeoclimatology, Palaeoecology, 207: 239- 275.

STRUVE, G. A. 1835 De silicia in plantis nonnullis. University of Berlin.

TEERI, J.A., Stowe, L.G. 1976. Climatic patterns and the distribution of C4 grasses in North America. Oecologia (Berl.) 23:1 - 12.

TERUGGI, M. 1955. Algunas observaciones microscópicas sobre vidrio volcánico y ópalo organógeno en sedimentos pampianos. Notas del Museo, Facultad de Ciencias Naturales y Museo, Universidad Nacional de Eva Perón, XVIII Serie Geología. 66: $17-26$.

TERUGGI, M. E. 1957. The nature and origin of Argentine loess. Journal of Sedimentary Petrology, 27(3): 322-332.

THORN, V. C. 2004a. Phytolith evidence for C4-dominated grassland since the early Holocene at Long Pocket, northeast Queensland, Australia. Quaternary Research, 61: $168-180$.

THORN, V. C. 2004b. Phytoliths from subantarctic Campbell Island: plant production and soil surface spectra. Review of Palaeobotany and Palynology, 132: 37- 59.

TIESZEN, L.L., Senyimba, M.M., Imbamba, S.K., 1979. The distribution of C3 and C4 grasses and carbon isotope discrimination along a altitudinal and moisture gradient in Kenya. Oecologia 37:337-350.

TOMLINSON, P. B. 1961. Anatomy of the Monocotyledons. II. Palmae. Oxford University Press.

TONNI, E. y Fidalgo F. 1978. Consideraciones sobre los cambios climáticos durante el Pleistoceno Tardío-Reciente en la Provincia de Buenos Aires. Aspectos ecológicos y zoogeográficos relacionados. Ameghiniana. 15(1-2):235-253.

TONNI, E. P. 1992. Tapirus Brisson, 1972 (Mammalia, Perissodactyla) en el Lujanense (Pleistoceno superior-Holoceno inferior) de la Provincia de Buenos Aires. Ameghiniana, 29 (1): 3-8.

TONNI, E.P., Cione, A.L. y Figini, A.J. 1999. Predominance of arid climates indicated by mammals in the pampas of Argentina during the Late Pleistocene and Holocene. Palaeogeography, Palaeoclimatology, Palaeoecology 147: 257-281.

TONNI, E.P., Cione, A.L. Figini, A.J., Noriega, J.I., Carlini A.A. y Miquel, S. 2001. Extensión del período árido del Holoceno hasta los siglos $\mathrm{X}$ a XIII basada en el registro de moluscos terrestres en Entre Ríos (Argentina). $11^{\circ}$ Congreso 
Latinoamericano y $3^{\circ}$ Congreso Uruguayo de Geología, Actas versión electrónica; Montevideo.

TSOAR, H. y Pye, K. 1987.Dust transport and the question of desert loess formation. Sedimentology. 34:139-154.

TWISS, P. C. 1983. Dust deposition and opal phytoliths in the Great Plains. Transactions of the Nebraska Academy of Science, XI (Special Issue): 73-82.

TWISS, P. C. 1987. Grass-opal phytoliths as climatic indicators of the Great Plains Pleistocene. In: Johnson WC, ed. Quaternary environments of Kansas. Lawrence: Kansas Geological Survey, 179-188.

TWISS, P.C. 1992. Predicted world distribution of C3 and C4 grass phytoliths. En: Rapp, G. Jr \& S.C. Mulholland (eds.), "Phytoliths Systematics. Emerging Issues" Advances in Archaelogical and Museum Science 1: 113-128.

TWISS, P.C.; Suess, E. y Smith, R. M. 1969. Morphological classification of grass phytoliths. Soil Science of America, Proceedings 33:109-115.

VIGLIZZO, E. F., F. C. Frank y L. Carreño. 2006. Situación ambiental en las ecorregiones pampa y campos y malezales. Brown, A., U. Martinez Ortiz, M. Acerbi y J. Corcuera (Eds.), La Situación Ambiental Argentina 2005, Fundación Vida Silvestre Argentina. 263-273.

VRYDAGHS, L., Doutrelepont, H. 2000. Analyses phytolithariennes: acquis et perspectives. In: Servant-Vildary, S., Servant, M. (Eds.), Dynamiques á long terme des ècosystèmes forestiers intertropicaux. UNESCO, Paris.

WALANUS, A. y D. Nalepka. 1999a. POLPAL. Program for counting pollen grains, diagrams plotting and numerical analysis. Acta Palaeobotanica Suppl. 2: 659-661.

WALANUS, A. y D. Nalepka. 1999b. POLPAL. Numerical analysis. W. Szafer Institute of Botany. Polish Academy of Sciences. Poland. pp. 10.

WALANUS, A. y D. Nalepka. 2002. POLPAL. Counting pollen, tables storage and diagrams plotting. System manual. W. Szafer Institute of Botany. Polish Academy of Sciences. Poland. pp. 25.

WALLIS, L. A. 2003. An overview of leaf phytolith production patterns in selected northwest Australian flora. Review of Palaeobotany and Palynology, 125: 201-248.

WINSLOW, J.C., Hunt, E.R.J., Piper, S.C.2003. The influence of seasonal water availability on global C3 versus C4 grassland biomass and its implications for climate change research. Ecological Modelling 163 (1-2), 153- 173.

WU, Z. y Gao, F. 1985. The formation of loess in China. En Liu, T. (ed.). Quat. Geol. In global Environ. of China. 137:138.

ZARATE, M. 2003. Loess of southern South America. Quaternary Science Reviews 22 (2003) 1987-2006.

ZUCOL, A. F. 1992. Microfitolitos: I. Antecedentes y terminología. Ameghiniana 29 (4): 353-362.

ZUCOL, A. F. 1995. Microfitolitos: II. Análisis de las clasificaciones. Ameghiniana, 32 (3): 243-248.

ZUCOL, A. F. 1996a. Estudios morfológicos comparativos de especies de los géneros Stipa, Panicum y Paspalum (Poaceae), de la Provincia de Entre Ríos. Tesis Doctoral, UNLP. pp. 558.

ZUCOL, A. F. 1996b Microfitolitos de las Poaceae argentinas: I. Microfitolitos foliares de algunas especies del género Stipa (Stipeae: Arundinoideae: Poaceae), en la provincia de Entre Ríos. Darwiniana 34 (1-4): 151-172. 
ZUCOL, A. F. 1998. Microfitolitos de la Poaceae argentinas: II. Microfitolitos foliares de algunas especies del género Panicum (Paniceae: Panicoideae: Poaceae), en la provincia de Entre Ríos. Darwiniana 36 (1-4): 29-50.

ZUCOL, A. F.1999. Fitolitos: hacia un sistema clasificatorio. Ameghiniana 36 (4) Suplementos, Resúmenes: 43R.

ZUCOL, A. F. 2000. Fitolitos de Poaceae de argentinas: III. Fitolitos foliares de algunas especies del género Paspalum (Paniceae: Panicoideae: Poaceae), en la provincia de Entre Ríos. Darwiniana, 38 (1-2): 11-32.

ZUCOL, A. F. 2001. Fitolitos III. Una nueva metodología descriptiva. Asociaciones fitolíticas de Piptochaetium montevidense (Stipeae: Poaceae). Boletín de la Sociedad Argentina de Botánica, 36: 69-85.

ZUCOL, A. F. y Osterrieth, M. 1999. Asociaciones fitolíticas de las secuencias sedimentarias costeras del Holoceno Tardío de Mar Chiquita, Buenos Aires, Argentina. Ameghiniana, 36 (4-suplemento): 43-44R.

ZUCOL , A. F. y M. Osterrieth. 2002. Técnicas de preparación de muestras sedimentarias para la extracción de fitolitos. Ameghiniana 39 (3): 379-382.

ZUCOL , A.F., Brea, M., Madden, R. y Bellosi, E. 2004a. Análisis fitolítico de la transición Eoceno- Oligoceno en el perfil tipo de la Formación Sarmiento (Gran Barranca), Chubut. Ameghiniana, 41 (4) Suplemento: 25R.

ZUCOL, A. F. y Brea, M. 2000. Análisis fitolítico de la Formación Paraná en la provincia de Entre Ríos. En: Aceñolaza, G. \& R. Herbst (eds.), El Neógeno de Argentina. Serie Correlación Geológica, 14: 67 -76.

ZUCOL, A. F. y Brea, M. 2005a. Sistemática de fitolitos, pautas para un sistema clasificatorio. Un caso en estudio en la Formación Alvear (Pleistoceno inferior). Ameghiniana, 42 (4): 685-704.

ZUCOL, A. F. y Brea, M. 2005b. Actas del XVI Congreso Geológico Argentino. El registro fitolítico de los sedimentos cenozoicos de la localidad de Gran Barranca: su aporte a la reconstrucción paleoecológica.

ZUCOL, A. F. y Brea, M. 2006. Asociación fitolítica de la Formación Alvear (Pleistoceno inferior), Entre Ríos, Argentina. En: Zucol, A. F.; Osterrieth, M. y Brea, M. (Eds.) Fitolitos en suelos, sedimentos y sitios arqueológicos: Estado actual de sus conocimientos en América del Sur. (en prensa).

ZUCOL, A.F. y Bonomo, M. 2005. Nutria Mansa 1 site ethnobotany studies (General Alvarado, Buenos Aires province):IIComparative phytolith analysis of mills. The Phytolitarien 17(2): 6-7.

ZUCOL, A. F., Mazzoni, M. M. y Madden, R. H. 1999. Análisis fitolíticos en la secuencia sedimentaria de Gran Barranca, Chubut. Ameghiniana, 36 (4-suplemento): 43R.

ZUCOL, A. ; Brea, M. y Passeggi, E. Estudios paleoagrostológicos comparativos en sedimentos cenozoicos argentinos. . Temas de la Biodiversidad del Litoral fluvial argentino INSUGEO, Miscelánea, 12: 103 - 116.

ZUCOL, A. F., Brea M. y Passeggi E. 2008. Los estudios fitolíticos en América del Sur, una visión retrospectiva. Matices Interdisciplinarios en Estudios Fitolíticos y de Otros Microfósiles. M. A. Korstanje y M. del P. Babot, Ed. BAR International Series S 1870. 3-21.

ZUCOL, A. F., M. Brea, M. L. Osterrieth y G. A. Martínez. 2002. Análisis fitolítico de un horizonte sedimentario del sitio 2 de la Localidad Arqueológica Amalia, provincia de Buenos Aires. En Publicación especial, II Congreso de Arqueología de la Región Pampeana Argentina. Del mar a los salitrales, Diez mil años de Historia 
Pampeana en el umbral del Tercer Milenio, editado por D. L. Mazzanti, M. A. Berón y F. W. Oliva. pp. 355-363.

ZUCOL, A. F.; Gallego, L. y Fernández Honaine, M. 2005a. Capítulo 2. Análisis fitolíticos de la vegetación y su aspecto metodológico. En: Zucol, A.F.; Osterrieth, M. y Brea, M. (Eds.) Fitolitos. Estado actual de sus conocimientos en América del Sur 8 p. (en prensa)

ZUCOL, A. F.; Brea, M. y Scopel, A. 2005b. First record of fossil wood and phytolith assemblages of the late pleistocene in El Palmar National Park (Argentina). Journal of South American Earth Science, 20: 33-43.

ZUCOL, A. F.; Passeggi, E.; y Fernández Honaine, M. 2005c. Guía del curso: "Análisis fitolíticos: metodologías básicas y su aplicación a los estudios paleoecológicos". Univ. Autónoma de Entre Ríos. Facultad de Ciencia y Técnica.

ZUCOL, A. F; Fernández Honaine, M. y Brea, M. 2006a. Estudio comparativo de las asociaciones fitolíticas foliares de las especies de palmeras (Arecaceae) de Argentina y Uruguay. Resúmenes XIII Simposio Argentino de Paleobotánica y Palinología, Bahía Blanca: 137.

ZUCOL, A. F., Brea, M. y Matheos, M. 2006b. Estudio preliminar de microrestos silíceos del Paleoceno de la Formación Salamanca, provincia del Chubut, Argentina. En: Zucol, A. F.; Osterrieth, M. y Brea, M. (Eds.) Fitolitos en suelos, sedimentos y sitios arqueológicos: Estado actual de sus conocimientos en América del Sur. (en prensa)

ZUCOL, A. F., Brea, M., Carlini, A. A. y Madden, R. H. 2001. Análisis fitolíticos en la secuencia sedimentaria de Gran Barranca, Chubut, Argentina: II. El Miembro Colhué Huapi (Formación Sarmiento). Ameghiniana, 38 (4-suplemento): 50R.

ZUCOL, A. F.; Matheos, S. D.; Prámparo, M.; Brea, M. y Raigemborn, M. S. 2004. Enfoque multidisciplinario aplicado al estudio del Paleoceno inferior del Bosque José Ormaechea, Chubut, Argentina. Revista de la Asociación Argentina de Sedimentología, II (2): 85-86. 


\section{DESCRIPCIONES FITOLÍTICAS DE LAS MUESTRAS}

\section{PERFIL VIAL MAT \\ Muestra 1099}

En el grupo de los fitolitos prismáticos se hallaron dominando la muestra aquellos de bordes lisos Macroprismatolithum psilaristathum, presentes de manera muy frecuente $(33,62 \%)$. Fue escasa la presencia de los prismáticos de bordes ondulados, M. ondulathum $(3,47 \%)$ y rara la de los prismáticos elongados Euprismatolita elongata $(1,73 \%)$, los prismáticos de bordes serrados E. serrata, y los de bordes dentados M. denticulathum (0,65\% ambos). Los fitolitos prismáticos menores a $40 \mu \mathrm{m}$ estuvieron presentes de manera escasa (5,63\%). El grupo de los fitolitos esféricos se encontró dominado por el morfotipo Globulolithum sphaerochinulathum presente de manera frecuente $(11,27 \%)$. La presencia de G. sphaeropsilathum fue escasa $(8,24 \%)$, mientras que los fitolitos elípticos equinados, los esféricos con ornamentación clavada y elípticos lisos se presentaron de manera rara $(0,65 \%, 0,43 \%$ y $0,21 \%$ respectivamente). Otro grupo presente en la muestra fue el de los pelos, ganchos y aguijones, que incluye Aculeolithum ancistrathum (3,00\%), A. rostrathum $(1,73 \%)$, A. acuminatum $(0,65 \%)$, y $A$. aciculatum $(0,21 \%)$ todos presentes de manera rara. Dentro de los fitolitos bilobados o con forma de halterio, los que se hallaron presentes fueron los Euhalteriolita bitestata, E. botulata, Euhalteriolita de centro largo, formas pseudocapitadas, E. testilobata, y E. testicaudiculata presentes de manera rara $(1,95 \%, 1,73 \%, 0,43 \%, 0,43 \%$, $0,43 \%$, y $0,21 \%$ respectivamente). Los fitolitos flabelados se encontraron de manera rara, representados por los morfotipos Flabelolithum complanatum $(2,38 \%)$, Flabelolita elongata (1,95\%), Flabelolithum euflabelathum $(1,73 \%)$, Flabelolita excavata $(0,43 \%)$ y formas hemiflabeladas $(0,21 \%)$. El grupo de los fitolitos en cono truncado se encontró dominado por el morfotipo Estrobilolita complanata, presente de manera escasa $(4,77 \%)$ y por E. aplanada, $(0,65 \%)$, y E. equidimensionata $(0,43 \%)$ de manera rara. Doliolitas equidimensionata se presentó de manera rara $(2,77 \%)$. También de manera rara estuvieron presentes los elementos de conducción $(0,21 \%)$, Longolita $(0,43 \%)$, formas macroglobosas $(0,43 \%)$, Euhalteriolita tipo Stipa $(1,70 \%)$, Plurihalteriolita trilobata y P. catenulata (ambos $0,21 \%)$, Pileolita $(0,21 \%)$, fitolitos poliédricos 
mayores a $40 \mu \mathrm{m}(1,95 \%)$, menores a $40 \mu \mathrm{m}(1,73 \%)$ y placas hexagonales $(0,65 \%)$.

\section{Muestra 1100}

Dentro del grupo de los fitolitos prismáticos se hallaron dominando la muestra aquellos de bordes lisos Macroprismatolithum psilaristathum, presentes de manera muy frecuente (35,73\%). Fue escasa la presencia de los prismáticos de bordes ondulados, $M$. ondulathum $(3,59 \%)$ y rara la de Euprismatolita elongata $(1,91 \%), M$. denticulathum $(1,67 \%)$ y prismáticos de bordes serrados E. serrata (1,19\%). El grupo de los fitolitos en cono truncado se encontró dominado por Estrobilolita complanata, que se presentó de manera frecuente $(21,10 \%)$, mientras E. aplanada se presentó de manera escasa $(3,83 \%)$, y $E$. equidimensionata $(2,15 \%)$ fue rara. El grupo de los fitolitos esféricos estuvo dominado por el morfotipo Globulolithum sphaerochinulathum que se presentó de manera escasa $(10,07 \%)$ al igual que G. sphaeropsilathum $(5,27 \%)$. Otro grupo presente en la muestra fue el de los pelos, ganchos y aguijones, que incluye Aculeolithum ancistrathum $(0,71 \%)$, A. rostrathum $(0,47 \%)$, y formas intermedias $(0,23 \%)$ todas presentes de manera rara. Dentro de los fitolitos bilobados o con forma de halterio, los que se hallaron presentes fueron Euhalteriolita bitestata (2,51\%), Euhalteriolita centro largo, y E. testicaudiculata (ambos $0,23 \%$ ) todos presentes de manera rara. Las formas flabeladas se encontraron todas de manera rara, representadas por los morfotipos Flabelolithum complanathum (0,71\%), Flabelolita excavata $(0,47 \%)$ y Flabelolithum euflabelathum (0,23\%). Las Doliolitas que se hallaron fueron únicamente $D$. equidimensionata de manera rara $(0,71 \%)$, al igual que fitolitos prismáticos lisos menores a $40 \mu \mathrm{m}(1,91 \%)$. También fue rara la presencia de Longolita (2,23\%), los prismáticos lisos menores a $40 \mu \mathrm{m} \quad(0,71 \%)$, Euhalteriolita tipo Stipa $(1,65 \%)$, Plurihalteriolita trilobata $(0,23 \%)$, poliédricos mayores a $40 \mu \mathrm{m}$ y menores a $40 \mu \mathrm{m}$ (ambos 1,43\%) y placas hexagonales $(0,23 \%)$. 


\section{Muestra 1101}

En el grupo de los fitolitos prismáticos se hallaron dominando la muestra los de bordes lisos Macroprismatolithum psilaristathum, presentes de manera muy frecuente $(35,41 \%)$. Fue rara la presencia de los prismáticos de bordes ondulados, M. ondulathum (2,49\%), como de M. denticulathum (1,99\%), de Euprismatolita elongata $(0,99 \%)$, de prismáticos de bordes serrados, E. serrata, $(0,74 \%)$ y de Euprismatolita excavata $(0,24 \%)$. Los fitolitos esféricos se encontraron representados por los morfotipos Globulolithum sphaerochinulathum presente de manera frecuente $(14,71 \%)$ y $G$. sphaeropsilathum cuya presencia fue escasa $(5,98 \%)$. Los fitolitos en cono truncado estuvieron dominados por los morfotipos Estrobilolita complanata $(9,97 \%)$ y $E$. aplanada $(5,73 \%)$, que se presentaron de manera escasa. También estuvieron presentes de manera rara E. equidimensionata $(1,24 \%)$ y E. elongata $(0,99 \%)$. Los poliédricos estuvieron presentes, tanto mayores a 40 $\mu \mathrm{m}$ como los menores de manera rara $(3,24 \%$ y $1,99 \%$ respectivamente). De manera rara estuvieron también presentes los pelos, ganchos, y aguijones Aculeolithum ancistrathum $(0,24 \%)$, y A. rostrathum $(0,74 \%)$, los prismáticos breves $(2,74 \%)$, los halterios en forma de cruz Euhalteriolita cruciformata $(0,24 \%)$, aquellos en forma de silla de montar o saddle Doliolita equidimensionata $(0,99 \%)$, los bilobados Euhalteriolita bitestata $(0,99 \%)$, E. testicaudiculata $(1,99 \%)$, los fitolitos en forma flabelo Flabelolithum complanatum, formas intermedias, F. euflabelathum y Flabelolita excavata $(0,24 \%, 1,24 \%, 0,99 \%$ y $0,99 \%$ respectivamente), Longolita $(0,49 \%)$, formas esféricas lisas de gran tamaño $(0,24 \%)$, Euhalteriolita tipo Stipa $(0,98 \%)$, prismáticos menores a $40 \mu \mathrm{m}(0,99 \%)$ y placas hexagonales $(0,49 \%)$.

\section{Muestra 1102}

En el grupo de los fitolitos prismáticos se hallaron dominando la muestra aquellos de bordes lisos Macroprismatolithum psilaristathum, presentes de manera muy frecuente $(27,83 \%)$. Fue escasa la presencia de los prismáticos de bordes ondulados, $\mathrm{M}$. ondulathum $(3,69 \%)$ y rara la de los elongados $\mathrm{M}$. denticulathum $(1,97 \%)$, los de bordes dentados $M$. denticulathum $(1,72 \%)$ y los de bordes serrados, E. serrata $(1,47 \%)$. El grupo de los fitolitos en cono truncado se encontró dominado por el morfotipo Estrobilolita complanata, que 
se presenta de manera frecuente $(14,53 \%)$. E. aplanada de manera escasa $(6,89 \%)$ al igual que E. equidimensionata. (4,18\%). Fue rara la presencia de $\mathrm{E}$. elongata (2,70\%). El grupo de los fitolitos esféricos se encontró dominado por el morfotipo Globulolithum sphaerochinulathum que se presentó de manera frecuente $(13,05 \%)$, G. sphaeropsilathum de manera escasa $(3,69 \%)$ y las elípticas equinadas de manera rara $(0,24 \%)$. Aculeolithum rostrathum $(1,23 \%)$, A. aciculathum $(0,98 \%)$, A. ancistrathum $(0,73 \%)$, y A. acuminathum $(0,24 \%)$ todas presentes de manera rara. Dentro de los fitolitos bilobados o con forma de halterio, los que se hallaron presentes fueron Euhalteriolita bitestata $(1,72 \%)$, E. testicaudiculata $(1,23 \%)$, Euhalteriolita centro largo y E. testilobata (ambos 0,24\%) todos presentes de manera rara. Las flabeladas se encontraron de manera rara, representadas por los morfotipos Flabelolita excavata y Flabelolithum euflabelathum (0,49\%). Las Doliolitas se hallaron representadas únicamente por Doliolita equidimensionata de manera rara $(2,21 \%)$, al igual que las prismáticas breves $(1,72 \%)$, los elementos de conducción y las cruces Euhalteriolita cruciformata (ambas 0,24\%). También fue rara la presencia de Longolita (2,23\%), de los prismáticos menores a $40 \mu \mathrm{m}(1,97 \%)$, Euhalteriolita tipo Stipa $(2,16 \%)$, Plurihalteriolita trilobata $(0,49 \%)$, poliédricos mayores a 40 $\mu \mathrm{m}(1,23 \%)$ y menores a $40 \mu \mathrm{m}(1,47 \%)$ y placas hexagonales $(0,24 \%)$.

\section{Muestra 1103}

En el grupo de los fitolitos prismáticos se hallaron dominando la muestra aquellos de bordes lisos Macroprismatolithum psilaristathum, presentes de manera muy frecuente $(26,05 \%)$. Fue rara la presencia de los prismáticos de bordes ondulados, $M$. ondulathum $(2,23 \%)$, de $M$. denticulathum $(1,48 \%)$, Euprismatolita elongata $(0,99 \%)$, y de los de bordes serrados E. serrata $(0,49 \%)$. El grupo de los fitolitos esféricos se encontró dominado por el morfotipo Globulolithum sphaerochinulathum, presente de manera muy frecuente $(24,06 \%)$, G. sphaeropsilathum (1,98\%) y elípticos equinados se presentaron de manera rara $(0,74 \%)$. El grupo de los fitolitos en cono truncado se encontró dominado por Estrobilolita complanata, presente de manera frecuente $(13,64 \%)$. E. aplanada de manera escasa $(5,21 \%)$ al igual que $E$. equidimensionata. $(3,47 \%)$. Fue rara la presencia de E. elongata $(1,73 \%)$, Estrobilolita cotilata $(0,74 \%)$. Otro grupo presente en la muestra de manera rara 
fue el de las aculeolitas, que incluye Aculeolithum rostrathum (1,98\%) y A. ancistrathum $(1,24 \%)$. Los poliédricos se encontraron de manera escasa $(3,97 \%)$. Las Doliolitas estuvieron presentes de manera rara, representadas por las Doliolita equidimensionata $(1,24 \%)$. Dentro de los fitolitos bilobados Euhalteriolita testicaudiculata $(0,74 \%)$, E. bitestata $(0,49 \%)$, y formas intermedias $(0,49 \%)$ se presentaron de manera rara. Las flabeladas se encontraron de manera rara, representadas por Flabelolita excavata $(1,24 \%)$, Flabelolithum complanatum $(0,99 \%)$ y $\mathrm{F}$. euflabelathum $(0,74 \%)$. También fue rara la presencia de los prismáticos breves, de Longolita, prismáticos lisos menores a $40 \mu \mathrm{m}$, formas macroglobosas lisas, Pileolita, formas triangulares, y elementos con papilas (todos $0,24 \%$ ), Plurihalteriolita trilobata $(0,49 \%)$, y Euhalteriolita tipo Stipa $(1,22 \%)$.

\section{PERFIL GAUCHITO GIL}

\section{Muestra 1105}

El grupo de los fitolitos prismáticos rectangulares se halló dominado por el morfotipo Macroprismatolithum psilaristathum, prismático de bordes lisos, de manera muy frecuente (22,52\%). Aquellos de bordes dentados (M. denticulathum) fueron escasos $(3,60 \%)$. Raros los prismáticos de bordes ondulados $\mathrm{M}$. ondulathum $(2,02 \%)$, los prismáticos elongados, Euprismatolita elongata, $(1,35 \%)$, y los prismáticos de bordes serrados E. serrata $(0,90 \%)$. Los prismáticos menores a $40 \mu \mathrm{m}(3,37 \%)$ se presentaron de manera escasa. Los estróbilos acampanados Estrobilolita complanata $(21,39 \%)$ fueron muy frecuentes y los aplanados E. aplanada $(10,13 \%)$ frecuentes. Los equidimensionales, E. equidimensionata $(5,40 \%)$ escasos. Los estróbilos elongados con cintura E. elongata $(0,67 \%)$ fueron raros. Dentro de los fitolitos esféricos se presentaron de manera escasa los equinados, Globulolithum sphaerochinulathum (3,15\%). Mientras que los esféricos lisos (G. sphaeropsilathum) fueron raros $(0,67 \%)$. Los bilobados que se presentaron de manera escasa, fueron Euhalteriolita bitestata $(2,70 \%)$. Euhalteriolita centro largo $(1,12 \%)$, E. testicaudiculata $(0,90 \%)$, E. testilobata $(0,22 \%)$, E. botulata $(0,22 \%)$. Los pseudocapitados $(0,45 \%)$ lo hicieron de forma rara, al igual que los polilobados Plurihalteriolita inequilobata $(0,22 \%)$, P. catenulata $(0,45 \%)$ y $\mathrm{P}$. trilobata $(1,57 \%)$, las cruces Halteriolita cruciformata $(0,22 \%)$ y los halterios 
Euhalteriolita tipo Stipa $(1,57 \%)$. Fueron raros: los poliédricos superiores a 40 $\mu \mathrm{m}$ y los inferiores (ambos 1,80\%), los pelos, ganchos, y aguijones Aculeolithum rostrathum (0,90\%), A. ancistrathum (0,22\%), y formas intermedias $(0,22 \%)$, Doliolita equidimensionata $(0,90 \%)$, elementos de conducción $(0,45 \%)$, los naviculados Longolita $(0,90 \%)$, las bulliformes Flabelolita excavata $(0,22 \%)$ y Flabelolithum complanathum $(0,45 \%)$, formas multilobuladas $(0,22 \%)$, elípticas a circulares $(1,57 \%)$, redondeadas y triangulares $(0,22 \%)$.

\section{Muestra 1106}

El grupo de los fitolitos prismáticos rectangulares se halló dominado por el morfotipo Macroprismatolithum psilaristathum, prismático de bordes lisos, de manera muy frecuente $(26,66 \%)$. Los prismáticos elongados, Euprismatolita elongata, $(2,88 \%)$ y aquellos de bordes ondulados $M$. ondulathum $(3,55 \%)$ fueron escasos. Raros los prismáticos de bordes dentados (M. denticulathum) $(0,88 \%)$, los prismáticos de bordes serrados E. serrata $(1,11 \%)$ y los prismáticos lisos menores a $40 \mu \mathrm{m}(1,33 \%)$. Los estróbilos acampanados Estrobilolita complanata $(26,66 \%)$ fueron muy frecuentes y los aplanados $E$. aplanada (10,00\%) frecuentes. Los equidimensionales, E. equidimensionata $(3,11 \%)$ escasos. Los estróbilos elongados con cintura E. elongata $(2,44 \%)$ fueron raros. Dentro de los fitolitos esféricos se presentaron de manera escasa los equinados, Globulolithum sphaerochinulathum (3,33\%), mientras que los esféricos lisos (G. sphaeropsilathum) fueron raros $(1,11 \%)$. Los bilobados que se presentaron de manera escasa, fueron Euhalteriolita bitestata $(4,22 \%)$, mientras Euhalteriolita centro largo $(0,22 \%)$, E. botulata $(0,66 \%)$, E. testicaudiculata $(0,44 \%)$, y E. testilobata $(0,44 \%)$, lo hicieron de forma rara, al igual que los polilobados Plurihalteriolita trilobata $(0,22 \%)$, los halterios Euhalteriolita tipo Stipa $(1,11 \%)$ y las cruces Halteriolita cruciformata $(0,22 \%)$. Fueron raros: los poliédricos superiores a $40 \mu \mathrm{m}(1,55 \%)$ y poliédricos inferiores a $40 \mu \mathrm{m}(0,22 \%)$, pelos, ganchos, y aguijones Aculeolithum rostrathum $(0,66 \%), A$. ancistrathum $(0,22 \%)$, y formas intermedias $(1,55 \%)$, los prismáticos breves $(0,88 \%)$, aquellos en forma de silla de montar Doliolita equidimensionata $(0,66 \%)$, los naviculados Longolita $(0,66 \%)$, elementos de 
conducción (0,44\%), las bulliformes Flabelolita excavata $(0,22 \%)$ y Flabelolithum euflabelathum (1,33\%).

\section{Muestra 1107}

El grupo de los fitolitos prismáticos rectangulares se halló dominado por el morfotipo Macroprismatolithum psilaristathum, prismático de bordes lisos, de manera muy frecuente $(24,89 \%)$. Fueron escasos los prismáticos elongados, Euprismatolita elongata, $(4,32 \%)$, y los prismáticos de bordes ondulados $\mathrm{M}$. ondulathum (2,59\%). Raros los prismáticos de bordes serrados E. serrata $(1,15 \%)$, los de extremos cóncavos (E. excavata) (0,21\%), y los menores a 40 $\mu \mathrm{m}(2,37 \%)$. Los estróbilos acampanados Estrobilolita complanata $(23,37 \%)$ fueron muy frecuentes y los aplanados E. aplanada (12,98\%) frecuentes. Los equidimensionales, E. equidimensionata (3,46\%) escasos. Los estróbilos elongados con cintura E. elongata $(1,51 \%)$ fueron raros. Dentro de los fitolitos esféricos se presentaron de manera escasa los equinados, Globulolithum sphaerochinulathum (6,27\%). Mientras que los esféricos lisos (G. sphaeropsilathum) fueron raros (1,08\%). Los bilobados que se presentaron de manera escasa, fueron Euhalteriolita bitestata (3,24\%). E. testicaudiculata $(1,15 \%)$, E. testilobata $(0,64 \%)$, E. centro largo $(0,43 \%)$, y $E$. botulata $(0,21 \%)$, lo hicieron de forma rara, al igual que los halterios Euhalteriolita tipo Stipa $(2,16 \%)$. Fueron raros: los poliédricos superiores a $40 \mu \mathrm{m}(0,64 \%)$, los naviculados Longolita $(0,21 \%)$, los elementos de conducción $(0,64 \%)$, las bulliformes Flabelolithum euflabelathum (0,64\%). Aquellos en forma de silla de montar o saddle Doliolita equidimensionata (0,43\%), los aguijones Aculeolithum rostrathum (1,73\%), y $\mathrm{A}$. acuminathum (1,08\%).

\section{Muestra 1108}

El grupo de los fitolitos prismáticos rectangulares se halló dominado por el morfotipo Macroprismatolithum psilaristathum, prismático de bordes lisos, de manera muy frecuente $(28,46 \%)$. Fueron escasos los prismáticos elongados, Euprismatolita elongata, (3,34\%), y los prismáticos de bordes ondulados $\mathrm{M}$. ondulathum (3,58\%). Raros los prismáticos de bordes serrados $E$. serrata $(0,95 \%), M$. denticulathum $(0,71 \%)$ y los prismáticos lisos menores a $40 \mu \mathrm{m}$ $(1,66 \%)$. Los estróbilos acampanados Estrobilolita complanata $(19,37 \%)$ fueron 
muy frecuentes y los aplanados E. aplanada (12,67\%) frecuentes. Los equidimensionales, E. equidimensionata, los estróbilos elongados con cintura E. elongata (ambos 1,19\%), y E. cotilata (0,23\%) fueron raros. Dentro de los fitolitos esféricos se presentaron de manera frecuente los equinados, Globulolithum sphaerochinulathum (9,80\%). Mientras que los esféricos lisos (G. sphaeropsilathum) fueron raros $(0,71 \%)$. Los bilobados o halterios que se presentaron de manera escasa, fueron Euhalteriolita bitestata (4,06\%). E. testicaudiculata $(2,63 \%)$, E. testilobata $(0,47 \%)$, E. centro largo $(0,23 \%)$, y E. botulata $(0,71 \%)$, lo hicieron de forma rara, al igual que los polilobados Plurihalteriolita inequilobata $(0,23 \%)$, las cruces Halteriolita cruciformata $(0,47 \%)$ y los halterios Euhalteriolita tipo Stipa (1,67\%). También fueron raros: los poliédricos superiores a $40 \mu \mathrm{m}$, las bulliformes Flabelolithum euflabelathum y formas hemiflabeladas $(0,23 \%)$, Doliolita equidimensionata $(1,43 \%)$, los aguijones Aculeolithum rostrathum (0,71\%), A. ancistrathum (0,95\%), y A. acuminatum $(0,47 \%)$.

\section{Muestra 1109}

El grupo de los fitolitos prismáticos rectangulares se halló dominado por el morfotipo Macroprismatolithum psilaristathum, prismático de bordes lisos, de manera muy frecuente $(24,81 \%)$. Aquellos de bordes ondulados $\mathrm{M}$. ondulathum fueron escasos $(3,16 \%)$. Raros los prismáticos de bordes dentados (M. denticulathum) $(0,48 \%)$, los prismáticos elongados, Euprismatolita elongata $(2,18 \%)$, y los prismáticos de bordes serrados E. serrata $(1,19 \%)$. También fueron raros los prismáticos lisos menores a $40 \mu \mathrm{m}(2,17 \%)$. Los estróbilos acampanados Estrobilolita complanata $(21,16 \%)$ fueron muy frecuentes y los aplanados E. aplanada $(12,65 \%)$ frecuentes. Los equidimensionales, E. equidimensionata $(2,67 \%)$ escasos. Los E. elongata $(1,70 \%)$ raros. Dentro de los fitolitos esféricos se presentaron de manera frecuente los equinados, Globulolithum sphaerochinulathum (13,86\%). Mientras que los esféricos lisos (G. sphaeropsilathum) $(1,21 \%)$ y los elípticos lisos $(0,24 \%)$ fueron raros. Los bilobados que se presentaron de manera escasa, fueron Euhalteriolita bitestata $(2,67 \%)$. E. botulata, E. testilobata (ambos $0,24 \%)$ y E. testicaudiculata $(0,72 \%)$ lo hicieron de forma rara, al igual que los polilobados Plurihalteriolita inequilobata $(0,24 \%)$, las cruces Halteriolita cruciformata $(0,48 \%)$ y los halterios 
Euhalteriolita tipo Stipa $(1,94 \%)$. Fueron raros: los poliédricos superiores a 40 $\mu \mathrm{m}(0,24 \%)$ y los inferiores a $40 \mu \mathrm{m}(0,97 \%)$, Aculeolithum rostrathum $(1,21 \%)$, Doliolita equidimensionata $(1,45 \%)$, los elementos de conducción $(0,24 \%)$ y Longolita $(0,48 \%)$.

\section{Muestra 1110}

El grupo de los fitolitos prismáticos rectangulares se halló dominado por el morfotipo Macroprismatolithum psilaristathum, prismático de bordes lisos, de manera muy frecuente $(29,43 \%)$. Raros aquellos de bordes ondulados $M$. ondulathum (1,63\%), los prismáticos de bordes dentados (M. denticulathum) $(1,16 \%)$, los prismáticos elongados, Euprismatolita elongata, $(0,93 \%)$, y los prismáticos de bordes serrados E. serrata $(1,86 \%)$. También fueron raros los prismáticos lisos menores a $40 \mu \mathrm{m}(2,80 \%)$. Los estróbilos acampanados Estrobilolita complanata $(21,96 \%)$ fueron muy frecuentes y los aplanados $E$. aplanada (12,85\%) frecuentes. Los equidimensionales, E. equidimensionata $(1,63 \%)$, los elongados con cintura E. elongata $(2,57 \%)$ y E. cotilata $(0,23 \%)$ raros. Dentro de los fitolitos esféricos se presentaron de manera frecuente los equinados, Globulolithum sphaerochinulathum (10,04\%). Mientras que los esféricos lisos (G. sphaeropsilathum) $(0,93 \%)$ fueron raros. También fueron raros: los bilobados Euhalteriolithum testicaudiculata (1,63\%), E. bitestata $(1,16 \%)$, y E. testilobata $(0,93 \%)$, Euhalteriolita tipo Stipa $(2,10 \%)$, los poliédricos superiores a $40 \mu \mathrm{m}$ y los inferiores a $40 \mu \mathrm{m}(0,46 \%)$, Aculeolithum rostrathum $(1,16 \%)$ y formas intermedias correspondientes a aguijones $(0,23 \%)$, Doliolita equidimensionata $(1,63 \%)$ y Longolita $(1,16 \%)$.

\section{Muestra 1111}

El grupo de los fitolitos prismáticos rectangulares se halló dominado por el morfotipo Macroprismatolithum psilaristathum de manera muy frecuente (25,05\%). Fueron escasos M. ondulathum (3,30\%). Raros los prismáticos de bordes serrados, E. serrata $(1,89 \%)$, los prismáticos de bordes dentados (M. denticulathum) (1,65\%) y los prismáticos elongados, Euprismatolita elongata $(1,18 \%)$. También fueron raros los prismáticos lisos menores a $40 \mu \mathrm{m}(1,40 \%)$. Los estróbilos acampanados Estrobilolita complanata (22,93\%) fueron muy frecuentes y los aplanados E. aplanada (10,63\%) frecuentes. Fueron escasos 
los equidimensionales, E. equidimensionata (3,54\%). Mientras que los elongados con cintura E. elongata $(0,94 \%)$ fueron raros. Dentro de los fitolitos esféricos se presentaron de manera frecuente los equinados, Globulolithum sphaerochinulathum (11,34\%). Mientras que los esféricos lisos (G. sphaeropsilathum) $(0,94 \%)$ y los elípticos lisos $(0,23 \%)$ fueron raros. Los bilobados que se presentaron de manera escasa fueron los Euhalteriolithum testicaudiculata $(2,60 \%)$ mientras que E. bitestata $(0,47 \%)$, E. botulata y $\mathrm{E}$. testilobata $(0,23 \%)$ lo hicieron en forma rara al igual que los halterios Euhalteriolita tipo Stipa $(1,41 \%)$ y los polilobados Plurihalteriolita inequilobata $(0,23 \%)$. También fueron raros los poliédricos superiores a $40 \mu \mathrm{m}(0,23 \%)$, las placas hexagonales $(0,23 \%)$, los pelos, ganchos, y aguijones Aculeolithum rostrathum $(1,65 \%)$ y $A$. acuminathum $(0,47 \%)$, Doliolita equidimensionata $(2,12 \%)$, las flabeladas Flabelolithum euflabelathum $(0,47 \%)$ y los naviculados Longolita $(1,18 \%)$.

\section{Muestra 1112}

El grupo de los fitolitos prismáticos rectangulares se halló dominado por el morfotipo Macroprismatolithum psilaristathum, prismático de bordes lisos, de manera muy frecuente $(31,86 \%)$. Fueron raros los prismáticos elongados, Euprismatolita elongata, $(2,94 \%)$, aquellos de bordes ondulados $\mathrm{M}$. ondulathum $(2,69 \%)$, los prismáticos de bordes serrados (E. serrata) $(1,71 \%)$ y los prismáticos de bordes dentados (M. denticulathum) (1,22\%). También fueron raros los prismáticos lisos menores a $40 \mu \mathrm{m}$ (4,16\%). Los estróbilos acampanados Estrobilolita complanata $(15,68 \%)$ y los aplanados E. aplanada $(11,02 \%)$ fueron frecuentes. Mientras que los elongados con cintura E. elongata $(1,22 \%)$ y los $E$. equidimensionata $(1,96 \%)$ fueron raros. Dentro de los fitolitos esféricos se presentaron de manera escasa los equinados, Globulolithum sphaerochinulathum $(9,55 \%)$ y los esféricos lisos (G. sphaeropsilathum) $(2,45 \%)$ raros. También fueron raros los bilobados Euhalteriolita bitestata $(1,47 \%)$, E. testicaudiculata $(1,22 \%)$, E. botulata $(0,49 \%)$ y $E$. testilobata $(0,24 \%)$, los halterios E. tipo Stipa $(1,22 \%)$ y los polilobados Plurihalteriolita inequilobata $(0,49 \%)$, los poliédricos superiores a $40 \mu \mathrm{m}(0,98 \%)$ y los inferiores a $40 \mu \mathrm{m}(0,73 \%)$, las placas hexagonales $(0,24 \%)$, Aculeolithum rostrathum $(2,45 \%)$, y $A$. acuminatum $(0,24 \%)$, Doliolita equidimensionata $(1,22 \%)$, las 
flabeladas Flabelolita excavata y Flabelolithum complanatum $(0,24 \%)$ y los naviculados Longolita $(0,73 \%)$.

\section{Muestra 1113}

El grupo de los fitolitos prismáticos rectangulares se halló dominado por el morfotipo Macroprismatolithum psilaristathum, prismático de bordes lisos, de manera muy frecuente $(26,76 \%)$. Aquellos de bordes ondulados $\mathrm{M}$. ondulathum fueron escasos (5,39\%). Euprismatolita elongata, prismáticos elongados (2,58\%), M. denticulathum (prismáticos de bordes dentados) $(0,93 \%)$ y los prismáticos de bordes serrados, E. serrata $(0,93 \%)$ fueron raros, al igual que los prismáticos lisos menores a $40 \mu \mathrm{m}(2,34 \%)$. Los estróbilos acampanados Estrobilolita complanata $(13,61 \%)$ fueron frecuentes y los aplanados $E$. aplanada $(6,10 \%)$ escasos. Los estróbilos elongados con cintura E. elongata $(0,93 \%)$, y los equidimensionales, E. equidimensionata $(0,70 \%)$ fueron raros. Dentro de los fitolitos esféricos se presentaron de manera frecuente los equinados, Globulolithum sphaerochinulathum (8,68\%). Mientras que los esféricos lisos (G. sphaeropsilathum) fueron raros $(1,87 \%)$, al igual que los elípticos lisos $(0,23 \%)$ y formas esféricas con ornamentación clavada $(0,70 \%)$. Los bilobados que se presentaron de manera escasa, fueron Euhalteriolita bitestata $(4,69 \%)$. E. testicaudiculata $(0,70 \%)$, E. testilobata $(0,70 \%)$, E. botulata $(0,46 \%)$, y formas pseudocapitadas $(0,93 \%)$ lo hicieron de forma rara, al igual que los polilobados Plurihalteriolita inequilobata $(0,23 \%), P$. catenulata $(0,46 \%)$ y $P$. trilobata $(0,70 \%)$ y las cruces Halteriolita cruciformata $(0,23 \%)$. Los halterios Euhalteriolita tipo Stipa, fueron escasos $(2,81 \%)$. Fueron raros: los poliédricos superiores a $40 \mu \mathrm{m}$ y los inferiores (ambos 1,87\%), Aculeolithum rostrathum $(2,58 \%)$, A. ancistrathum $(1,17 \%)$, formas intermedias correspondientes a aguijones $(1,65 \%)$ y $A$. acuminatum $(0,23 \%)$, Flabelolithum euflabelathum, Flabelolita excavata (ambas 0,70\%), Flabelolithum complanathum, Flabelolita elongata $(0,23 \%)$, placas verrucosas $(0,46 \%)$, Doliolita equidimensionata $(0,93 \%)$, Longolita $(0,93 \%)$, formas multilobadas $(0,23 \%)$ y estrelladas $(0,23 \%)$. 


\section{PERFIL LAS CUEVAS}

\section{Muestra 1200}

Los fitolitos en cono truncado se encontraron representados de manera muy frecuente por los estróbilos acampanados Estrobilolita complanata $(17,63 \%)$ y los aplanados E. aplanada (12,80\%). Los estróbilos equidimensionales (E. equidimensionata) fueron frecuentes $(5,31 \%)$. Tanto los estróbilos con cintura E. elongata como los de punta en un extremo se presentaron de manera escasa $(3,86$ y $2,17 \%)$, mientras que $E$. cotilata lo hizo en forma rara $(1,44 \%)$. El grupo de los fitolitos prismáticos se halló dominado por el morfotipo Macroprismatolithum psilaristathum, prismático de bordes lisos, de manera frecuente (9,90\%). Fue escasa la presencia de M. ondulathum, fitolitos prismáticos de bordes ondulados (3,86\%) y Euprismatolita elongata, prismáticos elongados (1,69\%). M. denticulathum y Euprismatolita serrata (prismáticos de bordes dentados y serrados respectivamente) (1,69\% y 0,24\%) fueron raros. Dentro de los fitolitos esféricos se presentaron de manera frecuente los equinados Globulolithum sphaerochinulathum (7,48\%). Mientras que la presencia de los esféricos lisos (G. sphaeropsilathum) y elípticos lisos $(0,72$ y $0,24 \%)$ fue rara. Las doliolitas o sillas de montar estuvieron representadas de manera escasa $(1,93 \%)$ por Doliolita equidimensionata y de manera rara por D. oblata y D. elongata $(0,48 \%$ ambas $)$. Los bilobados 0 halterios se presentaron de manera rara, tanto con Euhalteriolita bitestata, E. testicaudiculata, E. botulata, E. testilobata y Euhalteriolita de centro largo $(1,44 \%, 0,72 \%, 0,72 \%, 0,48 \%, y$ y $0,24 \%$ respectivamente). Aquellos en forma de abanico representados de manera escasa por Flabelolithum euflabelathum $(2,17 \%)$ y rara por F. excavata $(1,69 \%)$ y $\mathrm{F}$. complanatum $(1,20 \%)$. Otro grupo presente en la muestra fue el de los pelos, ganchos y aguijones, o aculeolitas, incluyendo Aculeolithum ancistrathum, A. rostrathum, A. acuminathum, y A aciculathum, todas presentes de manera rara $(1,44 \%, 1,20 \%, 1,20 \%$ y $0,24 \%$ respectivamente). Los poliédricos superiores a $40 \mu \mathrm{m}$ fueron frecuentes $(5,79 \%)$. Los halterios Euhalteriolita tipo Stipa, escasos (1,93\%). Otros morfotipos cuya presencia fue rara fueron: los prismáticos breves, $(0,72 \%)$, los Longolita $(1,44 \%)$, las formas multilobadas $(0,24 \%)$, los prismáticos lisos menores a $40 \mu \mathrm{m}(1,44 \%)$, Plurihalteriolita trilobata $(0,48 \%)$, Pileolita $(1,46 \%)$, 
poliédricos inferiores a $40 \mu \mathrm{m}(0,72 \%)$, formas triangulares $(0,96 \%)$ y placas hexagonales $(0,24 \%)$.

\section{Muestra 1201}

Los fitolitos en cono truncado se encontraron representados de manera muy frecuente por los estróbilos acampanados Estrobilolita complanata $(15,36 \%)$ y por los aplanados E. aplanada (12,56\%). Los estróbilos con cintura E. elongata fueron escasos (4,01\%). Los equidimensionales (E. equidimensionata), los de punta en un extremo y $\mathrm{E}$. cotilata se presentaron de manera rara $(1,41 \%, 0,94 \%$ y $0,47 \%)$. El grupo de los fitolitos prismáticos se halló dominado por el morfotipo Macroprismatolithum psilaristathum, prismático de bordes lisos, de manera muy frecuente (10,16\%). Fue escasa la presencia de $M$. ondulathum, fitolitos prismáticos de bordes ondulados $(3,07 \%)$. Euprismatolita elongata, prismáticos elongados $(0,94 \%)$, Euprismatolita excavata y Euprismatolita serrata (prismáticos de bordes serrados, E. serrata y de bordes serrados respectivamente) $(0,70 \%$ y $0,47 \%)$ fueron raros. Dentro de los fitolitos esféricos se presentaron de manera muy frecuente los equinados Globulolithum sphaerochinulathum (11,11\%). Mientras que la presencia de los esféricos lisos (G. sphaeropsilathum) y elípticos equinados $(0,70$ y $0,47 \%)$ fue rara. Las doliolitas o sillas de montar estuvieron representadas de manera frecuente $(6,38 \%)$ por las Doliolita equidimensionata. Los bilobados que se presentaron de manera escasa, fueron Euhalteriolita bitestata $(2,60 \%)$ y $E$. testicaudiculata $(2,83 \%)$; mientras E. botulata, E. testilobata y, Euhalteriolita centro largo $(1,41 \%, 0,70 \%$, y $0,47 \%)$ lo hicieron de forma rara. Los de formas de abanico se presentaron de manera rara con Flabelolithum euflabelathum $(0,47 \%)$, formas hemiflabeladas $(0,70 \%)$, Flabelolita excavata $(1,18 \%)$ y Flabelolithum complanatum $(1,18 \%)$. Los poliédricos superiores a $40 \mu \mathrm{m}$ fueron escasos $(3,78 \%)$, mientras que los inferiores a $40 \mu \mathrm{m}$ fueron raros $(0,70 \%)$. Los halterios Euhalteriolita tipo Stipa, fueron escasos $(2,83 \%)$, al igual que los prismáticos lisos menores a $40 \mu \mathrm{m}(2,83 \%)$. Otro grupo presente en la muestra fue el de los aguijones, o aculeolitas, incluyendo Aculeolithum ancistrathum presente de manera escasa $(2,12 \%)$, A. rostrathum, A aciculathum, y formas intermedias todas presentes de manera rara $(1,41 \%, 0,70 \%, 0,23 \%$ y $0,23 \%$ respectivamente). Otros morfotipos cuya presencia fue rara fueron: los 
prismáticos breves, $(0,70 \%)$, las cruces Halteriolita cruciformata $(0,23 \%)$, los Longolita $(0,70 \%)$, Plurihalteriolita trilobata $(0,47 \%)$, poliédricos inferiores a 40 $\mu \mathrm{m}(0,70 \%)$, formas triangulares $(0,94 \%)$, elementoa con papilas $(0,23 \%)$ y Placas hexagonales $(0,23 \%)$.

\section{Muestra 1202}

Los fitolitos en cono truncado se encontraron representados de manera muy frecuente por los estróbilos acampanados Estrobilolita complanata $(16,76 \%)$ y los aplanados E. aplanada (12,44\%). Los equidimensionales ( $E$. equidimensionata) fueron frecuentes $(5,50 \%)$. Los estróbilos elongados con cintura $E$. elongata fueron escasos $(4,78 \%)$. los de punta en un extremo y $E$. cotilata se presentaron de manera rara $(0,23 \%)$. El grupo de los fitolitos prismáticos rectangulares se halló dominado por el morfotipo Macroprismatolithum psilaristathum, prismático de bordes lisos, de manera muy frecuente $(10,52 \%)$. Los fitolitos de bordes ondulados $M$. ondulathum fueron frecuentes $(6,45 \%)$. Mientras que M. anisocornisathum (0,47\%), Euprismatolita elongata, prismáticos elongados $(0,71 \%), M$. denticulathum $(1,19 \%)$ y Euprismatolita serrata $(0,23 \%)$ (prismáticos de bordes dentados y de bordes serrados respectivamente) fueron raros. Dentro de los fitolitos esféricos se presentaron de manera muy frecuente los equinados, Globulolithum sphaerochinulathum (12,44\%). Mientras que la presencia de los esféricos lisos (G. sphaeropsilathum) y elípticos lisos fue rara $(0,95$ y $0,23 \%)$. Las doliolitas 0 sillas de montar estuvieron representadas de manera escasa $(3,82 \%)$ por las Doliolita equidimensionata y rara por D. elongata $(0,71 \%)$. Los bilobados 0 halterios que se presentaron de manera escasa, fueron Euhalteriolita bitestata $(2,87 \%)$. Mientras E. testicaudiculata, E. testilobata, Euhalteriolita centro largo y E. botulata $(1,67 \%, 1,43 \%, 1,19 \%$ y $0,47 \%)$ lo hicieron de forma rara. Otro grupo presente en la muestra fue el de los aguijones, o aculeolitas, incluyendo Aculeolithum ancistrathum, A. acuminathum (ambas 0,71\%), A. rostrathum $(0,47 \%)$ y $A$ aciculathum $(0,23 \%)$. Los halterios Euhalteriolita tipo Stipa, fueron escasos (1,91\%) al igual que Prismáticos lisos menores a $40 \mu \mathrm{m}(2,63 \%)$. Los de formas de abanico se presentaron de manera rara con Flabelolithum euflabelathum, F. excavata (ambas $0,95 \%$ ) y F. complanathum $(1,43 \%)$. Los poliédricos superiores a $40 \mu \mathrm{m}$ también fueron raros $(3,78 \%)$, junto a los 
Longolita $(0,95 \%)$, elementos de conducción $(0,23 \%)$, formas triangulares, prismáticos breves, Plurihalteriolita trilobata $(0,47 \%)$, Pileolita, placas hexagonales, y Halteriolita cruciformata $(0,23 \%)$.

\section{Muestra 1203}

Fueron muy frecuentes los estróbilos acampanados Estrobilolita complanata $(18,26 \%)$ y los aplanados E. aplanada (11,94\%). Los estróbilos con cintura $E$. elongata fueron frecuentes $(6,08 \%)$. Los equidimensionales ( $E$. equidimensionata) fueron escasos (2,34\%). los de punta en un extremo y $E$. cotilata se presentaron de manera rara $(1,63 \%$ y $0,23 \%$ respectivamente). EI grupo de los fitolitos prismáticos rectangulares se halló dominado por el morfotipo Macroprismatolithum psilaristathum, prismático de bordes lisos, de manera frecuente $(7,96 \%)$. Los fitolitos de bordes ondulados $M$. ondulathum fueron escasos (5,15\%). Euprismatolita elongata, prismáticos elongados $(1,63 \%)$ y $\mathrm{M}$. denticulathum $(1,17 \%)$ (prismáticos de bordes dentado) fueron raros. Dentro de los fitolitos esféricos se presentaron de manera muy frecuente los equinados, Globulolithum sphaerochinulathum (11,47\%). Mientras que la presencia de los esféricos lisos (G. sphaeropsilathum) y elípticos equinados fue rara $(0,70 \%$ y $0,46 \%)$. Otro grupo presente en la muestra fue el de los aguijones, o aculeolitas con la presencia escasa de Aculeolithum ancistrathum $(2,10 \%)$, y rara de $A$. rostrathum $(1,40 \%)$, A. aculsuficthum y $A$ aciculathum $(0,70 \%)$ y $A$. acutemeditullium y formas intermedias $(0,23 \%)$. Los bilobados 0 halterios que se presentaron de manera escasa, fueron Euhalteriolita bitestata $(3,27 \%)$. E. testicaudiculata, E. botulata y E. testilobata $(1,40 \%, 1,17 \%$ y $0,70 \%)$ lo hicieron de forma rara, al igual que Plurihalteriolita trilobata $(0,46 \%)$. Los halterios Euhalteriolita tipo Stipa, fueron escasos (2,57\%). También fueron escasas las doliolitas o sillas de montar representadas por Doliolita equidimensionata $(5,38 \%)$. Los poliédricos superiores a $40 \mu \mathrm{m}$ fueron escasos $(4,44 \%)$ y Los inferiores a $40 \mu \mathrm{m}$ raros $(0,93 \%)$. Otros elementos presentes en la muestra de forma rara fueron: formas prismáticas breves, Halteriolita cruciformata, Elementos de conducción, Pileolita $(0,46 \%)$, Formas triangulares $(0,70 \%)$, Flabelolita excavata $(0,93 \%)$ y formas hemiflabeladas $(0,46 \%)$, Longolita $(0,46 \%)$ y Prismáticos lisos menores a $40 \mu \mathrm{m}(0,93 \%)$. 


\section{Muestra 1204}

Fueron muy frecuentes los estróbilos acampanados Estrobilolita complanata $(15,12 \%)$ y los aplanados E. aplanada $(10,73 \%)$. Los equidimensionales $E$. equidimensionata $(1,95 \%)$ y los estróbilos con cintura $E$. elongata $(4,39 \%)$ fueron escasos. los de punta en un extremo y $\mathrm{E}$. cotilata se presentaron de manera rara $(0,97 \%$ y $0,73 \%$ respectivamente). El grupo de los fitolitos prismáticos rectangulares se halló dominado por el morfotipo Macroprismatolithum psilaristathum, prismático de bordes lisos, de manera frecuente $(8,29 \%)$. Los fitolitos de bordes ondulados $M$. ondulathum fueron escasos (2,68\%). Euprismatolita elongata, prismáticos elongados $(0,73 \%)$ y $\mathrm{M}$. denticulathum $(0,97 \%)$ (prismáticos de bordes dentado) fueron raros. Los prismáticos lisos menores a $40 \mu \mathrm{m}$ fueron escasos $(0,93 \%)$. Dentro de los fitolitos esféricos se presentaron de manera muy frecuente los equinados, Globulolithum sphaerochinulathum (14,14\%). Mientras que la presencia de los esféricos lisos (G. sphaeropsilathum) y elípticos equinados fue rara $(1,21 \%$ y $0,24 \%)$. Doliolita equidimensionata fue muy frecuente $(11,46 \%)$, mientras que D. elongata $(1,46 \%)$ fue rara. Otro grupo presente en la muestra fue el de los aguijones, o aculeolitas con la presencia escasa de Aculeolithum ancistrathum $(2,19 \%)$, y rara de $A$. rostrathum $(1,46 \%)$, $A$. aculsuficthum $(0,48 \%)$ y $A$ aciculathum $(0,70 \%)$ y $A$. acutemeditullium y $A$. unculiformathum $(0,24 \%)$. Los bilobados $O$ halterios que se presentaron de manera escasa, fueron Euhalteriolita bitestata $(3,65 \%)$. E. testicaudiculata y Euhalteriolita centro largo $(0,73 \%)$, mientras $E$. botulata y $E$. testilobata $(0,48 \%)$ lo hicieron de forma rara, al igual que Plurihalteriolita trilobata $(0,48 \%)$. Euhalteriolita tipo Stipa, también fueron raros $(0,97 \%)$. Los poliédricos superiores a $40 \mu \mathrm{m}$ fueron escasos $(3,17 \%)$ y los inferiores raros $(0,73 \%)$. Otros elementos presentes en la muestra de forma rara fueron: los prismáticos breves, Halteriolita cruciformata, elementos de conducción, placa hexagonal $(0,24 \%)$, formas triangulares $(0,73 \%)$, Flabelolithum complanathum y Flabelolita excavata $(0,97 \%)$, formas hemiflabeladas $(0,24 \%)$, Flabelolithum euflabelathum $(1,21 \%)$ y Longolita $(0,48 \%)$. 


\section{Muestra 1205}

Los estróbilos acampanados Estrobilolita complanata (8,93\%) y los aplanados E. aplanada $(11,83 \%)$ fueron muy frecuentes. Los estróbilos elongados con cintura E. elongata $(1,69 \%)$ fueron escasos. Los equidimensionales, E. equidimensionata $(1,44 \%)$ y los los de punta en un extremo se presentaron de manera rara $(0,48 \%)$. El grupo de los fitolitos prismáticos rectangulares se halló dominado por el morfotipo Macroprismatolithum psilaristathum, prismático de bordes lisos, de manera muy frecuente $(14,73 \%)$. Aquellos de bordes ondulados $M$. ondulathum fueron frecuentes $(6,52 \%)$. Euprismatolita elongata, prismáticos elongados $(1,93 \%)$ y M. denticulathum (2,65\%) (prismáticos de bordes dentados) fueron escasos. Euprismatolita excavata $(0,48)$ y Euprismatolita serrata $(0,72 \%)$ (prismáticos de bordes serrados, E. serrata y de bordes serrados respectivamente) fueron raros. Los prismáticos lisos menores a $40 \mu \mathrm{m}$ fueron escasos (1,93\%). Dentro de los fitolitos esféricos se presentaron de manera muy frecuente los equinados, Globulolithum sphaerochinulathum (14,00\%). Mientras que la presencia de los esféricos lisos (G. sphaeropsilathum) y elípticos equinados fue rara $(0,96 \%$ y $0,24 \%)$. Doliolita equidimensionata fue escasa $(4,34 \%)$, mientras que $D$. elongata $(0,72 \%)$ fue rara. Otro grupo presente en la muestra fue el de las aculeolitas con la presencia escasa de Aculeolithum ancistrathum $(2,17 \%)$, y $A$. aciculathum $(1,69 \%)$. Rara de A. rostrathum y A. acutemeditullium $(0,48 \%)$, $y$ formas indeterminadas $(1,10 \%)$. Los bilobados o halterios que se presentaron de manera escasa, fueron Euhalteriolita bitestata (3,14\%). E. testicaudiculata $(0,48 \%)$, E. botulata $(0,72 \%)$, E. testilobata $(0,48 \%)$ y E. pseudocapitatum $(0,24 \%)$ lo hicieron de forma rara, al igual que los polilobados Plurihalteriolita trilobata y $\mathrm{P}$. catenata $(0,48 \%)$. Los halterios Euhalteriolita tipo Stipa, fueron escasos $(2,17 \%)$. Los poliédricos superiores a $40 \mu \mathrm{m}$ fueron escasos $(3,86 \%)$. El grupo de las buliformes con Flabelolithum complanathum $(0,72 \%)$, F. euflabelathum $(1,20 \%)$, formas hemiflabeladas $(0,48 \%)$, de manera rara y $F$. excavata $(2,17 \%)$ escasa. Otros elementos presentes en la muestra de forma rara fueron: los prismáticos breves $(0,72 \%)$, los elementos de conducción $(0,48 \%)$, Longolita $(0,48 \%)$, Halteriolita cruciformata, elemento con papilas, Placa hexagonal, y formas triangulares $(0,24 \%)$. 


\section{Muestra 1206}

Los estróbilos Estrobilolita complanata y los aplanados E. aplanada $(15,82 \%)$ fueron muy frecuentes. Los estróbilos elongados con cintura $E$. elongata $(4,79 \%)$ y los equidimensionales, E. equidimensionata $(6,23 \%)$ fueron frecuentes. Mientras que los de punta en un extremo fue raro (0,95\%). El grupo de los fitolitos prismáticos rectangulares se halló dominado por el morfotipo Macroprismatolithum psilaristathum, prismático de bordes lisos, de manera muy frecuente $(9,59 \%)$. Aquellos de bordes ondulados $M$. ondulathum fueron frecuentes $(6,47 \%)$. Euprismatolita elongata, prismáticos elongados, $M$. denticulathum (prismáticos de bordes dentados) y Euprismatolita serrata $(0,23 \%)$ (prismáticos de bordes serrados) fueron raros, al igual que Prismáticos lisos menores a $40 \mu \mathrm{m}(0,95 \%)$. Dentro de los fitolitos esféricos se presentaron de manera frecuente los equinados, Globulolithum sphaerochinulathum $(8,63 \%)$. Mientras que los esféricos lisos (G. sphaeropsilathum) fueron raros $(0,47 \%)$. Los poliédricos superiores a $40 \mu \mathrm{m}$ fueron escasos $(4,55 \%)$ mientras que los inferiores a $40 \mu \mathrm{m}$ fueron raros $(0,23 \%)$. El grupo de las bulliformes con Flabelolithum euflabelathum (3,59\%), F. complanathum y F. excavata $(1,67 \%)$ de manera escasa, formas hemiflabeladas $(0,23 \%)$ rara. Aquellos en forma de silla de montar o saddle estuvieron presentes con Doliolita equidimensionata de manera escasa y $\mathrm{D}$. oblata rara. Los bilobados o halterios que se presentaron de manera escasa, fueron Euhalteriolita bitestata (1,91\%). E. testicaudiculata $(0,47 \%)$, E. botulata $(0,23)$ y Euhalteriolita centro largo $(0,47 \%)$ lo hicieron de forma rara, al igual que los polilobados Plurihalteriolita trilobata $(0,23 \%)$. Los halterios Euhalteriolita tipo Stipa, fueron escasos (2,87\%). Fue rara la presencia de los aguijones Aculeolithum aciculatum (0,47\%), A. rostrathum (0,95\%), A. aculusfictum $(1,19 \%)$, y $A$. ancistrathum $(1,43 \%)$, de los elementos de conducción $(0,70 \%)$, de Longolita $(1,19 \%)$, Pileolita $(0,23 \%)$, y formas triangulares $(0,71 \%)$. 


\section{PERFIL DIAMANTE NORTE}

\section{Muestra 1138}

Dentro del grupo de los fitolitos en forma de estróbilo se presentaron los acampanados Estrobilolita complanata $(17,33 \%)$ y los aplanados E. aplanada $(16,00 \%)$ de manera muy frecuente. Los equidimensionales, $E$. equidimensionata, E. cotilata (3,33\%), y los estróbilos elongados con cintura E. elongata $(4,00 \%)$, escasos, mientras que los estróbilos con punta en un extremo $(1,33 \%)$ fueron raros. Los bilobados que se presentaron de manera frecuente, fueron Euhalteriolita bitestata (6,66\%). Mientras E. testicaudiculata $(3,55 \%)$ y $E$. testilobata $(3,33 \%)$ fueron escasos y E. centro largo, E. botulata $(0,88 \%)$ y $E$. $(0,44 \%)$ lo hicieron de forma rara, al igual que los polilobados Plurihalteriolita inequilobata, P. trilobata $(1,11 \%)$ y $P$. catenata $(0,22 \%)$ y las cruces Halteriolita cruciformata $(0,22 \%)$. Los Euhalteriolita tipo Stipa fueron frecuentes $(8,44 \%)$ al igual que aquellos en forma de silla de montar o saddle con Doliolita equidimensionata $(5,33 \%)$, mientras que los $D$. elongata fueron raros $(0,22 \%)$. Dentro de los fitolitos esféricos se presentaron de manera frecuente los esféricos equinados, Globulolithumhum sphaerochinulathum $(6,66 \%)$ y los elípticos equinados fueron raros $(0,22 \%)$. El grupo de los prismáticos rectangulares se halló representado por los morfotipos Macroprismatolithum psilaristathum, prismático de bordes lisos, (4,44\%) y los prismáticos de bordes ondulados $\mathrm{M}$. ondulathum $(2,88 \%)$ de manera escasa. Los de bordes dentados (M. denticulathum) $(0,22 \%)$, los de bordes serrados (E. serrata) $(0,44 \%)$, los prismáticos elongados, Euprismatolita elongata, $(0,66 \%)$ y prismáticos asimétricos $(0,22 \%)$ fueron raros al igual que los prismáticos lisos breves (0,66\%), los poliédricos superiores a $40 \mu \mathrm{m}(0,22 \%)$, formas formas triangulares $(0,44 \%)$, placas hexagonales $(0,22 \%)$, Longolita $(0,22 \%)$, elementos de conducción $(0,44 \%)$, Aculeolithum rostrathum $(0,22 \%)$, A. ancistrathum y $A$. aciculathum $(1,11 \%)$ y las bulliformes Flabelolithum euflabelathum $(0,44 \%)$.

\section{Muestra 1139}

Dentro del grupo de los fitolitos en forma de estróbilo se presentaron los acampanados, Estrobilolita complanata $(18,44 \%)$ y los aplanados E. aplanada $(18,68 \%)$ de manera muy frecuente. Los estróbilos elongados con cintura $\mathrm{E}$. 
elongata $(6,31 \%)$, fueron frecuentes. Los equidimensionales, $E$. equidimensionata $(3,88 \%)$ escasos mientras que los $E$. cotilata $(1,21 \%)$ y estróbilos con punta en un extremo $(0,72 \%)$ fueron raros. Los bilobados 0 halterios que se presentaron de manera escasa, fueron Euhalteriolita bitestata $(3,15 \%)$, y de manera rara E. botulata $(1,21 \%)$, E. testicaudiculata $(0,97 \%)$, E. testilobata $(0,48 \%)$, formas intermedias no identificadas $(0,24 \%)$, al igual que los polilobados Plurihalteriolita inequilobata, $(0,72 \%)$ y $P$. trilobata $(0,24 \%)$. Los Euhalteriolita tipo Stipa fueron escasos (2,91\%). Aquellos en forma de silla de montar o saddle Doliolita equidimensionata $(3,15 \%)$, y D. elongata $(2,18 \%)$ fueron escasos y raros D. oblata $(0,97 \%)$. De manera frecuente se presentaron los esféricos equinados, Globulolithum sphaerochinulathum $(8,25 \%)$ y rara los esféricos lisos G. sphaeropsilathum $(0,72 \%)$, los elípticos equinados $(1,45 \%)$, los elípticos lisos $(0,24 \%)$ y los esféricos con ornamentación clavada, $(0,24 \%)$. El grupo de los prismáticos rectangulares se halló representado por los morfotipos Macroprismatolithum psilaristathum, prismático de bordes lisos, $(8,49 \%)$ de manera frecuente, los prismáticos de bordes ondulados, $M$. ondulathum $(2,18 \%)$ de manera escasa, y los de bordes dentados (M. denticulathum) (0,97\%) y los prismáticos elongados, Euprismatolita elongata, $(0,72 \%)$ de forma rara, al igual que los Prismáticos menores a $40 \mu \mathrm{m}(1,69 \%)$, Prismáticos lisos breves $(0,48 \%)$, formas formas triangulareses $(1,45 \%)$, los poliédricos superiores a $40 \mu \mathrm{m}(1,21 \%)$ y menores a $40 \mu \mathrm{m}(0,48 \%)$, Pileolita $(0,24 \%)$, Formas macroglobosas $(0,24 \%), \%)$. Los elementos de conducción $(0,72 \%)$, Longolita $(0,24 \%)$, los aguijones Aculeolithum rostrathum, y formas indeterminadas (0,24\%), A. ancistrathum, A. aciculathum (ambos 0,48\%) y las bulliformes Flabelolithum euflabelathum (0,72\%), Flabelolita excavata, Flabelolithum complanathum $(0,48 \%)$.

\section{Muestra 1140}

Dentro del grupo de los fitolitos en forma de estróbilo se presentaron los acampanados, Estrobilolita complanata $(18,20 \%)$ y los aplanados E. aplanada $(20,08 \%)$ de manera muy frecuente. Los estróbilos elongados con cintura $E$. elongata $(3,88 \%)$, y los equidimensionales, E. equidimensionata $(4,12 \%)$ fueron escasos, mientras que los $\mathrm{E}$. cotilata $(0,97 \%)$, de un extremo con punta $(0,97 \%)$ y los de forma de doble cunea $(0,24 \%)$ fueron raros. Los bilobados o 
halterios que se presentaron de manera escasa, fueron Euhalteriolita bitestata $(4,12 \%)$, y $E$. testicaudiculata $(2,42 \%)$, de manera rara $E$. testilobata $(0,97 \%)$, E. botulata, E. centro largo y E. faseolata $(0,24 \%)$, al igual que los polilobados Plurihalteriolita inequilobata, y P. trilobata $(0,48 \%)$ y los, Euhalteriolita tipo Stipa $(1,69 \%)$. Aquellos en forma de silla de montar o saddle que se presentaron de manera escasa fueron los Doliolita equidimensionata (3,39\%), mientras que D. elongata $(1,21 \%)$ y $D$. oblata $(0,24 \%)$ fueron raros. De manera escasa se presentaron los esféricos equinados, Globulolithum sphaerochinulathum $(3,88 \%)$ y rara los esféricos lisos G. sphaeropsilathum $(0,48 \%)$, los elípticos equinados $(1,69 \%)$ y los elípticos lisos $(0,48 \%)$. El grupo de los prismáticos rectangulares se halló representado por los morfotipos Macroprismatolithum psilaristathum, prismático de bordes lisos, $(8,49 \%)$ de manera frecuente, los prismáticos de bordes ondulados, $M$. ondulathum $(2,18 \%)$, los de bordes dentados (M. denticulathum) (1,45\%) y los prismáticos elongados, Euprismatolita elongata, $(1,21 \%)$ de forma rara. También fueron raros los Prismáticos menores a $40 \mu \mathrm{m}(1,69 \%)$, Prismáticos lisos breves $(2,18 \%)$, Formas triangulares $(1,94 \%)$, los poliédricos superiores a $40 \mu \mathrm{m}(1,21 \%)$ y menores a $40 \mu \mathrm{m}(0,24 \%)$, Pileolita $(0,24 \%)$. Los elementos de conducción $(0,48 \%)$, los aguijones Aculeolithum rostrathum, A. aciculathum $(0,48 \%), A$. ancistrathum $(0,97 \%)$, formas intermedias no determinadas, $(1,94 \%)$ y las bulliformes Flabelolithum complanathum (0,72\%) y Flabelolita excavata $(0,24 \%)$.

\section{Muestra 1141}

Fueron muy frecuentes los estróbilos acampanados Estrobilolita complanata $(16,09 \%)$ y los aplanados E. aplanada $(25,85 \%)$. Los estróbilos elongados con cintura E. elongata $(4,63 \%)$ y los equidimensionales (E. equidimensionata) $(6,58 \%)$ fueron escasos. Ios de punta en un extremo y $E$. cotilata se presentaron de manera rara $(0,48 \%$ y $1,95 \%$ respectivamente). EI grupo de los fitolitos prismáticos rectangulares se halló dominado por el morfotipo Macroprismatolithum psilaristathum, prismático de bordes lisos, de manera frecuente $(7,80 \%)$. Los fitolitos de bordes ondulados $M$. ondulathum $(1,46 \%)$, E. serrata (prismáticos de bordes serrados) $(0,24 \%)$, Euprismatolita elongata, prismáticos elongados y $\mathrm{M}$. denticulathum (prismáticos de bordes 
dentados) $(1,21 \%)$ fueron raros, igual que prismáticos lisos breves $(1,70 \%)$. Los prismáticos menores a $40 \mu \mathrm{m}$ fueron escasos (2,68\%). Dentro de los fitolitos esféricos se presentaron de manera escasa los equinados, Globulolithum sphaerochinulathum (4,39\%). Mientras que la presencia de los esféricos lisos y elípticos equinados fue rara (1,46\% y $0,97 \%)$. Fueron escasas las Doliolita equidimensionata $(4,87 \%)$ y raras las elongadas $D$. elongata $(0,48 \%)$ y las comprimidas lateralmente $D$. oblata $(0,73 \%)$. Otros elementos presentes en la muestra de forma rara fueron: el grupo de los aguijones, o aculeolitas con Aculeolithum ancistrathum (0,97\%), y A. rostrathum (0,48\%). Los bilobados o halterios con Euhalteriolita bitestata $(2,43 \%)$, E. botulata $(0,73 \%)$, E. testicaudiculata $(1,95 \%)$, y E. testilobata $(1,46 \%)$, los polilobados Plurihalteriolita catenata y $\mathrm{P}$. inequilobata $(0,24 \%)$, los, Euhalteriolita tipo Stipa $(1,95 \%)$ y las cruces Halteriolita cruciformata $(0,24 \%)$, Formas multilobadas $(0,24 \%)$, los flabelos Flabelolita excavata $(0,73 \%)$, F. complanathum y $F$. euflabelathum $(0,24 \%)$, Longolita $(0,24 \%)$ y formas triangulares $(1,21 \%)$.

\section{Muestra 1142}

Fueron muy frecuentes los estróbilos aplanados Estrobilolita aplanada $(17,44 \%)$ y los acampanados E. complanata (13,48\%). Los estróbilos elongados con cintura E. elongata $(4,65 \%)$ y los equidimensionales (E. equidimensionata) (3,95\%) fueron escasos. E. cotilata se presentaron de manera rara $(0,93 \%)$. El grupo de los fitolitos prismáticos rectangulares se halló dominado por el morfotipo Macroprismatolithum psilaristathum, prismático de bordes lisos, de manera frecuente $(10,00 \%)$. Los fitolitos de bordes ondulados M. ondulathum $(1,62 \%)$, Euprismatolita elongata, prismáticos elongados $(0,69 \%)$, Prismáticos de extremos cóncavos $(0,23 \%)$ y $M$. denticulathum (prismáticos de bordes dentados) $(1,62 \%)$ fueron raros, igual que Prismáticos menores a $40 \mu \mathrm{m}(1,62 \%)$. Prismáticos lisos breves fueron escasos $(2,55 \%)$. Dentro de los fitolitos esféricos se presentaron de manera frecuente los equinados, Globulolithum sphaerochinulathum (9,53\%). Mientras que la presencia de los esféricos lisos y elípticos equinados fue rara (1,16\% y $0,93 \%)$. Fueron escasas las doliolitas o sillas de montar Doliolita equidimensionata $(4,41 \%)$ y raras las elongadas D. elongata $(0,23 \%)$ y las comprimidas lateralmente D. oblata $(0,69 \%)$. Los bilobados o halterios Euhalteriolita 
bitestata $(4,18 \%)$, E. botulata $(2,32 \%)$ y E. testicaudiculata $(1,86 \%)$, fueron escasos, mientras que E. testilobata $(0,93 \%)$ y $E$. centro largo y $E$. faseolata $(0,46 \%)$ fueron raros, igual que los polilobados Plurihalteriolita trilobata $(0,93 \%)$ y $P$. inequilobata $(0,23 \%)$, y las cruces Halteriolita cruciformata $(0,69 \%)$. Euhalteriolita tipo Stipa (2,55\%) escasas. El grupo de los aguijones, o aculeolitas con Aculeolithum ancistrathum $(1,86 \%)$ de manera escasa, y $A$. rostrathum, A. aciculathum $(0,93 \%)$, formas intermedias $(0,23 \%)$. Otros elementos presentes en la muestra de forma rara fueron: los flabelos Flabelolithum euflabelathum $(0,23 \%)$. poliédricos superiores a $40 \mu \mathrm{m}(0,93 \%)$, formas triangulares $(0,93 \%)$ y elementos de conducción $(0,46 \%)$.

\section{Muestra 1143}

Fueron muy frecuentes los estróbilos acampanados Estrobilolita complanata $(21,41 \%)$ y los aplanados E. aplanada $(15,29 \%)$. Los estróbilos equidimensionales (E. equidimensionata) (2,58\%) fueron escasos. Los elongados con cintura $E$. elongata $(1,64 \%)$, los con punta en un extremo y $E$. cotilata raros $(1,41 \%$ y $1,88 \%$ respectivamente). El grupo de los fitolitos prismáticos rectangulares se halló dominado por el morfotipo Macroprismatolithum psilaristathum, prismático de bordes lisos, de manera frecuente $(6,58 \%)$. Los de bordes ondulados $M$. ondulathum y $M$. denticulathum (prismáticos de bordes dentados) (ambos 2,35\%) escasos. Euprismatolita elongata, prismáticos elongados $(2,11 \%)$, y prismáticos con ornamentación dendriforme $(0,47 \%)$ fueron raros, igual que los prismáticos menores a $40 \mu \mathrm{m}(0,94 \%)$ y prismáticos lisos breves $(1,17 \%)$. Dentro de los fitolitos esféricos se presentaron de manera frecuente los esféricos equinados, Globulolithum sphaerochinulathum (7,05\%) y los elípticos equinados de manera rara $(0,47 \%)$. Fueron escasas las doliolitas o sillas de montar Doliolita equidimensionata $(3,52 \%)$ y raras las elongadas D. elongata $(0,94 \%)$ y las comprimidas lateralmente D. oblata $(1,64 \%)$. Los bilobados o halterios Euhalteriolita bitestata $(4,70 \%)$, E. botulata $(2,58 \%)$, E. testilobata $(2,35 \%)$ y E. testicaudiculata $(2,35 \%)$, fueron escasos, mientras que $E$. centro largo y $E$. faseolata $(0,47 \%)$ fueron raros, igual que los polilobados Plurihalteriolita

trilobata $(1,88 \%)$ y $P$. inequilobata $(1,64 \%)$, y las cruces Halteriolita cruciformata $(0,47 \%)$. Los Euhalteriolita tipo Stipa $(3,29 \%)$ escasos. Otros 
elementos presentes en la muestra de forma rara fueron:los pelos, ganchos, y aguijones, con Aculeolithum ancistrathum, A. aciculathum (0,94\%), A. rostrathum, $(1,41 \%)$ y forma indeterminada $(0,47 \%)$. Los flabelos Flabelolithum euflabelathum, F. complanathum y Flabelolita excavata $(0,47 \%)$ y formas triangulares $(0,23 \%)$.

\section{Muestra 1144}

Fueron muy frecuentes los estróbilos aplanados Estrobilolita aplanada $(9,13 \%)$ y los acampanados E. complanata $(12,74 \%)$. Los estróbilos elongados con cintura $E$. elongata $(2,40 \%)$ y los equidimensionales (E. equidimensionata) $(3,12 \%)$ fueron escasos, mientras que los que tienen punta en un extremo raros $(0,96 \%)$. El grupo de los fitolitos prismáticos rectangulares se halló dominado por el morfotipo Macroprismatolithum psilaristathum, prismático de bordes lisos, de manera muy frecuente $(12,25 \%)$. Los de bordes ondulados $M$. ondulathum $(4,32 \%)$, frecuentes. Euprismatolita elongata, prismáticos elongados $(2,16 \%)$, los de bordes serrados, $E$. serrata, $(1,44 \%)$ y $M$. denticulathum (prismáticos de bordes dentados) (2,64\%) fueron escasos. Prismáticos menores a $40 \mu \mathrm{m}(1,62 \%)$ fueron frecuentes. Dentro de los fitolitos esféricos se presentaron de manera muy frecuente los equinados, Globulolithum sphaerochinulathum (11,29\%). Mientras que la presencia de los esféricos lisos (G. sphaeropsilathum) $(0,96 \%)$, los elípticos equinados $(0,48 \%)$ y los elípticos lisos $(0,48 \%)$ fue rara. Fueron escasas las doliolitas o sillas de montar Doliolita equidimensionata $(2,64 \%)$ y raras las elongadas D. elongata $(0,48 \%)$. Los bilobados o halterios Euhalteriolita bitestata $(2,64 \%)$ y $\mathrm{E}$. botulata $(1,44 \%)$ fueron escasos, mientras que $E$. testicaudiculata $(0,48 \%)$ y $E$. centro largo $(0,96 \%)$ fueron raros, igual que los polilobados Plurihalteriolita trilobata y P. inequilobata $(0,48 \%)$ y Euhalteriolita tipo Stipa $(1,20 \%)$. El grupo de los aguijones, o aculeolitas con Aculeolithum ancistrathum (2,16\%) de manera escasa, y A. rostrathum, A. aciculathum (0,48\%), y formas intermedias $(1,20 \%)$ raros. Los flabelos Flabelolithum euflabelathum $(5,04 \%)$ y $\mathrm{F}$. complanathum $(4,80 \%)$ fueron frecuentes, mientras Flabelolita excavata $(1,20 \%)$ y formas hemiflabeladas $(0,48 \%)$ raros. poliédricos superiores a $40 \mu \mathrm{m}$ escasos $(3,12 \%)$. Otros elementos presentes en la muestra de forma rara fueron: Pileolita $(0,48 \%)$, y Formas triangulares $(0,48 \%)$. 


\section{Muestra 1145}

El grupo de los fitolitos prismáticos rectangulares se halló dominado por el morfotipo Macroprismatolithum psilaristathum, prismático de bordes lisos, de manera muy frecuente $(27,52 \%)$. Los fitolitos de bordes ondulados $M$. ondulathum $(6,11 \%)$ fueron escasos. Euprismatolita elongata, prismáticos elongados $(0,70 \%)$, E. serrata (prismáticos de bordes serrados) $(0,23 \%)$ y $\mathrm{M}$. denticulathum (prismáticos de bordes dentados) $(0,94 \%)$ fueron raros, igual que prismáticos menores a $40 \mu \mathrm{m}(0,70 \%)$ y prismáticos lisos breves $(0,70 \%)$. Fueron frecuentes los estróbilos aplanados Estrobilolita aplanada $(9,88 \%)$ y los acampanados E. complanata (12,00\%). Los estróbilos elongados con cintura E. elongata $(4,70 \%)$, los equidimensionales ( $E$. equidimensionata) $(1,88 \%)$, los de punta en un extremo $(0,23 \%)$ y E. cotilata $(0,70 \%)$ fueron raros. Dentro de los fitolitos esféricos se presentaron de manera frecuente los equinados, Globulolithum sphaerochinulathum $(9,17 \%)$. Mientras que la presencia de los esféricos lisos (G. sphaeropsilathum) y los elípticos equinados fue rara $(0,70 \%$ y $0,23 \%)$. Los bilobados o halterios Euhalteriolita bitestata $(1,17 \%)$, E. botulata $(1,64 \%)$, E. centro largo $(0,47 \%)$, E. testicaudiculata $(2,58 \%)$ y E. testilobata $(1,64 \%)$, fueron raros, igual que las cruces Halteriolita cruciformata $(0,23 \%)$, mientras que Euhalteriolita tipo Stipa $(3,76 \%)$ escasos. Otros elementos presentes en la muestra de forma rara fueron: las doliolitas o sillas de montar Doliolita equidimensionata $(1,88 \%)$ y las elongadas D. elongata $(0,70 \%)$. El grupo de los aguijones, o aculeolitas con Aculeolithum aciculathum (1,88\%), formas intermedias no identificadas $(2,10 \%)$ y $A$. rostrathum $(0,70 \%)$. Los flabelos Flabelolithum euflabelathum (2,58\%), formas hemiflabeladas $(0,47 \%)$, Flabelolita excavata $(1,17 \%)$ y $\mathrm{F}$. complanathum $(0,70 \%)$. Longolita $(0,47 \%)$. Pileolita $(0,46 \%)$. poliédricos superiores a $40 \mu \mathrm{m}(1,64 \%)$, Formas triangulares $(0,47 \%)$, Placa hexagonal $(0,47 \%)$.

\section{Muestra 1146}

El grupo de los fitolitos prismáticos rectangulares se halló dominado por el morfotipo Macroprismatolithum psilaristathum, prismático de bordes lisos, de manera muy frecuente $(17,29 \%)$. Los fitolitos de bordes ondulados $M$. ondulathum $(5,21 \%)$ fueron frecuentes. Euprismatolita elongata, prismáticos elongados $(0,71 \%)$, E. serrata $(1,42 \%)$ y $\mathrm{M}$. denticulathum (prismáticos de 
bordes dentados) (1,18\%) fueron raros, igual que Prismáticos menores a 40 $\mu \mathrm{m}(1,18 \%)$ y Prismáticos lisos breves $(0,71 \%)$. Fueron frecuentes los estróbilos aplanados Estrobilolita aplanada $(11,84 \%)$ y los acampanados E. complanata $(12,08 \%)$. Los estróbilos elongados con cintura E. elongata $(2,60 \%)$ y los equidimensionales (E. equidimensionata) $(3,79 \%)$ escasos. Los de punta en un extremo $(1,65 \%)$ y E. cotilata $(0,71 \%)$ fueron raros. Dentro de los fitolitos esféricos se presentaron de manera muy frecuente los equinados, Globulolithum sphaerochinulathum (10,66\%). Mientras que la presencia de los esféricos lisos (G. sphaeropsilathum) y elípticos equinados fue rara $(0,47 \%$ y $0,23 \%)$. Los bilobados o halterios Euhalteriolita bitestata (1,42\%), E. botulata $(1,18 \%)$, E. testicaudiculata $(1,18 \%)$ y E. testilobata $(0,47 \%)$, fueron raros, igual que las cruces Halteriolita cruciformata $(0,23 \%)$, y los polilobados Plurihalteriolita trilobata $(0,23 \%)$, mientras que Euhalteriolita tipo Stipa $(2,84 \%)$ escasos. poliédricos superiores a $40 \mu \mathrm{m}(4,97 \%)$ fueron escasos, mientras que los menores a $40 \mu \mathrm{m}$ raros $(1,18 \%)$. Los flabelos Flabelolithum euflabelathum $(2,58 \%)$ fueron escasos, formas hemiflabeladas $(0,47 \%)$, Flabelolita excavata y F. complanathum $(1,18 \%)$ raros. Otros elementos presentes en la muestra de forma rara fueron: las doliolitas o sillas de montar Doliolita equidimensionata $(1,42 \%)$ y las elongadas $D$. elongata $(0,71 \%)$. El grupo de los aguijones, o aculeolitas con Aculeolithum aciculathum (0,71\%), A. ancistrathum (0,94\%), A. rostrathum $(0,47 \%)$, formas indeterminadas $(1,88 \%)$ y. Longolita $(0,23 \%)$. Pileolita $(0,23 \%)$. Formas triangulares $(0,47 \%)$ y Placa hexagonal $(0,47 \%)$.

\section{$\underline{\text { Muestra } 1147}$}

El grupo de los fitolitos prismáticos rectangulares se halló dominado por el morfotipo Macroprismatolithum psilaristathum, prismático de bordes lisos, de manera muy frecuente $(19,81 \%)$. Los fitolitos de bordes ondulados $M$. ondulathum $(7,31 \%)$ fueron frecuentes. escasos Euprismatolita elongata, prismáticos elongados $(2,59 \%)$ y $\mathrm{M}$. denticulathum (prismáticos de bordes dentados) (2,12\%). Los prismáticos de bordes serrados (E. serrata) (1,17\%), los de extremos cóncavos $(0,70 \%)$ y los de lados asimétricos $(0,47 \%)$ fueron raros, igual que los menores a $40 \mu \mathrm{m}(1,65 \%)$ y Prismáticos lisos breves $(0,70 \%)$. Fueron frecuentes los estróbilos aplanados Estrobilolita aplanada $(11,32 \%)$ y los acampanados E. complanata $(9,66 \%)$. Los equidimensionales 
(E. equidimensionata) $(3,06 \%)$ escasos. Los estróbilos elongados con cintura E. elongata $(1,17 \%)$, los que presentan una punta en un lado $(1,65 \%)$, los de forma de doble cunea y E. cotilata $(0,23 \%)$ fueron raros. Dentro de los fitolitos esféricos se presentaron de manera escasa los equinados, Globulolithum sphaerochinulathum $(4,71 \%)$ y los esféricos lisos (G. sphaeropsilathum) rara $(1,17 \%)$. Los bilobados o halterios Euhalteriolita bitestata $(2,35 \%)$ fueron escasos. E. botulata $(0,94 \%)$, E. testicaudiculata $(0,94 \%)$ y E. testilobata $(0,47 \%)$, fueron raros, igual que las cruces Halteriolita cruciformata $(0,23 \%)$, los polilobados Plurihalteriolita trilobata $(0,23 \%)$, y Euhalteriolita tipo Stipa $(1,41 \%)$. poliédricos superiores a $40 \mu \mathrm{m}(2,83 \%)$ fueron escasos, mientras que los poliédricos menores a $40 \mu \mathrm{m}$ raros $(1,88 \%)$. En el grupo de los aguijones, o aculeolitas con Aculeolithum ancistrathum (4,95\%), A. aculsuficthum (2,83\%), y A. rostrathum $(2,35 \%)$ presentes de manera escasa. A. acuminathum $(0,23 \%)$ y $A$. aciculathum $(0,70 \%)$ de manera rara. Otros elementos presentes en la muestra de forma rara fueron: las doliolitas o sillas de montar Doliolita equidimensionata $(1,65 \%)$ y las elongadas $D$. elongata $(0,23 \%)$. Los elementos de conducción $(0,70 \%)$. Los flabelos Flabelolithum euflabelathum $(1,17 \%), F$. complanathum $(0,94 \%)$ y Flabelolita excavata $(0,23 \%)$. Longolita $(0,47 \%)$. Pileolita $(0,46 \%)$. Formas triangulares $(0,47 \%)$ y Redondeadas $(0,70 \%)$.

\section{Muestra 1148}

El grupo de los fitolitos prismáticos rectangulares se halló dominado por el morfotipo Macroprismatolithum psilaristathum, prismático de bordes lisos, de manera muy frecuente $(14,73 \%)$. Los de bordes ondulados M. ondulathum $(1,93 \%)$ y los prismáticos elongados Euprismatolita elongata, $(2,17 \%)$, fueron escasos igual que los Prismáticos menores a $40 \mu \mathrm{m}(2,89 \%)$. Los prismáticos de bordes serrados, E. serrata, $(0,48 \%)$, prismáticos asimétricos $(0,24 \%)$ y $\mathrm{M}$. denticulathum (prismáticos de bordes dentados) $(0,96 \%)$ fueron raros, como los prismáticos lisos breves $(1,20 \%)$. Fueron muy frecuentes los estróbilos aplanados Estrobilolita aplanada (13,52\%) y los acampanados E. complanata $(14,73 \%)$. Los estróbilos elongados con cintura E. elongata $(5,79 \%)$ fueron frecuentes. escasos los equidimensionales (E. equidimensionata) $(4,34 \%)$. Los de punta en un extremo $(1,44 \%)$ y E. cotilata $(0,72 \%)$ fueron raros. Dentro de los fitolitos esféricos se presentaron de manera muy frecuente los equinados, 
Globulolithum sphaerochinulathum (9,90\%), mientras que la presencia de los esféricos lisos (G. sphaeropsilathum) (0,24\%), los elípticos lisos $(0,24 \%)$, y los de ornamentación clavada $(0,96 \%)$ fue rara. Los bilobados o halterios Euhalteriolita bitestata $(2,17 \%)$ y $\mathrm{E}$. testicaudiculata $(1,69 \%)$ fueron escasos. $\mathrm{E}$. botulata $(1,20 \%)$, E. centro largo $(0,48 \%)$, y E. testilobata $(0,96 \%)$, raros, igual que los polilobados Plurihalteriolita catenata $(0,48 \%)$ y $P$. vermiculathum $(0,24 \%)$. Los, Euhalteriolita tipo Stipa (1,93\%) escasos. Las doliolitas o sillas de montar Doliolita equidimensionata $(3,62 \%)$ fueron escasas y las elongadas $D$. elongata $(0,96 \%)$ raras. El grupo de los aguijones, 0 aculeolitas con Aculeolithum ancistrathum (1,44\%), A. acutemeditulium (0,24\%), A. acantathum $(0,24 \%)$ y $A$. rostrathum $(0,72 \%)$ presentes de forma rara y $A$. aculsuficthum $(2,41 \%)$ escasa. Los flabelos Flabelolita excavata y $\mathrm{F}$. complanathum $(0,24 \%)$ fueron raros igual que Longolita $(0,24 \%)$, los poliédricos poliédricos superiores a $40 \mu \mathrm{m}$ y poliédricos menores a 40 $\mu \mathrm{m}(0,96 \%)$ y Formas triangulares $(1,20 \%)$.

\section{Muestra 1149}

El grupo de los fitolitos prismáticos rectangulares se halló dominado por el morfotipo Macroprismatolithum psilaristathum, prismático de bordes lisos, de manera muy frecuente $(15,67 \%)$. M. denticulathum (prismáticos de bordes dentados) $(2,37 \%)$ y los de bordes ondulados $M$. ondulathum $(4,03 \%)$ fueron escasos. Los prismáticos elongados Euprismatolita elongata, $(0,71 \%)$, los de lados asimétricos $(0,47 \%)$ y los prismáticos de bordes serrados, E. serrata, $(0,95 \%)$ raros igual que los prismáticos menores a $40 \mu \mathrm{m}(0,95 \%)$. Fueron muy frecuentes los estróbilos acampanados Estrobilolita complanata (14,01\%). Los aplanados E. aplanada $(9,26 \%)$ y los equidimensionales (E. equidimensionata) $(5,22 \%)$ frecuentes. Los estróbilos elongados con cintura E. elongata $(4,51 \%)$ fueron escasos. Mientras los estróbilos con punta en un lado $(0,47 \%)$ y $E$. cotilata $(0,23 \%)$ raros. Dentro de los fitolitos esféricos se presentaron de manera muy frecuente los equinados, Globulolithum sphaerochinulathum $(15,20 \%)$, y la presencia de los esféricos lisos (G. sphaeropsilathum) (1,18\%), los elípticos lisos $(0,71 \%)$, y los esféricos de ornamentación clavada $(0,23 \%)$ fue rara. Los bilobados o halterios Euhalteriolita bitestata $(3,32 \%)$ fueron escasos. E. testicaudiculata $(1,42 \%)$, E. botulata $(0,71 \%)$, E. centro largo 
$(0,47 \%)$, y E. testilobata $(1,42 \%)$ raros, igual que los polilobados Plurihalteriolita trilobata $(0,71 \%)$. Euhalteriolita tipo Stipa $(1,90 \%)$ escasos. Las doliolitas o sillas de montar Doliolita equidimensionata $(2,37 \%)$ fueron escasas y las elongadas $D$. elongata $(0,23 \%)$ raras. Otros elementos presentes de forma rara: el grupo de los pelos, ganchos y aguijones, o aculeolitas con Aculeolithum ancistrathum (1,42\%), A. aciculathum (0,47\%), A. acuminathum $(0,95 \%)$, y $A$. rostrathum $(1,18 \%)$. Los flabelos Flabelolita excavata $(0,71 \%)$, Flabelolithum complanathum, $\quad F$. euflabelathum $(0,47 \%)$, y formas hemiflabeladas $(0,23 \%)$. Longolita $(0,47 \%)$, los poliédricos superiores a $40 \mu \mathrm{m}$ $(0,47 \%)$ y Formas triangulares $(1,66 \%)$.

\section{Muestra 1150}

Fueron muy frecuentes los estróbilos acampanados Estrobilolita complanata $(18,61 \%)$ y los aplanados E. aplanada (14,55\%). Los estróbilos elongados con cintura $E$. elongata $(6,92 \%)$ frecuentes. Los equidimensionales (E. equidimensionata) $(5,01 \%)$ fueron escasos. Los de forma de doble cunea y E. cotilata $(0,23 \%)$ raros. El grupo de los fitolitos prismáticos rectangulares se halló dominado por el morfotipo Macroprismatolithum psilaristathum, prismático de bordes lisos, de manera muy frecuente $(13,60 \%)$. M. denticulathum (prismáticos de bordes dentados) $(1,90 \%)$ y los de bordes ondulados $\mathrm{M}$. ondulathum $(2,17 \%)$ fueron escasos. Los prismáticos elongados Euprismatolita elongata, y los prismáticos de bordes serrados (E. serrata) $(0,23 \%)$ raros igual que Prismáticos menores a $40 \mu \mathrm{m}(0,95 \%)$. Dentro de los fitolitos esféricos se presentaron de manera frecuente los equinados, Globulolithum sphaerochinulathum (10,50\%), y los esféricos lisos (G. sphaeropsilathum) $(0,71 \%)$ fueron raros. Los bilobados o halterios Euhalteriolita bitestata $(2,38 \%)$ y E. testicaudiculata $(1,42 \%)$ fueron escasos. E. botulata $(1,19 \%)$, y $E$. testilobata $(1,43 \%)$ raros, igual que los polilobados Plurihalteriolita trilobata $(1,19 \%)$ y las cruces Halteriolita cruciformata $(0,23 \%)$. Euhalteriolita tipo Stipa $(1,90 \%)$ escasos. Las doliolitas o sillas de montar Doliolita equidimensionata $(1,90 \%)$ fueron escasas. El grupo de los aguijones, o aculeolitas con Aculeolithum ancistrathum (2,62\%), de manera escasa y A. acantathum $(0,23 \%)$ y $A$. rostrathum $(0,47 \%)$ raras. Otros elementos presentes de forma rara: Ios flabelos Flabelolithum euflabelathum $(0,47 \%)$, Flabelolita excavata, $F$. 
complanathum, y Flabelolita elongata $(0,23 \%)$. Longolita $(0,47 \%)$, Pileolita $(1,43 \%)$, los poliédricos poliédricos superiores a $40 \mu \mathrm{m}(0,95 \%)$ y los menores a $(1,43 \%)$, Elementos con papilas $(0,23 \%)$ y Formas triangulares $(0,71 \%)$.

\section{Muestra 1151}

El grupo de los fitolitos prismáticos rectangulares se halló dominado por el morfotipo Macroprismatolithum psilaristathum, prismático de bordes lisos, de manera muy frecuente $(31,65 \%)$. Los de bordes ondulados $M$. ondulathum $(1,19 \%), M$. denticulathum (prismáticos de bordes dentados) $(2,12 \%)$, Euprismatolita elongata, prismáticos elongados $(1,67 \%)$ y $E$. serrata, prismáticos de bordes serrados $(0,47 \%)$ fueron raros, igual que los prismáticos menores a $40 \mu \mathrm{m}(0,71 \%)$ y prismáticos lisos breves $(0,47 \%)$. Fueron frecuentes los estróbilos aplanados Estrobilolita aplanada $(11,03 \%)$ y los acampanados E. complanata $(16,78 \%)$. Los equidimensionales (E. equidimensionata) $(3,11 \%)$, los estróbilos elongados con cintura $E$. elongata $(2,39 \%)$, los de un extremo con punta $(0,47 \%)$, y E. cotilata $(0,95 \%)$ fueron raros. Dentro de los fitolitos esféricos se presentaron de manera escasa los equinados, Globulolithum sphaerochinulathum (6,71\%). Los elípticos equinados $(0,23 \%)$ y los esféricos lisos (G. sphaeropsilathum) $(1,67 \%)$ rara. Los bilobados o halterios Euhalteriolita bitestata $(0,95 \%)$, los de centro largo y final globosos $(0,23 \%)$, E. testicaudiculata $(1,19 \%)$ y E. testilobata $(0,95 \%)$, fueron raros, igual que los polilobados Plurihalteriolita inequilobata $(0,23 \%)$, mientras que Euhalteriolita tipo Stipa $(3,35 \%)$ fueron escasos. Raros: los poliédricos superiores a $40 \mu \mathrm{m}(1,67 \%)$, el grupo de los aguijones, o aculeolitas con Aculeolithum ancistrathum (1,43\%), A. aculsuficthum (0,23\%), A. rostrathum $(2,87 \%)$, A. acutemeditulium $(0,23 \%)$ y $A$. aciculathum $(0,47 \%)$. Las doliolitas o sillas de montar Doliolita equidimensionata $(2,39 \%)$ y las elongadas D. elongata $(0,23 \%)$. Los elementos de conducción $(0,23 \%)$. Los flabelos Flabelolithum euflabelathum $(0,47 \%)$. Longolita $(0,47 \%)$ y Placa hexagonal (3,11\%). 


\section{Muestra 1152}

El grupo de los fitolitos prismáticos rectangulares se halló dominado por el morfotipo Macroprismatolithum psilaristathum, prismático de bordes lisos, de manera muy frecuente $(26,01 \%)$. Los fitolitos de bordes ondulados $M$. ondulathum $(2,62 \%)$ fueron escasos. Los prismáticos elongados Euprismatolita elongata, $(0,95 \%), M$. denticulathum (prismáticos de bordes dentados) $(0,71 \%)$, los prismáticos de bordes serrados, E. serrata, $(0,47 \%)$, fueron raros. Fueron frecuentes los estróbilos aplanados Estrobilolita aplanada $(11,45 \%)$ y los acampanados E. complanata (11,69\%). escasos los equidimensionales ( $E$. equidimensionata) $(3,57 \%)$ y los estróbilos elongados con cintura $E$. elongata $(2,62 \%)$. Mientras que E. cotilata $(1,19 \%)$ fueron raros. Dentro de los fitolitos esféricos se presentaron de manera frecuente los equinados, Globulolithum sphaerochinulathum (10,50\%), mientras que la presencia de los esféricos lisos (G. sphaeropsilathum) $(1,19 \%)$ y los elípticos equinados $(0,23 \%)$, fueron raros. Los bilobados Euhalteriolita bitestata $(2,17 \%)$ fueron escasos. E. testicaudiculata $(1,43 \%)$, E. botulata $(0,71 \%)$, E. centro largo $(1,19 \%)$, y $E$. testilobata $(1,43 \%)$, raros, igual que los polilobados Plurihalteriolita inequilobata $(0,23 \%)$. Euhalteriolita tipo Stipa $(3,81 \%)$ escasos. Las doliolitas o sillas de montar Doliolita equidimensionata $(1,67 \%)$ y las elongadas $D$. elongata $(0,23 \%)$ raras, al igual que el grupo de los aguijones, o aculeolitas con Aculeolithum ancistrathum (1,67\%), A. acutemeditulium $(0,23 \%), A$. aculsuficthum $(0,95 \%)$ y

A. rostrathum $(1,19 \%)$. Los flabelos Flabelolita excavata $(0,47 \%)$, F. euflabelathum $(1,19 \%)$, formas hemiflabeladas $(0,23 \%)$ y $F$. complanathum $(0,71 \%)$. Longolita $(0,47 \%)$, Pileolita, los poliédricos superiores a $40 \mu \mathrm{m}$ $(2,38 \%)$ y Placa hexagonal $(0,23 \%)$.

\section{Muestra 1153}

El grupo de los fitolitos prismáticos rectangulares se halló dominado por el morfotipo Macroprismatolithum psilaristathum, prismático de bordes lisos, de manera muy frecuente $(21,42 \%)$. Fueron escasos los prismáticos elongados Euprismatolita elongata, $(2,38 \%)$. Los de bordes ondulados $M$. ondulathum $(0,95 \%), M$. denticulathum (prismáticos de bordes dentados) $(1,19 \%)$, y prismáticos de bordes serrados (E. serrata ) $(0,95 \%)$ fueron raros, igual que los prismáticos lisos breves $(1,90 \%)$. Fueron muy frecuentes los estróbilos 
acampanados E. complanata $(14,28 \%)$ y frecuentes los aplanados Estrobilolita aplanada (11,66\%). escasos los equidimensionales ( $E$. equidimensionata) $(6,19 \%)$ y los estróbilos elongados con cintura E. elongata $(3,09 \%)$, mientras que E. cotilata $(1,19 \%)$ fueron raros. Dentro de los fitolitos esféricos se presentaron de manera frecuente los equinados, Globulolithum sphaerochinulathum $(9,28 \%)$. Los elípticos equinados $(0,47 \%)$ y los esféricos lisos (G. sphaeropsilathum) (0,95\%) rara. Los bilobados o halterios Euhalteriolita testicaudiculata (2,85\%), fueron escasos. E. bitestata(2,14\%), E. botulata $(0,71 \%)$ y $\mathrm{E}$. testilobata $(0,95 \%)$, fueron raros, igual que los polilobados Plurihalteriolita trilobata $(0,23 \%)$, mientras que los, Euhalteriolita tipo Stipa $(3,09 \%)$ fueron escasos como el poliédrico poliédricos superiores a $40 \mu \mathrm{m}(3,57 \%)$. Las doliolitas o sillas de montar Doliolita equidimensionata $(3,09 \%)$ fueron escasas y las elongadas $D$. elongata $(0,23 \%)$ raras. Raros: el grupo de los aguijones, o aculeolitas con Aculeolithum ancistrathum (1,90\%), A. rostrathum $(0,47 \%)$, y $A$. aciculathum $(0,47 \%)$. Los flabelos Flabelolithum euflabelathum, formas hemiflabeladas, F. complanathum $(0,23 \%)$ y Flabelolita excavata $(0,71 \%)$. Pileolita $(0,23 \%)$ y Longolita $(0,47 \%)$.

\section{Muestra 1154}

El grupo de los prismáticos rectangulares se halló representado por los morfotipos Macroprismatolithum psilaristathum, prismático de bordes lisos, $(24,45 \%)$ de manera muy frecuente, los de bordes dentados (M. denticulathum) $(2,66 \%)$ fueron escasos, los prismáticos de bordes ondulados, M. ondulathum $(0,72 \%)$, los prismáticos elongados, Euprismatolita elongata, $(0,48 \%)$ y $E$. serrata $(0,24 \%)$ raros, al igual que los Prismáticos lisos breves $(1,21 \%)$. Dentro del grupo de los fitolitos en forma de estróbilo se presentaron los acampanados, Estrobilolita complanata $(15,98 \%)$ de manera muy frecuente. Los aplanados E. aplanada (20,08\%) frecuente. Los elongados con cintura E. elongata $(4,60 \%)$, y los equidimensionales, E. equidimensionata $(6,53 \%)$ fueron escasos, mientras que los $\mathrm{E}$. cotilata $(1,45 \%)$, y los de un extremo con punta $(0,48 \%)$ fueron raros al igual que los bilobados o halterios Euhalteriolita bitestata (1,69\%), E. botulata $(0,48 \%)$, E. testicaudiculata $(1,69 \%)$, E. testilobata $(0,96 \%)$, los polilobados Plurihalteriolita inequilobata, $(0,48 \%)$ y Euhalteriolita tipo Stipa $(2,42 \%)$. De manera frecuente se presentaron los 
esféricos equinados, Globulolithum sphaerochinulathum $(10,16 \%)$ y rara los esféricos lisos G. sphaeropsilathum (0,72\%). También fueron raros: aquellos en forma de silla de montar Doliolita equidimensionata $(2,17 \%)$, y D. elongata $(0,72 \%)$, los poliédricos superiores a $40 \mu \mathrm{m}(1,93 \%)$ y los menores $(0,48 \%)$, Pileolita $(0,24 \%)$. Longolita $(0,48 \%)$. las bulliformes Flabelolita elongata y $\mathrm{F}$. euflabelathum (0,24\%), los aguijones Aculeolithum ancistrathum, A. rostrathum $(0,96 \%)$ y formas indeterminadas $(1,10 \%)$,

\section{Muestra 1155}

El grupo de los prismáticos rectangulares se halló representado por los morfotipos Macroprismatolithum psilaristathum, prismático de bordes lisos, $(30,14 \%)$ de manera muy frecuente, los prismáticos de bordes ondulados, $M$. ondulathum (3,82\%), fueron escasos. Los de bordes dentados ( $M$. denticulathum) $(1,67 \%)$, los prismáticos elongados, Euprismatolita elongata, prismáticos de lados asimétricos $(0,71 \%)$ y $E$. serrata $(0,23 \%)$ raros, al igual que los Prismáticos menores a $40 \mu \mathrm{m}(0,47 \%)$ y prismáticos lisos breves $(0,71 \%)$. Dentro del grupo de los fitolitos en forma de estróbilo se presentaron los acampanados, Estrobilolita complanata (10,04\%) y los aplanados E. aplanada $(9,09 \%)$ de manera frecuente. Los equidimensionales, $\mathrm{E}$. equidimensionata $(7,41 \%)$ fueron escasos, mientras que los elongados con cintura E. elongata $(1,67 \%)$, E. cotilata $(0,23 \%)$ fueron raros al igual que los bilobados Euhalteriolita bitestata $(1,43 \%)$, E. botulata $(0,23 \%)$, E. centro largo $(0,47 \%)$, E. testicaudiculata $(1,19 \%)$, E. testilobata $(0,47 \%)$, las cruces Halteriolita cruciformata $(0,47 \%)$ y Euhalteriolita tipo Stipa $(1,67 \%)$. De manera frecuente se presentaron los esféricos equinados, Globulolithum sphaerochinulathum $(10,52 \%)$ y rara los elípticos equinados, los esféricos con ornamentación clavada y los esféricos lisos G. sphaeropsilathum $(0,23 \%)$. Los poliédricos superiores a $40 \mu \mathrm{m}(4,30 \%)$ fueron escasos y los menores a $40 \mu \mathrm{m}$ $(0,47 \%)$ raros. También fueron raros: aquellos en forma de silla de montar o saddle Doliolita equidimensionata y D. elongata (ambos 1,19\%), los elementos de conducción (0,71\%). Los aguijones Aculeolithum ancistrathum (1,67\%), A. rostrathum $(1,19 \%)$, A. aciculathum $(0,47 \%)$. y formas intermedias no identificadas $(0,23 \%)$ Las bulliformes Flabelolithum complanathum $(1,90 \%)$, y F. euflabelathum $(0,71 \%)$, y Longolita $(0,23 \%)$. 


\section{Muestra 1156}

El grupo de los prismáticos rectangulares se halló representado por los morfotipos Macroprismatolithum psilaristathum, prismático de bordes lisos, $(21,95 \%)$ de manera muy frecuente, los prismáticos de bordes ondulados, $M$. ondulathum $(3,34 \%)$, fueron escasos. Los de bordes dentados (M. denticulathum) (1,67\%), los prismáticos elongados, Euprismatolita elongata, y E. serrata $(0,23 \%)$ raros, al igual que los Prismáticos menores a $40 \mu \mathrm{m}(1,19 \%)$ y Prismáticos lisos breves $(0,47 \%)$. Dentro del grupo de los fitolitos en forma de estróbilo se presentaron los acampanados, Estrobilolita complanata $(14,55 \%)$ de manera muy frecuente. Los aplanados E. aplanada $(9,30 \%)$ y los equidimensionales, E. equidimensionata $(7,39 \%)$ de manera frecuente. Fueron escasos, los elongados con cintura E. elongata $(3,57 \%)$, mientras que $E$. cotilata $(0,95 \%)$, y estróbilo con un extremo agudo $(1,67 \%)$ fueron raros. De manera frecuente se presentaron los esféricos equinados, Globulolithum sphaerochinulathum $(10,26 \%)$ y rara los esféricos lisos G. sphaeropsilathum $(0,47 \%)$. Los poliédricos superiores a $40 \mu \mathrm{m}(3,34 \%)$ fueron escasos y los menores a $40 \mu \mathrm{m}(0,23 \%)$ raros. Aquellos en forma de silla de montar o saddle Doliolita equidimensionata $(3,81 \%)$, escasos y $\mathrm{D}$. elongata $(0,71 \%)$ raros. También fueron raros: los pelos, ganchos y aguijones Aculeolithum ancistrathum (1,67\%), A. rostrathum (1,19\%), formas no identificadas, $(0,71 \%)$ y A. aciculathum (0,95\%). Los elementos de conducción $(0,71 \%)$. Los bilobados o halterios Euhalteriolita bitestata $(1,43 \%)$, E. botulata $(0,23 \%)$, E. centro largo $(0,47 \%)$, E. testicaudiculata $(0,95 \%)$, E. testilobata $(0,71 \%)$, y formas de centro largo y extremos globosos $(0,47 \%)$, las cruces Halteriolita cruciformata $(0,23 \%)$ y Euhalteriolita tipo Stipa $(1,43 \%)$. Las bulliformes Flabelolithum complanathum $(1,19 \%)$, y $\mathrm{F}$. euflabelathum $(0,23 \%)$, Pileolita $(0,94 \%)$. Longolita $(0,23 \%)$.

\section{Muestra 1157}

El grupo de los prismáticos rectangulares se halló representado por los morfotipos Macroprismatolithum psilaristathum, prismático de bordes lisos, $(18,37 \%)$ de manera muy frecuente, mientras que los prismáticos de bordes ondulados, M. ondulathum (1,86\%), los de bordes dentados (M. denticulathum) $(1,39 \%)$, los prismáticos elongados, Euprismatolita elongata, $(1,39 \%)$, y $\mathrm{E}$. 
serrata $(0,69 \%)$ raros, al igual que los Prismáticos menores a $40 \mu \mathrm{m}(0,23 \%)$ y Prismáticos lisos breves $(0,46 \%)$. Dentro dEI grupo de los fitolitos en forma de estróbilo se presentaron los acampanados, Estrobilolita complanata $(24,18 \%)$ y los aplanados E. aplanada $(16,27 \%)$ de manera muy frecuente. Los equidimensionales, E. equidimensionata $(5,34 \%)$ y los elongados con cintura E. elongata $(4,41 \%)$ fueron escasos, mientras que $E$. cotilata $(0,23 \%)$, y los de un extremo con punta $(0,93 \%)$ fueron raros. De manera frecuente se presentaron los esféricos equinados, Globulolithum sphaerochinulathum $(7,44 \%)$ y rara los esféricos lisos G. sphaeropsilathum $(0,93 \%)$ y los elípticos equinados $(0,23 \%)$. También fueron raros: aquellos en forma de silla de montar o saddle Doliolita equidimensionata $(2,09 \%)$ y D. elongata $(0,23 \%)$, los aguijones Aculeolithum ancistrathum (2,32\%), A. rostrathum $(0,23 \%)$, formas intermedias $(1,85 \%)$ y A. aciculathum $(0,23 \%)$. Los bilobados o halterios Euhalteriolita bitestata $(1,86 \%)$, E. botulata $(0,46 \%)$, E. testicaudiculata $(1,16 \%)$, E. testilobata $(0,69 \%)$, Euhalteriolita tipo Stipa (1,62\%). Los poliédricos superiores a $40 \mu \mathrm{m}(0,23 \%)$ y los menores a $40 \mu \mathrm{m}(0,69 \%)$. Los polilobados Plurihalteriolita trilobata, las bulliformes Flabelolithum complanathum y F. euflabelathum, Pileolita y Formas macroglobosas (todas $0,23 \%)$.

\section{Muestra 1158}

Dentro del grupo de los fitolitos en forma de estróbilo se presentaron los acampanados Estrobilolita complanata (22,24\%) de manera muy frecuente. Los aplanados E. aplanada $(10,28 \%)$ de manera frecuente. Los equidimensionales, E. equidimensionata, $(6,69 \%)$, y los estróbilos elongados con cintura E. elongata $(2,87 \%)$ escasos, mientras que E. cotilata $(0,95 \%)$ fueron raros. El grupo de los prismáticos rectangulares se halló representado por los morfotipos Macroprismatolithum psilaristathum, prismático de bordes lisos, $(24,16 \%)$ de manera muy frecuente, los prismáticos de bordes ondulados M. ondulathum (1,67\%), los de bordes dentados (M. denticulathum) $(0,47 \%)$, los de bordes serrados, E. serrata, $(0,23 \%)$ y los prismáticos elongados, Euprismatolita elongata, $(0,23 \%)$ fueron raros como los prismáticos lisos breves $(1,19 \%)$ y los poliédricos superiores a $40 \mu \mathrm{m}(1,19 \%)$. Los bilobados Euhalteriolita bitestata $(0,71 \%)$, E. testilobata $(1,19 \%)$ y E. testicotilata $(0,47 \%)$ 
lo hicieron de forma rara, al igual que las cruces Halteriolita cruciformata $(0,71 \%)$. Euhalteriolita tipo Stipa fueron escasos $(3,11 \%)$ como aquellos en forma de silla de montar con Doliolita equidimensionata (4,06\%), mientras que los D. elongata fueron raros $(1,43 \%)$. Dentro de los fitolitos esféricos se presentaron de manera frecuente los esféricos equinados, Globulolithum sphaerochinulathum (9,56\%) y los esféricos lisos (G. sphaeropsilathum) fueron raros $(1,91 \%)$. También fueron raros los elementos de conducción $(0,23 \%)$, Pileolita $(0,23 \%)$, los naviculados Longolita $(0,23 \%)$, los aguijones Aculeolithum rostrathum $(0,47 \%)$, A. ancistrathum $(1,19 \%)$, A. aciculathum $(0,23 \%)$ y las bulliformes Flabelolithum euflabelathum y $\mathrm{F}$. complanathum $(0,23 \%)$.

\section{Muestra 1159}

Dentro del grupo de los fitolitos en forma de estróbilo se presentaron los acampanados Estrobilolita complanata $(25,29 \%)$ de manera muy frecuente. Los aplanados E. aplanada (13,81\%) fueron frecuentes. Los equidimensionales, E. equidimensionata, (5,15\%), y los estróbilos elongados con cintura E. elongata $(3,51 \%)$ escasos, mientras que E. cotilata $(0,46 \%)$ y los de punta en un extremo $(0,70 \%)$ fueron raros. Los bilobados o halterios que se presentaron de manera escasa, fueron Euhalteriolita testicaudiculata $(2,57 \%)$, mientras que E. bitestata (1,63\%), E. botulata $(0,23 \%)$, E. centro largo, $(0,46 \%)$ y E. testilobata $(0,70 \%)$ lo hicieron de forma rara, al igual que los polilobados Plurihalteriolita trilobata $(0,23 \%)$. Euhalteriolita tipo Stipa fueron escasos $(5,38 \%)$ como aquellos en forma de silla de montar o saddle Doliolita equidimensionata $(3,98 \%)$, mientras que los $D$. elongata fueron raros $(0,46 \%)$. Dentro de los fitolitos esféricos se presentaron de manera frecuente los esféricos equinados, Globulolithum sphaerochinulathum $(8,19 \%)$ y los esféricos lisos (G. sphaeropsilathum) fueron raros $(0,46 \%)$. El grupo de los prismáticos rectangulares se halló representado por los morfotipos Macroprismatolithum psilaristathum, prismático de bordes lisos, $(15,69 \%)$ de manera muy frecuente, los prismáticos de bordes ondulados $M$. ondulathum $(2,57 \%)$ de manera escasa, y aquellos de bordes dentados ( $M$. denticulathum) $(1,40 \%)$, los de bordes serrados, E. serrata, $(0,23 \%)$ y los prismáticos elongados, Euprismatolita elongata, $(0,46 \%)$ rara, al igual que los poliédricos superiores a $40 \mu \mathrm{m}(0,46 \%)$, los menores $(0,93 \%)$, Longolita $(0,46 \%)$, los aguijones 
Aculeolithum rostrathum (1,17\%), A. ancistrathum (1,87\%), formas indeterminadas $(0,46 \%)$, y $A$. aciculathum $(0,23 \%)$ y las bulliformes con Flabelolithum complanathum $(0,23 \%)$.

\section{Muestra 1160}

Dentro del grupo de los fitolitos en forma de estróbilo se presentaron los acampanados Estrobilolita complanata $(17,74 \%)$ y los aplanados E. aplanada $(13,42 \%)$ de manera muy frecuente. Los equidimensionales, $E$. equidimensionata, $(3,35 \%)$, y los estróbilos elongados con cintura E. elongata $(3,83 \%)$, escasos, mientras que los de un extremo con punta $(0,19 \%)$ y $E$. cotilata $(0,71 \%)$ fueron raros. Los bilobados o halterios que se presentaron de manera frecuente, fueron Euhalteriolita bitestata $(6,47 \%)$. E. botulata $(1,91 \%)$ y E. testicaudiculata $(3,59 \%)$ escasos, mientras E. testilobata $(1,43 \%)$ y E. centro largo, $(0,47 \%)$ lo hicieron de forma rara, al igual que los polilobados Plurihalteriolita trilobata $(0,71 \%)$. Euhalteriolita tipo Stipa fueron escasos $(2,87 \%)$ al igual que aquellos en forma de silla de montar o saddle con Doliolita equidimensionata $(2,39 \%)$, los $\mathrm{D}$. elongata fueron raros $(0,95 \%)$. Los pelos, ganchos y aguijones estuvieron presentes con Aculeolithum ancistrathum $(2,63 \%)$ y A. aculsufictum $(2,15 \%)$ de manera escasa, y A. rostrathum $(0,47 \%)$, y $A$. aciculathum $(0,23 \%)$ rara. Dentro de los fitolitos esféricos se presentaron de manera frecuente los esféricos equinados, Globulolithum sphaerochinulathum $(6,47 \%)$ y los esféricos lisos (G. sphaeropsilathum) fueron raros $(0,47 \%)$. El grupo de los prismáticos rectangulares se halló representado por los morfotipos Macroprismatolithum psilaristathum, prismático de bordes lisos, $(14,38 \%)$ de manera muy frecuente, los prismáticos de bordes ondulados M. ondulathum $(3,59 \%)$ de manera escasa. Los de bordes dentados (M. denticulathum) $(1,43 \%)$, los de bordes serrados, E. serrata, $(0,47 \%)$, los prismáticos elongados, Euprismatolita elongata, $(1,67 \%)$ y asimétricos $(0,47 \%)$ fueron raros como los prismáticos lisos breves $(0,23 \%)$, y los poliédricos superiores a $40 \mu \mathrm{m}(1,43 \%)$ y menores a $40 \mu \mathrm{m}(0,47 \%)$, Longolita $(0,23 \%)$, Pileolita $(0,23 \%)$ y las bulliformes Flabelolithum complanathum $(0,47 \%)$. 


\section{PERFIL PERFIL ALVEAR}

\section{Muestra 1184}

El grupo de los fitolitos prismáticos se halló dominado por el morfotipo Macroprismatolithum psilaristathum, presente de manera muy frecuente $(20,24 \%)$. Fue escasa la presencia de $M$. denticulathum y $M$. ondulathum $(2,68 \%$ y $2,19 \%$ respectivamente) y rara la de Euprismatolita elongata y los prismáticos de bordes serrados, Euprismatolita serrata $(0,97 \%$ y $0,48 \%$ respectivamente). El grupo de los estróbilos se encontró dominado por el morfotipo Estrobilolita complanata, que se presentó de manera muy frecuente $(12,43 \%)$. Tanto el morfotipo E. aplanada, E. equidimensionata, como E. elongata se presentaron de manera escasa $(4,87 \%, 4,39 \%$ y $2,68 \%$ respectivamente), mientras que $E$. cotilata lo hizo de forma rara $(0,48 \%)$. El grupo de los fitolitos esféricos estuvo dominado por el morfotipo Globulolithum sphaerochinulathum de manera muy frecuente $(12,92 \%)$. La presencia de G. sphaeropsilathum fue frecuente $(6,34 \%)$, mientras que los elípticos equinados y los elípticos lisos se presentaron de manera rara $(0,97 \%$ y $0,24 \%$ respectivamente). Dentro de aquellos bilobados los Euhalteriolita testicaudiculata, E. bitestata y E. testilobata se presentaron de manera escasa $(5,12 \%, 4,39 \%$ y $2,92 \%$ respectivamente) y $\mathrm{E}$. botulata, y Euhalteriolita cuello largo de manera rara $(0,48 \%$, y $0,24 \%$ respectivamente). Las doliolitas estuvieron representadas de manera escasa $(2,68 \%)$ sólo por las Doliolita equidimensionata. Otro grupo presente en la muestra Fue el de los Aculeolithum, que incluye A. ancistrathum, A. rostrathum y A. acuminathum, todas presentes de manera rara $(0,97 \%, 0,97 \%$ y $0,24 \%$ respectivamente). También de manera rara estuvieron presentes elementos de conducción $(0,48 \%)$, las flabeladas Flabelolithum complanathum y $F$. euflabelathum (ambas $0,24 \%)$, Longolita $(0,48 \%)$, Plurihalteriolita trilobata $(0,24 \%)$, Pileolita $(1,46 \%)$, los poliédricos superiores a $40 \mu \mathrm{m}(0,24 \%)$ y las placas hexagonales $(0,97 \%)$.

\section{Muestra 1185}

El grupo de los "rondel" o fitolitos en forma de cono truncado se encontró dominado por los morfotipos Estrobilolita complanata y E. aplanada que se presentaron de manera frecuente $(12,10 \%$ y $9,20 \%$ respectivamente). 
Los morfotipos E. equidimensionata y E. elongata se presentaron de manera escasa ( $5,08 \%$ y $2,66 \%$ respectivamente), mientras que $E$. cotilata lo hizo de forma rara $(0,48 \%)$. El grupo de los fitolitos esféricos se encontró dominado por el morfotipo Globulolithum sphaerochinulathum de manera muy frecuente $(22,03 \%)$. La presencia de G. sphaeropsilathum fue escasa (5,56\%), mientras que los elípticos equinados se presentaron de manera rara $(0,48 \%)$. El grupo de los fitolitos prismáticos se halló dominado por el morfotipo Macroprismatolithum psilaristathum, presente de manera muy frecuente $(20,82 \%)$. Fue rara la presencia de M. ondulathum, M. denticulathum y Euprismatolita elongata $(0,96 \%, 0,72 \%$ y $0,48 \%$ respectivamente). Dentro de los bilobados, los Euhalteriolita testicaudiculata y E. bitestata se presentaron de manera escasa ( $3,87 \%$, y $3,14 \%$ respectivamente). Las Doliolitas estuvieron representadas de manera escasa $(2,42 \%)$ sólo por Doliolita equidimensionata. El morfotipo Euhalteriolita tipo Stipa presente de manera escasa (2,90\%). Otro grupo presente en la muestra fue el de los pelos, ganchos y aguijones que incluye Aculeolithum ancistrathum, A. rostrathum y A. acuminathum, todas presentes de manera rara $(0,72 \%, 0,48 \%$ y $0,24 \%$ respectivamente). También de manera rara estuvieron presentes los elementos de conducción $(0,24 \%)$, las flabeladas Flabelolita elongata y Flabelolithum euflabelathum (ambas 0,48\%), Longolita $(0,48 \%)$, las prismáticas breves $(0,24 \%)$, Euhalteriolita cruciformata $(0,48 \%)$, Pileolita $(0,48 \%)$ y poliédricos superiores a $40 \mu \mathrm{m}(1,69 \%)$.

\section{Muestra 1186}

El grupo de los fitolitos en forma de cono truncado se encontró dominado por el morfotipo Estrobilolita complanata, que se presentó de manera muy frecuente $(15,62 \%)$. El morfotipo E. aplanada se presentó de manera frecuente $(10,81 \%)$, mientras que $E$. equidimensionata, como $E$. elongata se presentaron de manera escasa ( $3,84 \%$ y $2,40 \%$ respectivamente), E. cotilata lo hizo de forma rara $(0,24 \%)$. El grupo de los fitolitos prismáticos se halló dominado por el morfotipo Macroprismatolithum psilaristathum, presente de manera muy frecuente $(21,63 \%)$. Fue rara la presencia de $M$. ondulathum, M. denticulathum (prismáticos de bordes dentados), Euprismatolita serrata y $\mathrm{E}$. elongata $(1,44 \%, 1,20 \%, 0,96 \%$ y $0,48 \%$ respectivamente). El grupo de los fitolitos esféricos se encontró dominado por el morfotipo Globulolithum 
sphaerochinulathum que se presentó de manera frecuente (10,81\%). La presencia de G. sphaeropsilathum Fue escasa $(4,08 \%)$, mientras que los elípticos equinados y los elípticos lisos se presentaron de manera rara $(0,96 \%$ y $0,24 \%$ respectivamente). Las Doliolitas estuvieron representadas de manera frecuente $(7,21 \%)$ por Doliolita equidimensionata, y rara $(0,48 \%)$ por $\mathrm{D}$. elongata. Euhalteriolita tipo Stipa se presentó de manera escasa $(3,36 \%)$. Dentro de los bilobados, Euhalteriolita bitestata se presentaron de manera escasa $(3,12 \%)$ y rara E. testicaudiculata y E. botulata, $(1,20 \%$ y $0,48 \%$ respectivamente). Otro grupo presente en la muestra fue el de los aguijones, pelos y tricomas, que incluye a Aculeolithum ancistrathum y $A$. rostrathum presentes ambas de manera rara $(1,20 \%)$. También de manera rara estuvieron presentes las prismáticas breves $(0,72 \%)$, las cruces Euhalteriolita cruciformata $(0,24 \%)$, las naviculadas Longolita $(0,96 \%)$, Plurihalteriolita trilobata $(0,49 \%)$, poliédricos superiores a $40 \mu \mathrm{m}(1,20 \%)$, formas triangulares $(0,72 \%)$, placas hexagonales $(0,72 \%)$ y las flabeladas Flabelolithum complanathum y Flabelolita excavata (ambas 0,24\%).

\section{Muestra 1187}

El grupo de los fitolitos prismáticos se halló dominado por el morfotipo Macroprismatolithum psilaristathum, presente de manera muy frecuente $(30,07 \%)$. Fue rara la presencia de $M$. ondulathum, M. denticulathum, Euprismatolita elongata, Euprismatolita serrata y prismáticos de bordes serrados, E. serrata Euprismatolita excavata $(1,22 \%, 0,97 \%, 0,48 \%, 0,48 \%$ y $0,24 \%$ respectivamente). El grupo de los fitolitos esféricos se encontró dominado por el morfotipo Globulolithum sphaerochinulathum que se presentó de manera muy frecuente $(22,00 \%)$. La presencia de $G$. sphaeropsilathum fue escasa $(4,15 \%)$, mientras que los elípticos equinados se presentaron de manera rara $(0,48 \%)$. El grupo de los fitolitos en forma de cono truncado, se encontró dominado por Estrobilolita complanata presente de manera frecuente $(14,18 \%)$. El morfotipo E. aplanada se presentó de manera escasa $(5,13 \%)$, mientras que E. elongata, E. equidimensionata, y E.cotilata lo hicieron de forma rara $(1,95 \%, 1,71 \%$ y $0,73 \%$ respectivamente). Entre los bilobados o en forma de halterio, se encontraron los Euhalteriolita bitestata, E. botulata E. testicaudiculata, E. testilobata y E. testicotilata todos se presentaron de manera 
rara $(1,46 \%, 0,48 \%, 0,48 \%, 0,24 \%$ y $0,24 \%$ respectivamente). Las doliolitas estuvieron representadas de manera rara por las Doliolita equidimensionata y D. elongata $(2,68 \%$ y $0,24 \%$ respectivamente). Otro grupo presente en la muestra fue el de pelos, ganchos, y aguijones que incluye Aculeolithum ancistrathum, A. rostrathum, y otras variantes de este morfotipo todas presentes de manera rara $(1,46 \%, 0,73 \%, 0,24 \%, 0,24 \%$ y $0,24 \%)$. También de manera rara estuvieron presentes los elementos de conducción $(0,24 \%)$, Flabelolita excavata $(0,24 \%)$, Longolita $(0,24 \%)$, formas macroglobosas lisas $(0,24 \%)$, prismáticos menores a $40 \mu \mathrm{m}(0,48 \%)$, Euhalteriolita tipo Stipa $(1,95 \%)$, Plurihalteriolita inequilobata $(0,24 \%)$, poliédricos superiores a $40 \mu \mathrm{m}$ $(2,44 \%)$ y formas triangulares $(0,24 \%)$.

\section{Muestra 1188}

El grupo de los fitolitos esféricos se encontró dominado por el morfotipo Globulolithum sphaerochinulathum que se presentó de manera muy frecuente $(25,90 \%)$. La presencia de G. sphaeropsilathum fue escasa $(3,38 \%)$, mientras que los elípticos equinados se presentaron de manera rara $(0,24 \%)$. El grupo de los fitolitos prismáticos se halló dominado por el morfotipo Macroprismatolithum psilaristathum, presente de manera muy frecuente $(27,61 \%)$. Fue rara la presencia de $M$. ondulathum, prismáticos de bordes ondulados, prismáticos lisos menores a $40 \mu \mathrm{m}, \mathrm{M}$. denticulathum, y Euprismatolita elongata $(2,42 \%, 0,72 \%, 0,72 \%, 0,72 \%, 0,48 \%$ y $0,24 \%$ respectivamente). El grupo de los de forma de cono truncado se encontró dominado por el morfotipo Estrobilolita complanata presente de manera frecuente $(9,92 \%)$. El morfotipo E. aplanada se presentó de manera escasa $(3,63 \%)$ junto con $E$. equidimensionata $(3,14 \%)$, mientras que $E$. elongata y $E$. cotilata lo hicieron de forma rara $(1,45 \%$ y $0,24 \%$ respectivamente). Entre los bilobados o en forma de halterio, se encontraron los Euhalteriolita bitestata, E. testicaudiculata, E. botulata y E. testilobata, todos presentes de manera rara $(1,69 \%, 1,21 \%, 0,24 \%$ y $0,24 \%$ respectivamente). Las doliolitas estuvieron representadas de manera rara por Doliolita equidimensionata y D. elongata $(1,21 \%$ y $0,48 \%$ respectivamente). Entre los poliédricos, los superiores a 40 $\mu \mathrm{m}$ estuvieron presentes de manera escasa $(4,11 \%)$ y los inferiores a $40 \mu \mathrm{m}$ de manera rara $(0,72 \%)$. Otro grupo presente en la muestra fue el de los pelos, 
ganchos y aguijones incluyendo Aculeolithum ancistrathum y $A$. rostrathum presentes de manera rara $(0,99 \%$ y $0,74 \%$ respectivamente). También de manera rara estuvieron presentes los prismáticos breves $(0,72 \%)$, elementos de conducción $(0,48 \%)$, Flabelolithum euflabelathum y Flabelolita excavata $(1,93 \%$ y $0,48 \%)$, Longolita $(1,24 \%)$, formas multilobadas $(0,48 \%)$, Euhalteriolita tipo Stipa $(2,66 \%)$ y triangulares $(0,24 \%)$.

\section{Muestra 1189}

El grupo de los fitolitos prismáticos se halló dominado por el morfotipo Macroprismatolithum psilaristathum, presente de manera muy frecuente $(24,08 \%)$. Fue rara la presencia de los prismáticos elongados, Euprismatolita elongata, M. ondulathum, M. denticulathum, y prismáticos de bordes serrados, Euprismatolita serrata $(1,45 \%, 0,97 \%, 0,97 \%$ y 0,48\% respectivamente). En el grupo de los estróbilos se encontraron los morfotipos Estrobilolita complanata y E. aplanada de manera frecuente $(12,16 \%$ y $8,51 \%)$. El morfotipo E. equidimensionata se presentó de manera escasa $(3,89 \%)$, mientras que $E$. elongata, y E. cotilata lo hicieron de forma rara $(1,96 \%$, y $0,48 \%$ respectivamente). El grupo de los fitolitos esféricos se encontró dominado por el morfotipo Globulolithum sphaerochinulathum de manera muy frecuente $(19,46 \%)$. La presencia de G. sphaeropsilathum fue escasa $(5,83 \%)$, mientras que los elípticos equinados, los esféricos con ornamentación clavada y los elípticos lisos se presentaron de manera rara $(0,97 \%, 0,24 \%$ y 0,24\% respectivamente). Entre los bilobados $\mathrm{O}$ en forma de halterio, $E$. testicaudiculata se encontró de manera escasa $(2,91 \%)$ y de manera rara Euhalteriolita bitestata y E. botulata $(1,70 \%$ y $0,72 \%$ respectivamente). En el grupo de los poliédricos, los superiores a $40 \mu \mathrm{m}$ estuveron presentes de manera escasa $(2,43 \%)$ y los inferiores a $40 \mu \mathrm{m}$ con presencia rara $(0,48 \%)$. También de manera rara estuvieron presentes las aculeolitas, con Aculeolithum ancistrathum y $\mathrm{A}$. rostrathum (1,21\% y 0,97\% respectivamente), las doliolitas como Doliolita equidimensionata y $D$. elongata $(2,18 \%$ y $0,24 \%$ respectivamente), los prismáticos breves $(0,24 \%)$, elementos de conducción $(0,24 \%)$, plurihalteriolita inequilobata y $P$. trilobata (ambos 0,24\%), Euhalteriolita tipo Stipa $(1,94 \%)$ y placas hexagonales $(0,99 \%)$. 


\section{PERFIL PROTESTANTE}

\section{Muestra 1384}

Dentro del grupo de los fitolitos en forma de estróbilo se presentaron los acampanados Estrobilolita complanata $(19,27 \%)$ de manera muy frecuente. Frecuentes fueron los aplanados E. aplanada (10,60\%). Los equidimensionales, E. equidimensionata, $(2,89 \%)$ y los estróbilos elongados con cintura E. elongata $(2,16 \%)$ fueron escasos. Mientras que los estróbilos con punta en un extremo $(0,72 \%)$ fueron raros. Dentro de los fitolitos esféricos se presentaron de manera frecuente los esféricos equinados, Globulolitahum sphaerochinulathum $(11,08 \%)$, mientras los esféricos lisos $G$. sphaeropsilathum $(2,65 \%)$ y los elípticos equinados fueron raros $(0,72 \%)$. Los aguijones Aculeolithum ancistrathum (3,37\%), fueron escasos, mientras que $A$. rostrathum $(1,20 \%)$ y $A$. aculsuficthum fueron raros $(0,72 \%)$. El grupo de los fitolitos prismáticos se halló dominado por el morfotipo Macroprismatolithum psilaristathum, presente de manera frecuente $(8,43 \%)$. Fue rara la presencia de $M$. denticulathum, prismáticos de bordes dentados, $(0,48 \%)$, M. ondulathum, prismático de bordes ondulados $(0,96 \%)$, y Euprismatolita elongata, prismático elongado $(0,48 \%)$. Igual que los prismáticos rectangulares de tamaño inferior a $40 \mu \mathrm{m}(1,68 \%)$ y prismáticos breves $(0,48 \%)$. Los bilobados o halterios que se presentaron de manera frecuente, fueron Euhalteriolita bitestata $(6,74 \%)$. E. testicaudiculata $(0,96 \%)$, E. testilobata $(0,24 \%)$, E. botulata $(1,20 \%)$ y $E$. faseolata $(0,48 \%)$ lo hicieron de forma rara, al igual que los polilobados irregulares, Plurihalteriolita inequilobata, $(0,96 \%)$, los regulares, P. trilobata $(0,48 \%)$, P. catenata $(0,24 \%)$ y los bilobados Euhalteriolita tipo Stipa $(1,44 \%)$. Las formas triangulares $(2,65 \%)$ fueron escasas. Aquellos en forma de silla de montar o saddle que se presentaron también de manera escasa, fueron Doliolita equidimensionata $(3,85 \%)$, mientras que los $D$. elongata $(0,72 \%)$ y $D$. oblata $(0,72 \%)$ fueron raros. Las bulliformes con Flabelolithum complanathum de manera escasa $(2,40 \%)$ y $F$. euflabelathum $(1,92 \%)$. Flabelolita excavata $(0,72 \%)$ y formas hemiflabeladas $(1,20 \%)$ de manera rara, como los poliédricos superiores a $40 \mu \mathrm{m}(1,92 \%)$, los menores a $40 \mu \mathrm{m}(0,48 \%)$ y elementos de conducción $(0,24 \%)$. 


\section{Muestra 1385}

Dentro del grupo de los fitolitos en forma de estróbilo se presentaron los acampanados Estrobilolita complanata $(12,94 \%)$ de manera muy frecuente. Frecuentes fueron los aplanados E. aplanada (10,60\%). Los estróbilos elongados con cintura E. elongata (2,63\%) fueron escasos. Mientras que los equidimensionales, E. equidimensionata, $(1,67 \%)$ y los con punta en un extremo $(0,23 \%)$ fueron raros. Dentro de los fitolitos esféricos se presentaron de manera muy frecuente los esféricos equinados, Globulolithum sphaerochinulathum (19,42\%), los esféricos lisos G. sphaeropsilathum $(6,71 \%)$ fueron frecuentes y los elípticos equinados fueron raros $(1,43 \%)$. Los aguijones Aculeolithum ancistrathum (2,15\%), y A. rostrathum (2,87\%) fueron escasos, mientras que A. acutemeditulium fueron raros (0,47\%). El grupo de los fitolitos prismáticos se halló dominado por el morfotipo Macroprismatolithum psilaristathum, presente de manera frecuente $(8,87 \%)$. Fue rara la presencia tanto de M. denticulathum, prismáticos de bordes dentados, $(0,23 \%)$, como de M. ondulathum, prismático de bordes ondulados $(0,95 \%)$. Igual que de prismáticos rectangulares de tamaño inferior a $40 \mu \mathrm{m}(1,43 \%)$ y prismáticos breves $(0,71 \%)$. Los bilobados o halterios que se presentaron de manera escasa, fueron Euhalteriolita bitestata (4,07\%). E. testicaudiculata $(0,47 \%)$, E. testilobata $(0,23 \%)$, E. botulata $(0,95 \%)$ y E. faseolata $(0,23 \%)$ lo hicieron de forma rara, al igual que los polilobados irregulares, Plurihalteriolita inequilobata, $(1,43 \%)$. Los bilobados Euhalteriolita tipo Stipa (2,63\%) lo hicieron de manera escasa, al igual que las elípticas a circulares (2,15\%). Aquellos en forma de silla de montar o saddle que se presentaron de manera escasa, fueron Doliolita equidimensionata $(3,59 \%)$, mientras que los D. elongata $(0,95 \%)$ y D. oblata $(0,23 \%)$ fueron raros. El grupo de las bulliformes se presento de manera rara con Flabelolithum complanathum (1,91\%), F. euflabelathum $(1,91 \%)$, Flabelolita excavata $(1,43 \%)$ y $\mathrm{F}$. elongata $(0,23 \%)$, como los poliédricos superiores a $40 \mu \mathrm{m}(1,91 \%)$, y los menores a $40 \mu \mathrm{m}(0,47 \%)$, elementos de conducción $(0,23 \%)$ y formas triangulares $(0,95 \%)$. 


\section{Muestra 1386}

Dentro del grupo de los fitolitos en forma de estróbilo se presentaron los acampanados Estrobilolita complanata $(22,08 \%)$ de manera muy frecuente. Frecuentes fueron los aplanados E. aplanada (12,37\%). Los estróbilos elongados con cintura $E$. elongata y los equidimensionales, $E$. equidimensionata, (ambos 3,64\%) fueron escasos. Mientras los con punta en un extremo $(0,24 \%)$ fueron raros. Dentro de los fitolitos esféricos se presentaron de manera muy frecuente los esféricos equinados, Globulolithum sphaerochinulathum (13,34\%), los esféricos lisos G. sphaeropsilathum $(7,28 \%)$ fueron frecuentes y los elípticos equinados fueron raros $(0,48 \%)$. Los aguijones Aculeolithum ancistrathum (2,18\%), A. rostrathum (1,21\%), A. aciculathum $(0,48 \%)$, A. aculsuficthum $(0,72 \%)$ fueron raros. El grupo de los fitolitos prismáticos se halló dominado por el morfotipo Macroprismatolithum psilaristathum, presente de manera frecuente $(7,76 \%)$. Fue rara la presencia de $M$. ondulathum, prismático de bordes ondulados $(0,24 \%)$ y de los elongados E. elongata $(0,48 \%)$. Igual que de prismáticos rectangulares de tamaño inferior a $40 \mu \mathrm{m}(0,97 \%)$ y prismáticos breves $(0,72 \%)$. Los bilobados o halterios que se presentaron de manera escasa, fueron Euhalteriolita bitestata $(3,15 \%)$, mientras E. testilobata $(0,24 \%)$, E. botulata $(0,48 \%)$ y E. faseolata $(0,24 \%)$ lo hicieron de forma rara, al igual que los polilobados regulares,Plurihalteriolita trilobata, $(0,24 \%)$ y los bilobados Euhalteriolita tipo Stipa (1,69\%). Aquellos en forma de silla de montar o saddle que se presentaron de manera escasa, fueron Doliolita equidimensionata $(5,09 \%)$, mientras que los $D$. elongata $(0,24 \%)$ y D. oblata $(0,48 \%)$ fueron raros. El grupo de las bulliformes se presento de manera rara con Flabelolithum complanathum $(1,45 \%)$, $F$. euflabelathum $(0,48 \%)$, y Flabelolita excavata $(1,21 \%)$, como los poliédricos superiores a $40 \mu \mathrm{m}(0,72 \%)$, y los menores $(0,97 \%)$, formas triangulares $(2,18 \%)$, elípticas a circular $(0,97 \%)$ y redondeadas $(0,24 \%)$.

\section{Muestra 1387}

En el grupo de los fitolitos en forma de estróbilo se presentaron los acampanados Estrobilolita complanata $(19,04 \%)$ y los aplanados E. aplanada $(11,79 \%)$ de manera muy frecuente. Fueron frecuentes los estróbilos elongados con cintura E. elongata $(6,80 \%)$ y los equidimensionales, E. 
equidimensionata, $(7,93 \%)$. escasos E. cotilata $(0,24 \%)$. Dentro de los fitolitos esféricos se presentaron de manera muy frecuente los esféricos equinados, Globulolithum sphaerochinulathum $(12,47 \%)$, y los esféricos lisos G. sphaeropsilathum $(7,28 \%)$ fueron escasos. El grupo de los fitolitos prismáticos se halló dominado por el morfotipo Macroprismatolithum psilaristathum, presente de manera escasa $(4,53 \%)$, mientras que fue rara la presencia de $\mathrm{M}$. ondulathum, prismático de bordes ondulados $(0,90 \%)$ y de los denticulados $M$. denticulathum $(0,45 \%)$, igual que de prismáticos rectangulares de tamaño inferior a $40 \mu \mathrm{m}(0,90 \%)$. Los bilobados o halterios que se presentaron de manera frecuente, fueron Euhalteriolita bitestata $(7,70 \%)$, mientras $\mathrm{E}$. de cuello largo $(0,45 \%)$, E. botulata $(1,36 \%)$ y E. testicaudiculta $(0,45 \%)$ lo hicieron de forma rara, al igual que los polilobados irregulares,Plurihalteriolita inequilobata, $(0,90 \%)$. Los bilobados Euhalteriolita tipo Stipa (4,53\%) fueron escasos. Aquellos en forma de silla de montar o saddle que se presentaron de manera escasa, fueron Doliolita equidimensionata (4,98\%), mientras que D. elongata $(0,90 \%)$ fue rara. También fueron raros el grupo de las bulliformes con Flabelolithum euflabelathum $(0,90 \%)$, Flabelolita excavata $(1,81 \%)$, F. elongata $(0,45 \%)$ y formas hemiflabeladas $(0,45 \%)$, el de los aguijones Aculeolithum ancistrathum $(2,18 \%)$ y $A$. rostrathum $(1,21 \%)$, y los poliédricos superiores a 40 $\mu \mathrm{m}(1,13 \%)$ y formas triangulares $(0,68 \%)$.

\section{Muestra 1388}

Dentro del grupo de los fitolitos en forma de estróbilo se presentaron los acampanados Estrobilolita complanata $(17,27 \%)$ de manera muy frecuente. Frecuentes fueron los aplanados E. aplanada $(6,08 \%)$ y los equidimensionales, E. equidimensionata $(7,54 \%)$. Los estróbilos elongados con cintura E. elongata, $(4,13 \%)$ fueron escasos. Mientras los E. cotilata $(0,48 \%)$ fueron raros. Dentro de los fitolitos esféricos se presentaron de manera muy frecuente los esféricos equinados, Globulolithum sphaerochinulathum (17,76\%) y los esféricos lisos G. sphaeropsilathum $(4,13 \%)$ fueron escasos. Los aguijones Aculeolithum rostrathum $(2,67 \%)$, fueron escasos, y $A$. ancistrathum $(0,97 \%)$ y $A$. aciculathum $(0,48 \%)$ raros. El grupo de los fitolitos prismáticos se halló dominado por el morfotipo Macroprismatolithum psilaristathum, presente de manera frecuente $(5,59 \%)$. Fue rara la presencia de $M$. ondulathum, $(0,97 \%)$, 
M. denticulathum (0,97\%), Euprismatolita anisocornisata $(0,48 \%)$, E. excavata $(0,48 \%)$ y de los elongados $E$. elongata $(0,48 \%)$. Los prismáticos rectangulares de tamaño inferior a $40 \mu \mathrm{m}(1,94 \%)$ fueron escasos. Los bilobados o halterios que se presentaron de manera frecuente, fueron Euhalteriolita bitestata $(5,83 \%)$, mientras E. botulata $(1,94 \%)$ fue escasa y $E$. testilobata $(0,48 \%)$, E. testicaudiculata $(0,72 \%)$ y E. de centro largo $(0,48 \%)$ lo hicieron de forma rara, al igual que los polilobados irregulares,Plurihalteriolita inequilobata, $(0,97 \%)$. Los bilobados Euhalteriolita tipo Stipa (4,37\%) fueron escasos. Aquellos en forma de silla de montar o saddle que se presentaron de manera escasa, fueron Doliolita equidimensionata $(3,89 \%)$, y D. elongata $(2,91 \%)$ mientras D. oblata $(0,48 \%)$ fueron raros. El grupo de las bulliformes se presento de manera rara con Flabelolithum complanathum (0,97\%), F. euflabelathum $(0,48 \%)$, y Flabelolita excavata $(0,72 \%)$, como los poliédricos superiores a $40 \mu \mathrm{m}(1,70 \%)$ y formas oblongas $(0,97 \%)$.

\section{Muestra 1389}

Dentro del grupo de los fitolitos en forma de estróbilo se presentaron los acampanados Estrobilolita complanata $(17,49 \%)$ y los aplanados E. aplanada $(11,82 \%)$ de manera muy frecuente. Los estróbilos elongados con cintura $E$. elongata $(3,54 \%)$ y los equidimensionales, E. equidimensionata, $(1,67 \%)$ fueron escasos. Dentro de los fitolitos esféricos se presentaron de manera muy frecuente los esféricos equinados, Globulolithum sphaerochinulathum $(19,42 \%)$, los esféricos lisos G. sphaeropsilathum $(4,25 \%)$ fueron escasos, mientras que los elípticos equinados y los esféricos con ornamentación clavada $(0,23 \%)$ fueron raros. Aculeolithum rostrathum $(2,12 \%)$, fueron escasos, mientras que A. acutemeditulium $(0,23 \%)$, formas no identificadas $(0,94 \%)$ y A. ancistrathum $(1,65 \%)$ fueron raros. El grupo de los fitolitos prismáticos se halló dominado por el morfotipo Macroprismatolithum psilaristathum, presente de manera escasa (3,07\%). Fue rara la presencia tanto de $M$. denticulathum, prismáticos de bordes dentados, $(0,94 \%)$, como de M. ondulathum, prismático de bordes ondulados (1,18\%), E. serrata, prismático de bordes serrados $(0,23 \%)$ y los elongados Euprismatolita elongata $(0,94 \%)$. También fueron raros los prismáticos rectangulares de tamaño inferior a $40 \mu \mathrm{m}$ $(1,65 \%)$ y prismáticos breves $(0,70 \%)$. Los bilobados o halterios que se 
presentaron de manera frecuente, fueron Euhalteriolita bitestata (6,61\%). E. testicaudiculata $(1,18 \%)$, E. testicotilata $(0,23 \%)$, E. de centro largo $(0,23 \%), E$. botulata $(1,18 \%)$ y $\mathrm{E}$. faseolata $(0,47 \%)$ lo hicieron de forma rara, al igual que las cruces Halteriolita cruciformata $(0,23 \%)$, los polilobados irregulares, Plurihalteriolita inequilobata, $(1,65 \%)$ y los regulares $P$. trilobata $(0,70 \%)$. Los bilobados Euhalteriolita tipo Stipa $(4,25 \%)$ lo hicieron de manera escasa al igual que las formas elípticas a circular (2,12\%). Aquellos en forma de silla de montar o saddle que se presentaron de manera frecuente, fueron Doliolita equidimensionata $(5,91 \%)$, mientras que los D. elongata $(0,47 \%)$ y D. oblata $(0,70 \%)$ fueron raros. El grupo de las bulliformes se presento de manera rara con Flabelolithum complanathum (1,65\%), F. euflabelathum (1,65\%) y Flabelolita excavata $(0,23 \%)$, como Longolita $(0,23 \%)$, los poliédricos superiores a $40 \mu \mathrm{m}(0,23 \%)$, y menores a $40 \mu \mathrm{m}(0,23 \%)$, elementos de conducción $(0,23 \%)$, redondeadas $(0,70 \%)$ y formas triangulares $(1,41 \%)$.

\section{Muestra 1390}

Dentro del grupo de los fitolitos en forma de estróbilo se presentaron los acampanados Estrobilolita complanata (22,33\%) de manera muy frecuente. escasos fueron los estróbilos elongados con cintura E. elongata $(2,91 \%)$ y los equidimensionales, E. equidimensionata (3,15\%). Mientras los aplanados E. aplanada $(1,94 \%)$ fueron raros. Dentro de los fitolitos esféricos se presentaron de manera frecuente los esféricos equinados, Globulolithum sphaerochinulathum $(13,10 \%)$, y los esféricos lisos G. sphaeropsilathum $(3,15 \%)$ fueron escasos. Los aguijones Aculeolithum ancistrathum (2,91\%) fueron escasos, el resto raros, con $A$. rostrathum $(1,45 \%)$, A. aciculathum $(0,48 \%)$, formas indeterminadas $(0,72 \%)$. El grupo de los fitolitos prismáticos se halló dominado por el morfotipo Macroprismatolithum psilaristathum, presente de manera escasa $(6,31 \%)$. Fue rara la presencia de M. ondulathum, prismático de bordes ondulados $(1,45 \%)$ y de los elongados Euprismatolita elongata $(0,47 \%)$, de los prismáticos rectangulares de tamaño inferior a $40 \mu \mathrm{m}$ $(1,21 \%)$, de $M$. denticulathum (1,21\%) y prismáticos breves $(0,48 \%)$. Los bilobados $o$ halterios que se presentaron de manera escasa, fueron Euhalteriolita bitestata (6,31\%), mientras E. de centro largo $(0,48 \%)$, E. botulata $(0,72 \%)$ y E. testicaudiculata $(0,97 \%)$ lo hicieron de forma rara, al igual 
que los polilobados regulares, Plurihalteriolita trilobata, $(0,48 \%)$ y los irregulares $\mathrm{P}$. inequilobata $(0,72 \%)$. Los bilobados Euhalteriolita tipo Stipa $(3,88 \%)$ fueron escasos, como los poliédricos superiores a $40 \mu \mathrm{m}(2,42 \%)$ y las formas elípticas a circular (3,15\%). Aquellos en forma de silla de montar o saddle que se presentaron de manera frecuente, fueron Doliolita equidimensionata $(7,03 \%)$, mientras que D. elongata $(0,72 \%)$ y D. oblata $(0,48 \%)$ fueron raros. El grupo de las bulliformes se presento de manera escasa con Flabelolithum complanathum (2,91\%), y rara con F. euflabelathum y Flabelolita excavata (ambas 1,69\%). Otras morfotipos presentes de manera rara fueron las formas triangulares $(0,97 \%)$, Longolita $(0,48 \%)$ y formas oblongas $(0,48 \%)$.

\section{Muestra 1391}

Dentro del grupo de los fitolitos en forma de estróbilo se presentaron los acampanados Estrobilolita complanata $(23,52 \%)$ de manera muy frecuente. Frecuentes fueron los aplanados E. aplanada (10,04\%). Los estróbilos elongados con cintura E. elongata $(3,67 \%)$ y los equidimensionales, $E$. equidimensionata $(3,67 \%)$ fueron escasos. Mientras $E$. cotilata $(2,20 \%)$ fueron raros. Dentro de los fitolitos esféricos, los equinados, Globulolithum sphaerochinulathum $(11,51 \%)$, fueron frecuentes y los esféricos lisos G. sphaeropsilathum $(6,12 \%)$ fueron escasos. Los aguijones fueron raros con Aculeolithum ancistrathum $(1,71 \%)$, y $A$. rostrathum $(1,22 \%)$. Los fitolitos prismáticos estuvieron presentes con Macroprismatolithum psilaristathum $(3,18 \%)$ y los rectangulares de tamaño inferior a $40 \mu \mathrm{m}(2,45 \%)$ de manera escasa. Y rara con los elongados E. elongata (0,49\%). Los bilobados o halterios que se presentaron de manera escasa, fueron Euhalteriolita bitestata $(5,39 \%)$, mientras E. testicaudiculata $(0,49 \%)$ y E. botulata $(2,20 \%)$ lo hicieron de forma rara, al igual que los polilobados regulares,Plurihalteriolita trilobata, $(0,49 \%)$ y los irregulares $\mathrm{P}$. inequilobata $(0,73 \%)$. Euhalteriolita tipo Stipa $(5,14 \%)$ fue Escaso. Aquellos en forma de silla de montar o saddle que se presentaron fueron Doliolita equidimensionata (10,04\%), de manera frecuente, y D. elongata $(0,98 \%)$ rara. Las bulliformes se presentaron de manera rara con Flabelolithum complanathum, F. euflabelathum, y Flabelolita excavata (todas 
0,49\%), como los poliédricos superiores a $40 \mu \mathrm{m}(0,49 \%)$, y los menores $(0,49 \%)$, formas triangulares $(0,73 \%)$ y oblongas $(0,98 \%)$.

\section{Muestra 1392}

Dentro del grupo de los fitolitos en forma de estróbilo se presentaron los acampanados Estrobilolita complanata (22,08\%) de manera muy frecuente. Frecuentes fueron los aplanados E. aplanada (12,37\%). Los estróbilos elongados con cintura $E$. elongata y los equidimensionales, $E$. equidimensionata, (ambos 3,64\%) fueron escasos. Mientras los con punta en un extremo $(0,24 \%)$ fueron raros. Dentro de los fitolitos esféricos se presentaron de manera muy frecuente los esféricos equinados, Globulolithum sphaerochinulathum $(13,34 \%)$, los esféricos lisos G. sphaeropsilathum $(7,28 \%)$ fueron frecuentes y los elípticos equinados fueron raros $(0,48 \%)$. Los aguijones Aculeolithum ancistrathum (2,18\%), A. rostrathum $(1,21 \%)$, A. aciculathum $(0,48 \%)$, A. aculsuficthum $(0,72 \%)$ fueron raros. El grupo de los fitolitos prismáticos se halló dominado por el morfotipo Macroprismatolithum psilaristathum, presente de manera frecuente (7,76\%). Fue rara la presencia de $\mathrm{M}$. ondulathum, prismático de bordes ondulados $(0,24 \%)$ y de los elongados E. elongata $(0,48 \%)$. Igual que de prismáticos rectangulares de tamaño inferior a $40 \mu \mathrm{m}(0,97 \%)$ y prismáticos breves $(0,72 \%)$. Los bilobados o halterios que se presentaron de manera escasa, fueron Euhalteriolita bitestata $(3,15 \%)$, mientras E. testilobata $(0,24 \%)$, E. botulata $(0,48 \%)$ y $E$. faseolata $(0,24 \%)$ lo hicieron de forma rara, al igual que los polilobados regulares,Plurihalteriolita trilobata, $(0,24 \%)$ y los bilobados Euhalteriolita tipo Stipa (1,69\%). Aquellos en forma de silla de montar o saddle que se presentaron de manera escasa, fueron Doliolita equidimensionata $(5,09 \%)$, mientras que los D. elongata $(0,24 \%)$ y D. oblata $(0,48 \%)$ fueron raros. El grupo de las bulliformes se presento de manera rara con Flabelolithum complanathum (1,45\%), $\mathrm{F}$. euflabelathum $(0,48 \%)$, y Flabelolita excavata $(1,21 \%)$, como los poliédricos superiores a $40 \mu \mathrm{m}(0,72 \%)$, y los menores $(0,97 \%)$, formas triangulares $(2,18 \%)$, elípticas a circular $(0,97 \%)$ y redondeadas $(0,24 \%)$. 


\section{Muestra 1393}

Dentro del grupo de los fitolitos en forma de estróbilo se presentaron los acampanados Estrobilolita complanata $(22,08 \%)$ de manera muy frecuente. Frecuentes fueron los aplanados E. aplanada (12,37\%). Los estróbilos elongados con cintura $E$. elongata $y$ los equidimensionales, $E$. equidimensionata, (ambos 3,64\%) fueron escasos. Mientras los con punta en un extremo $(0,24 \%)$ fueron raros. Dentro de los fitolitos esféricos se presentaron de manera muy frecuente los esféricos equinados, Globulolithum sphaerochinulathum (13,34\%), los esféricos lisos G. sphaeropsilathum $(7,28 \%)$ fueron frecuentes y los elípticos equinados fueron raros $(0,48 \%)$. Los aguijones Aculeolithum ancistrathum $(2,18 \%)$, A. rostrathum (1,21\%), A. aciculathum $(0,48 \%)$, A. aculsuficthum $(0,72 \%)$ fueron raros. El grupo de los fitolitos prismáticos se halló dominado por el morfotipo Macroprismatolithum psilaristathum, presente de manera frecuente $(7,76 \%)$. Fue rara la presencia de $M$. ondulathum, prismático de bordes ondulados $(0,24 \%)$ y de los elongados E. elongata $(0,48 \%)$. Igual que de prismáticos rectangulares de tamaño inferior a $40 \mu \mathrm{m}(0,97 \%)$ y prismáticos breves $(0,72 \%)$. Los bilobados o halterios que se presentaron de manera escasa, fueron Euhalteriolita bitestata $(3,15 \%)$, mientras E. testilobata $(0,24 \%)$, E. botulata $(0,48 \%)$ y E. faseolata $(0,24 \%)$ lo hicieron de forma rara, al igual que los polilobados regulares,Plurihalteriolita trilobata, $(0,24 \%)$ y los bilobados Euhalteriolita tipo Stipa (1,69\%). Aquellos en forma de silla de montar o saddle que se presentaron de manera escasa, fueron Doliolita equidimensionata $(5,09 \%)$, mientras que los $D$. elongata $(0,24 \%)$ y D. oblata $(0,48 \%)$ fueron raros. El grupo de las bulliformes se presento de manera rara con Flabelolithum complanathum $(1,45 \%)$, $F$. euflabelathum $(0,48 \%)$, y Flabelolita excavata $(1,21 \%)$, como los poliédricos superiores a $40 \mu \mathrm{m}(0,72 \%)$, y los menores $(0,97 \%)$, formas triangulares $(2,18 \%)$, elípticas a circular $(0,97 \%)$ y redondeadas $(0,24 \%)$.

\section{Muestra 1394}

Dentro del grupo de los fitolitos en forma de estróbilo se presentaron los acampanados Estrobilolita complanata $(22,27 \%)$ de manera muy frecuente. Los estróbilos aplanados E. aplanada $(5,81 \%)$ y los equidimensionales, E. equidimensionata, $(2,90 \%)$ fueron escasos, y raros los elongados con cintura 
E. elongata $(2,17 \%)$. Dentro de los fitolitos esféricos se presentaron de manera frecuente los esféricos equinados, Globulolithum sphaerochinulathum $(11,62 \%)$ $y$ los esféricos lisos G. sphaeropsilathum $(2,42 \%)$ fueron escasos. Los aguijones Aculeolithum ancistrathum $(4,11 \%)$, fueron escasos, mientras que formas de aguijones no identificadas $(1,20 \%)$ y $A$. rostrathum $(0,96 \%)$ fueron raros. El grupo de los fitolitos prismáticos se halló dominado por el morfotipo Macroprismatolithum psilaristathum, presente de manera frecuente $(6,77 \%)$. Fue rara la presencia tanto de $\mathrm{M}$. denticulathum, prismáticos de bordes dentados, $(0,24 \%)$, como de $\mathrm{M}$. ondulathum, prismático de bordes ondulados $(0,96 \%)$ y $E$. serrata, prismático de bordes serrados $(0,24 \%)$. También fueron raros los prismáticos rectangulares de tamaño inferior a $40 \mu \mathrm{m}$ psilaristathum $(0,48 \%)$ y prismáticos breves $(0,24 \%)$. Los bilobados o halterios que se presentaron de manera escasa, fueron Euhalteriolita bitestata $(4,60 \%)$. E. testicaudiculata $(0,72 \%)$, E. testiloblata $(0,72 \%)$ y E. botulata $(0,48 \%)$ lo hicieron de forma rara. Los bilobados Euhalteriolita tipo Stipa $(2,42 \%)$ lo hicieron de manera escasa. Aquellos en forma de silla de montar o saddle que se presentaron de manera frecuente, fueron Doliolita equidimensionata $(8,95 \%)$, mientras que los $D$. elongata y $D$. oblata $(0,96 \%)$ fueron raros. $E$ grupo de las bulliformes se presento de manera escasa con Flabelolithum complanathum $(2,90 \%)$ y Flabelolita excavata $(3,14 \%)$ y rara con $F$. euflabelathum $(1,21 \%)$, como los elementos de conducción $(0,24 \%)$ y formas triangulares $(0,96 \%)$. Las formas elípticas a circulares fueron escasas $(3,63 \%)$. Los poliédricos superiores a $40 \mu \mathrm{m}(4,11 \%)$, escasos y menores a $40 \mu \mathrm{m}$ $(0,96 \%)$ raros.

\section{Muestra 1395}

Dentro del grupo de los fitolitos en forma de estróbilo se presentaron los acampanados Estrobilolita complanata $(19,41 \%)$ de manera muy frecuente. Fueron escasos los aplanados E. aplanada (3,93\%) y los equidimensionales, E. equidimensionata, $(4,22 \%)$ Los estróbilos elongados con cintura $E$. elongata $(1,71 \%)$ y los E. cotilata $(0,73 \%)$ fueron raros. Dentro de los fitolitos esféricos se presentaron de manera frecuente los esféricos equinados, Globulolithum sphaerochinulathum (9,33\%) y los esféricos lisos G. sphaeropsilathum $(0,73 \%)$ fueron raros. Los aguijones Aculeolithum ancistrathum $(3,19 \%)$ y $\mathrm{A}$. rostrathum 
$(4,17 \%)$ fueron escasos, mientras A. aciculathum $(0,73 \%)$ fue raro. El grupo de los fitolitos prismáticos se halló dominado por el morfotipo Macroprismatolithum psilaristathum, presente de manera frecuente $(6,87 \%)$. Aunque estuvieron presentes de forma rara otros prismáticos como $\mathrm{M}$. ondulathum, prismático de bordes ondulados $(1,71 \%)$, los elongados Euprismatolita elongata $(0,49 \%)$, $\mathrm{M}$. denticulathum $(0,73 \%)$ y los prismáticos rectangulares de tamaño inferior a 40 $\mu \mathrm{m}(0,73 \%)$. Los bilobados o halterios que se presentaron de manera escasa, fueron Euhalteriolita bitestata $(5,40 \%)$, mientras E. testicaudiculata $(0,73 \%)$, E. botulata $(0,73 \%)$ y $E$. de centro largo $(0,49 \%)$ lo hicieron de forma rara, al igual que los polilobados irregulares,Plurihalteriolita inequilobata, $(0,24 \%)$. Los bilobados Euhalteriolita tipo Stipa $(2,94 \%)$ fueron escasos. Aquellos en forma de silla de montar o saddle que se presentaron de manera escasa, fueron Doliolita equidimensionata $(5,40 \%)$, mientras que $D$. elongata $(1,47 \%)$ fue raro. El grupo de las bulliformes se presento de manera escasa con Flabelolithum complanathum $(4,91 \%)$ y $F$. euflabelathum $(2,45 \%)$, y Flabelolita excavata $(7,61 \%)$ fue frecuente. Los poliédricos superiores a $40 \mu \mathrm{m}(5,40 \%)$ fueron escasos. formas triangulares $(0,49 \%)$, oblongas $(0,73 \%)$ y Longolita $(0,49 \%)$.

\section{Muestra 1396}

Dentro del grupo de los fitolitos en forma de estróbilo se presentaron los acampanados Estrobilolita complanata $(11,08 \%)$ y los aplanados E. aplanada $(10,59 \%)$ de manera muy frecuente. Los equidimensionales, $E$. equidimensionata, $(3,69 \%)$ fueron frecuentes, los estróbilos elongados con cintura E. elongata $(3,20 \%)$ escasos, mientras E. cotilata( $0,98 \%$ ) y con punta en un extremo $(0,49 \%)$ raros. Dentro de los fitolitos esféricos se presentaron de manera muy frecuente los esféricos equinados, Globulolithum sphaerochinulathum $(7,63 \%)$, mientras que los esféricos lisos G. sphaeropsilathum $(0,24 \%)$, los elípticos equinados $(0,49 \%)$ y los elípticos lisos, $(0,24 \%)$ fueron raros. Los aguijones Aculeolithum aciculathum (1,23\%), A. ancistrathum $(2,46 \%)$ y formas intermedias $(1,72 \%)$ fueron escasos, mientras que A. rostrathum $(0,98 \%)$ fue raro. El grupo de los fitolitos prismáticos se halló dominado por el morfotipo Macroprismatolithum psilaristathum, presente de manera frecuente $(5,66 \%)$. Fue escasa la presencia tanto de $M$. denticulathum $(2,21 \%)$, como de $M$. ondulathum $(1,72 \%)$, mientras E. serrata, $(0,24 \%)$ y 
Euprismatolita elongata $(0,49 \%)$ fueron raros, igual que los prismáticos breves $(0,24 \%)$. Los prismáticos rectangulares de tamaño inferior a $40 \mu \mathrm{m}(1,97 \%)$ fueron escasos. Los bilobados o halterios que se presentaron de manera muy frecuente, fueron Euhalteriolita bitestata (7,63\%), mientras E. testicaudiculata $(1,23 \%)$ fue Escaso, y E. botulata $(0,49 \%)$, E. testilobata $(0,73 \%)$ y formas no identificadas $(0,24 \%)$ lo hicieron de forma rara, al igual que los polilobados irregulares, Plurihalteriolita inequilobata, $(0,73 \%)$, los regulares $P$. trilobata $(0,73 \%)$ y los catenados P. catenata $(0,49 \%)$. Los bilobados Euhalteriolita tipo Stipa $(7,88 \%)$ lo hicieron de manera muy frecuente. Aquellos en forma de silla de montar o saddle que se presentaron de manera muy frecuente, fueron Doliolita equidimensionata $(8,37 \%)$, mientras que los D. elongata $(0,73 \%)$ fueron raros y D. oblata $(1,23 \%)$ escasos. El grupo de las bulliformes se presentó de manera escasa con Flabelolithum euflabelathum $(1,72 \%)$ y Flabelolita excavata $(2,21 \%)$, y rara con F. complanathum $(0,98 \%)$, F. elongata $(0,49 \%)$ y formas hemiflabeladas $(0,24 \%)$, como los poliédricos superiores a 40 $\mu \mathrm{m}(0,98 \%)$, los menores a $40 \mu \mathrm{m}(0,24 \%)$, formas redondeadas $(0,73 \%)$ y triangulares $(0,49 \%)$. Las formas elípticas a circulares fueron escasas $(3,20 \%)$.

\section{PERFIL LA JUANITA}

\section{Muestra 1178}

Dentro del grupo de los fitolitos en forma de estróbilo se presentaron los acampanados Estrobilolita complanata $(18,51 \%)$ y los aplanados E. aplanada $(14,32 \%)$ de manera muy frecuente, mientras los equidimensionales, $E$. equidimensionata, fueron frecuentes $(7,65 \%)$, los estróbilos elongados con cintura E. elongata $(5,43 \%)$, escasos, y aquellos estróbilos con una punta en un extremo $(0,74 \%)$ raros. El grupo de los prismáticos rectangulares se halló representado por los morfotipos Macroprismatolithum psilaristathum, prismático de bordes lisos, $(10,37 \%)$ de forma frecuente y los prismáticos de bordes ondulados M. ondulathum (1,97\%) de manera escasa. Los de bordes dentados (M. denticulathum) $(0,98 \%)$, los de bordes serrados (Euprismatolita serrata) $(0,24 \%)$ y los prismáticos elongados, Euprismatolita elongata, $(1,48 \%)$ fueron raros, al igual que los prismáticos menores a $40 \mu \mathrm{m}(1,72 \%)$ y que los prismáticos breves $(0,74 \%)$. Aquellos en forma de silla de montar o saddle se presentaron de manera frecuente con Doliolita equidimensionata $(6,66 \%)$, y 
rara con D. elongata $(0,49 \%)$. Los bilobados se presentaron todos de manera rara, con Euhalteriolita bitestata $(1,72 \%)$, E. testilobata $(0,24 \%)$, Euhalteriolita centro largo $(0,98 \%)$, E. botulata $(1,48 \%)$ y E. testicotilata $(0,74 \%)$, menos el caso de los Euhalteriolita tipo Stipa que fueron frecuentes $(8,88 \%)$. Dentro de los fitolitos esféricos se presentaron de manera escasa los esféricos equinados, Globulolithum sphaerochinulathum (2,71\%), los elípticos equinados y los esféricos lisos G. sphaeropsilathum (ambos 0,74\%) fueron raros. La presencia de los poliédricos superiores a $40 \mu \mathrm{m}$ (2,96\%), fue escasa y menores a $40 \mu \mathrm{m}(0,24 \%)$ rara. Las formas triangulares $(2,22 \%)$, fueron escasas. Fue rara la presencia de: placas hexagonales $(0,24 \%)$, las naviculadas Longolita $(0,24 \%)$, las bulliformes Flabelolithum euflabelathum y Flabelolita excavata $(0,74 \%)$, los elementos de conducción $(0,74 \%)$, Aculeolithum rostrathum $(0,98 \%)$, y otrs formas indeterminadas de aguijones $(0,74 \%)$.

\section{Muestra 1179}

Dentro del grupo de los fitolitos en cono truncado o en forma de estróbilo se presentaron los acampanados Estrobilolita complanata $(22,16 \%)$ de manera muy frecuente. De manera frecuente los aplanados E. aplanada $(10,59 \%)$ mientras los equidimensionales, E. equidimensionata (3,94\%), y los estróbilos elongados con cintura E. elongata $(4,92 \%)$ de manera escasa. Dentro de los fitolitos esféricos se presentaron de manera escasa los esféricos equinados, Globulolithum sphaerochinulathum $(5,91 \%)$, y rara los esféricos lisos $G$. sphaeropsilathum $(0,98 \%)$ y los elípticos equinados $(0,49 \%)$. El grupo de los prismáticos rectangulares se halló representado por los morfotipos Macroprismatolithum psilaristathum, prismático de bordes lisos, $(6,89 \%)$ de manera frecuente, y de forma rara los de bordes dentados ( $M$. denticulathum) $(0,73 \%)$, los prismáticos de bordes ondulados $M$. ondulathum, $(1,23 \%)$, los prismáticos elongados, Euprismatolita elongata, (0,98\%), los de bordes serrados Euprismatolita serrata $(0,73 \%)$ y Euprismatolita anisocornisata $(1,47 \%)$, también fueron raros los prismáticos menores a $40 \mu \mathrm{m}(2,21 \%)$ y los prismáticos breves $(1,47 \%)$. Aquellos en forma de silla de montar o saddle se presentaron de manera escasa con Doliolita equidimensionata $(3,94 \%)$, y rara por $(1,23 \%)$ y D. elongata $(0,24 \%)$. Los bilobados que se presentaron de 
manera escasa fueron Euhalteriolita bitestata (2,95\%), mientras que E. botulata $(0,49 \%)$, E. testicaudiculata $(0,98 \%)$, y E. testilobata $(0,49 \%)$ fueron raros. Los Euhalteriolita tipo Stipa fueron escasos (6,40\%). Aculeolithum rostrathum $(2,46 \%)$, fueron escasos, mientras $A$. aciculathum $(1,23 \%), A$. ancistrathum $(1,47 \%)$, y $A$. acuminathum $(0,49 \%)$ fueron raros. Los polilobados irregulares Plurihalteriolita inequilobata fueron raros $(0,73 \%)$, al igual que los poliédricos superiores a $40 \mu \mathrm{m}(2,21 \%)$ y menores a $40 \mu \mathrm{m}(0,49 \%)$, las bulliformes Flabelolita excavata $(0,49 \%)$, F. complanathum $(1,72 \%)$, formas hemiflabeladas $(0,49 \%)$ y F. euflabelathum $(0,98 \%)$, las naviculadas Longolita $(0,98 \%)$, formas multilobadas $(0,73 \%)$, los elementos de conducción $(0,73 \%)$, formas oblongas $(0,73 \%)$, redondeados $(0,49 \%)$ y triangulares $(1,47 \%)$.

\section{Muestra 1180}

Dentro del grupo de los fitolitos en forma de estróbilo se presentaron los acampanados Estrobilolita complanata $(11,21 \%)$ y los aplanados E. aplanada $(15,60 \%)$ de manera muy frecuente, los equidimensionales $E$. equidimensionata, de manera frecuente (6,34\%), los estróbilos elongados con cintura E. elongata (4,39\%) y aquellos con punta en un extremo $(2,92 \%)$ de forma escasa. Dentro de los fitolitos esféricos se presentaron de manera muy frecuente los esféricos equinados, Globulolithum sphaerochinulathum $(12,92 \%)$, y rara los esféricos lisos G. sphaeropsilathum $(1,21 \%)$. El grupo de los prismáticos rectangulares se halló representado por los morfotipos Macroprismatolithum psilaristathum, prismático de bordes lisos, (6,34\%) de manera frecuente, los de bordes dentados (M. denticulathum) $(0,98 \%)$, escasa, y $M$. ondulathum, prismáticos de bordes ondulados $(1,46 \%)$ y prismáticos elongados, Euprismatolita elongata, $(0,48 \%)$ fueron raros, al igual que los prismáticos menores a $40 \mu \mathrm{m}(1,46 \%)$ y que los prismáticos breves $(0,97 \%)$. Aquellos en forma de silla de montar o saddle se presentaron de manera frecuente con Doliolita equidimensionata (6,34\%), escasa por D. oblata $(1,95 \%)$, y rara con $D$. elongata $(0,48 \%)$. Los bilobados o halterios que se presentaron de manera escasa fueron Euhalteriolita bitestata (3,41\%), E. botulata $(1,95 \%)$, y $E$. testicaudiculata $(1,95 \%)$, mientras que $E$. testilobata $(0,48 \%)$ fue raro. Los Euhalteriolita tipo Stipa fueron frecuentes $(7,31 \%)$. Los polilobados regulares, Plurihalteriolita trilobata $y$ los irregulares $P$. 
inequilobathum fueron raros (ambos 0,48\%), al igual que los poliédricos superiores a $40 \mu \mathrm{m}(1,97 \%)$ y los naviculados Longolita $(0,97 \%)$. Las bulliformes estuvieron presentes con Flabelolita excavata $(1,95 \%)$ de forma escasa y F. euflabelathum $(0,97 \%)$, rara. Los aguijones Aculeolithum rostrathum $(0,48 \%)$, y $A$. aciculathum $(0,97 \%)$ también fueron raros.

\section{Muestra 1181}

Dentro del grupo de los fitolitos en forma de estróbilo se presentaron los acampanados Estrobilolita complanata $(9,72 \%)$ y los aplanados E. aplanada $(12,03 \%)$ de manera frecuente, los equidimensionales, E. equidimensionata, de manera escasa $(3,24 \%)$, los estróbilos elongados con cintura E. elongata $(2,31 \%)$ y aquellos con punta en un extremo $(0,46 \%)$ rara. Dentro de los fitolitos esféricos se presentaron de manera muy frecuente los esféricos equinados, Globulolithum sphaerochinulathum $(24,53 \%)$ y rara los esféricos lisos G. sphaeropsilathum (1,38\%) y los elípticos equinados $(0,46 \%)$. El grupo de los prismáticos rectangulares se halló representado por los morfotipos Macroprismatolithum psilaristathum, prismático de bordes lisos, (5,09\%), y $\mathrm{M}$. ondulathum, prismáticos de bordes ondulados $(4,62 \%)$ de manera escasa, y por los de bordes dentados (M. denticulathum) (1,85\%) y los prismáticos elongados, Euprismatolita elongata, $(1,38 \%)$ de manera rara, al igual que los prismáticos menores a $40 \mu \mathrm{m}$ psilaristathum $(0,92 \%)$ y que los prismáticos breves $(0,92 \%)$. Aquellos en forma de silla de montar o saddle se presentaron de manera frecuente con Doliolita equidimensionata $(10,41 \%)$, y rara con $D$. oblata $(2,31 \%)$, y con D. elongata $(0,46 \%)$. En el grupo de los aguijones Aculeolithum aculsuficthum (2,77\%) fue Escaso, mientras que $A$. rostrathum $(0,46 \%)$, A. anicistrathum $(0,69 \%)$ y formas intermedias no identificadas $(0,97 \%)$ fueron raros. Los bilobados o halterios que se presentaron de manera rara fueron Euhalteriolita bitestata $(1,38 \%)$, E. botulata $(0,46 \%)$, formas intermedias indeterminadas $(0,46 \%)$ y $E$. testicaudiculata $(0,46 \%)$. Los Euhalteriolita tipo Stipa fueron escasos (5,09\%). Los polilobados regulares, Plurihalteriolita trilobata $(0,46 \%)$ y los irregulares $P$. inequilobata $(0,92 \%)$ fueron raros al igual que los poliédricos superiores a $40 \mu \mathrm{m}(1,38 \%)$, los naviculados Longolita, $(0,46 \%)$, las bulliformes Flabelolita excavata $(0,23 \%)$ y 
F. complanathum $(0,46 \%)$, los elementos de conducción $(0,46 \%)$, y las formas triangulares $(0,46 \%)$.

\section{Muestra 1182}

Dentro del grupo de los fitolitos en forma de estróbilo se presentaron los acampanados Estrobilolita complanata $(14,42 \%)$ de manera muy frecuente, los aplanados E. aplanada (10,33\%), fueron frecuentes. Los equidimensionales, E. equidimensionata $(1,92 \%)$, y los elongados con cintura $E$. elongata $(1,92 \%)$ escasos. Dentro de los fitolitos esféricos se presentaron de manera muy frecuente los esféricos equinados, Globulolithum sphaerochinulathum $(18,50 \%)$, escasa los esféricos lisos G. sphaeropsilathum $(2,16 \%)$ y los elípticos equinados, $(0,24 \%)$ fueron raros. El grupo de los prismáticos rectangulares se halló representado por los morfotipos Macroprismatolithum psilaristathum, prismático de bordes lisos, $(8,61 \%)$, de manera frecuente, por M. ondulathum, prismáticos de bordes ondulados $(4,30 \%)$, los de bordes dentados (M. denticulathum) $(2,16 \%)$ y Euprismatolita anisocornisata $(1,92 \%)$ de manera escasa. Mientras Euprismatolita serrata (prismáticos de bordes serrados) $(0,48 \%)$, E. excavata (prismáticos de final cóncavo) $(0,24 \%)$ y los prismáticos elongados, Euprismatolita elongata, $(0,24 \%)$ de manera rara, al igual que los prismáticos menores a $40 \mu \mathrm{m}(1,20 \%)$ y que los prismáticos breves $(0,72 \%)$. Aquellos en forma de silla de montar o saddle se presentaron de manera escasa con Doliolita equidimensionata $(2,40 \%)$, y rara con D. oblata $(0,72 \%)$, y con D. elongata $(0,72 \%)$. El grupo de los pelos, ganchos y aguijones también fue raro, con formas no identificadas $(0,96 \%)$, Aculeolithum rostrathum $(1,20 \%), A$. anicistrathum $(1,44 \%)$, A. acutemeditilium $(0,48 \%)$ y A. aciculathum $(0,72 \%)$. Los bilobados o halterios que se presentaron fueron Euhalteriolita bitestata $(2,16 \%)$, manera escasa, y de manera rara E. botulata $(0,72 \%)$, E. testicaudiculata $(0,48 \%)$, E. testilobata $(0,72 \%)$ y. Euhalteriolita tipo Stipa fue Escaso $(5,04 \%)$. Los polilobados regulares, Plurihalteriolita trilobata $(0,96 \%)$ y los irregulares $P$. inequilobathum $(0,72 \%)$ fueron raros al igual que los poliédricos menores a $40 \mu \mathrm{m}(1,44 \%)$, mientras los superiores $(1,92 \%)$ fueron escasos. Las formas naviculadas Longolita $(0,72 \%)$, las formas triangulares $(0,24 \%)$ y multilobadas $(0,24 \%)$ fueron raros. Las bulliformes estuvieron presentes con Flabelolithum euflabelathum $(2,64 \%)$ de manera escasa, 
mientras Flabelolita excavata $(1,20 \%)$, F. elongata $(0,24 \%)$ y Flabelolithum complanathum $(1,68 \%)$ de manera rara.

\section{PERFIL TIPO TEZANOS PINTO}

\section{Muestra 1328}

Dentro del grupo de los fitolitos en forma de cono truncado se presentaron los acampanados Estrobilolita complanata $(21,37 \%)$ y los aplanados E. aplanada $(14,49 \%)$ de manera muy frecuente. Los estróbilos elongados con cintura E. elongata $(6,38 \%)$ y los equidimensionales, E. equidimensionata, $(2,70 \%)$ fueron escasos. Los halterios bilobados que se presentaron de manera escasa, fueron Euhalteriolita bitestata $(6,38 \%)$, E. botulata $(2,70 \%)$ y $E$. testicaudiculata $(2,45 \%)$. E. testilobata $(0,98)$, E. cuello largo $(0,73 \%)$ y E. faseolata $(0,24 \%)$ lo hicieron de forma rara, al igual que los polilobados Plurihalteriolita inequilobata $(0,73 \%)$ y $P$. trilobata $(0,49 \%)$. Los halterios Euhalteriolita tipo Stipa fueron escasos (2,70\%). Aquellos en forma de silla de montar o saddle se presentaron de manera frecuente con Doliolita equidimensionata $(7,37 \%)$, mientras $D$. elongata $(1,71 \%)$ y $D$. oblata $(0,73 \%)$ fueron raros. Dentro de los fitolitos esféricos se presentaron de manera escasa los esféricos equinados, Globulolithum sphaeroechinulathum $(5,89 \%)$, y los esféricos lisos $\mathrm{G}$. sphaeropsilathum $(1,47 \%)$ raros. El grupo de los prismáticos rectangulares se halló representado por los morfotipos Macroprismatolithum psilaristathum, prismático de bordes lisos, $(5,15 \%)$ de manera escasa, mientras fue rara la presencia de los prismáticos de bordes ondulados $\mathrm{M}$. ondulathum $(1,96 \%)$, los de bordes dentados (M. denticulathum) $(1,22 \%)$, los de bordes serrados Euprismatolita serrata $(0,24 \%)$ y los prismáticos elongados, Euprismatolita elongata, $(1,22 \%)$ fueron raros. Otras formas cuya presencia fue rara fueron: triangulares $(1,47 \%)$, redondeadas $(0,73 \%)$, oblongas $(0,49 \%)$, los poliédricos superiores a $40 \mu \mathrm{m}(1,47 \%)$, los inferiores a $40 \mu \mathrm{m}(0,24 \%)$, Longolita $(0,49 \%)$, los flabelos Flabelolithum euflabelathum $(0,24 \%)$, Flabelolita excavata $(0,24 \%)$ y Flabelolithum complanathum $(0,73 \%)$; y también los pelos, ganchos y aguijones representados por Aculeolithum rostrathum (2,97\%), A. ancistrathum $(1,47 \%)$ y $A$. aciculathum $(0,73 \%)$. 


\section{Muestra 1329}

Dentro del grupo de los fitolitos en forma de cono truncado se presentaron los acampanados Estrobilolita complanata $(17,35 \%)$ y los aplanados E. aplanada $(13,20 \%)$ de manera muy frecuente. De manera frecuente, los estróbilos elongados con cintura E. elongata $(5,86 \%)$ y los equidimensionales, E. equidimensionata, $(7,33 \%)$. Los halterios bilobados que se presentaron fueron Euhalteriolita bitestata $(4,40 \%)$, de forma escasa y $E$. botulata $(0,97 \%)$, E. testicaudiculata $(1,22 \%)$ y E. testilobata $(0,97 \%)$, de forma rara, al igual que los polilobados Plurihalteriolita inequilobata $(0,48 \%)$ y $P$. trilobata $(0,48 \%)$ y las cruces Halteriolita cruciformata $(0,97 \%)$. Los halterios Euhalteriolita tipo Stipa fueron escasos (3,17\%). Dentro de los fitolitos esféricos se presentaron de manera frecuente los esféricos equinados, Globulolithum sphaeroechinulathum $(7,33 \%)$, mientras los esféricos lisos G. sphaeropsilathum $(2,93 \%)$ fueron escasos. Los prismáticos rectangulares con Macroprismatolithum psilaristathum, prismático de bordes lisos, (4,64\%), los de bordes dentados $M$. denticulathum (1,95\%) y los de bordes ondulados $M$. ondulathum $(2,93 \%)$ de manera escasa, mientras los prismáticos de bordes serrados Euprismatolita serrata $(0,97 \%)$, los elongados Euprismatolita elongata $(0,48 \%)$ y los prismáticos menores a $40 \mu \mathrm{m}(0,48 \%)$ fueron raros. Los pelos, ganchos y aguijones representados por Aculeolithum rostrathum (2,20\%), y A. ancistrathum $(1,95 \%)$ de forma escasa. Los poliédricos superiores a $40 \mu \mathrm{m}$ $(1,71 \%)$ fueron escasos y raros los inferiores $(1,95 \%)$. Otras formas raras fueron: aquellos en forma de silla de montar o saddle con Doliolita equidimensionata $(1,22 \%)$, D. elongata $(1,46 \%)$ y $D$. oblata $(1,71 \%)$, las naviculadas Longolita $(0,97 \%)$, triangulares $(0,71 \%)$, oblongos y elípticocircular $(0,73 \%)$, los flabelos Flabelolithum euflabelathum $(0,97 \%)$, $F$. complanathum $(1,71 \%)$, Flabelolita excavata $(0,97 \%)$ y F. elongata $(0,73 \%)$.

\section{Muestra 1330}

Dentro del grupo de los fitolitos en forma de cono truncado se presentaron los acampanados Estrobilolita complanata $(18,59 \%)$ y los aplanados E. aplanada $(13,28 \%)$ de manera muy frecuente. De manera frecuente los equidimensionales, E. equidimensionata, (6,52\%), y los estróbilos elongados con cintura E. elongata $(5,79 \%)$. Los bilobados presentes en la 
muestra fueron Euhalteriolita bitestata (6,03\%) de manera frecuente. Mientras que E. botulata $(0,48 \%)$, E. testicaudiculata $(1,20 \%)$, E. testilobata $(0,72)$ y Euhalteriolita cuello largo $(0,48 \%)$ de forma rara, al igual que los polilobados Plurihalteriolita inequilobata $(0,72 \%)$ y las cruces Halteriolita cruciformata $(0,24 \%)$. Los bilobados Euhalteriolita tipo Stipa fueron escasos $(4,10 \%)$. Aquellos en forma de silla de montar o saddle que se presentaron de manera frecuente fueron Doliolita equidimensionata $(8,21 \%)$, mientras D. elongata $(1,93 \%)$ fue escasa y D. oblata $(0,96 \%)$ rara. Dentro de los fitolitos esféricos se presentaron de manera frecuente los esféricos equinados, Globulolithum sphaeroechinulathum $(5,79 \%)$, mientras los esféricos lisos $G$. sphaeropsilathum $(1,20 \%)$ y los elípticos equinados $(0,48 \%)$ fueron raros. Los prismáticos rectangulares con Macroprismatolithum psilaristathum, prismático de bordes lisos, $(5,07 \%)$ de manera escasa, mientras los prismáticos de bordes dentados Macroprismatolithum denticulathum (0,96\%), los prismáticos de bordes ondulados $M$. ondulathum $(0,72 \%)$ y los prismáticos lisos menores a $40 \mu \mathrm{m}(1,20 \%)$ fueron raros. Los poliédricos superiores a $40 \mu \mathrm{m}(3,38 \%)$, fueron escasos, y los inferiores $(0,72 \%)$ raros. Los flabelos Flabelolithum complanathum $(2,41 \%)$, fueron escasos, mientras $F$. euflabelathum $(0,96 \%)$ y Flabelolita excavata $(1,69 \%)$ fueron raros. Otras formas raras fueron: triangulares $(1,20 \%)$, oblongas $(0,72 \%)$, Longolita $(0,48 \%)$; y también los pelos, ganchos y aguijones representados por Aculeolithum rostrathum (0,72\%), A. acuminathum $(0,72 \%)$ y $A$. ancistrathum $(1,69 \%)$.

\section{Muestra 1331}

Dentro del grupo de los fitolitos en forma de cono truncado se presentaron los acampanados Estrobilolita complanata (15,80\%) y los aplanados E. aplanada $(10,61 \%)$ de manera muy frecuente. De manera frecuente los equidimensionales, E. equidimensionata, $(5,18 \%)$, mientras los estróbilos elongados con cintura $E$. elongata (2,96\%) fueron escasos y $E$. cotilata $(0,74 \%)$ raro. Los bilobados presentes en la muestra fueron Euhalteriolita bitestata $(5,92 \%)$ de forma frecuente, E. testilobata $(2,71 \%)$ de forma escasa y el resto, E. botulata $(1,48 \%)$, E. testicaudiculata $(1,23 \%)$ y $E$. cuello largo $(0,74 \%)$ de forma rara, al igual que los polilobados Plurihalteriolita inequilobata $(1,23 \%)$ y $\mathrm{P}$. trilobata $(1,23 \%)$. Los bilobados Euhalteriolita tipo 
Stipa fueron frecuentes $(6,41 \%)$. Aquellos en forma de silla de montar o saddle que se presentaron de manera muy frecuente fueron Doliolita equidimensionata $(12,09 \%)$, mientras $\mathrm{D}$. elongata $(1,97 \%)$ lo hizo de manera escasa y D. oblata $(0,74 \%)$ rara. Dentro de los fitolitos esféricos se presentaron de manera frecuente los esféricos equinados, Globulolithum sphaeroechinulathum $(6,41 \%)$, mientras los esféricos lisos $G$. sphaeropsilathum $(1,48 \%)$ fueron raros. Los prismáticos rectangulares Macroprismatolithum psilaristathum, prismático de bordes lisos, $(2,96 \%)$ de manera escasa, igual que los prismáticos lisos menores a $40 \mu \mathrm{m}(1,72 \%)$, mientras los prismáticos de bordes serrados Euprismatolita serrata $(0,74 \%)$, los prismáticos de bordes dentados Macroprismatolithum denticulathum (0,49\%) y los prismáticos de bordes ondulados $M$. ondulathum $(0,49 \%)$ fueron raros. Los pelos, ganchos y aguijones representados por Aculeolithum ancistrathum $(2,22 \%)$ de manera escasa y por $A$. rostrathum $(1,48 \%)$, y $A$. acuminathum $(0,74 \%)$ de manera rara. Las formas Oblongas $(2,22 \%)$ fueron escasas. Otras formas raras fueron: Longolita $(0,24 \%)$, triangulares $(0,49 \%)$, formas elípticas a circulares $(0,98 \%)$, los poliédricos superiores a $40 \mu \mathrm{m}(1,23 \%)$, los inferiores $(0,74 \%)$, los flabelos Flabelolithum euflabelathum $(0,74 \%)$, F. complanathum $(0,74 \%)$, Flabelolita excavata $(0,49 \%)$ y $\mathrm{F}$. elongata $(0,49 \%)$.

\section{Muestra 1332}

Dentro del grupo de los fitolitos en forma de cono truncado se presentaron los acampanados Estrobilolita complanata $(26,16 \%)$ de manera muy frecuente. Los aplanados E. aplanada $(12,61 \%)$ de manera frecuente, mientras los estróbilos elongados con cintura E. elongata $(6,30 \%)$ y los equidimensionales, E. equidimensionata, (4,20\%) fueron escasos. Los bilobados presentes en la muestra fueron Euhalteriolita bitestata $(1,40 \%)$, E. botulata $(0,93 \%)$, E. testicaudiculata $(0,93 \%)$ y E. testilobata $(1,86 \%)$, de forma rara, al igual que los polilobados Plurihalteriolita inequilobata $(0,46 \%)$. Los bilobados Euhalteriolita tipo Stipa fueron escasos (2,80\%). Aquellos en forma de silla de montar o saddle se presentaron de manera frecuente fueron Doliolita equidimensionata $(8,41 \%)$, mientras D. elongata $(2,57 \%)$ y D. oblata $(1,40 \%)$ fueron raros. Dentro de los fitolitos esféricos se presentaron de manera frecuente los esféricos equinados, Globulolithum sphaeroechinulathum 
$(9,81 \%)$, mientras los esféricos lisos G. sphaeropsilathum $(1,40 \%)$ y los elípticos equinados $(0,93 \%)$ fueron raros. Los prismáticos rectangulares Macroprismatolithum psilaristathum, prismático de bordes lisos, (5,60\%) de manera escasa, mientras los prismáticos de bordes serrados Euprismatolita serrata $(0,46 \%)$ y los prismáticos menores a $40 \mu \mathrm{m}(1,40 \%)$ fueron raros. Otras formas raras fueron: triangulares $(0,46 \%)$, los poliédricos superiores a $40 \mu \mathrm{m}$ $(0,93 \%)$, los inferiores $(0,46 \%)$, los flabelos Flabelolithum euflabelathum $(0,46 \%)$, F. complanathum $(1,86 \%)$, Flabelolita excavata $(0,46 \%)$ y $\mathrm{F}$. elongata $(0,93 \%)$. Los pelos, ganchos y aguijones representados por Aculeolithum rostrathum $(0,93 \%)$, y A. ancistrathum $(2,33 \%)$.

\section{Muestra 1333}

Dentro del grupo de los fitolitos en forma de cono truncado se presentaron los acampanados Estrobilolita complanata $(15,18 \%)$ de manera muy frecuente. Los aplanados E. aplanada (8,91\%) y los equidimensionales, E. equidimensionata, $(4,57 \%)$ de manera frecuente. Mientras los estróbilos elongados con cintura E. elongata $(2,89 \%)$ y E. cotilata $(1,92 \%)$ fueron escasos. Los bilobados presentes en la muestra fueron Euhalteriolita bitestata $(2,89 \%)$ y $\mathrm{E}$. testicaudiculata $(1,92 \%)$ de forma escasa, y $\mathrm{E}$. testilobata $(0,48 \%)$, E. botulata $(0,96 \%)$, y E. cuello largo $(0,48 \%)$ de forma rara, al igual que los polilobados Plurihalteriolita inequilobata $(0,48 \%)$. Los bilobados Euhalteriolita tipo Stipa fueron escasos (3,61\%). Aquellos en forma de silla de montar o saddle que se presentaron de manera frecuente fueron Doliolita equidimensionata $(5,54 \%)$, mientras $\mathrm{D}$. elongata $(1,20 \%)$ y $\mathrm{D}$. oblata $(0,72 \%)$ lo hicieron de manera rara. Dentro de los fitolitos esféricos se presentaron de manera escasa los esféricos equinados, Globulolithum sphaeroechinulathum $(3,85 \%)$, mientras los esféricos con ornamentación clavada $(0,48 \%)$ fueron raros. Los prismáticos rectangulares Macroprismatolithum psilaristathum, prismático de bordes lisos, $(4,81 \%)$ fueron frecuentes, mientras los prismáticos de bordes dentados Macroprismatolithum denticulathum (3,37\%) y los prismáticos de bordes ondulados $M$. ondulathum $(2,40 \%)$ fueron escasos. Fueron raros, los prismáticos menores a $40 \mu \mathrm{m}(0,48 \%)$, los prismáticos de bordes serrados Euprismatolita serrata $(0,48 \%)$, los prismáticos elongados, Euprismatolita elongata, $(0,96 \%)$ y los prismáticos de extremos cóncavos E. 
excavata $(0,96 \%)$. Los pelos, ganchos y aguijones representados por Aculeolithum ancistrathum (3,61\%) de manera escasa y por A. rostrathum $(0,72 \%)$, y A. acuminathum $(0,48 \%)$ y $A$. aciculathum $(0,72 \%)$ de manera rara. Los flabelos estuvieron presentes con Flabelolita excavata $(5,06 \%)$ de manera frecuente, con Flabelolithum euflabelathum (2,16\%), F. complanathum (2,65\%), de manera escasa, y por Flabelolita elongata $(0,72 \%)$ de manera rara. Los poliédricos superiores a $40 \mu \mathrm{m}(5,54 \%)$ fueron frecuentes, y los inferiores $(2,89 \%)$ escasos. Las formas oblongas $(2,16 \%)$ también fueron escasas. Raros fueron: las formas multilobadas $(0,48 \%)$, las formas triangulares $(0,72 \%)$, las elípticas a circular $(1,44 \%)$, redondeadas $(0,48 \%)$.

\section{Muestra 1334}

Dentro del grupo de los fitolitos en forma de cono truncado se presentaron los acampanados Estrobilolita complanata $(23,60 \%)$ de manera muy frecuente. Los aplanados E. aplanada $(10,70 \%)$ de manera frecuente. Mientras los estróbilos elongados con cintura E. elongata $(4,86 \%)$, y los equidimensionales, E. equidimensionata, (5,10\%) fueron escasos y E. cotilata $(0,48 \%)$ raros. Los bilobados presentes en la muestra fueron Euhalteriolita bitestata $(3,64 \%)$ de forma escasa, y $\mathrm{E}$. testicaudiculata $(1,21 \%)$, E. testilobata $(1,45 \%)$, y E. botulata $(1,45 \%)$ de forma rara. Los bilobados Euhalteriolita tipo Stipa fueron escasos (4,37\%). Aquellos en forma de silla de montar o saddle que se presentaron de manera escasa fueron Doliolita equidimensionata $(6,08 \%)$, mientras D. elongata $(2,18 \%)$ y D. oblata $(0,72 \%)$ lo hicieron de manera rara. Dentro de los fitolitos esféricos se presentaron de manera escasa los esféricos equinados, Globulolithum sphaeroechinulathum $(4,13 \%)$, mientras los esféricos lisos, G. sphaeropsilathum (1,70\%) fueron raros. Los prismáticos rectangulares Macroprismatolithum psilaristathum, prismático de bordes lisos, $(2,67 \%)$ fueron escasos, mientras los prismáticos de bordes dentados Macroprismatolithum denticulathum (2,18\%), los prismáticos de bordes ondulados $\mathrm{M}$. ondulathum (1,70\%), los prismáticos menores a $40 \mu \mathrm{m}(1,96 \%)$, los prismáticos elongados, Euprismatolita elongata, $(0,48 \%)$, los prismáticos de extremos cóncavos E. excavata $(0,48 \%)$, los prismáticos breves $(0,72 \%)$ fueron raros. Los pelos, ganchos y aguijones representados por Aculeolithum ancistrathum $(3,64 \%)$ de manera escasa y por $A$. rostrathum $(1,45 \%)$, y $A$. 
aciculathum $(0,24 \%)$ de manera rara. Los flabelos estuvieron presentes con Flabelolita excavata $(3,65 \%)$ de manera escasa y con Flabelolithum complanathum $(0,97 \%)$, de manera rara. Otros morfotipos presentes de manera rara fueron: los poliédricos superiores a $40 \mu \mathrm{m}(1,21 \%)$ y los inferiores $(0,48 \%)$, las formas oblongas $(1,94 \%)$, las formas triangulares $(1,21 \%)$, las elípticas a circular $(1,45 \%)$, redondeadas $(0,72 \%)$, Longolita $(0,48 \%)$.

\section{Muestra 1335}

Dentro del grupo de los fitolitos en forma de cono truncado se presentaron los acampanados Estrobilolita complanata $(18,09 \%)$ de manera muy frecuente. Los aplanados E. aplanada $(10,71 \%)$ de manera frecuente, mientras los estróbilos elongados con cintura E. elongata (3,80\%), los equidimensionales, E. equidimensionata, $(4,28 \%)$ y $E$. cotilata $(2,14 \%)$ fueron escasos. Los bilobados presentes en la muestra fueron Euhalteriolita bitestata $(7,38 \%)$ de manera frecuente, mientras $E$. testilobata $(0,71)$, E. testicaudiculata $(1,42 \%)$, E. rotulata $(0,71 \%)$, y de $E$. cuello largo $(0,47 \%)$ de forma rara. Los bilobados Euhalteriolita tipo Stipa fueron escasos $(5,00 \%)$. Los polilobados Plurihalteriolita inaquilobata $(0,71 \%)$ fueron raros. Aquellos en forma de silla de montar o saddle que se presentaron de manera frecuente fueron Doliolita equidimensionata $(8,33 \%)$, mientras $D$. elongata $(1,66 \%)$ y $D$. oblata $(0,71 \%)$ fueron raros. Dentro de los fitolitos esféricos se presentaron de manera frecuente los esféricos equinados, Globulolithum sphaeroechinulathum $(7,14 \%)$, mientras los esféricos lisos G. sphaeropsilathum $(1,42 \%)$ y los elípticos equinados $(0,47 \%)$ fueron raros. Los prismáticos rectangulares con Macroprismatolithum psilaristathum, prismático de bordes lisos $(4,28 \%)$ de manera escasa, mientras los prismáticos de bordes serrados Euprismatolita serrata $(0,47 \%)$, los prismáticos de bordes dentados Macroprismatolithum denticulathum $(0,47 \%)$, los prismáticos de bordes ondulados $M$. ondulathum $(0,47 \%)$, los prismáticos menores a $40 \mu \mathrm{m}(0,71 \%)$ y los prismáticos elongados, Euprismatolita elongata, $(0,47 \%)$ fueron raros. Los poliédricos superiores a $40 \mu \mathrm{m}(0,95 \%)$, fueron raros. Formas oblongas $(0,73 \%)$, y elíptico a circular $(0,73 \%)$ fueron escasas. Los flabelos Flabelolithum euflabelathum $(0,95 \%)$, F. complanathum (0,95\%), y Flabelolita excavata $(0,47 \%)$ y $\mathrm{F}$. elongata $(0,47 \%)$ estuvieron presentes de manera rara. Los pelos, ganchos y 
aguijones representados por Aculeolithum ancistrathum (3,80\%), A. rostrathum $(2,85 \%)$ de manera escasa y $A$. aciculathum $(0,47 \%)$ de manera rara. Otras formas raras fueron las multilobadas $(0,47 \%)$ y triangular $(1,66 \%)$.

\section{Muestra 1336}

Dentro del grupo de los fitolitos en forma de cono truncado se presentaron los acampanados Estrobilolita complanata (15,67\%) de manera muy frecuente. Los aplanados E. aplanada (5,97\%) de manera frecuente. Mientras los estróbilos equidimensionales, E. equidimensionata, $(3,73 \%)$ y los elongados con cintura E. elongata $(2,48 \%)$ fueron escasos y $E$. cotilata $(0,74 \%)$ raro. Los bilobados presentes en la muestra fueron Euhalteriolita bitestata $(2,48 \%)$ de forma escasa, y E. testicaudiculata $(0,99 \%)$ y $E$. testilobata $(0,49 \%)$, de forma rara, al igual que los bilobados Euhalteriolita tipo Stipa $(0,99 \%)$. Aquellos en forma de silla de montar o saddle que se presentaron de manera escasa fueron Doliolita equidimensionata $(2,23 \%)$, mientras D. elongata $(0,49 \%)$ hizo de manera rara. Dentro de los fitolitos esféricos se presentaron de manera frecuente los esféricos equinados, Globulolithum sphaeroechinulathum $(6,46 \%)$, de manera escasa los esféricos lisos Globulolithum sphaeropsilathum $(1,99 \%)$ y los elípticos lisos y los elípticos equinados (ambos 0,49\%) fueron raros. Los prismáticos rectangulares Macroprismatolithum psilaristathum, prismático de bordes lisos, (14,17\%) fueron muy frecuentes, mientras los prismáticos de bordes ondulados $M$. ondulathum $(2,98 \%)$ fueron escasos. Los de bordes dentados Macroprismatolithum denticulathum $(0,49 \%)$ fueron raros. Los pelos, ganchos y aguijones representados por Aculeolithum ancistrathum (8,45\%) de manera frecuente, por A. rostrathum $(4,48 \%)$, escasa, y A. aciculathum $(1,49 \%)$ de manera rara. Los flabelos estuvieron presentes con Flabelolita excavata $(6,21 \%)$ de manera frecuente, con Flabelolithum complanathum $(2,98 \%)$, de manera escasa, mientras F. euflabelathum (1,49\%), Flabelolita elongata $(0,74 \%)$, y las hemiflabeladas $(0,99 \%)$ de manera rara. Los poliédricos superiores a $40 \mu \mathrm{m}(5,97 \%)$ fueron frecuentes, y los inferiores $(0,99 \%)$ raros. También fueron raros: las Pileolitas $(0,74 \%)$, las formas triangulares $(1,49 \%)$ y las elípticas a circular $(0,99 \%)$. 


\section{Muestra 1337}

Dentro del grupo de los fitolitos en forma de cono truncado se presentaron los acampanados Estrobilolita complanata (19,95\%) de manera muy frecuente. Los aplanados E. aplanada $(10,09 \%)$ de manera frecuente, mientras los estróbilos elongados con cintura E. elongata $(2,95 \%)$ y los equidimensionales, E. equidimensionata, $(2,70 \%)$ fueron escasos y $\mathrm{E}$. cotilata $(1,72 \%)$ raro. Los bilobados presentes en la muestra fueron Euhalteriolita bitestata $(1,72 \%)$ y $E$. testilobata $(0,98 \%)$, de forma rara. Los bilobados Euhalteriolita tipo Stipa fueron escasos (3,94\%). Aquellos en forma de silla de montar o saddle que se presentaron de manera escasa fueron Doliolita equidimensionata $(3,69 \%)$, mientras D. elongata $(1,97 \%)$ fueron raros. Dentro de los fitolitos esféricos se presentaron de manera escasa los esféricos equinados, Globulolithum sphaeroechinulathum (4,43\%), mientras los esféricos lisos G. sphaeropsilathum (1,97\%) y los elípticos equinados $(0,49 \%)$ y los elípticos lisos $(0,49 \%)$ fueron raros. Los prismáticos rectangulares con Macroprismatolithum psilaristathum, prismático de bordes lisos, $(12,80 \%)$ de manera muy frecuente, mientras los prismáticos de bordes serrados Euprismatolita serrata $(0,73 \%)$, los prismáticos de bordes dentados Macroprismatolithum denticulathum $(0,98 \%)$, los prismáticos de bordes ondulados $\mathrm{M}$. ondulathum $(1,72 \%)$ y los prismáticos menores a $40 \mu \mathrm{m}(0,49 \%)$ fueron raros. Los poliédricos superiores a $40 \mu \mathrm{m}(3,44 \%)$, fueron escasos, y los inferiores $(0,49 \%)$ raros. Los flabelos Flabelolithum euflabelathum $(2,21 \%), F$. complanathum $(3,44 \%)$, y Flabelolita excavata $(4,92 \%)$ estuvieron presentes de manera escasa y $\mathrm{F}$. elongata $(0,73 \%)$ rara. Los pelos, ganchos y aguijones representados por Aculeolithum ancistrathum (3,94\%) de manera escasa, mientras A. rostrathum $(1,47 \%)$ y $A$. acuminatum $(0,98 \%)$ de manera rara. Otras formas raras fueron: triangulares $(0,73 \%)$, oblongas $(0,73 \%)$, elíptico a circular $(0,73 \%)$, Pileolita $(0,49 \%)$ y Longolita $(0,73 \%)$.

\section{Muestra 1338}

Dentro del grupo de los fitolitos en forma de cono truncado se presentaron los acampanados Estrobilolita complanata $(22,08 \%)$ de manera muy frecuente. Los aplanados E. aplanada $(8,18 \%)$ y los elongados con cintura E. elongata $(7,19 \%)$ de manera frecuente, mientras los equidimensionales, $E$. 
equidimensionata, $(1,98 \%)$ y los de punta en un extremo $(0,99 \%)$ fueron raros. Los bilobados presentes en la muestra fueron Euhalteriolita bitestata $(7,44 \%)$, de forma frecuente y E. botulata $(0,74 \%)$, E. de centro largo $(0,49 \%)$, y $E$. testicaudiculata $(1,24 \%)$, de forma rara. Los Euhalteriolita tipo Stipa fueron escasos (3,47\%). Aquellos en forma de silla de montar o saddle que se presentaron de manera escasa fueron Doliolita equidimensionata $(5,70 \%)$, mientras D. elongata $(1,98 \%)$ y $D$. oblata $(0,49 \%)$ fueron raros. Dentro de los fitolitos esféricos se presentaron de manera frecuente los esféricos equinados, Globulolithum sphaeroechinulathum (8,68\%), mientras los esféricos lisos G. sphaeropsilathum $(0,74 \%)$ fueron raros. Los prismáticos rectangulares con Macroprismatolithum psilaristathum, prismático de bordes lisos, (5,21\%) de manera escasa, mientras los prismáticos de bordes dentados Macroprismatolithum denticulathum $(0,74 \%)$, los prismáticos de bordes ondulados M. ondulathum (0,99\%), los prismáticos elongados Euprismatolita elongata $(0,74 \%)$ y los prismáticos menores a $40 \mu \mathrm{m}(0,99 \%)$ fueron raros. Los poliédricos superiores a $40 \mu \mathrm{m}(2,23 \%)$ fueron escasos, raros. Los flabelos Flabelolithum euflabelathum (2,23\%) y F. complanathum (4,96\%), estuvieron presentes de manera escasa y Flabelolita excavata $(0,99 \%)$ rara. Los pelos, ganchos y aguijones representados por Aculeolithum ancistrathum $(3,47 \%)$ y A. rostrathum $(2,97 \%)$ de manera escasa, mientras $A$. aciculathum $(1,48 \%)$ de manera rara. Las formas oblongas $(0,99 \%)$ fueron raras.

\section{Muestra 1339}

Dentro del grupo de los fitolitos en forma de cono truncado se presentaron los acampanados Estrobilolita complanata $(16,30 \%)$ de manera muy frecuente. Los aplanados E. aplanada $(8,87 \%)$ y los equidimensionales, $E$. equidimensionata $(7,43 \%)$ de manera frecuente. Los elongados con cintura $E$. elongata $(2,87 \%)$ fueron escasos. Los prismáticos rectangulares con Macroprismatolithum psilaristathum, prismático de bordes lisos, $(6,23 \%)$ fueron frecuentes, y los prismáticos de bordes ondulados $M$. ondulathum $(0,95 \%)$, los de bordes serrados Euprismatolita serrata $(0,47 \%)$ y los prismáticos menores a $40 \mu \mathrm{m}(0,71 \%)$ raros. Los poliédricos superiores a $40 \mu \mathrm{m}(3,59 \%)$ fueron escasos. Los flabelos Flabelolithum complanathum $(7,19 \%)$ y Flabelolita excavata $(7,67 \%)$ estuvieron presentes de manera frecuente y Flabelolithum 
euflabelathum $(1,91 \%)$ escasa. Dentro de los fitolitos esféricos se presentaron de manera frecuente los esféricos equinados, Globulolithum sphaeroechinulathum (5,27\%), mientras los esféricos lisos G. sphaeropsilathum $(1,43 \%)$ fueron raros. Los pelos, ganchos y aguijones representados por Aculeolithum ancistrathum (5,03\%) de manera frecuente, $A$. rostrathum $(2,87 \%)$ de manera escasa, y A. aciculathum $(0,95 \%)$ rara. Doliolita equidimensionata $(8,15 \%)$ fue frecuente, mientras D. elongata $(3,59 \%)$ escasa. Otras formas presentes de manera rara fueron: las oblongas $(0,71 \%)$, elípticas a circular $(1,19 \%)$, triangulares $(0,47 \%)$. Los bilobados presentes en la muestra fueron Euhalteriolita bitestata $(1,43 \%)$ y E. testilobata (0,95\%). Plurihalteriolita inequilobata $(0,95 \%)$, P. trilobata $(0,71 \%)$ y los bilobados Euhalteriolita tipo Stipa $(1,43 \%)$.

\section{Muestra 1340}

Dentro del grupo de los fitolitos en forma de cono truncado se presentaron los acampanados Estrobilolita complanata $(16,09 \%)$ de manera muy frecuente. Los aplanados E. aplanada $(5,12 \%)$ de manera frecuente. Los elongados con cintura E. elongata (3,69\%) fueron raros y los equidimensionales, E. equidimensionata (3,90\%) escasos. Los flabelos Flabelolithum complanathum $(7,56 \%)$ y Flabelolita excavata $(7,80 \%)$ fueron frecuentes. Mientras Flabelolithum euflabelathum (2,68\%), estuvieron presentes de manera escasa y Flabelolita elongata $(0,73 \%)$ rara. Los prismáticos rectangulares con Macroprismatolithum psilaristathum, prismático de bordes lisos, $(10,73 \%)$ fueron muy frecuentes y los prismáticos de bordes ondulados $\mathrm{M}$. ondulathum $(4,61 \%)$ raros y los prismáticos menores a $40 \mu \mathrm{m}$ $(2,68 \%)$ escasos. Los poliédricos superiores a $40 \mu \mathrm{m}(9,02 \%)$, fueron frecuentes. Los bilobados presentes fueron Euhalteriolita bitestata (3,90\%) de manera escasa y E. botulata $(0,48 \%)$ y E. testicaudiculata $(0,97 \%)$ de manera rara. Los bilobados Euhalteriolita tipo Stipa fueron escasos (1,95\%). Dentro de los fitolitos esféricos se presentaron de manera frecuente los esféricos equinados, Globulolithum sphaeroechinulathum (5,60\%), mientras los esféricos lisos G. sphaeropsilathum $(0,97 \%)$ fueron raros. Los pelos, ganchos y aguijones representados por Aculeolithum ancistrathum (4,63\%) y $A$. rostrathum $(4,14 \%)$ de manera escasa, y $A$. aciculathum $(0,73 \%)$ rara. Doliolita 
equidimensionata $(5,36 \%)$, fue frecuente, mientras D. elongata $(1,43 \%)$ rara. Formas redondeadas $(0,48 \%)$ y elípticas a circulares $(0,73 \%)$ también fueron raras.

\section{Muestra 1341}

Dentro del grupo de los fitolitos en forma de cono truncado se presentaron los acampanados Estrobilolita complanata $(16,46 \%)$ de manera muy frecuente. Los aplanados E. aplanada (6,92\%) de manera frecuente. Los equidimensionales, E. equidimensionata (2,86\%) fueron escasos, mientras los elongados con cintura E. elongata $(1,19 \%)$ y $E$. cotilata $(1,19 \%)$ raros. Los prismáticos rectangulares con Macroprismatolithum psilaristathum, prismático de bordes lisos, $(5,54 \%)$ fueron muy frecuentes. Los prismáticos menores a 40 $\mu \mathrm{m}(2,86 \%)$ escasos, y los prismáticos de bordes ondulados $\mathrm{M}$. ondulathum $(1,19 \%)$, los de bordes dentados Macroprismatolithum denticulathum (3,23\%), E. anisocornisata $(0,47 \%)$, los prismáticos de bordes serrados Euprismatolita serrata $(0,71 \%)$, y los elongados Euprismatolita elongata $(0,47 \%)$ raros Los poliédricos superiores a $40 \mu \mathrm{m}$ (5,25\%), fueron frecuentes. Los flabelos Flabelolithum complanathum (3,81\%) y Flabelolita excavata $(2,38 \%)$, fueron escasos. Mientras Flabelolithum euflabelathum (0,71\%), formas hemiflabeladas $(0,47 \%)$ y Flabelolita elongata $(0,95 \%)$ raros. Los bilobados presentes fueron Euhalteriolita bitestata $(4,05 \%)$ y $E$. botulata $(1,67 \%)$ de manera escasa y $E$. testicaudiculata $(0,95 \%)$ de forma rara al igual que los Plurihalteriolita inequilobata (1,43\%). Los bilobados Euhalteriolita tipo Stipa fueron escasos $(2,38 \%)$. Dentro de los fitolitos esféricos se presentaron de manera muy frecuente los esféricos equinados, Globulolithum sphaeroechinulathum $(10,73 \%)$, mientras los esféricos lisos G. sphaeropsilathum $(2,86 \%)$ fueron escasos. Los pelos, ganchos y aguijones representados por Aculeolithum ancistrathum $(1,90 \%)$ y $A$. rostrathum $(4,77 \%)$ de manera escasa, y rara por A. aciculathum (0,47\%). Doliolita equidimensionata $(4,53 \%)$, fue escasa, mientras D. elongata $(0,71 \%)$ y $D$. oblata $(0,47 \%)$ raras. Otras formas presentes de manera rara fueron: Longolita $(0,95 \%)$, formas oblongas $(0,47 \%)$, redondeadas $(1,19 \%)$ y elípticas a circulares $(0,71 \%)$. 


\section{Muestra 1342}

Dentro del grupo de los fitolitos en forma de cono truncado se presentaron los acampanados Estrobilolita complanata (18,35\%) de manera muy frecuente. Los aplanados E. aplanada $(4,83 \%)$, E. cotilata $(2,65 \%)$ y los elongados con cintura E. elongata $(3,38 \%)$ de manera escasa. Fueron raros los de un extremo con punta $(0,72 \%)$ y los equidimensionales, E. equidimensionata (1,69\%). Los prismáticos rectangulares con Macroprismatolithum psilaristathum, prismático de bordes lisos, $(7,48 \%)$ fueron frecuentes y el resto de los prismáticos raros: los de bordes ondulados $\mathrm{M}$. ondulathum $(0,48 \%)$, los de bordes dentados Macroprismatolithum denticulathum $(0,96 \%)$ y los de bordes serrados Euprismatolita serrata $(0,96 \%)$. Los poliédricos superiores a $40 \mu \mathrm{m}(3,14 \%)$ fueron escasos. Los flabelos Flabelolita excavata $(6,03 \%)$, fueron frecuentes, mientras Flabelolithum complanathum $(3,14 \%)$ y Flabelolithum euflabelathum $(3,38 \%)$ escasas, y raras las formas hemiflabeladas. Los bilobados presentes en la muestra fueron Euhalteriolita bitestata $(4,10 \%)$ de manera escasa y $\mathrm{E}$. botulata $(0,48 \%)$ y $\mathrm{E}$. testicaudiculata $(0,48 \%)$ de manera rara, al igual que los polilobados Plurihalteriolita inequilobata $(0,48 \%)$ y $P$. trilobata $(0,96 \%)$. Los bilobados Euhalteriolita tipo Stipa fueron escasos (2,65\%). Dentro de los fitolitos esféricos se presentaron de manera frecuente los esféricos equinados, Globulolithum sphaeroechinulathum (8,45\%), mientras los esféricos lisos G. sphaeropsilathum $(0,72 \%)$ fueron raros. Los pelos, ganchos y aguijones representados por Aculeolithum ancistrathum (4,58\%) y A. rostrathum (2,89\%) de manera escasa, mientras A. aciculathum $(0,96 \%)$ y $A$. acuminathum $(0,48 \%)$ de manera rara. Doliolita equidimensionata $(7,97 \%)$ fue frecuente, mientras $D$. elongata $(2,17 \%)$ escasa y $D$. oblata $(0,48 \%)$ rara. Longolita fue $(0,72 \%)$ rara, al igual que las formas oblongas $(0,96 \%)$, elípticas a circulares $(1,20 \%)$ y triangulares $(0,48 \%)$.

\section{Muestra 1343}

Dentro del grupo de los fitolitos en forma de cono truncado se presentaron los acampanados Estrobilolita complanata $(6,60 \%)$, los aplanados E. aplanada $(4,40 \%)$ y los equidimensionales, E. equidimensionata $(4,15 \%)$ de manera frecuente. Los elongados con cintura E. elongata $(1,46 \%)$ y E. cotilata 
$(1,95 \%)$ de manera escasa. Los prismáticos rectangulares con Macroprismatolithum psilaristathum, prismático de bordes lisos (12,71\%) de manera muy frecuente. Los prismáticos de bordes ondulados $\mathrm{M}$. ondulathum $(3,91 \%)$ fueron frecuentes. Los de bordes dentados Macroprismatolithum denticulathum $(3,17 \%)$ fueron escasos, y raros los prismáticos de bordes serrados Euprismatolita serrata $(0,97 \%)$, los prismáticos menores a $40 \mu \mathrm{m}$ $(0,48 \%)$, los E. anisocornisata $(0,48 \%)$ y los elongados Euprismatolita elongata $(0,97 \%)$. Los poliédricos superiores a $40 \mu \mathrm{m}(9,04 \%)$, fueron muy frecuentes y los menores $(0,97 \%)$ raros. Los flabelos Flabelolithum complanathum $(5,86 \%)$, Flabelolithum euflabelathum $(6,11 \%)$ y Flabelolita excavata $(7,57 \%)$ fueron frecuentes. Mientras formas hemiflabeladas $(1,46 \%)$ estuvieron presentes de manera escasa. Los bilobados presentes en la muestra fueron Euhalteriolita bitestata $(4,88 \%)$, de manera frecuente y $E$. botulata $(0,73 \%)$ y $E$. testilobata $(0,97 \%)$ de forma rara al igual que los Plurihalteriolita inequilobata $(0,48 \%)$. Los bilobados Euhalteriolita tipo Stipa fueron escasos $(1,46 \%)$. Dentro de los fitolitos esféricos se presentaron de manera escasa los esféricos equinados, Globulolithum sphaeroechinulathum (2,20\%), mientras los esféricos lisos G. sphaeropsilathum $(0,73 \%)$ fueron raros, al igual que las formas macroglobosas $(0,97 \%)$. Doliolita equidimensionata $(2,68 \%)$ fue escasa, mientras D. elongata $(0,48 \%)$ y $\mathrm{D}$. oblata $(0,48 \%)$ raras. Los pelos, ganchos y aguijones representados por Aculeolithum ancistrathum (2,93\%), A. aciculathum (1,71\%) y A. rostrathum $(2,44 \%)$ de manera escasa. Otros elementos presentes de forma rara fueron: Longolita $(0,46 \%)$.Las formas oblongas, elípticas a circulares, redondeadas, y triangulares (todas 0,73\%).

\section{Muestra 1344}

Dentro del grupo de los fitolitos en forma de cono truncado se presentaron los acampanados Estrobilolita complanata $(12,20 \%)$ de manera muy frecuente. Los aplanados E. aplanada $(6,22 \%)$ de manera frecuente. Los equidimensionales, E. equidimensionata $(3,34 \%)$ fueron escasos, mientras los elongados con cintura E. elongata $(0,95 \%)$, E. cotilata $(0,95 \%)$ y los de un extremo con punta $(0,71 \%)$ raros. Los prismáticos rectangulares Macroprismatolithum psilaristathum, prismático de bordes lisos, $(7,65 \%)$ fueron muy frecuentes y los prismáticos de bordes ondulados $M$. ondulathum $(3,82 \%)$ 
frecuentes. Los prismáticos de bordes dentados Macroprismatolithum denticulathum (3,34\%) escasos. Mientras E. anisocornisata $(0,47 \%)$, los prismáticos de bordes serrados Euprismatolita serrata (0,47\%), los elongados Euprismatolita elongata $(0,71 \%)$ y los prismáticos menores a $40 \mu \mathrm{m}(0,95 \%)$ fueron raros. Los poliédricos superiores a $40 \mu \mathrm{m}(5,26 \%)$, fueron frecuentes y los menores $(0,47 \%)$ raros. Los flabelos Flabelolithum complanathum $(6,45 \%)$, F. euflabelathum $(6,69 \%)$, y Flabelolita excavata $(6,93 \%)$, fueron frecuentes, mientras Flabelolita elongata $(0,47 \%)$ rara. Los bilobados presentes en la muestra fueron Euhalteriolita bitestata $(1,91 \%)$ de manera escasa y $\mathrm{E}$. botulata $(0,95 \%)$ y $\mathrm{E}$. testicaudiculata $(0,95 \%)$ de manera rara. Los bilobados Euhalteriolita tipo Stipa fueron escasos $(1,91 \%)$. Dentro de los fitolitos esféricos se presentaron de manera frecuente los esféricos equinados, Globulolithum sphaeroechinulathum (6,93\%), mientras los esféricos lisos G. sphaeropsilathum $(0,47 \%)$ fueron raros. Los pelos, ganchos y aguijones representados por Aculeolithum ancistrathum $(3,82 \%)$ de manera frecuente. A. rostrathum (2,63\%), A. acuminathum (1,43\%). y A. aciculathum (1,67\%). de manera escasa. Doliolita equidimensionata $(5,50 \%)$ fue frecuente, mientras $D$. elongata $(0,95 \%)$ y $\mathrm{D}$. oblata $(0,95 \%)$ raras. Las formas oblongas $(0,47 \%)$ y Longolita $(0,71 \%)$ fueron raras.

\section{Muestra 1345}

Dentro del grupo de los fitolitos en forma de cono truncado se presentaron los acampanados Estrobilolita complanata (12,24\%) de manera muy frecuente. Los aplanados E. aplanada $(6,23 \%)$ y los elongados con cintura E. elongata $(3,69 \%)$ de manera frecuente. E. cotilata $(1,38 \%)$ fueron escasos. Raros los de un extremo con punta $(0,46 \%)$ y los equidimensionales, E. equidimensionata (0,92\%). Los prismáticos rectangulares con Macroprismatolithum psilaristathum, prismático de bordes lisos, $(5,54 \%)$ y los prismáticos de bordes ondulados $M$. ondulathum $(4,61 \%)$ fueron frecuentes. Los prismáticos de bordes dentados Macroprismatolithum denticulathum $(3,23 \%)$ y $E$. anisocornisata $(1,38 \%)$ fueron escasos, y raros los prismáticos de bordes serrados Euprismatolita serrata $(0,46 \%)$, los prismáticos menores a 40 $\mu \mathrm{m}(0,92 \%)$ y los elongados Euprismatolita elongata $(0,46 \%)$. Los poliédricos superiores a $40 \mu \mathrm{m}(6,00 \%)$, fueron frecuentes. Los flabelos Flabelolithum 
complanathum $(8,54 \%)$ fueron muy frecuentes. Mientras Flabelolita excavata (6,92\%), y Flabelolithum euflabelathum (3,69\%), estuvieron presentes de manera frecuente, y Flabelolita elongata $(0,46 \%)$ rara. Las formas oblongas fueron escasas $(1,38 \%)$. Los bilobados presentes en la muestra fueron Euhalteriolita bitestata $(4,15 \%)$,de manera frecuente y $E$. botulata $(1,84 \%)$ y $E$. testicaudiculata $(1,84 \%)$ de manera escasa, y E. testilobata $(0,92 \%)$ de forma rara al igual que los Plurihalteriolita inequilobata $(0,46 \%)$. Los bilobados Euhalteriolita tipo Stipa fueron escasos (2,77\%). Dentro de los fitolitos esféricos se presentaron de manera frecuente los esféricos equinados, Globulolithum sphaeroechinulathum $(4,38 \%)$, mientras los esféricos lisos G. sphaeropsilathum $(2,54 \%)$ fueron escasos. Raras las formas macroglobosas $(0,92 \%)$. Los pelos, ganchos y aguijones representados por Aculeolithum ancistrathum (3,46\%), A. rostrathum (2,54\%) y $A$. aciculathum $(1,38 \%)$ de manera escasa. Doliolita equidimensionata $(1,84 \%)$, fue escasa, mientras D. elongata $(0,92 \%)$ y D. oblata $(0,46 \%)$ raras. Longolita fue $(0,46 \%)$ rara.

\section{Muestra 1346}

Dentro del grupo de los fitolitos en forma de cono truncado se presentaron los acampanados Estrobilolita complanata (12,53\%) y los aplanados E. aplanada $(8,67 \%)$ de manera muy frecuente. De manera frecuente los equidimensionales, E. equidimensionata $(6,26 \%)$, mientras los estróbilos elongados con cintura $E$. elongata $(3,13 \%)$ fueron escasos y $E$. cotilata $(1,20 \%)$ y los de un extremo con punta fueron raros. Los bilobados presentes en la muestra fueron Euhalteriolita bitestata $(2,16 \%)$, E. botulata $(1,68 \%)$ y $E$. testicaudiculata $(1,68 \%)$ de manera escasa, y E. testilobata $(0,96 \%)$ de forma rara. Los bilobados Euhalteriolita tipo Stipa fueron escasos $(1,44 \%)$. Dentro de los fitolitos esféricos se presentaron de manera frecuente los esféricos equinados, Globulolithum sphaeroechinulathum $(7,64 \%)$, mientras los esféricos lisos G. sphaeropsilathum $(1,20 \%)$ y los elípticos equinados $(0,48 \%)$ fueron raros. Los prismáticos rectangulares con Macroprismatolithum psilaristathum, prismático de bordes lisos, $(8,43 \%)$ de manera muy frecuente, mientras los prismáticos de bordes ondulados $M$. ondulathum $(4,57 \%)$ fueron frecuentes, y los prismáticos de bordes dentados Macroprismatolithum denticulathum $(1,68 \%)$ fueron escasos, y raros los prismáticos de bordes 
serrados Euprismatolita serrata $(0,72 \%)$, los prismáticos menores a $40 \mu \mathrm{m}$ $(0,96 \%)$, los elongados Euprismatolita elongata $(0,96 \%)$, y los $E$. anisocornisata $(0,48 \%)$. Los poliédricos superiores a $40 \mu \mathrm{m}(2,40 \%)$, fueron escasos, y los inferiores $(0,72 \%)$ raros. Los flabelos Flabelolithum complanathum $(6,74 \%)$, y Flabelolita excavata $(3,85 \%)$ fueron frecuentes, mientras Flabelolithum euflabelathum (1,68\%), estuvieron presentes de manera escasa. Los pelos, ganchos y aguijones representados por Aculeolithum ancistrathum (6,74\%) de manera frecuente, y escasa por $A$. rostrathum $(3,13 \%)$ y $A$. aciculathum $(1,68 \%)$. Otras formas raras fueron: aquellos en forma de silla de montar o saddle Doliolita equidimensionata $(0,96 \%)$, D. elongata $(0,96 \%)$ y D. oblata $(0,48 \%)$, triangulares $(0,48 \%)$, oblongas $(1,20 \%)$ y redondeadas $(0,48 \%)$.

\section{Muestra 1347}

Dentro del grupo de los fitolitos flabelados Flabelolithum complanathum $(12,14 \%)$, se presentó de manera muy frecuente, F. euflabelathum $(6,30 \%)$, y Flabelolita excavata $(7,24 \%)$ de manera frecuente, y estuvieron presentes de manera rara $F$. elongata $(0,70 \%)$ y las formas hemiflabeladas $(0,46 \%)$. Los prismáticos rectangulares con Macroprismatolithum psilaristathum, prismático de bordes lisos, $(17,99 \%)$ se presentaron de manera muy frecuente, mientras los prismáticos de bordes ondulados $M$. ondulathum $(6,54 \%)$ fueron frecuentes, los prismáticos de bordes dentados Macroprismatolithum denticulathum $(2,33 \%)$ escasos, y raros los prismáticos de bordes serrados Euprismatolita serrata $(0,46 \%)$, los prismáticos menores a $40 \mu \mathrm{m}(0,93 \%)$, Euprismatolita anisocornisata $(1,16 \%)$ y $E$. elongata $(0,70 \%)$ fueron raros. Los poliédricos superiores a $40 \mu \mathrm{m}(8,41 \%)$, fueron frecuentes, y los inferiores $(1,16 \%)$ raros. Los fitolitos en forma de cono truncado se presentaron con los acampanados Estrobilolita complanata $(8,64 \%)$ de manera frecuente. Mientras los aplanados E. aplanada (1,40\%), los estróbilos elongados con cintura E. elongata $(1,16 \%)$, los equidimensionales, E. equidimensionata, $(1,63 \%)$ y $E$. cotilata $(0,70 \%)$ fueron raros. Los bilobados presentes en la muestra fueron Euhalteriolita bitestata $(4,90 \%)$ de forma escasa, y E. testilobata $(0,70 \%)$, y E. botulata $(0,46 \%)$ de forma rara. Al igual que los polilobados Plurihalteriolita trilobata $(0,70 \%)$. Los bilobados Euhalteriolita tipo Stipa fueron escasos $(1,86 \%)$. Dentro 
de los fitolitos esféricos se presentaron de manera escasa los esféricos equinados, Globulolithum sphaeroechinulathum (2,10\%), mientras los esféricos lisos G. sphaeropsilathum $(0,70 \%)$ fueron raros. Los pelos, ganchos y aguijones representados por Aculeolithum ancistrathum (2,57\%) y $\mathrm{A}$. aciculathum $(1,86 \%)$ de manera escasa, mientras $A$. rostrathum $(0,70 \%)$ de manera rara. Otras formas raras fueron: aquellos en forma de silla de montar o saddle con Doliolita equidimensionata $(0,46 \%)$, y D. elongata $(0,70 \%)$, Longolita $(0,46 \%)$, formas oblongas $(0,70 \%)$, redondeadas $(0,46 \%)$.

\section{Muestra 1348}

Dentro del grupo de los fitolitos prismáticos rectangulares estuvieron presentes Macroprismatolithum psilaristathum, prismático de bordes lisos, $(20,49 \%)$ de manera muy frecuente, mientras los prismáticos de bordes dentados Macroprismatolithum denticulathum (6,41\%) y los prismáticos de bordes ondulados $\mathrm{M}$. ondulathum $(7,65 \%)$ fueron frecuentes, y los de bordes serrados Euprismatolita serrata $(0,98 \%)$ raros. Los flabelos Flabelolita excavata $(12,09 \%)$ y Flabelolithum complanathum $(10,61 \%)$ fueron frecuentes. escasos Flabelolithum euflabelathum $(2,71 \%)$, y raros Flabelolita elongata $(0,98 \%)$ y las formas hemiflabeladas $(1,48 \%)$. Los poliédricos superiores a $40 \mu \mathrm{m}(6,91 \%)$, fueron frecuentes, y los inferiores $(2,96 \%)$ escasos. Los pelos, ganchos y aguijones representados por Aculeolithum ancistrathum (4,98\%) de manera escasa, mientras A. rostrathum $(0,74 \%)$ y A. aciculathum $(0,98 \%)$ de manera rara. Dentro de los fitolitos esféricos se presentaron de manera escasa los esféricos equinados, Globulolithum sphaeroechinulathum (3,95\%), mientras los elípticos equinados $(0,49 \%)$ fueron raros. Los fitolitos en forma de cono truncado presentes fueron los aplanados Estrobilolita aplanada (4,19\%) de manera escasa, y los acampanados E. complanata (1,97\%), los equidimensionales, E. equidimensionata, (1,48\%) y $E$. cotilata $(1,23 \%)$ de manera rara. Otras formas presentes en la muestra de forma rara fueron: las triangulares $(0,74 \%)$, las redondeadas, los Longolita $(0,98 \%)$, los bilobados Euhalteriolita bitestata $(0,98 \%)$, E. botulata (0,49\%), y Euhalteriolita tipo Stipa $(0,49 \%)$. Aquellos en forma de silla de montar o saddle que se presentaron fueron Doliolita equidimensionata $(1,97 \%)$. 


\section{Muestra 1349}

Dentro del grupo de los fitolitos en forma de cono truncado se presentaron los acampanados Estrobilolita complanata $(20,59 \%)$ de manera muy frecuente. Los aplanados E. aplanada $(12,15 \%)$ y los estróbilos elongados con cintura E. elongata $(6,69 \%)$ fueron frecuentes, los equidimensionales, $E$. equidimensionata, $(5,45 \%)$ fueron escasos, mientras que E. cotilata $(0,49 \%)$ raro. Dentro de los bilobados se presentaron de manera escasa Euhalteriolita bitestata (5,70\%). Mientras E. testicaudiculata $(0,49 \%)$, E. testilobata $(0,49, y$ E. botulata $(0,24 \%)$ lo hicieron de forma rara, al igual que los polilobados Plurihalteriolita inequilobata $(0,74 \%)$, P. trilobata $(0,24 \%)$ y P. catenulata $(0,24 \%)$ y las cruces Halteriolita cruciformata $(0,24 \%)$. Los bilobados Euhalteriolita tipo Stipa fueron escasos $(3,72 \%)$ al igual que aquellos en forma de silla de montar o saddle con Doliolita equidimensionata $(2,48 \%)$, mientras que los D. elongata $(0,24 \%)$ y D. oblata $(0,99 \%)$ fueron raros. Dentro de los fitolitos esféricos se presentaron de manera frecuente los esféricos equinados, Globulolithum sphaeroechinulathum (7,94\%), los esféricos lisos G. sphaeropsilathum $(1,24 \%)$ y los elípticos equinados $(0,24 \%)$ fueron raros. El grupo de los prismáticos rectangulares se halló representado por los morfotipos Macroprismatolithum psilaristathum, prismático de bordes lisos, $(6,69 \%)$ de manera frecuente y por los prismáticos de bordes ondulados $\mathrm{M}$. ondulathum $(2,88 \%)$ de manera escasa. Los de bordes dentados (M. denticulathum) $(1,48 \%)$, los de bordes serrados Euprismatolita serrata $(0,24 \%)$ y los prismáticos elongados, Euprismatolita elongata, $(0,74 \%)$ fueron raros, como los prismáticos rectangulares de tamaño inferior a $40 \mu \mathrm{m}(0,99 \%)$. Los poliédricos superiores a $40 \mu \mathrm{m}(2,72 \%)$, fueron escasos, mientras los inferiores $(1,24 \%)$ raros. Los triangulares $(0,49 \%)$ también fueron raros, igual que los flabelos Flabelolithum euflabelathum (1,24\%), F. complanathum $(1,73 \%)$, y Flabelolita excavata $(0,99 \%)$, placas hexagonales $(0,22 \%)$ y Longolita $(0,49 \%)$. Los pelos, ganchos y aguijones estuvieron representados por Aculeolithum rostrathum $(2,97 \%)$, y $A$. ancistrathum $(2,48 \%)$ de manera escasa y por $A$. aciculathum $(0,99 \%)$ de manera rara. 


\section{Muestra 1350}

Dentro del grupo de los fitolitos en forma de cono truncado se presentaron los acampanados Estrobilolita complanata $(24,39 \%)$ de manera muy frecuente. Los aplanados E. aplanada (10,62\%) fueron frecuentes, los estróbilos elongados con cintura E. elongata (5,31\%), escasos y los equidimensionales, E. equidimensionata, $(2,41 \%)$ fueron raros. El grupo de los prismáticos rectangulares se halló representado por los morfotipos Macroprismatolithum psilaristathum, prismático de bordes lisos, (7,97\%) de manera frecuente y por los prismáticos de bordes ondulados $\mathrm{M}$. ondulathum $(1,44 \%)$, los de bordes dentados (M. denticulathum) $(1,93 \%)$, los de bordes serrados Euprismatolita serrata $(0,96 \%)$ y los prismáticos elongados, Euprismatolita elongata, $(1,44 \%)$ de manera rara, como los prismáticos rectangulares de tamaño inferior a $40 \mu \mathrm{m}(2,41 \%)$ y los poliédricos superiores a $40 \mu \mathrm{m}(1,20 \%)$, y los inferiores $(0,48 \%)$. Los bilobados que se presentaron de manera escasa, fueron Euhalteriolita bitestata (3,62\%). E. testicaudiculata $(2,17 \%)$, E. testilobata $(0,48)$ y E. botulata $(0,48 \%)$ lo hicieron de forma rara, al igual que los polilobados Plurihalteriolita inequilobata $(0,96 \%)$, P. trilobata $(0,72 \%)$ y $\mathrm{P}$. catenulata $(0,48 \%)$. Los bilobados Euhalteriolita tipo Stipa fueron escasos $(4,34 \%)$ al igual que aquellos en forma de silla de montar o saddle con Doliolita equidimensionata $(3,86 \%)$, mientras que los D. elongata $(1,20 \%)$ y D. oblata $(0,72 \%)$ fueron raros. Dentro de los fitolitos esféricos se presentaron de manera escasa los esféricos equinados, Globulolithum sphaeroechinulathum $(7,24 \%)$, los esféricos lisos G. sphaeropsilathum $(2,41 \%)$ y los elípticos equinados $(0,72 \%)$ fueron raros. También fueron raras las formas triangulares $(1,44 \%)$, oblongas $(0,96 \%)$, redondeadas $(0,48 \%)$, Longolita $(0,48 \%)$, los flabelos Flabelolithum euflabelathum (1,20\%), F. complanathum $(0,72 \%)$, y Flabelolita excavata (1,44\%), los pelos, ganchos y aguijones Aculeolithum rostrathum $(0,72 \%)$, A. ancistrathum $(0,96 \%)$ y A. aciculathum $(0,48 \%)$.

\section{PERFIL ACCESORIO RINCÓN DEL DOLL}

\section{Muestra 1120}

El grupo de los fitolitos prismáticos se halló dominado por el morfotipo Macroprismatolithum psilaristathum, prismático de bordes lisos, de manera muy frecuente $(46,88 \%)$. Fue rara la presencia de $M$. denticulathum, fitolitos 
prismáticos de bordes dentados (2,62\%), Euprismatolita elongata, prismáticos elongados $(3,60 \%)$, M. ondulathum $(4,26 \%)$, E. serrata (2,62\%) (prismáticos de bordes ondulados y serrados respectivamente) y Euprismatolita excavata (prismáticos de extremos cóncavos) (0,65\%). Los prismáticos rectangulares de tamaño inferior a $40 \mu \mathrm{m}(1,96 \%)$ también fueron raros, igual que los prismáticos breves $(2,62 \%)$. Los fitolitos en cono truncado acampanados Estrobilolita complanata $(9,83 \%)$ fueron escasos y raros los equidimensionales (E. equidimensionata) $(1,63 \%)$, los elongados con cintura $E$. elongata $(0,65 \%)$ y los aplanados E. aplanada (4,26\%). El resto de los fitolitos se presentaron de manera rara, estos son: los bilobados o halterios representados por Euhalteriolita bitestata $(2,62 \%)$, E. testicaudiculata y E. testilobata (ambos $0,65 \%)$, los polilobados Plurihalteriolita trilobata $(0,32 \%)$, las bulliformes en forma de abanico con Flabelolithum euflabelathum (3,60\%) y F. complanatum $(0,98 \%)$, los poliédricos de tamaño superior a $40 \mu \mathrm{m}(3,27 \%)$ y los inferiores $(2,29 \%)$, Longolita $(0,32 \%)$, las doliolitas o sillas de montar con Doliolita equidimensionata $(0,32 \%)$, las aculeolitas, Aculeolithum rostrathum y $\mathrm{A}$. aciculathum (ambas 0,32\%).

\section{Muestra 1121}

El grupo de los fitolitos prismáticos se halló dominado por el morfotipo Macroprismatolithum psilaristathum, prismático de bordes lisos, de manera muy frecuente $(44,55 \%)$. Fue escasa la presencia de $\mathrm{M}$. denticulathum, fitolitos prismáticos de bordes dentados $(6,93 \%)$ y rara la de Euprismatolita elongata, prismáticos elongados $(3,63 \%)$, M. ondulathum $(3,30 \%)$, E. serrata $(1,98 \%)$ (prismáticos de bordes ondulados y serrados respectivamente) y Euprismatolita excavata (prismáticos de extremos cóncavos) (0,33\%). Los prismáticos rectangulares de tamaño inferior a $40 \mu \mathrm{m}(0,99 \%)$ también fueron raros, igual que los prismáticos breves $(1,32 \%)$. Los fitolitos en cono truncado fueron escasos con los estróbilos acampanados Estrobilolita complanata $(7,59 \%)$ y los aplanados E. aplanada (4,95\%). Raros los estróbilos equidimensionales (E. equidimensionata) (1,98\%) y los elongados $\mathrm{E}$. elongata $(0,99 \%)$. El resto de los fitolitos se presentaron de manera rara, estos son: los bilobados representados por Euhalteriolita bitestata $(0,99 \%)$, E. testicaudiculata $(0,66 \%)$, E. botulathum $(0,33 \%)$ y $\mathrm{E}$. testilobata $(0,99 \%)$; las bulliformes Flabelolithum euflabelathum 
$(2,31 \%)$, F. complanatum (1,32\%) y Flabelolita excavata $(0,33 \%)$, los poliédricos de tamaño superior a $40 \mu \mathrm{m}(3,96 \%)$ y los inferiores $(1,32 \%)$, Doliolita equidimensionata $(0,66 \%)$, elementos de conducción $(0,33 \%)$, fitolitos esféricos Globulolithum sphaeroechinulathum (esférico equinado) $(2,31 \%)$ y G. sphaeropsilathum (esférico liso) $(0,99 \%)$, los pelos, ganchos y aguijones, o aculeolitas, estuvieron presentes Aculeolithum rostrathum (1,65\%), formas intermedias no identificadas $(1,32 \%)$ y $A$. ancistrathum $(1,32 \%)$.

\section{Muestra 1122}

El grupo de los fitolitos prismáticos se halló dominado por el morfotipo Macroprismatolithum psilaristathum, prismático de bordes lisos, de manera muy frecuente $(37,58 \%)$. Fue rara la presencia de $M$. denticulathum, fitolitos prismáticos de bordes dentados (2,94\%), Euprismatolita elongata, prismáticos elongados $(2,28 \%)$, M. ondulathum (2,28\%) (prismáticos de bordes ondulados). Los prismáticos rectangulares de tamaño inferior a $40 \mu \mathrm{m}(1,30 \%)$ también fueron raros, igual que los prismáticos breves $(0,65 \%)$. Entre los fitolitos en cono truncado fueron frecuentes los estróbilos acampanados Estrobilolita complanata $(11,43 \%)$, escasos los estróbilos equidimensionales ( $E$. equidimensionata) $(7,51 \%)$, y raros los elongados con cintura $E$. elongata $(2,28 \%)$, los estróbilos con punta en un extremo $(0,32 \%)$, E. cotilata $(0,65 \%)$ y los aplanados E. aplanada (1,96\%). Los poliédricos estuvieron presentes de manera escasa con los de tamaño superior a $40 \mu \mathrm{m}(5,88 \%)$ y rara con los inferiores $(0,32 \%)$. El resto de los fitolitos se presentaron todos de manera rara, estos son: el grupo de las aculeolitas, con Aculeolithum rostrathum (1,96\%), formas no identificadas $(1,29 \%)$ y $\mathrm{A}$. ancistrathum $(2,61 \%)$, las doliolitas con Doliolita equidimensionata $(0,98 \%)$, los bilobados o halterios representados por Euhalteriolita bitestata $(2,61 \%)$, E. testicaudiculata, E. botulata (ambos $0,65 \%$ ), y E. testilobata $(0,32 \%)$. Los polilobados Plurihalteriolita inequilobata $(0,32 \%)$. Las bulliformes en forma de abanico con Flabelolithum euflabelathum (1,96\%), Flabelolita excavata $(0,65 \%)$, formas hemiflabeladas $(1,63 \%)$ y $\mathrm{F}$. complanatum $(1,30 \%)$, los fitolitos esféricos con Globulolithum sphaeroechinulathum (esférico equinado) $(2,61 \%)$ y G. sphaeropsilathum (esférico liso) (0,65\%) y Pileolita $(1,30 \%)$. 


\section{Muestra 1123}

El grupo de los fitolitos prismáticos se halló dominado por el morfotipo Macroprismatolithum psilaristathum, prismático de bordes lisos, de manera muy frecuente $(37,10 \%)$. Fue rara la presencia de $M$. denticulathum, fitolitos prismáticos de bordes dentados $(0,94 \%)$, Euprismatolita elongata, prismáticos elongados $(2,20 \%)$ y $\mathrm{M}$. ondulathum $(1,88 \%)$, también fueron raros, igual que los prismáticos breves $(0,31 \%)$. Los fitolitos en cono truncado fueron frecuentes con los estróbilos acampanados Estrobilolita complanata (17,92\%). Fue escasa la presencia de los estróbilos equidimensionales ( $E$. equidimensionata) $(4,71 \%)$, y los aplanados E. aplanada $(6,91 \%)$ y rara la de los elongados $E$. elongata $(2,51 \%)$, E. cotilata $(0,94 \%)$ y estróbilos con punta en un extremo $(0,62 \%)$. Los poliédricos de tamaño superior a $40 \mu \mathrm{m}(4,40 \%)$ fueron escasos. El grupo de los aguijones, o aculeolitas, estuvo presente de manera escasa con Aculeolithum rostrathum $(3,77 \%)$ y rara con A. aciculathum $(0,31 \%)$, A. ancistrathum $(2,83 \%)$ y $A$. acuminathum $(0,62 \%)$. Los fitolitos esféricos representados por Globulolithum sphaeroechinulathum (esférico equinado) $(4,71 \%)$ de manera escasa y rara por G. sphaeropsilathum (esférico liso) $(0,62 \%)$ y los elípticos equinados $(0,94 \%)$. El resto de los fitolitos se presentaron de manera rara, estos son: los bilobados o halterios representados por Euhalteriolita bitestata $(2,20 \%)$, y E. botulata $(0,31 \%)$, los polilobados Plurihalteriolita trilobata $(0,62 \%)$, las bulliformes en forma de abanico con Flabelolita excavata $(0,31 \%)$ y Flabelolithum complanathum $(0,31 \%)$, las doliolitas o sillas de montar con Doliolita equidimensionata $(0,94 \%)$ y elementos de conducción $(0,31 \%)$.

\section{PERFIL ACCESORIO VILLA VALLE MARIA}

\section{Muestra 371}

El grupo de los fitolitos prismáticos se halló dominado por el morfotipo Macroprismatolithum psilaristathum, prismático de bordes lisos, de manera muy frecuente $(23,47 \%)$. Fue escasa la presencia de $\mathrm{M}$. denticulathum, fitolitos prismáticos de bordes dentados (3,66\%). Euprismatolita elongata, prismáticos elongados $(1,46 \%)$, M. ondulathum $(2,20 \%)$, Euprismatolita serrata $(0,97 \%)$ (prismáticos de bordes ondulados y serrados respectivamente), prismáticos con prominencias laterales dispuestas simétricamente $(1,22 \%)$ y $\mathrm{E}$. anisocornisata (con prominencias laterales 
dispuestas asimétricamente) $(0,24 \%)$ fueron raros. Los prismáticos rectangulares de tamaño inferior a $40 \mu \mathrm{m}(2,44 \%)$ fueron escasos, al igual que los cuerpos ramificados con un mamelón o papila pronunciada en la cara frontal $(6,60 \%)$, y los prismáticos breves de lados ondulados, $(0,97 \%)$, mientras que los lisos $(3,90 \%)$ fueros raros. Dentro de los fitolitos esféricos se presentaron de manera frecuente los equinados Globulolita sphaerochinulathum (11,00\%). Los esféricos lisos (G. sphaeropsilathum) $(3,17 \%)$ fueron escasos, mientras que los esféricos con ornamentación clavada, los elípticos lisos (ambos 0,24\%) y los elípticos equinados $(0,48 \%)$ fueron raros. Los fitolitos en cono truncado se encontraron representados de manera escasa por los estróbilos acampanados Estrobilolita complanata $(3,42 \%)$ y rara por los estróbilos equidimensionales (E. equidimensionata) $(0,48 \%)$, los elongados E. elongata $(0,97 \%)$, los aplanados E. aplanada (1,95\%), y E. cotilata $(0,24 \%)$. Los bilobados o halterios estuvieron representados de manera escasa, por Euhalteriolita bitestata $(2,68 \%)$ y rara por E. testicaudiculata, E. botulata, formas intermedias no identificadas, formas pseudocapitadas, y E. de centro largo $(0,24 \%, 0,48 \%, 0,24 \%, 1,46 \%$, y $1,46 \%$ respectivamente), también por Euhalteriolita tipo Stipa $(0,24 \%)$, y las cruces Euhalteriolita cruciformata $(0,24 \%)$. Los polilobados Plurihalteriolita catenata, P. inequilobata y $\mathrm{P}$. trilobata $(0,48 \%, 0,24 \%, 0,24 \%)$ se presentaron todos de manera rara. Los poliédricos de tamaño superior a $40 \mu \mathrm{m}$ fueron escasos $(5,86 \%)$ y raros los inferiores, y formas no identificadas $(1,46 \%$ y $0,97 \%)$. Otros morfotipos cuya presencia fue rara fueron: Doliolita equidimensionata $(0,24 \%)$, Flabelolithum euflabelathum $(1,71 \%)$, formas hemiflabeladas $(0,48 \%)$, Flabelolita elongata $(0,48 \%)$ y $F$. complanathum $(0,73 \%)$, Aculeolithum ancistrathum, A. rostrathum y $\mathrm{A}$ aciculathum $(0,24 \%, 1,46 \%$, y $0,24 \%)$, y varias formas de aculeolitas no identificadas (que suman $3,89 \%)$, formas redondeadas $(1,22 \%)$, multilobadas $(0,97 \%)$, Longolita $(0,24 \%)$ y elementos de conducción $(0,73 \%)$.

\section{Muestra 372}

El grupo de los fitolitos prismáticos se halló dominado por el morfotipo Macroprismatolithum psilaristathum, prismático de bordes lisos, de manera muy frecuente $(32,22 \%)$. Fue escasa la presencia de $\mathrm{M}$. ondulathum (prismáticos de bordes ondulados) (3,91\%). M. denticulathum (fitolitos prismáticos de bordes dentados) $(0,97 \%)$, Euprismatolita elongata (prismáticos elongados) $(3,17 \%)$, Euprismatolita serrata $(2,20 \%)$ (prismáticos de bordes serrados), formas prismáticas rectangulares de bordes con proyecciones dendriformes en los bordes $(0,24 \%)$ y Euprismatolita excavata (prismáticos de final cóncavo) 
$(0,24 \%)$ fueron raros. Igual que los cuerpos ramificados con un mamelón $(0,24 \%)$, los prismáticos menores a $40 \mu \mathrm{m}(2,20 \%)$ y prismáticos breves (2,93\%). Los poliédricos de tamaño superior a $40 \mu \mathrm{m}$ fueron escasos $(8,06 \%)$, y los inferiores $(1,46 \%)$ raros. Dentro de los fitolitos esféricos se presentaron de manera escasa tanto los equinados Globulolita sphaerochinulathum $(9,53 \%)$ como los esféricos lisos (G. sphaeropsilathum) (4,40\%). Los fitolitos en cono truncado se encontraron representados de manera escasa por los estróbilos acampanados Estrobilolita complanata (4,40\%) y los aplanados E. aplanada $(4,64 \%)$, y rara por los estróbilos equidimensionales ( $E$. equidimensionata) $(0,48 \%)$ y los elongados $E$. elongata $(0,24 \%)$. Flabelolithum euflabelathum $(4,15 \%)$ se presentó de manera escasa, mientras Flabelolita excavata $(0,48 \%)$, formas hemiflabeladas $(0,24 \%)$ y $F$. complanathum $(1,95 \%)$ de manera rara. Otros morfotipos cuya presencia fue rara fueron: Doliolita equidimensionata $(0,73 \%)$ y $D$. elongata $(0,24 \%)$, los elementos de conducción $(1,21 \%)$, los bilobados con Euhalteriolita bitestata $(1,22 \%)$ y pseudocapitadas $(0,48 \%)$, el grupo de los aguijones, o aculeolitas, incluyendo Aculeolithum ancistrathum, A. acuminathum, indeterminados, $A$. rostrathum, $(1,95 \%, 0,24 \%, 0,24 \%$, y $0,48 \%$ respectivamente), formas triangulares $(0,48 \%)$, Longolita $(0,24 \%)$.y formas macroglobosas $(0,24 \%)$.

\section{Muestra 373}

Dentro de los fitolitos esféricos se presentaron de manera muy frecuente los equinados Globulolita sphaerochinulathum (24,62\%). Los esféricos lisos (G. sphaeropsilathum) (2,23\%) y los elípticos lisos $(0,24 \%)$ fueron raros. Los fitolitos en cono truncado se encontraron representados de manera frecuente por los estróbilos aplanados E. aplanada (9,20\%) y los acampanados Estrobilolita complanata $(8,70 \%)$, y de manera rara por los equidimensionales (E. equidimensionata) $(0,49 \%)$ y los elongados E. elongata $(0,49 \%)$. El grupo de los fitolitos prismáticos se halló dominado por el morfotipo Macroprismatolithum psilaristathum, prismático de bordes lisos, de manera muy frecuente $(24,12 \%)$. Fue escasa la presencia de $M$. ondulathum $(2,20 \%)$ (prismáticos de bordes ondulados), mientras que M. denticulathum, (fitolitos prismáticos de bordes dentados) (1,99\%), Euprismatolita elongata, prismáticos elongados $(1,74 \%)$ y Euprismatolita excavata $(0,24 \%)$ fueron raros, al igual que 
los cuerpos ramificados con un mamelón o papila pronunciada en la cara frontal $(0,24 \%)$ y los prismáticos breves $(1,24 \%)$. Los prismáticos rectangulares de tamaño inferior a $40 \mu \mathrm{m}(4,97 \%)$ fueron escasos. Los bilobados estuvieron representados de manera escasa, por Euhalteriolita bitestata $(2,73 \%)$ y rara por E. testicaudiculata, E. botulata y E. testilobata $(0,49 \%, 0,49 \%$ y $0,76 \%)$. El grupo de los pelos, ganchos, y aguijones, o aculeolitas, representado de manera escasa por Aculeolithum rostrathum (5,97\%). Aquellos en forma de abanico con Flabelolithum euflabelathum y Flabelolita excavata (ambos $0,99 \%$ ) estuvieron presentes de forma rara, igual que Longolita $(0,73 \%)$, los poliédricos de tamaño inferior a $40 \mu \mathrm{m}(1,24 \%)$ y poliédricos asimétricos $(1,13 \%)$

\section{Muestra 374}

El grupo de los fitolitos prismáticos se halló dominado por el morfotipo Macroprismatolithum psilaristathum, prismático de bordes lisos, de manera muy frecuente $(29,36 \%)$. Fue rara la presencia de Euprismatolita elongata, prismáticos elongados $(0,97 \%), M$. ondulathum $(0,97 \%)$, Euprismatolita serrata $(2,18 \%)$ (prismáticos de bordes ondulados y serrados respectivamente), igual que los prismáticos rectangulares de tamaño inferior a $40 \mu \mathrm{m}(1,21 \%)$, los cuerpos ramificados con un mamelón en la cara frontal $(0,24 \%)$, y prismáticos breves $(1,21 \%)$. Dentro de los fitolitos esféricos se presentaron de manera frecuente los equinados Globulolithum sphaerochinulathum $(17,47 \%)$, mientras que los esféricos lisos (G. sphaeropsilathum) $(7,28 \%)$ fueron escasos. Los fitolitos en cono truncado se encontraron representados de manera frecuente por los estróbilos acampanados Estrobilolita complanata $(9,95 \%)$ y los aplanados E. aplanada $(9,70 \%)$ y de manera rara por los estróbilos equidimensionales (E. equidimensionata) (2,18\%) y los elongados E. elongata $(1,21 \%)$. Los halterios estuvieron presentes de manera escasa, con Euhalteriolita bitestata $(5,09 \%)$ y rara por E. testicaudiculata, E. botulata, E. testilobata, E. de centro largo $(0,24 \%, 0,48 \%, 0,72 \%$, y $0,97 \%$ respectivamente) y las cruces Euhalteriolita cruciformata $(0,48 \%)$. Otros morfotipos cuya presencia fue rara fueron: aquellos en forma de abanico Flabelolithum euflabelathum $(0,72 \%)$, aculeolitas tales como Aculeolithum ancistrathum $(0,24 \%)$, A aciculathum $(0,24 \%)$, formas no identificadas $(1,69 \%)$, A. rostrathum $(1,69 \%)$, elementos de conducción $(0,24 \%)$, los polilobados Plurihalteriolita catenata, y P. trilobata $(0,48 \%$ y $0,72 \%)$, poliédricos de tamaño superior a $40 \mu \mathrm{m}(0,48 \%)$ y los inferiores $(0,97 \%)$. 


\section{Muestra 375}

El grupo de los fitolitos prismáticos se halló dominado por el morfotipo Macroprismatolithum psilaristathum, prismático de bordes lisos, de manera muy frecuente $(25,79 \%)$. Fue escasa la presencia de $M$. ondulathum $(3,64 \%)$ (prismáticos de bordes ondulados) y rara la de Euprismatolita elongata, prismáticos elongados $(1,45 \%)$, y de los prismáticos rectangulares de tamaño inferior a $40 \mu \mathrm{m}(1,70 \%)$, y prismáticos breves $(1,70 \%)$. Dentro de los fitolitos esféricos se presentaron de manera muy frecuente los equinados Globulolithum sphaerochinulathum (19,70\%), mientras que los esféricos lisos (G. sphaeropsilathum) (5,83\%) fueron escasos. Los fitolitos en cono truncado se encontraron representados de manera frecuente por los estróbilos acampanados Estrobilolita complanata $(9,97 \%)$ y los aplanados E. aplanada $(9,00 \%)$, escasa fue la presencia de los elongados E. elongata $(4,13 \%)$, y rara la de los estróbilos equidimensionales (E. equidimensionata) $(0,72 \%)$ y los estróbilos con punta en un extremo $(0,24 \%)$. Los bilobados 0 halterios estuvieron presentes de manera escasa, con Euhalteriolita bitestata (5,59\%) y rara por E. botulata, E. testilobata, E. de centro largo (todos 0,97\%), los polilobados Plurihalteriolita trilobata $(0,48 \%)$ y las cruces Euhalteriolita cruciformata $(0,24 \%)$. El grupo de los aguijones, o aculeolitas, con Aculeolithum rostrathum $(2,67 \%)$, presente de manera escasa, y $\mathrm{A}$. ancistrathum, A aciculathum, y $A$. acuminathum $(0,24 \%)$ todas presentes de manera rara. Otros morfotipos cuya presencia fue rara fueron: Flabelolithum euflabelathum $(0,48 \%)$, Doliolita equidimensionata $(0,48 \%)$, los elementos de conducción $(0,24 \%)$, poliédricos de tamaño superior a $40 \mu \mathrm{m}(0,48 \%)$ y los inferiores $(0,72 \%)$.

\section{Muestra 376}

El grupo de los fitolitos prismáticos se halló dominado por el morfotipo Macroprismatolithum psilaristathum, prismático de bordes lisos, de manera muy frecuente $(23,45 \%)$. Fue escasa la presencia de $\mathrm{M}$. ondulathum (prismáticos de bordes ondulados) $(2,71 \%)$, mientras los prismáticos rectangulares con proyecciones dendriformes en los bordes $(0,24 \%)$, Euprismatolita elongata (1,97\%), Euprismatolita serrata $(1,97 \%)$ y los prismáticos menores a $40 \mu \mathrm{m}(1,23 \%)$ fueron raros. Igual que los prismáticos breves $(1,48 \%)$ y los poliédricos de tamaño superior a $40 \mu \mathrm{m}(0,49 \%)$ y los 
inferiores $(0,74 \%)$. Dentro de los fitolitos esféricos se presentaron de manera muy frecuente los equinados Globulolita sphaerochinulathum $(19,01 \%)$, de manera escasa los esféricos lisos (G. sphaeropsilathum) (5,92\%) y rara los esféricos con ornamentación clavada $(0,49 \%)$, los elípticos lisos $(0,49 \%)$ y los elípticos equinados $(1,72 \%)$. Los fitolitos en cono truncado se encontraron representados de manera frecuente por los estróbilos acampanados Estrobilolita complanata $(9,62 \%)$, de manera escasa por los aplanados E. aplanada $(6,91 \%)$, y rara por los estróbilos equidimensionales (E. equidimensionata) (1,72\%) y los elongados E. elongata $(1,72 \%)$. Los de forma de abanico Flabelolithum euflabelathum $(0,49 \%)$ y Flabelolita elongata $(1,23 \%)$ estuvieron presentes de manera rara. Entre los bilobados o halterios fueron frecuentes Euhalteriolita bitestata (7,65\%), y raros E. botulata, E. testilobata (ambos $0,49 \%)$, E. de centro largo (0,98\%), y E. testicotilata (0,24\%). También fueron raras las cruces Euhalteriolita cruciformata $(0,24 \%)$, los polilobados Plurihalteriolita inequilobata $(0,49 \%)$, las doliolitas con Doliolita equidimensionata $(0,24 \%)$ y $D$. elongata $(0,49 \%)$, el grupo de los pelos, ganchos y aguijones, o aculeolitas, incluyendo Aculeolithum ancistrathum, A. acuminathum, A. aciculathum, A. acantathum y A. rostrathum, $(0,49 \%, 0,24 \%, 0,49 \%, 0,24 \%$ y $0,98 \%$ respectivamente) y placas hexagonales $(1,97 \%)$.

\section{Muestra 377}

El grupo de los fitolitos prismáticos se halló dominado por el morfotipo Macroprismatolithum psilaristathum, prismático rectangular de bordes lisos, de manera muy frecuente $(23,44 \%)$. Fue escasa la presencia de M. ondulathum (prismáticos de bordes ondulados) $(2,74 \%)$ y rara la de $\mathrm{M}$. denticulathum, $(1,99 \%)$, Euprismatolita elongata $(1,74 \%)$, E. serrata $(0,74 \%)$ y E. excavata $(0,24 \%)$. Igual que los poliédricos de tamaño superior a $40 \mu \mathrm{m}(1,74 \%)$ y los inferiores $(0,24 \%)$. Dentro de los fitolitos esféricos se presentaron de manera muy frecuente los equinados Globulolita sphaerochinulathum $(19,20 \%)$, escasa los esféricos lisos (G. sphaeropsilathum) (6,23\%) y rara los elípticos lisos $(0,74 \%)$. Los fitolitos en cono truncado se encontraron representados de manera frecuente por los estróbilos acampanados Estrobilolita complanata $(10,72 \%)$, de manera escasa por los aplanados E. aplanada $(6,48 \%)$, y los elongados $E$. elongata $(3,24 \%)$ y rara por los estróbilos equidimensionales (E. equidimensionata) $(1,49 \%)$. Entre los bilobados o halterios fueron frecuentes Euhalteriolita bitestata $(8,22 \%)$, y raros E. botulata, E. testicaudiculata (ambos 
$0,74 \%)$, E. de centro largo (1,74\%), y E. testilobata $(0,49 \%)$. También fueron raras las cruces Euhalteriolita cruciformata, los polilobados Plurihalteriolita inequilobata y $\mathrm{P}$. catenata, las bulliformes con forma de abanico Flabelolithum euflabelathum, los elementos de conducción, las doliolitas o sillas de montar con Doliolita equidimensionata, formas multilobadas y formas macroglobosas (todos $0,24 \%$ ); el grupo de los pelos, ganchos y aguijones, o aculeolitas, Aculeolithum acuminathum $(0,24 \%)$, formas no identificadas $(0,24 \%)$ y $A$. rostrathum, $(1,49 \%)$ y placas hexagonales $(1,49 \%)$.

\section{Muestra 378}

El grupo de los fitolitos prismáticos se halló dominado por el morfotipo Macroprismatolithum psilaristathum, prismático de bordes lisos, de manera muy frecuente $(25,67 \%)$. Fue rara la presencia de M. denticulathum $(0,98 \%)$, Euprismatolita elongata $(2,46 \%), M$. ondulathum $(2,46 \%)$, Euprismatolita serrata $(0,98 \%)$, y de prismáticos rectangulares de bordes con proyecciones dendriformes $(0,49 \%)$. También fueron raros los cuerpos ramificados con mamelón o papila $(0,24 \%)$, los prismáticos breves $(0,98 \%)$ y los poliédricos de tamaño superior a $40 \mu \mathrm{m}(0,98 \%)$ y los inferiores $(0,74 \%)$. Dentro de los fitolitos esféricos se presentaron de manera muy frecuente los equinados Globulolita sphaerochinulathum (18,27\%). Los esféricos lisos (G. sphaeropsilathum) $(6,91 \%)$ fueron escasos, mientras que los elípticos lisos $(0,49 \%)$ fueron raros. Los fitolitos en cono truncado se encontraron representados de manera frecuente por los estróbilos acampanados Estrobilolita complanata $(7,90 \%)$, escasa por los aplanados E. aplanada $(6,91 \%)$, y rara por los estróbilos equidimensionales ( $E$. equidimensionata) $(1,97 \%)$ y los elongados E. elongata $(0,74 \%)$. Las Placas hexagonales fueron escasas $(2,71 \%)$. El grupo de los aguijones, o aculeolitas, estuvo representado de manera escasa por Aculeolithum rostrathum $(2,71 \%)$ y rara por $A$. ancistrathum $(0,49 \%)$, A. acuminathum $(0,24 \%)$ y formas intermedias no identificadas $(0,98 \%)$. Los bilobados o halterios estuvieron representados de manera escasa, por Euhalteriolita bitestata $(4,93 \%)$ y rara por $E$. testicaudiculata $(2,46 \%)$, E. botulata $(1,23 \%)$, E. testilobata $(0,74 \%)$, y E. de centro largo $(0,24 \%)$. Los polilobados Plurihalteriolita inequilobata y $\mathrm{P}$. trilobata (ambos $0,24 \%$ ) también de manera rara. Otros morfotipos cuya presencia fue 
rara fueron: las doliolitas o sillas de montar con Doliolita equidimensionata $(1,48 \%)$, los elementos de conducción $(0,24 \%)$, las bulliformes en forma de abanico con Flabelolithum euflabelathum $(0,24 \%)$ y formas macroglobosas $(0,74 \%)$.

\section{Muestra 379}

El grupo de los fitolitos prismáticos se halló dominado por el morfotipo Macroprismatolithum psilaristathum, prismático de bordes lisos, de manera muy frecuente $(23,39 \%)$. Fue escasa la presencia de Euprismatolita elongata, prismáticos elongados $(5,17 \%)$, mientras que $M$. denticulathum, fitolitos prismáticos de bordes dentados (1,23\%), M. ondulathum $(0,98 \%)$, Euprismatolita serrata $(1,23 \%)$ (prismáticos de bordes ondulados y serrados respectivamente), fueron raros, igual que los prismáticos menores a $40 \mu \mathrm{m}$, $(0,49 \%)$ y prismáticos breves $(1,23 \%)$. Los poliédricos de tamaño superior a 40 $\mu \mathrm{m}$ fueron escasos $(2,46 \%)$ y raros los inferiores $(0,49 \%)$. Dentro de los fitolitos esféricos se presentaron de manera muy frecuente los equinados Globulolita sphaerochinulathum (22,16\%). Los esféricos lisos (G. sphaeropsilathum) $(5,91 \%)$ fueron escasos. Los fitolitos en cono truncado se encontraron representados de manera frecuente por los estróbilos acampanados Estrobilolita complanata $(3,42 \%)$, escasa por los aplanados E. aplanada $(5,41 \%)$, y rara por los estróbilos equidimensionales ( $E$. equidimensionata) $(1,72 \%)$ y los elongados $E$. elongata $(1,97 \%)$. Los bilobados o halterios estuvieron representados de manera escasa, por Euhalteriolita bitestata $(4,67 \%)$ y $E$. testicaudiculata $(3,94 \%)$, y rara por E. botulata $(1,23 \%)$, E. de centro largo $(0,49 \%)$ y E. testilobata $(1,23 \%)$. Los polilobados Plurihalteriolita catenata, $(0,24 \%)$ también fueron raros. Otros morfotipos cuya presencia fue rara fueron: las doliolitas o sillas de montar Doliolita equidimensionata $(1,23 \%)$, los elementos de conducción $(0,24 \%)$, las bulliformes en forma de abanico Flabelolithum euflabelathum $(0,73 \%)$, Pileolita $(0,24 \%)$, placas hexagonales $(0,98 \%)$, el grupo de los aguijones, o aculeolitas, incluyendo Aculeolithum acuminathum, aculeolitas no identificadas, A. rostrathum, y A aciculathum $(0,24 \%, 0,73 \%, 0,98 \%$ y $0,24 \%$ respectivamente). 


\section{Muestra 380}

El grupo de los fitolitos prismáticos se halló dominado por el morfotipo Macroprismatolithum psilaristathum, prismático de bordes lisos, de manera muy frecuente $(21,01 \%)$. Fue rara la presencia de M. denticulathum, fitolitos prismáticos de bordes dentados (1,20\%), Euprismatolita elongata, prismáticos elongados $(0,96 \%)$ y $M$. ondulathum $(0,48 \%)$ (prismáticos de bordes ondulados), igual que los prismáticos rectangulares de tamaño inferior a $40 \mu \mathrm{m}$ $(0,96 \%)$. Fueron escasos los prismáticos breves $(2,89 \%)$. Dentro de los fitolitos esféricos se presentaron de manera muy frecuente los equinados Globulolita sphaerochinulathum $(21,25 \%)$ y los esféricos lisos (G. sphaeropsilathum) $(13,52 \%)$. Raros los elípticos lisos $(0,48 \%)$. Los fitolitos en cono truncado se encontraron representados de manera frecuente por los estróbilos acampanados Estrobilolita complanata $(7,48 \%)$, escasa por los aplanados E. aplanada $(6,03 \%)$, y los estróbilos equidimensionales ( $E$. equidimensionata) $(2,41 \%)$, y rara por los elongados E. elongata $(0,96 \%)$ y los estróbilos con punta en un extremo $(0,48 \%)$. Las doliolitas o sillas de montar Doliolita equidimensionata $(2,89 \%)$ fueron escasas y las $D$. elongata $(0,48 \%)$ raras. Los bilobados o halterios estuvieron representados de manera escasa, por Euhalteriolita bitestata $(5,07 \%)$ y $\mathrm{E}$. testicaudiculata $(2,65 \%)$, y rara por $\mathrm{E}$. botulata $(0,96 \%)$, E. de centro largo $(0,24 \%)$ y E. testilobata $(1,93 \%)$. También fueron raros otros morfotipos como: los polilobados Plurihalteriolita inequilobata $(0,24 \%)$ y P. trilobata $(0,48 \%)$, los poliédricos de tamaño superior a $40 \mu \mathrm{m}$ y los inferiores (ambos 0,96\%), placas hexagonales $(1,20 \%)$, elementos de conducción $(0,24 \%)$, las bulliformes en forma de abanico Flabelolithum euflabelathum $(0,24 \%)$, el grupo de los aguijones, o aculeolitas, incluyendo Aculeolithum acuminathum y $\mathrm{A}$. rostrathum, $(0,24 \%$ y $0,72 \%)$.

\section{Muestra 381}

El grupo de los fitolitos prismáticos se halló dominado por el morfotipo Macroprismatolithum psilaristathum, de manera frecuente $(12,61 \%)$. Fue escasa la presencia de $\mathrm{M}$. ondulathum $(2,38 \%)$ y rara la de $\mathrm{M}$. denticulathum, $(1,66 \%)$, Euprismatolita elongata $(1,90 \%)$, prismáticos con prominencias laterales dispuestas simétricamente $(0,95 \%)$, Euprismatolita excavata $(0,23 \%)$ y Euprismatolita serrata $(0,95 \%)$. escasos los prismáticos rectangulares de 
tamaño inferior a $40 \mu \mathrm{m}(2,61 \%)$ y raros los prismáticos breves $(1,19 \%)$. Los cuerpos ramificados con un mamelón o papila pronunciada en la cara frontal fueron escasos $(2,85 \%)$. Dentro de los fitolitos esféricos se presentaron de manera muy frecuente los equinados Globulolita sphaerochinulathum $(22,38 \%)$. Los esféricos lisos (G. sphaeropsilathum) (11,66\%) fueron frecuentes, mientras que los elípticos equinados $(1,19 \%)$ y los esféricos con ornamentación clavada $(0,47 \%)$ fueron raros. Los fitolitos en cono truncado se encontraron representados de manera escasa por los estróbilos acampanados Estrobilolita complanata $(2,85 \%)$, y rara por E. aplanada $(2,14 \%)$, E. equidimensionata $(0,95 \%)$, E. elongata $(0,47 \%)$, E. cotilata y los estróbilos con punta en un extremo (ambos $0,23 \%$ ). Doliolita equidimensionata $(0,95 \%)$ y D. oblata $(0,71 \%)$ fueron raras. Los bilobados estuvieron representados de manera escasa, por Euhalteriolita bitestata $(3,33 \%)$ y rara por $E$. testicaudiculata $(1,19 \%)$, E. botulata $(2,14 \%)$, E. de centro largo $(0,71 \%)$, E. testicotilata $(0,23 \%)$ y $E$. testilobata $(0,71 \%)$. También fueron raras las cruces Euhalteriolita cruciformata $(0,23 \%)$ y los polilobados Plurihalteriolita catenata $(0,23 \%)$ y $P$. trilobata $(0,71 \%)$. El grupo de los aguijones, o aculeolitas, incluyendo Aculeolithum ancistrathum $(2,61 \%)$ de manera escasa, y rara $A$. rostrathum, (1,90\%), aculeolitas no identificadas (suman 2,37\%) y $A$. acuminahum $(0,23 \%)$. También fueron raros los elementos de conducción $(0,23 \%)$, las bulliformes Flabelolithum euflabelathum $(0,47 \%)$ y $F$. complanathum $(0,23 \%)$, los poliédricos de tamaño superior a $40 \mu \mathrm{m}$, los inferiores, y formas asimétricas $(0,71 \%, 1,42 \%$, y $0,94 \%)$, formas triangulares $(0,47 \%)$, formas redondeadas $(0,95 \%)$ y Pileolita $(0,70 \%)$. 


\section{INDICE DE FIGURAS Y TABLAS}

Figura 2.1. Esquema cronológico del Cuaternario Superior

Figura 2.2. Mapa de ubicación de la Pampa Norte y la Pampa Sur

Figura 2.3. Mapa donde se esquematiza el sistema morfosedimentario

desarrollado en la llanura pampeana durante el Último Máximo Glacial (UMG)

Figura 2.4. Mapa de la provincia de Entre Ríos donde se diferencian las

Unidades geomorfológicas

Figura 2.5. Perfil Punta Gorda, representativa del sudoeste de la provincia de

Entre Ríos

Figura 3.1. Esquema diseñado a partir de los trabajos de Twiss (1992) y

Gallego y Distel (2004) relacionando morfotipos presentes, ruta metabólica y distribución geográfica

Figura 3.2. Esquema diseñado a partir del trabajo de Fredlund y Tieszen (1994)

cortas de gramíneas)

Figura 4.1. Mapa de la provincia de Entre Ríos, con la ubicación del área de

estudio (Colinas Loéssicas de Crespo) y sitios de muestreo

Figura 4.2. Imagen satelital del área de estudio en la que se señalan los perfiles muestreados

Figura 4.3. Procesamiento en el laboratorio

Figura 4.4. Gráfico $x$ e $y$ (tamaño muestral vs. variabilidad) utilizado para la obtención de la muestra mínima

Tabla 4.1. Valores de abundancia

Figura 4.5. Esquemas de los morfotipos utilizados para este análisis

Tabla 4.2. Listado de morfotipos fitolíticos con sus equivalencias dadas por los autores mas reconocidos

Tabla 4.3. Número de muestra y su número correspondiente del acta de colección

Figura 5.1. Fotografía y esquema del perfil Vial Mat indicando la procedencia de las muestras

Figura 5.2. Fotografía del perfil Vial Mat y detalle de la procedencia de las muestras

Figura 5.3. Lámina microfitolitos perfil Vial Mat

Figura 5.4. Lámina macrofitolitos perfil Vial Mat

Figura 5.5. Diagrama de asociación perfil Vial Mat

Figura 5.6. Fotografía del perfil Gauchito Gil y esquema indicando la procedencia de las muestras

Figura 5.7. Lámina microfitolitos perfil Gauchito Gil

Figura 5.8. Lámina macrofitolitos perfil Gauchito Gil

Figura 5.9. Diagrama de asociación perfil Gauchito Gil

Figura 5.10. Fotografía del perfil Las Cuevas y esquema indicando la

procedencia de las muestras

Figura 5.11. Lámina microfitolitos perfil Las Cuevas

Figura 5.12. Lámina macrofitolitos perfil Las Cuevas

Figura 5.13. Diagrama de asociación perfil Las Cuevas

Figura 5.14. Fotografía del perfil Diamante Norte y esquema indicando la

Figura 5.15. Lámina microfitolitos perfil Diamante Norte

Figura 5.16. Lámina macrofitolitos perfil Diamante Norte 
Figura 5.17. Diagrama de asociación perfil Diamante Norte

Figura 5.18. Fotografía del perfil Alvear y esquema indicando la procedencia de

las muestras

Figura 5.19. Lámina microfitolitos perfil Alvear

Figura 5.20. Lámina macrofitolitos perfil Alvear

Figura 5.21. Diagrama de asociación perfil Alvear

Figura 5.22. Fotografía del perfil Protestante y esquema indicando la 105 procedencia de las muestras

Figura 5.23. Lámina microfitolitos perfil Protestante

Figura 5.24. Lámina macrofitolitos perfil Protestante

Figura 5.25. Diagrama de asociación perfil Protestante

Figura 5.26. Fotografía del perfil La Juanita y esquema indicando la procedencia de las muestras.

Figura 5.27. Lámina microfitolitos perfil La Juanita

Figura 5.28. Lámina macrofitolitos perfil La Juanita

Figura 5.29. Diagrama de asociación perfil La Juanita

Figura 5.30. Fotografía del perfil Tezanos Pinto Tipo y esquema indicando la procedencia de las muestras.

Figura 5.31. Vista del perfil en el campo perfil Tezanos Pinto Tipo

Figura 5.32. Facies de relleno canal abandonado perfil Tezanos Pinto Tipo

Figura 5.33. Facies torrencial perfil Tezanos Pinto Tipo

Figura 5.34. Facies eólica primaria perfil Tezanos Pinto Tipo

Figura 5.35. Lámina microfitolitos perfil Tezanos Pinto Tipo

Figura 5.36. Lámina macrofitolitos perfil Tezanos Pinto Tipo 132

Figura 5.37. Diagrama de asociación perfil Tezanos Pinto Tipo

Figura 5.38. Esquema del perfil Rincón del Doll indicando la procedencia de las muestras

Figura 5.39. Lámina fitolitos perfil Rincón del Doll

Figura 5.40. Diagrama de asociación perfil Rincón del Doll

Figura 5.41. Esquema del perfil Villa Valle María indicando la procedencia de

Figura 5.42. Lámina macro y microfitolitos perfil Villa Valle María

Figura 5.43. Lámina macrofitolitos perfil Villa Valle María

Figura 5.44. Diagrama de asociación perfil Villa Valle María

Figura 6.1. Dendrograma mostrando la asociación entre las muestras de los perfiles Tezanos Tipo y Diamante Norte y esquema donde se representa esta asociación en la columna de los perfiles

Figura 6.2. Análisis de componentes principales de las muestras de los perfiles Tezanos Tipo y Diamante Norte

Figura 6.3. Representación esquemática de la vinculación entre las muestras en los perfiles, Gauchito Gil, Protestante, Tezanos Tipo y Diamante Norte

Figura 6.4. Dendrograma mostrando la asociación entre las muestras de los perfiles Tezanos Tipo, Gauchito Gil, Diamante Norte y Protestante

Figura 6.5. Dendrograma mostrando la asociación entre las muestras de los perfiles Tipo y Protestante

Figura 6. 6. Dendrograma mostrando la asociación entre las muestras de los

Figura 6.8. Cluster cruzando muestras de los perfiles Tipo, Vial Mat, La Juanita, 
Las Cuevas, y Alvear

Figura 6.9. Representación esquemática de la vinculación entre las muestras

en los perfiles, Gauchito Gil, Protestante, Tezanos Tipo y Diamante Norte

Tezanos Tipo, Gauchito Gil y Diamante Norte

Santa Fe y Córdoba 